\author{
Universidade de São Paulo \\ Instituto de Física
}

\title{
Carbonatos em altas pressões como possíveis hospedeiros de carbono no interior da Terra
}

\author{
Michel Lacerda Marcondes dos Santos
}

Orientadora: Profa. Dra. Lucy Vitória Credidio Assali

Tese apresentada ao Instituto de Física da Universidade de São Paulo para a obtenção do título de Doutor em Ciências

\section{Banca Examinadora:}

Profa. Dra. Lucy Vitória Credidio Assali (IFUSP)

Prof. Dr. Armando Corbani Ferraz (IFUSP)

Profa. Dra. Helena Maria Petrilli (IFUSP)

Prof. Dr. Fernando Rei Ornellas (IQUSP)

Profa. Dra. Lara Kühl Teles (ITA)

São Paulo

2016 


\section{FICHA CATALOGRÁFICA \\ Preparada pelo Serviço de Biblioteca e Informação do Instituto de Física da Universidade de São Paulo}

Santos, Michel Lacerda Marcondes dos

Carbonatos em altas pressões como possíveis hospedeiros de carbono no interior da terra. São Paulo, 2016.

Tese (Doutorado) - Universidade de São Paulo. Instituto de Física. Depto. de Física dos Materiais e Mecânica

Orientador: Profa. Dra. Lucy Vitória Credidio Assali

Área de Concentração: Física

Unitermos: 1. Física do estado sólido; 2. Estrutura dos sólidos;

3. Geofísica; 4. Carbonatos; 5. Física de altas pressões.

USP/IF/SBI-053/2016 
Dedico este trabalho ao meu pai Jorge Marcondes dos Santos e à minha mãe Nair Lacerda Marcondes dos Santos. 



\section{Agradecimentos}

Os meus agradecimentos:

À minha mãe, à minha irmã e à minha namorada, Tamires, pelo apoio quando mais precisei.

À Profa. Lucy V. C. Assali, pela orientação e paciência em todos estes anos que trabalhamos juntos.

Ao Prof. João Francisco Justo pelas valorosas discussões e sugestões.

À Profa. Renata Wentzcovitch pela grande contribuição ao supervisionar meu estágio sanduíche na universidade de Minnesota.

Ao meu grande amigo Marcelo Meireles dos Santos, que muito me ajudou nessa caminhada, desde os tempos de graduação.

Ao meu amigo Samuel Silva dos Santos, com quem tive diversas conversas que proporcionaram muitas ideias para este projeto.

Aos colegas Joelson Cott e Rolando Larico, pelas diversas dicas e sugestões sobre os cálculos aqui apresentados.

A todos meus amigos e amigas.

À Sandra e à Rosana, secretárias do Departamento de Física dos Materiais e Mecânica, e ao pessoal da Comissão de PósGraduação, Cláudia, Andrea, Éber, Paula e Renata, pelo suporte na área administrativa.

Ao Laboratório de Computação Científica Avançada (LCCAUSP) e ao Centro Nacional de Processamento de Alto Desempenho de São Paulo (CENAPAD-SP), pelas facilidades computacionais. Ao Minnesota Supercomputing Institute por grande parte do tempo computacional.

Ao CNPq e à CAPES pelo apoio financeiro. 

Abstract vii

1 Introdução 1

2 Fundamentos teóricos e metodologia $\quad \mathbf{1 5}$

2.1 Introdução . . . . . . . . . . . . . . . . . . . . . . . 15

2.2 Aproximação de Born-Oppenheimer . . . . . . . . . . . . . . . . . 16

2.3 Equação de Schrödinger eletrônica . . . . . . . . . . . . . . . . . . 17

2.4 Teoria do Funcional da Densidade . . . . . . . . . . . . . . . . . . 18

2.4.1 Teoremas de Hohenberg e Kohn . . . . . . . . . . . . . . 18

2.4.2 Equações de Kohn - Sham . . . . . . . . . . . . . . . . . 19

2.4.3 Métodos de Pseudopotencial . . . . . . . . . . . . . . . 23

2.5 Propriedades termodinâmicas . . . . . . . . . . . . . . . . . . . . . 32

2.5.1 Cálculo de fônons por primeiros princípios . . . . . . . . . . 34

2.6 Teoria elástica de cristais . . . . . . . . . . . . . . . . . . . . . . . . 37

2.6.1 O tensor de deformação . . . . . . . . . . . . . . . . 37

2.6.2 O tensor de stress . . . . . . . . . . . . . . . . . . . . 41

2.6.3 Materiais isotrópicos . . . . . . . . . . . . . . . 45

2.6.4 Equações de movimento de um sistema isotrópico . . . . . 49

2.6.5 Materiais anisotrópicos ... . . . . . . . . . . 51

2.6.6 Equações de movimento de um sistema anisotrópico . . . . 53

2.7 Equações de Estado . . . . . . . . . . . . . . . . . . . . . . . . . 55 
2.8 Detalhes computacionais . . . . . . . . . . . . . . . . . 58

2.8.1 Parâmetros de convergência . . . . . . . . . . . . 58

2.8.2 Minimização estrutural . . . . . . . . . . . . . . . . . 60

2.8 .3 Propriedades elásticas . . . . . . . . . . . . . . . . . 61

3 Propriedades do $\mathrm{MgSiO}_{3} \quad 63$

3.1 Introdução . . . . . . . . . . . . . . . . . . . 63

3.2 Propriedades estruturais . . . . . . . . . . . . . . . . . . . 64

3.3 Propriedades eletrônicas . . . . . . . . . . . . . . . . 66

3.4 Propriedades elásticas . . . . . . . . . . . . . . . . . . . . . . . . . 69

$3.5 \mathrm{MgSiO}_{3}$ sob pressão . . . . . . . . . . . . . . . . . . 72

3.5.1 Propriedades estruturais . . . . . . . . . . . . . . 73

3.5.2 Propriedades eletrônicas . . . . . . . . . . . . . . . 75

3.5.3 Propriedades elásticas . . . . . . . . . . . . . . . . 77

3.6 Transição de fase estrutural do $\mathrm{MgSiO}_{3} \ldots \ldots$. . . . . . . . . 81

3.7 Conclusões . . . . . . . . . . . . . . . . . . . . . . . . . 86

4 Compostos de carbono em altas pressões $\quad 89$

4.1 Introdução . . . . . . . . . . . . . . . . . . . . . . . . . . . . . . . 89

4.2 Cristal de $\mathrm{MgCO}_{3} \ldots \ldots \ldots$. . . . . . . . . . . . . . . . 90 90

4.2.1 Propriedades eletrônicas . . . . . . . . . . . . . . . . 93

4.2 .2 Propriedades elásticas . . . . . . . . . . . . . . . . . . . . 94

4.2.3 Comportamento do $\mathrm{MgCO}_{3}$ sob altas pressões . . . . . . . 99

4.3 Cristal de $\mathrm{CaCO}_{3} \ldots \ldots \ldots \ldots$

4.3.1 Propriedades eletrônicas . . . . . . . . . . . . . . . 117

4.3.2 Propriedades elásticas . . . . . . . . . . . . . . . . 118

4.3.3 Comportamento do cristal sob altas pressões . . . . . . . 122

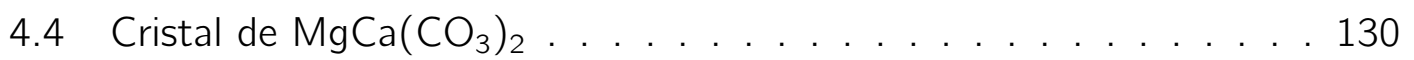

4.4.1 Propriedades eletrônicas . . . . . . . . . . . . . . . . 132

4.4 .2 Propriedades elásticas . . . . . . . . . . . . . . . . . 134

4.4 .3 Estabilidade da dolomita . . . . . . . . . . . . . . . 138 
4.5 Impurezas de carbono no $\mathrm{MgSiO}_{3} \ldots \ldots \ldots . \ldots . \ldots . . \ldots 140$

4.6 Conclusões . . . . . . . . . . . . . . . . . . . . . . . . . . . . . . . . . . 148

5 Estabilidade de compostos de carbono em altas pressões 153

5.1 Introdução . . . . . . . . . . . . . . . . . . . . . . . 153

5.2 Compostos de carbono . . . . . . . . . . . . . . . . . . . 154

5.2.1 Dióxido de carbono em altas pressões . . . . . . . . . . . 154

5.2 .2 Oxigênio a altas pressões . . . . . . . . . . . . . . . . . . 161

5.2 .3 Interações de van der Waals . . . . . . . . . . . . . . . 164

5.3 Propriedades termodinâmicas . . . . . . . . . . . . . . . 167

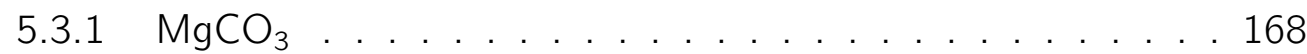

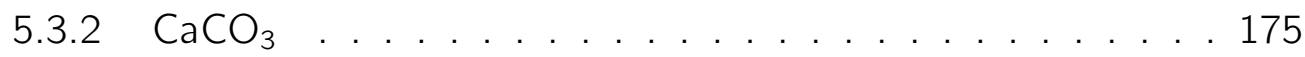

5.4 Propriedades elásticas a altas temperaturas . . . . . . . . . . 184

5.5 Conclusões . . . . . . . . . . . . . . . . . . . . . . . . . . 195

6 Conclusão 197

A Aproximações LDA e GGA 201

A.1 Aproximação da Densidade Local . . . . . . . . . . . . . . . . 202

A.2 Aproximação do Gradiente Generalizado . . . . . . . . . . . . . 203

$\begin{array}{ll}\text { B Constantes elásticas } & 207\end{array}$

$\begin{array}{ll}\text { Referências Bibliográficas } & 209\end{array}$ 



\section{Resumo}

O estudo do interior da Terra apresenta diversos desafios, principalmente devido à impossibilidade de observações diretas de suas propriedades. Ondas sísmicas liberadas por terremotos são a melhor fonte de informação sobre a estrutura do planeta, mas sua correta interpretação depende do conhecimento das propriedades de seus elementos constituintes. Entretanto, estes estudos devem ser feitos nas condições extremas de temperatura e pressão do interior terrestre, condições difíceis de serem alcançadas em laboratório. Neste contexto, o estudo teórico de materiais tem sido muito importante na elaboração de modelos sobre a estrutura interna da Terra e na correta interpretação de dados sísmicos.

Pesquisas recentes têm mostrado que a quantidade de carbono no manto inferior da Terra é maior do que se pensava anteriormente, e é importante compreender seus efeitos no interior profundo da Terra. Apesar da importância de entender os efeitos do carbono no interior da Terra, existem poucos estudos deste elemento nestas condições extremas de pressão e temperatura. Neste trabalho, utilizamos métodos e técnicas da física do estado sólido para estudar as propriedades de compostos de carbono nas condições de pressão e temperatura do manto inferior terrestre.

Estudamos, primeiramente, as propriedades estruturais, eletrônicas e elásticas do $\mathrm{MgSiO}_{3}$ nas estruturas perovskita e pós-perovskita, considerado o principal mineral do manto inferior. Os resultados obtidos para as velocidades acústicas neste mineral mostraram variações maiores em relação às direções cristalinas, quando comparadas com mudanças devido à transição de fase estrutural. Isso indica que uma orientação preferencial dos eixos (anisotropia) pode ajudar a explicar algumas regiões com aumento descontínuo nas velocidades sísmi- 
cas.

Posteriormente, foram obtidas as propriedades do $\mathrm{MgCO}_{3}$ e do $\mathrm{CaCO}_{3}$ em suas estruturas mais estáveis, em função da pressão. Nossos resultados foram comparados com os do $\mathrm{MgSiO}_{3}$, mostrando que carbonatos de cálcio e de magnésio são estáveis nas condições do manto terrestre e que sua formação é energeticamente favorável. Resultados dos cálculos dos coeficientes elásticos e das velocidades acústicas nestes minerais mostram que as velocidades são menores que aquelas no $\mathrm{MgSiO}_{3}$. Dessa forma, em regiões ricas em carbono deve ocorrer a formação destes carbonatos e, por conseguinte, as velocidades sísmicas seriam menores nessas regiões. Isso pode explicar a existência das zonas de baixa velocidade na fronteira do manto inferior com o núcleo. Foram estudadas, também, as consequências da introdução de efeitos térmicos. Entretanto, obteve-se que os resultados não apresentam alterações significativas, de modo que mesmo nas altas temperaturas do interior da Terra nossas conclusões permanecem válidas, onde propomos que as regiões de baixa velocidade no manto inferior possam ser provocadas pela presença de carbono na forma de carbonatos e que a formação destes seria um modelo adicional para explicar onde e como o carbono pode ser armazenado no manto profundo. 


\section{Abstract}

Investigations on the Earth's interior face several challenges, especially due to the infeasibility of direct observations of its properties. Earthquake seismic waves are the best information source about our planet's structure, but its correct interpretation depends on the knowledge of its forming elements. However, these studies must consider the extreme pressures and temperatures of the Earth's interior, hard to achieve experimentally. In this way, theoretical methods have emerged as an essential tool in elaborating models for the Earth internal structure and in the correct interpretation of seismic data.

Recent studies have shown that the Earth must have much more carbon than previous thought, and it is important to understand its effects on the Earth's deep interior. Despite its importance, there are few studies on carbon in these extreme conditions of pressure and temperature and on its effects in the Earth's interior. In this investigation, we use theoretical solid state physics methods to investigate the properties of carbon compounds in the pressure and temperature conditions of Earth's deep interior.

First of all, we studied the electronic and elastic properties of $\mathrm{MgSiO}_{3}$ in the perovskite and post perovskite structures. This silicate is considered the main mineral in the Earth's lower mantle. Our results show that seismic velocities have a larger variation with respect to the propagation direction than that with the phase transition. This indicates that a lattice preferred orientation can explain some seismic discontinuities.

Thereafter, the properties of the $\mathrm{MgCO}_{3}$ and $\mathrm{CaCO}_{3}$ minerals were obtained in their more stable structures with respect to pressure. The results were compared with those of the $\mathrm{MgSiO}_{3}$, showing that calcium and magnesium carbonates are stable in the Earth's mantle and that their formation is energetically 
favorable. The elastic coefficients and the acoustic velocities in these carbonates show seismic velocities considerably lower than those in the $\mathrm{MgSiO}_{3}$. In this way, in regions with high carbon concentration the formation of carbonates could favorably occur and therefore the seismic velocities would be lower in those regions. This may explain the existence of low velocity zones near the bottom of Earth's lower mantle. We also studied the consequences of the introduction of thermal effects. However, our results do not show any significant variation with temperature. Hence, even in the high temperatures of Earth's interior, our conclusions are still valid where we propose that low velocity regions can be caused by the presence of carbon in the form of carbonates. Its formation could provide an additional model to explain where and how carbon can be stored in the deep mantle. 


\section{Introdução}

Science, my lad, has been built upon many errors; but they are errors which it was good to fall into, for they led to the truth.

- Jules Verne, A journey into the Interior of the Earth, chap XXXI

A humanidade sempre buscou entender o planeta em que vivemos. Desde a Grécia antiga vem-se desvendando as características da Terra. Erastóteles, por exemplo, calculou seu diâmetro com uma precisão incrível para a época, obtendo o valor de $6237 \mathrm{~km}$ [1] (o valor atual é 6378,1 km [2]). Conforme o desenvolvimento das civilizações, o conhecimento acerca do planeta foi crescendo. Todavia, todo o conhecimento estava concentrado na superfície do planeta e muito pouco era conhecido sobre o interior da Terra, sendo inclusive comum se pensar que a Terra era oca por dentro.

O estudo preciso da estrutura interna da Terra só se tornou possível quando seu volume e sua massa foram bem determinados, pois o conhecimento da densidade do planeta é importante para o cálculo de diversas outras propriedades, tais como rigidez, compressibilidade, velocidades sísmicas, entre outras. O diâmetro da Terra já era conhecido, não só pelos cálculos de Erastóteles, como por diversos outros [3]. Entretanto, a determinação de sua massa só foi possível a partir da teoria da gravitação de Newton. O próprio Newton propôs um método para se determinar a massa da Terra a partir da inclinação de um prumo ao lado de uma montanha. Cavendish, com seu famoso experimento do pêndulo de torção calculou a densidade da Terra como sendo $\rho=5,5 \mathrm{~g} / \mathrm{cm}^{3}$ [4]. A densidade média das rochas na crosta terrestre é de 2 a $3 \mathrm{~g} / \mathrm{cm}^{3}$, assim este resultado 
mostrou que a densidade do interior da Terra deve ser da ordem de duas vezes a densidade da superfície. Pode-se chegar à mesma conclusão através de cálculos do momento de inércia do planeta. O momento de inércia de uma esfera perfeita e homogênea, de raio $r$ e massa $M$, é $0,4 M r^{2}$. Podemos, em um modelo aproximado, supor a Terra como uma esfera e considerarmos seu momento de inércia médio na forma $I=y \mathrm{Mr}^{2}$, onde $y=0,4$ corresponderia à uma esfera homogênea. Através de estudos sobre a dinâmica do movimento da Lua e da Terra obtém-se o valor $y=0,3308$ [2], o que implica numa maior densidade no interior da Terra do que na superfície. Assim, é possível concluir que o material existente nas regiões profundas deve ter uma densidade relativamente maior que os encontrados na crosta do planeta. O primeiro cálculo teórico da densidade do interior da Terra foi feito por Wiechert [5]. Ele assumiu que a Terra é composta por um núcleo metálico, com densidade praticamente constante, cercada por um manto rochoso, com densidade também não muito variável. Com a introdução de mais algumas suposições, ele concluiu que a razão entre o raio do núcleo e a espessura da crosta deveria estar entre 3 e 4 e, assim, a densidade média do núcleo deveria ser um pouco maior do que 8 $\mathrm{g} / \mathrm{cm}^{3}$. Esta é a densidade esperada se o núcleo for composto for ferro comprimido. Deste modo, Wiechert inferiu que a Terra é composta por um núcleo de ferro de cerca de 5000 km cercado por uma crosta de $1400 \mathrm{~km}$.

No entanto, o conhecimento através da observação direta só é possível até alguns kilômetros abaixo da superfície. Por isso, o conhecimento que se tem do interior terrestre está essencialmente baseado em estudos geofísicos indiretos. Isso torna difícil a determinação precisa da estrutura interna da Terra. A maioria das informações sobre as propriedades de regiões profundas do planeta são obtidas através da observação de fenômenos que ocorrem na superfície. Por exemplo, uma das principais fontes de informação da estrutura interna da Terra são as ondas sísmicas liberadas por terremotos ou causadas por explosões artificiais. Terremotos irradiam energia sísmica como ondas de vários tipos que se movem de diferentes maneiras. Os dois tipos principais de ondas são as ondas de "corpo ou volume" e as ondas de superfície. As ondas de superfície são ondas de baixa frequência, propagam-se pela superfície, a partir do epicentro de um sismo, e deslocam-se mais lentamente que as ondas de corpo, que são as 
ondas que se propagam pelo interior da Terra. Através do estudo de medidas de diferentes propriedades destas ondas pode-se obter diversas informações sobre o interior do planeta [6].

As ondas de superfície podem ser de dois tipos, as chamadas ondas de Rayleigh e as ondas de Love e são utilizadas para estudar a crosta terrestre, enquanto que as ondas de corpo são as mais importantes para estudos geofísicos. Existem dois tipos de ondas de corpo possíveis, descritas teoricamente por Poisson em 1828, em seus estudos sobre elasticidade. Ele descreveu estes dois tipos de onda, que podem se propagar em um meio isotrópico elástico, que são chamadas de ondas $\mathrm{P}$ (primárias) e ondas $\mathrm{S}$ (secundárias). As ondas $\mathrm{P}$ são ondas de compressão e a deformação do meio se dá na direção de propagação da onda. Já as ondas $S$ são ondas em que a deformação se dá perpendicularmente à direção de propagação, por isso também são chamadas de ondas de cisalhamento. A característica mais marcante das ondas $S$ é o fato delas não se propagarem em meios líquidos ou gasosos, pois nestes estados físicos da matéria a tensão de cisalhamento é nula.

Estes dois tipos de ondas foram detectadas por Oldham, em 1901, que em 1906 elaborou a primeira tentativa de se determinar a estrutura interior da Terra, através da análise das ondas sísmicas [7]. Detectando um atraso substancial no tempo de chegada de ondas $\mathrm{P}$ em uma distância angular maior que $120^{\circ}$ do epicentro de um terremoto, ele concluiu que a Terra possui uma região central (núcleo), onde a velocidade das ondas $\mathrm{P}$ é consideravelmente menor que na sua vizinhança. Ele ainda estimou que o raio deste núcleo deveria ser de 1600 $\mathrm{km}$. Mais tarde, essa região ao redor do núcleo foi chamada de manto terrestre. A figura 1.1 mostra, esquematicamente, a propagação das ondas sísmicas e como elas têm sido usadas para se inferir a estrutura interna da Terra. Uma onda $\mathrm{P}$ que chega (é detectada) em uma distância angular de $105^{\circ}$ do epicentro do terremoto não chegou a atravessar o núcleo e sua propagação foi sempre através do manto terrestre. Por outro lado, uma onda $P$ que chega em uma distância angular de $140^{\circ}$ do epicentro atravessou a fronteira manto-caroço e se propagou também através do núcleo. Se o valor da velocidade desta onda no núcleo for menor do que no manto, ela passará boa parte do tempo se propagando no núcleo e só irá ser detectada numa região mais distante do que 


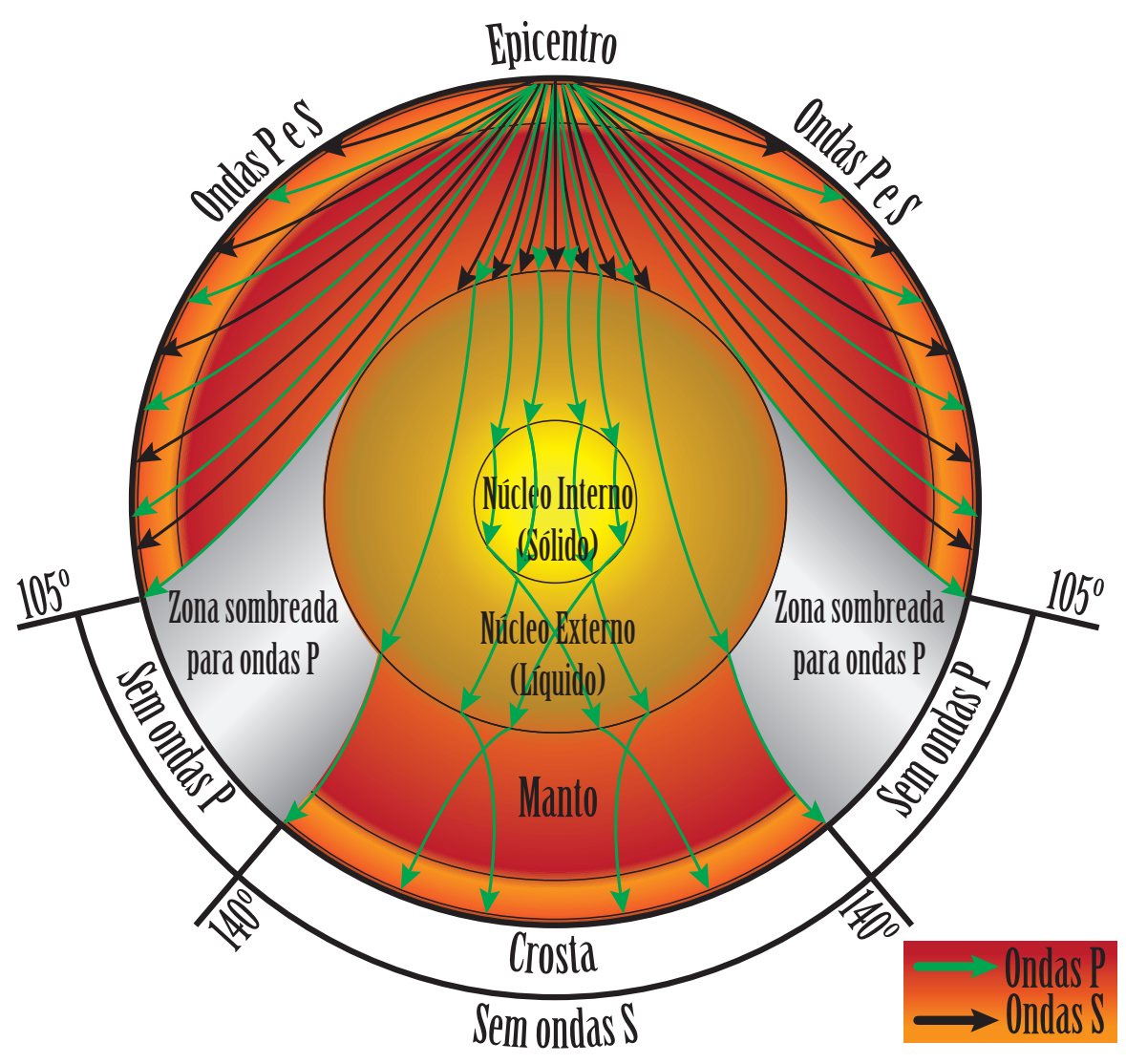

Figura 1.1: Representação esquemática da propagação das ondas sísmicas $P$ e $S$ no interior da Terra.

aquela que foi detectada em $105^{\circ}$ do epicentro, como mostra a figura 1.1. Isso gera uma zona conhecida como "zona sombreada" para ondas $\mathrm{P}(P$-wave shadow zone), definida pelas distâncias angulares entre $105^{\circ}$ e $140^{\circ}$ do epicentro de um terremoto. Dessa forma sabe-se que estas ondas atravessaram uma região de descontinuidade. Por outro lado, como em uma região na crosta terrestre, oposta ao epicentro do terremoto, não são detectadas ondas S, sabe-se que essas ondas sísmicas encontraram uma interface sólido/líquido, implicando na existência de um núcleo líquido.

Em 1909, A. Mohorovičić, estudando o tempo de chegada de ondas sísmicas provenientes de um terremoto na região do vale do rio Kupa, na Croácia, percebeu que a partir de uma distância de $\approx 300 \mathrm{~km}$ do epicentro do terremoto, 


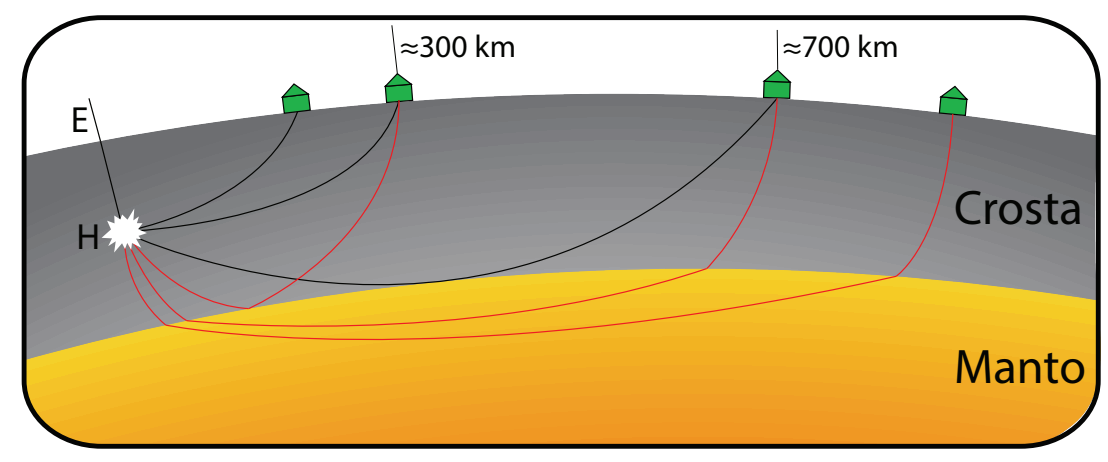

Figura 1.2: Esquema da descontinuidade de Mohorovičić: a partir do epicentro (E) do terremoto $(H)$, para distâncias menores do que $300 \mathrm{~km}$, somente ondas $P$ e $S$ diretas do sismo chegam à superfície. Entre 300 e 700 km de distância, dois tipos de ondas são observadas, tanto ondas diretas como ondas que também atravessam o manto. A partir de 700 km de distância, apenas as segundas são detectadas.

chegavam na superfície duas ondas $\mathrm{P}$ e duas ondas $\mathrm{S}$ distintas. Isto se repetia até distâncias de $\approx 700 \mathrm{~km}$ do epicentro, distância a partir da qual chegavam apenas as ondas do segundo tipo, uma onda P e uma S. Segundo Mohorovičić, é impossível que um terremoto libere duas ondas do mesmo tipo com velocidades diferentes. Portanto, ele concluiu que essas duas ondas, na verdade, eram a mesma onda, mas que chegavam na superfície se propagando por caminhos diferentes. Estas observações levaram à conclusão de que a Terra não é homogênea, ou seja, em uma certa profundidade da superfície existe uma interface que separa dois meios com diferentes propriedades elásticas, como mostra a figura 1.2. Um terremoto no ponto $\mathrm{H}$, com epicentro no ponto $\mathrm{E}$, libera ondas em diversas direções. A partir de distâncias maiores do que $\approx 300 \mathrm{~km}$ do epicentro, chegam nas estações não apenas as ondas diretas (linhas pretas), mas também uma onda que passa pelo manto (linha vermelha), que teve sua direção alterada devido à mudança nas propriedades elásticas do meio por onde se propaga. A partir de $\approx 700 \mathrm{~km}$ do epicentro, não é mais possível a chegada de ondas diretas e apenas as ondas que atravessam o manto são detectadas pelas estações.

Mais tarde, outros trabalhos mostraram que essa descontinuidade é global $[3,8]$. Hoje ela é conhecida como descontinuidade de Mohorovičić, ou Moho, 
e é uma das maneiras de se dividir a crosta do manto. Sua profundidade varia, mas está entre $5 \mathrm{~km}$ e $10 \mathrm{~km}$ no fundo dos oceanos e de $35 \mathrm{~km}$ a $40 \mathrm{~km}$ sob os continentes. Os estudos pioneiros de Wiechert, Oldham e Mohorovičić formaram a base para o primeiro modelo para a estrutura interna da Terra, a qual é divida em 3 regiões concêntricas: a crosta, o manto e o núcleo. Este modelo e esta nomenclatura são utilizados até hoje como uma primeira aproximação para descrever o interior do planeta.

Com o desenvolvimento da teoria de ondas sísmicas $[9,10]$, diversas outras regiões de descontinuidade foram encontradas [7,11-13]. Por volta de 1940, E. Bullen introduziu a nomenclatura A, B, C, D, E, F e G para 7 regiões concêntricas na Terra, com descontinuidades conhecidas [14,15]. A região $A$ corresponde à crosta terrestre, acima da descontinuidade Moho. As regiões B e C, juntas, constituem o manto superior. A região $D$ é o manto inferior, enquanto que as regiões $\mathrm{E}, \mathrm{F}$ e $\mathrm{G}$ constituem o núcleo. Bullen, mais tarde, percebeu que a região $\mathrm{D}$, correspondente ao manto inferior, representava duas regiões distintas. Ele a subdividiu no que hoje são conhecidas como região $\mathrm{D}^{\prime}$ ( $D$ prime) e $\mathrm{D}^{\prime \prime}$ ( $D$ double prime) [16]. O modelo proposto por Bullen é usado, até hoje, para descrever o interior do planeta e está esquematizado na figura 1.3.

Além dessas, existem outras regiões que apresentam anomalias nas ondas sísmicas. Na região em torno de $660 \mathrm{~km}$ de profundidade existe um aumento súbito nas velocidades destas ondas, em geral atribuído à mudança de fase estrutural nos materiais constituintes. Outra região com anomalia sísmica ocorre no topo do manto superior, onde verifica-se uma diminuição na velocidade de propagação, principalmente das ondas S. Estas são chamadas zonas de baixa velocidade (Low Velocity Zone, $L V Z$ ) e têm sido atribuídas à fusão parcial dos elementos, nessa parte do manto. Algumas regiões do manto inferior, principalmente próximas à fronteira com o núcleo, também exibem propriedades sísmicas anômalas. Nelas, tanto as ondas $\mathrm{P}$ como as $\mathrm{S}$ sofrem uma redução de velocidade da ordem de $10 \%$ e por isso são chamadas zonas de ultra baixa velocidade (Ultra Low Velocity Zone, ULVZ) [17-20]. Apesar dessa redução algumas vezes ser consistente com o modelo de fusão parcial, diversos estudos têm mostrado que apenas considerações termodinâmicas não são capazes de explicar essas anomalias $[17,21]$. A ausência das ULVZ em várias regiões da 


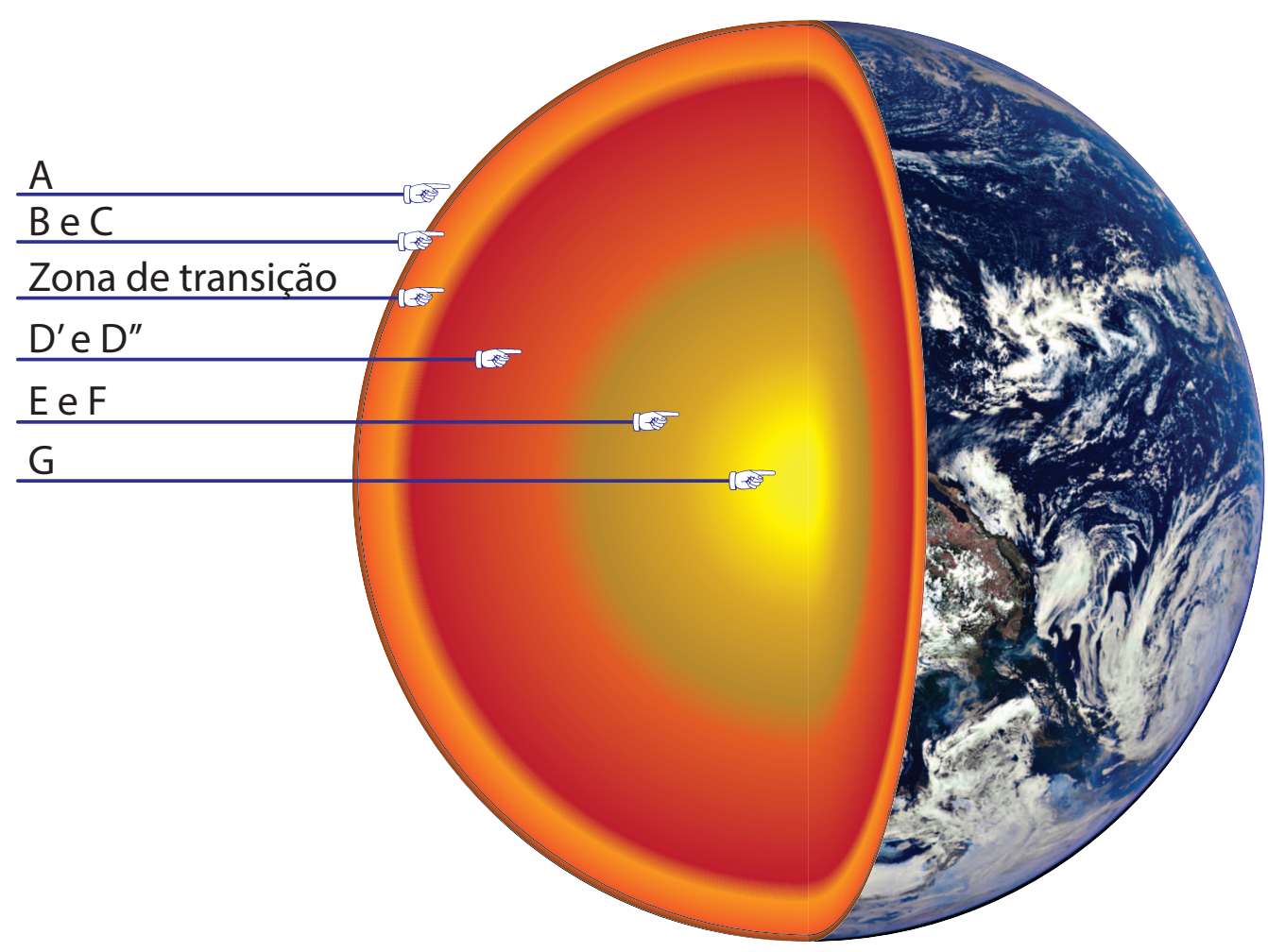

Figura 1.3: modelo proposto por E. Bullen para o interior da Terra, onde A corresponde à crosta terrestre, B e C ao manto superior, $D^{\prime}$ e $D^{\prime \prime}$ ao manto inferior, E e $\mathrm{F}$ correspondem ao núcleo externo e $\mathrm{G}$ ao núcleo interno.

fronteira do manto inferior com o núcleo tem sugerido que alguma diferenciação química deve ser considerada para explicar estas regiões. Estas atribuições têm motivado estudos na direção de se utilizar estas ULVZ para mapear reservatórios de diversos elementos no manto inferior [17].

Recentemente, grande atenção tem sido dada à região $D$ (manto inferior), devido à observação de um aumento descontínuo nas velocidades de ondas sísmicas. Bullen introduziu a designação $\mathrm{D}^{\prime \prime}$ para especificar a região na base do manto inferior, pois esta apresenta uma redução da velocidade de ondas sísmicas. Assim, utiliza-se a nomenclatura $\mathrm{D}^{\prime \prime}$ para designar a região baixa do manto inferior, com velocidade de ondas menores que a região pouco acima, denominada como região $\mathrm{D}^{\prime}$. A terminologia descontinuidade $\mathrm{D}^{\prime \prime}$ é utilizada para referenciar o aumento anômalo da velocidade de ondas sísmicas que, em geral, 
coincide com o topo da região $D^{\prime \prime}$ [22]. O motivo da existência desta descontinuidade ainda não é claro, mas algumas teorias propõem que ela é consequência de interações entre o manto e o núcleo, ou de materiais remanescentes de zonas de subducção (afundamento de uma placa tectônica sob outra) ou ainda de transições de fase nos materiais componentes desta região [23].

A estrutura interna da Terra é determinada por sua composição química como função da posição geográfica e da profundidade. Propriedades como a densidade e a elasticidade têm importância indireta, pois não fornecem diretamente informações sobre a origem, composição e evolução do planeta. Entretanto, dados geofísicos, como velocidades sísmicas e campo gravitacional, proporcionam informações sobre essas propriedades, ao invés da composição química e temperatura. Portanto, não há meios diretos nos quais a estrutura composicional do interior da Terra possa ser determinada através dos dados geofísicos disponíveis. Por isso, um grande desafio é extrapolar informações sismológicas a fim de se identificar a composição química do manto terrestre. Para tanto, associa-se as propriedades obtidas por meio de ondas sísmicas àquelas de materiais conhecidos e estudados em laboratório, em condições equivalentes de pressão e temperatura às do manto terrestre. Isto é feito em um processo de duas etapas. Primeiro, modelos para a densidade e elasticidade são derivados dos dados sismológicos. Segundo, através do estudo teórico e experimental relativos às propriedades de materiais terrestres, modelos para a composição química da Terra podem ser obtidos. O conhecimento desta composição química é importante para a determinação de diversas propriedades, tais como a evolução das placas tectônicas, a transmissão de radiação e o ciclo do carbono [24,25]. Além disso, inferir a composição química é importante para entender a evolução e dinâmica da Terra e de planetas semelhantes.

Um ponto de partida para se estabelecer a constituição do interior da Terra são as rochas encontradas na crosta [6,26]. Entretanto, uma análise destas rochas, assim como estudos petrológicos e geoquímicos, mostram que elas não podem ser representativas do interior da Terra, por causa de suas pequenas densidades médias, mesmo quando efeitos de compressão são considerados [26]. Durante a formação do planeta, a Terra sofreu processos de diferenciação química, como por exemplo por fusão parcial, e cada camada do planeta 
deve reproduzir estes processos. Portanto, o interior do planeta deve ter uma composição diferente do que a crosta. Por isso, uma teoria para a diferenciação química na Terra pode servir de base para um modelo de composição, baseado nos minerais encontrados na superfície. Ringwood propôs um modelo desse tipo [26,27]. Uma das rochas mais ambundantes na crosta é o basalto. Assim, o ponto de partida deste modelo é a noção de que a formação de basalto por fusão parcial de materiais do manto é a atividade vulcânica mais importante na Terra. Por isso, os minerais do manto devem ser capazes de produzir basalto. Através deste raciocínio, Ringwood propôs uma rocha hipotética, chamada pyrolite, capaz de produzir basalto oceânico por fusão parcial e portanto a maior parte do manto deve ser composta por este elemento hipotético. Neste modelo, amostras típicas do manto encontradas na superfície são interpretadas como resíduos dessa fusão parcial da pyrolite. Assim, Ringwood sugeriu que a composição química tanto do manto superior como do manto inferior deve ser similar à composição da pyrolite e a variação das propriedades elásticas e da densidade devem ser explicadas como resultado de transformações de fase, compressão e expansão térmica deste mineral [26].

Um outro modelo propõe que a Terra possui a mesma constituição química da composição média do sistema solar. A teoria aceita para a formação do sistema solar é de que o Sol e os planetas foram formados por um colapso gravitacional de uma nébula solar primitiva [26, 28]. Portanto, a composição tanto do Sol como dos outros planetas deve ser similar. Uma das fontes de informação da composição química do sistema solar são os meteoritos, pois estes são considerados fragmentos de materiais que falharam em se tornar planetas. Dentre todos os tipos de meteoritos, os condritos carbonáceos são um tipo único, pois sua idade da ordem de 4,56 bilhões de anos os torna um dos objetos mais antigos do sistema solar. Por isso são considerados como material remanescente do sistema solar primitivo e sua composição representativa da composição de todo sistema. Alguns cientistas consideram que a composição química da Terra deve ser similar à destes meteoritos, o que dá origem ao modelo condrito para a composição da Terra $[26,28]$.

Estes dois modelos fornecem uma composição parecida para o planeta. Uma diferença significativa entre eles é a razão $(\mathrm{Mg}+\mathrm{Fe}) / \mathrm{Si}$. No modelo con- 
drito, a quantidade de silício no manto é maior do que no modelo pyrolite. Algumas fontes de informação estimam que a composição química do manto superior é muito parecida com o modelo pyrolite. Portanto, se a Terra de fato possui uma composição química parecida com a de meteoritos condritos, a quantidade de silício no manto inferior deve ser bem maior [26].

Diversos outros modelos mais complexos foram propostos [29-31]. Entretanto, é importante salientar que todos estes modelos possuem diversas incertezas $[8,26]$. Sua principal função não é estabelecer uma ideia definitiva da composição da Terra, mas sim fornecer hipóteses testáveis. De qualquer forma, todos os modelos consideram que o manto é formado basicamente por olivina. Dependendo da razão $\mathrm{Mg} / \mathrm{Fe}$, este mineral pode formar a forsterita $\left(\mathrm{Mg}_{2} \mathrm{SiO}_{4}\right)$ ou a faialita $\left(\mathrm{Fe}_{2} \mathrm{SiO}_{4}\right)$. Em altas pressões a olivina possui uma transição estrutural, assumindo uma estrutura conhecida como ringwoodita, que forma a maior parte do manto superior. Um grande avanço no entendimento da estrutura da Terra se deu na década de 1970, quando se descobriu a estrutura perovskita ortorrômbica do $\mathrm{MgSiO}_{3}$ [32]. Logo em seguida, foi demonstrado que, para valores de pressão em torno de $25 \mathrm{GPa}$, a ringwoodita se dissocia em $\mathrm{MgSiO}_{3}$ + $\mathrm{MgO}[33,34]$. Essa pressão corresponde à zona de transição e explica a descontinuidade em $660 \mathrm{~km}$, sendo esta a interpretação atual para a separação do manto em regiões inferior e superior. Atualmente, é consenso na comunidade científica que o manto inferior é formado principalmente por $\mathrm{MgSiO}_{3}$ perovskita, com uma certa concentração de ferro, ainda não bem determinada, mas da ordem de $20 \%$. Este composto $\mathrm{Mg}_{1-x} \mathrm{Fe}_{\times} \mathrm{O}_{3}$ ocupa entre $75 \%$ e $80 \%$ do manto inferior, tornando-o o mineral mais abundante na Terra. O resto do manto é formado por $\mathrm{MgO}$ e outros elementos.

Um elemento extremamente importante, não só para o estudo da Terra como para diversas outras áreas do conhecimento, é o carbono, pois é um dos componentes chave da vida na Terra. O ciclo do carbono na superfície do planeta influencia o clima, o fornecimento de combustíveis fósseis e a saúde de todo ecossistema. Nenhum outro elemento possui tantas possibilidades de ligações químicas, formando estruturas com diversas hibridizações e configurações microscópicas. O comportamento químico do carbono no interior profundo da Terra resume os processos dinâmicos que diferenciam nosso planeta dos de- 
mais. Como já mencionado, o modelo condrito para a formação do planeta sugere que a Terra tenha uma composição similar à destes tipos de meteoritos. Os condritos carbonáceos possuem uma alta concentração de carbono, cerca de duas ordens de grandeza superior àquela encontrada na Terra. Se estes modelos estão corretos, uma pergunta pertinente é onde está escondido este carbono. Isso nos leva a concluir que boa parte do carbono deve estar no manto e no núcleo da Terra. Atualmente, estima-se que cerca de $90 \%$ de todo o carbono do planeta esteja em regiões profundas da Terra $[35,36]$. Recentes estudos em diamantes mostram inclusões provenientes do manto inferior da Terra [37]. Essas inclusões são incorporadas na formação do diamante, o que indica que eles foram formados em regiões bem mais profundas. Esses estudos mostram a presença de carbono no manto inferior. Entretanto, nosso conhecimento do carbono em tais regiões é limitado e diversas questões ainda permanecem em aberto.

Um dos grandes desafios é entender o ciclo geológico do carbono, ou seja, seu transporte da superfície para o interior da Terra e vice-versa. O estudo do ciclo do carbono tem se concentrado em seus efeitos na superfície do planeta, mas pouco ainda é conhecido sobre o ciclo do carbono profundo [35]. Para se construir modelos mais precisos para a composição do planeta, é importante determinar quanto e como o carbono está armazenado no manto e no núcleo. Como a solubilidade do carbono nos minerais do manto é baixa, uma das formas em que o carbono pode se encontrar no manto é em carbonatos, tais como o $\mathrm{MgCO}_{3}$ e o $\mathrm{CaCO}_{3}$.

Entretanto, para uma correta compreensão dos efeitos do carbono no interior do planeta, é necessário o estudo destes carbonatos nas condições extremas de pressão e temperatura do interior da Terra. Nas últimas duas décadas, o estudo de materiais a altas pressões permitiu a compreensão de diversas propriedades geofísicas. Entretanto, estes experimentos são limitados, pois estas condições não são facilmente alcançáveis em laboratório. Neste contexto, o estudo teórico de materiais, baseado em simulações atomísticas, se torna muito importante, pois pode ser a única forma de se obter as propriedades de materiais nessas condições extremas. Assim, cálculos teóricos, baseados em métodos da física do estado sólido, têm sido fundamentais na elaboração de modelos 
da estrutura interna não só da Terra como também de outros planetas [38-43].

Com isso exposto, o objetivo de nosso trabalho é utilizar métodos de primeiros princípios para tentar elucidar o efeito da presença de carbono no manto inferior. Como a maior parte do manto é composta por $\mathrm{MgSiO}_{3}$, começaremos obtendo suas propriedades, comparando-as com resultados disponíveis na literatura. Estes resultados servirão para validar os métodos utilizados e também como um molde dessa parte do planeta. Posteriormente, calcularemos as propriedades de diversos carbonatos, possíveis minerais a fazerem parte da composição do interior da Terra. Calcularemos suas propriedades eletrônicas e estruturais a fim de inferir sua possível influência nas propriedades sísmicas do manto, comparando-as com as do $\mathrm{MgSiO}_{3}$. Estudaremos ainda, do ponto de vista da estabilidade, as formas mais estáveis para o carbono se encontrar nas condições extremas do manto. Começaremos com cálculos estáticos e com efeitos de pressão e, por fim, iremos incluir efeitos térmicos, a fim de se verificar se as conclusões permanecem válidas em altas temperaturas. Como o carbono é capaz de formar diversos compostos, estudaremos a estabilidade dos carbonatos com relação à formação de $\mathrm{CO}_{2}$ e diamante, determinando se, de fato, a presença dos carbonatos é energeticamente favorável.

No capítulo 2, apresentamos a metodologia utilizada, primeiro apresentando a teoria do funcional da densidade (DFT), método utilizado neste trabalho. Posteriormente, descrevemos a teoria elástica de cristais, necessária para o estudo de velocidades acústicas em qualquer material. Neste capítulo também descrevemos os métodos utilizados para cálculos de propriedades termodinâmicas de materiais. No capítulo 3, apresentamos os resultados para as propriedades eletrônicas e estruturais da célula primitiva do $\mathrm{MgSiO}_{3}$, onde calculamos as velocidades acústicas no cristal e validamos os resultados com outros disponíveis na literatura. Também estudamos a fase pós-perovskita deste mineral, calculando a pressão de transição e as propriedades elásticas desta fase. No capítulo 4, apresentamos os resultados para os carbonatos $\mathrm{MgCO}_{3}, \mathrm{CaCO}_{3}$ e $\mathrm{MgCa}\left(\mathrm{CO}_{3}\right)_{2}$, onde estudamos suas propriedades eletrônicas, estruturais e elásticas. Estudamos a estabilidade destes minerais com respeito a diversas estruturas, a fim de se corroborar resultados teóricos recentes. Calculamos as velocidades acústicas nestes minerais em diversas fases e comparamos com as 
velocidades no $\mathrm{MgSiO}_{3}$. Com isso inferimos a modificação que a presença destes carbonatos pode provocar no manto inferior. Por fim, no capítulo 5, estudamos a estabilidade destes carbonatos com relação à sua dissociação formando $\mathrm{CO}_{2}$ e diamante. Verificamos se, sob estas condições, as estruturas permanecem estáveis. Neste capítulo também incluímos efeitos térmicos, utilizando a aproximação quase-harmônica, a fim de verificar alguma alteração, em resultados precedentes, devido às altas temperaturas do manto. Por fim, quando possível, estudamos os efeitos térmicos nas propriedades elásticas de alguns cristais. No capítulo 6, apresentamos as principais conclusões referentes a este trabalho. 



\section{Fundamentos teóricos e metodologia}

The underlying physical laws necessary for the mathematical theory of a large part of physics and the whole of chemistry are thus completely known, and the difficulty is only that the exact application of these laws leads to equations much too complicated to be soluble. It therefore becomes desirable that approximate practical methods of applying quantum mechanics should be developed.

- Paul Dirac, Proc. Royal Soc. London, 123, 714 (1929)

\subsection{Introdução}

Uma das principais maneiras de se estudar o interior de planetas é comparar resultados obtidos em medidas de ondas sísmicas com propriedades de materiais medidas em laboratório. A composição química da Terra não é conhecida a priori de tal forma que diversos experimentos são necessários, inclusive para se determinar a composição do planeta. Além disso, as altas pressões e temperaturas que o interior da Terra atinge limitam estes estudos. Dessa forma, cálculos de primeiros princípios têm se tornado fundamentais para elucidar diversas propriedades de materiais nessas condições extremas.

Os estudos desenvolvidos neste trabalho englobam dois grandes temas: estabilidade de cristais a altas pressões e propriedades elásticas. Neste capítulo, são apresentadas a fundamentação teórica e a metodologia de cálculo utilizadas nesta pesquisa. 


\subsection{Aproximação de Born-Oppenheimer}

Os blocos fundamentais de construção da matéria são os íons e os elétrons. A descrição destes elementos é feita pela equação de Schrödinger

$$
\hat{\mathcal{H}} \Psi=E \Psi
$$

em que a hamiltoniana $\mathcal{H}$ é dado por

$$
\hat{\mathcal{H}}=\hat{T}_{e}+\hat{T}_{N}+\hat{V}_{e N}+\hat{V}_{e e}+\hat{V}_{N N}
$$

em que $\hat{T}_{e}$ e $\hat{T}_{N}$ são os operadores energia cinética dos elétrons e dos núcleos atômicos, respectivamente, $\hat{V}_{e N}$ é a interação entre os núcleos atômicos e os elétrons, $\hat{V}_{e e}$ é o potencial coulombiano entre os elétrons e $\hat{V}_{N N}$ é o potencial entre os núcleos. A solução completa da equação (2.1) é uma função de onda $\Psi(\vec{r}, \vec{R})$ dependente das posições dos elétrons $\vec{r}$ e dos núcleos $\vec{R}$, não conhecida mesmo para os sólidos mais simples. Uma primeira aproximação para se solucionar esta equação é considerar que os núcleos atômicos são muito mais pesados que os elétrons e, por isso, se movem mais lentamente. Assim, podese desacoplar as funções de onda dos elétrons e dos núcleos

$$
\psi(\vec{r}, \vec{R})=R(\vec{R}) \psi(\vec{r}, \vec{R})
$$

em que $R(\vec{R})$ é uma função de onda que descreve o movimento dos íons e $\psi(\vec{r}, \vec{R})$ a função de onda eletrônica, que depende parametricamente das posições atômicas $\vec{R}$. Esta função de onda eletrônica obedece à equação

$$
\left[\hat{T}_{e}+\hat{V}_{e N}+\hat{V}_{e e}(\vec{R})\right] \psi_{n}(\vec{r}, \vec{R})=E_{n}(\vec{R}) \psi_{n}(\vec{r}, \vec{R}) .
$$

Já a função de onda $R(\vec{R})$ obedece à equação

$$
\left[\hat{T}_{N}+\hat{V}_{N N}+E_{n}(\vec{R})\right] R(\vec{R})=\epsilon R(\vec{R}) .
$$

Esta é chamada aproximação de Born-Oppenheimer. Ela desacopla os graus de liberdade dos elétrons dos íons e desconsidera a excitação eletrônica induzida pelo movimento iônico. 


\subsection{Equação de Schrödinger eletrônica}

Na aproximação de Born-Oppenheimer, descrita na seção anterior, é considerado que o movimento dos íons é muito mais lento do que o dos elétrons. Pode-se extrapolar esta aproximação e dizer que os íons estão estáticos e contribuem apenas como um potencial externo. Este movimento iônico é o que dá origem à temperatura de um sistema, de tal forma que esta aproximação corresponde à temperatura de $0 \mathrm{~K}$ e desconsidera efeitos da energia de ponto zero. Este nível de aproximação é suficiente para diversas aplicações, principalmente para descrever sistemas na temperatura ambiente, onde a energia térmica é menor. A solução apenas da parte eletrônica fornece diversas informações úteis e é o primeiro passo para qualquer cálculo de primeiros princípios, por isso descreveremos os métodos de solução em detalhes.

A equação (2.4) pode ser escrita da forma

$$
\hat{\mathcal{H}}_{e l} \psi(\vec{r})=E \psi(\vec{r})
$$

em que a hamiltoniana eletrônica $\mathcal{H}_{e l}$ é dada por

$$
\hat{\mathcal{H}}_{e l}=-\frac{\hbar^{2}}{2} \sum_{i=1} \frac{\nabla_{r_{i}}^{2}}{m_{e}}-\frac{1}{4 \pi \epsilon_{0}} \sum_{i \neq j} \frac{Z_{i} e^{2}}{\left|\vec{R}_{i}-\vec{r}_{j}\right|}+\frac{1}{8 \pi \epsilon_{0}} \sum_{i \neq j} \frac{e^{2}}{\left|\vec{r}_{i}-\vec{r}_{j}\right|},
$$

onde $\vec{r}_{i}\left(i=1, \ldots N_{e}\right)$ denotam as posições dos elétrons de massa $m_{e}$ e $\vec{R}_{i}$ as posições dos núcleos com números atômicos $Z_{i}$. Como estamos considerando uma rede estática, esta hamiltoniana não contém a energia cinética dos núcleos atômicos. No sistema de unidades atômicas em Rydbergs, a hamiltoniana pode ser escrita como

$$
\hat{\mathcal{H}}_{e l}=-\sum_{i} \nabla_{r_{i}}^{2}-\sum_{i \neq j} \frac{2 Z_{i}}{\left|\vec{R}_{i}-\vec{r}_{j}\right|}+\sum_{i \neq j} \frac{1}{\left|\vec{r}_{i}-\vec{r}_{j}\right|} .
$$

Mesmo com a aproximação de Born-Oppenheimer, ainda ficamos com uma equação de muitas partículas interagentes, sem possibilidade prática de resolução. A teoria do funcional da densidade (DFT) $[44,45]$ é um esquema que permite resolver este problema de muitos corpos utilizando, como parâmetro principal a ser determinado, a densidade eletrônica do sistema. A primeira teoria a utilizar a densidade eletrônica como variável básica, ao invés da função de 
onda, estabelecendo uma relação implícita entre o potencial externo e a densidade eletrônica do sistema, foi a do átomo de Thomas-Fermi, em 1937 [46, 47]. No entanto, até 1964 o uso da densidade era considerada apenas um modelo, quando Hohenberg e Kohn propuseram um método prático e poderoso para descrever um sistema de elétrons interagentes. Na DFT, as partículas são tratadas através do mapeamento de um sistema auxiliar, não interagente, no qual se movem em um potencial efetivo local de partícula única. Os resultados obtidos neste trabalho utilizam um esquema prático para resolver as equações de KohnSham (KS), provenientes da DFT, conhecido como método de pseudopotenciais [48-52], implementado no código computacional Quantum ESPRESSO [53], e constitui uma poderosa ferramenta na descrição das propriedades físicas de materiais. Esta metodologia está descrita nas próximas seções.

\subsection{Teoria do Funcional da Densidade}

\section{Teoremas de Hohenberg e Kohn}

Os teoremas de Hohenberg e Kohn (HK) [44] são:

Teorema 1: A energia total de um sistema quântico de vários elétrons é um funcional único do potencial externo.

Teorema 2: A correta densidade eletrônica para o estado fundamental é aquela que minimiza o funcional energia total do sistema.

O primeiro teorema diz que o potencial externo é um funcional único da densidade eletrônica do sistema, estabelecendo uma relação biunívoca entre a densidade eletrônica e o potencial externo. O segundo teorema é o princípio variacional de Rayleight-Ritz aplicado à densidade eletrônica, ao invés de à função de onda, e pode ser considerado como uma maneira formal de tornar exata a teoria de Thomas-Fermi. Assim, o teorema 1, ao estabelecer que existe uma correspondência única entre a densidade $\rho(\vec{r})$ do estado fundamental de um sistema de muitos elétrons e o potencial externo $V_{\text {ext }}$, ela estabelece que o valor esperado, no estado fundamental, para um observável descrito pelo operador 
Ô, é um funcional único da densidade eletrônica do estado fundamental do sistema, que depende de $V_{\text {ext }}$. Isto leva ao teorema 2, pois se o operador $\hat{O}$ for a hamiltoniana $\hat{H}$, então existe um funcional energia total, do estado fundamental de um sistema de elétrons interagentes, que é um funcional da densidade de carga eletrônica, que depende de $V_{\text {ext }}$.

\section{Equações de Kohn - Sham}

Utilizando os teoremas de HK, Kohn e Sham (KS) [45] desenvolveram um método eficaz para se calcular as propriedades de um sistema de muitos corpos. Utilizando o primeiro teorema de $\mathrm{HK}$, o funcional energia total é escrito como

$$
E[\rho(\vec{r})]=V_{e x t}[\rho(\vec{r})]+G[\rho(\vec{r})],
$$

com $G[\rho(\vec{r})]$ sendo um funcional universal, independente do sistema considerado, e pode ser escrito em termos do funcional energia cinética e do funcional energia de interação eletrônica do sistema

$$
G[\rho(\vec{r})]=T[\rho(\vec{r})]+V_{e e}[\rho(\vec{r})] .
$$

A forma analítica do funcional $G[\rho(\vec{r})]$ não é conhecida, mas os teoremas de HK garantem que ele é um funcional da densidade. Em 1965, Kohn e Sham [45] propuseram uma maneira de escrever este funcional, o qual denominamos $F_{K S}[\rho(\vec{r})]$, que trata as partículas interagentes do sistema em termos de um sistema efetivo não interagente, com a mesma densidade total do problema de muitos corpos. A expressão proposta para o funcional de KS tem a seguinte forma

$$
F_{K S}[\rho(\vec{r})]=\iint \frac{\rho(\vec{r}) \rho\left(\vec{r}^{\prime}\right)}{\left|\vec{r}-\vec{r}^{\prime}\right|} d \vec{r} d \vec{r}^{\prime}+T_{s}[\rho(\vec{r})]+E_{x c}[\rho(\vec{r})],
$$

em que o primeiro termo do segundo membro da equação (2.11) define as interações elétron-elétron puramente coulombianas, $T_{s}[\rho(\vec{r})]$ representa o funcional energia cinética de um gás de elétrons não interagentes e $E_{x c}[\rho(\vec{r})]$ corresponde ao funcional energia de troca e correlação e incorpora o termo de troca (devido ao princípio de exclusão de Pauli) e parte do funcional $T[\rho(\vec{r})]$ da equação 
(2.10), desprezado em $T_{s}[\rho(\vec{r})]$. Assim, o funcional energia total do sistema fica

$$
E[\rho(\vec{r})]=\int \rho(\vec{r}) V_{\text {ext }}(\vec{r}) d \vec{r}+\iint \frac{\rho(\vec{r}) \rho\left(\vec{r}^{\prime}\right)}{\left|\vec{r}-\vec{r}^{\prime}\right|} d \vec{r} d \vec{r}^{\prime}+T_{s}[\rho(\vec{r})]+E_{x c}[\rho(\vec{r})] .
$$

Utilizando o segundo teorema de $\mathrm{HK}$, a correta densidade para o estado fundamental é a que minimiza o funcional energia total do sistema, dado pela equação (2.12), com a restrição de que o número total de partículas $N$, expresso por

$$
N=\int \rho(\vec{r}) d \vec{r},
$$

deva ser constante. Sendo $\varepsilon$ um multiplicador de Lagrange, a condição de mínimo é obtida por meio de

$$
\delta\{E[\rho(\vec{r})]-\varepsilon N\}=0 .
$$

Substituindo as expressões (2.12) e (2.13) na equação (2.14), obtemos $\delta\left\{\int \rho(\vec{r}) V_{e x t}(\vec{r}) d \vec{r}+\iint \frac{\rho(\vec{r}) \rho\left(\vec{r}^{\prime}\right)}{\left|\vec{r}-\vec{r}^{\prime}\right|} d \vec{r} d \vec{r}^{\prime}+T_{s}[\rho(\vec{r})]+E_{x c}[\rho(\vec{r})]-\varepsilon \int \rho(\vec{r}) d \vec{r}\right\}=0$.

Explicitando a variação, separadamente, de cada um dos termos da equação (2.15), temos

$$
\begin{aligned}
\delta\left\{\int \rho(\vec{r}) V_{\text {ext }}(\vec{r}) d \vec{r}\right\} & =\int V_{\text {ext }}(\vec{r}) \delta \rho(\vec{r}) d \vec{r} ; \\
\delta\left\{\iint \frac{\rho(\vec{r}) \rho\left(\vec{r}^{\prime}\right)}{\left|\vec{r}-\vec{r}^{\prime}\right|} d \vec{r} d \vec{r}^{\prime}\right\} & =2 \int \frac{\rho\left(\vec{r}^{\prime}\right)}{\left|\vec{r}-\vec{r}^{\prime}\right|} \delta \rho(\vec{r}) d \vec{r}^{\prime} ; \\
\delta T_{s}[\rho(\vec{r})] & =\int\left[\frac{\delta T_{s}}{\delta \rho}\right] \delta \rho(\vec{r}) d \vec{r} ; \\
\delta E_{x c}[\rho(\vec{r})] & =\int\left[\frac{\delta E_{x c}}{\delta \rho}\right] \delta \rho(\vec{r}) d \vec{r} ; \\
\delta\left\{\int \rho(\vec{r}) d \vec{r}\right\} & =\int \delta \rho(\vec{r}) d \vec{r} .
\end{aligned}
$$

Substituindo as equações (2.16)-(2.20) na equação (2.15) obtemos 


$$
\int d \vec{r}\left\{V_{e x t}(\vec{r})+2 \int \frac{\rho\left(\vec{r}^{\prime}\right)}{\left|\vec{r}-\vec{r}^{\prime}\right|} d \vec{r}^{\prime}+\frac{\delta T_{s}}{\delta \rho}+\frac{\delta E_{x c}}{\delta \rho}-\varepsilon\right\} \delta \rho(\vec{r})=0 .
$$

Como a variação $\delta \rho(\vec{r})$ é arbitrária, então a expressão entre parênteses, na equação acima, deve ser nula, levando à

$$
V_{\text {ext }}(\vec{r})+2 \int \frac{\rho\left(\vec{r}^{\prime}\right)}{\left|\vec{r}-\vec{r}^{\prime}\right|} d \vec{r}^{\prime}+\frac{\delta T_{s}}{\delta \rho}+\frac{\delta E_{x c}}{\delta \rho}-\varepsilon=0 .
$$

Podemos expressar a densidade eletrônica do sistema em termos de um conjunto de $N$ funções ortonormais, de modo que

$$
\rho(\vec{r})=\sum_{k=1}^{N} \varphi_{k}^{*}(\vec{r}) \varphi_{k}(\vec{r}) .
$$

Com isso, podemos, no processo variacional anterior, substituir a variação em $\rho(\vec{r})$ por variações nas funções $\varphi_{k}^{*}(\vec{r})$ e $\varphi_{k}(\vec{r})$. Iremos variar $\varphi_{k}^{*}(\vec{r})$ e, portanto $\delta \rho(\vec{r})=\left[\delta \varphi_{k}^{*}(\vec{r})\right] \varphi_{k}(\vec{r})$. No caso considerado de um sistema auxiliar de elétrons não interagentes, o funcional energia cinética também pode ser expresso em termos do conjunto de $N$ funções ortonormais, como

$$
T_{s}[\rho]=\sum_{i=1}^{N} \int \nabla \varphi_{k}^{*}(\vec{r}) \cdot \nabla \varphi_{k}(\vec{r}) d \vec{r}
$$

Desse modo, a variação do funcional energia cinética fica

$$
\begin{aligned}
\delta T_{s}[\rho(\vec{r})] & =\int \nabla\left[\delta \varphi_{k}^{*}(\vec{r})\right] \cdot \nabla \varphi_{k}(\vec{r}) d \vec{r} \\
& =\int \nabla \cdot\left[\delta \varphi_{k}^{*}(\vec{r}) \nabla \varphi_{k}(\vec{r})\right] d \vec{r}-\int \delta \varphi_{k}^{*}(\vec{r}) \nabla^{2} \varphi_{k}(\vec{r}) d \vec{r} \\
& =\underbrace{\int \delta \varphi_{k}^{*}(\vec{r}) \nabla \varphi_{k}(\vec{r}) d \vec{S}}_{=0}-\int \delta \varphi_{k}^{*}(\vec{r}) \nabla^{2} \varphi_{k}(\vec{r}) d \vec{r}
\end{aligned}
$$

em que a integral de superfície, na equação (2.25), é nula, pois ou $\varphi_{k}$ é nula no infinito ou temos condições periódicas de contorno. Utilizando a definição de derivadas funcionais, temos que a equação (2.25) fica

$$
\frac{\delta T_{s}[\rho]}{\delta \rho}=-\frac{\delta}{\delta \rho} \int \delta \varphi_{k}^{*}(\vec{r}) \nabla^{2} \varphi_{k}(\vec{r}) d \vec{r}=-\nabla^{2} \varphi_{k}(\vec{r}) .
$$


Usando essa expressão na equação (2.22), chegamos às equações de KohnSham:

$$
\left\{-\nabla^{2}+2 \int \frac{\rho(\vec{r})}{\left|\vec{r}-\vec{r}^{\prime}\right|} d \vec{r}^{\prime}+V_{e x t}(\vec{r})+V_{x c}(\vec{r})\right\} \varphi_{k}(\vec{r})=\varepsilon_{k} \varphi_{k}(\vec{r})
$$

em que, por definição, $V_{x c}(\vec{r})=\frac{\delta E_{x c}}{\delta \rho}$ é o potencial de troca e correlação.

A teoria do funcional da densidade relaciona um sistema de elétrons interagentes com um de elétrons não interagentes que possua a mesma densidade $\rho(\vec{r})$ no estado fundamental. Estas equações são muito semelhantes às equações de Hartree, mas contém o termo $V_{x c}(\vec{r})$, que representa o potencial de troca mais o de correlação, os quais derivam do funcional energia de troca e correlação $E_{x c}[\rho(\vec{r})]$. $O$ termo de troca e correlação contém todos os efeitos de muitos corpos não incorporados na teoria de Hartree. As equações de KS são exatas. No entanto, a atribuição de qualquer significado físico às funções de onda $\varphi_{j}(\vec{r})$ e aos auto-valores $\varepsilon_{j}$ deve ser feita de modo judicioso, pois, em princípio, as auto-funções obtidas pela solução das equações de KS são aquelas utilizadas como base para determinar a densidade eletrônica do estado fundamental do sistema eletrônico. No entanto, todos os $\varepsilon_{j}$ e $\varphi_{j}(\vec{r})$ possuem um valor semi-quantitativo pois contêm os efeitos de troca e correlação e são consistentes com a densidade física exata $\rho(\vec{r})$. Para se obter os estados eletrônicos de um sistema, através da utilização das equações de KS, encontramos dois problemas:

(a) Como o potencial efetivo deste sistema fictício auxiliar depende de um funcional da densidade eletrônica, as equações de KS devem ser resolvidas de maneira autoconsistente;

(b) Deve-se tomar uma forma aproximada para o funcional energia de troca e correlação pois, na prática, para a maior parte das densidades, ele não é conhecido exatamente.

O primeiro destes problemas é superado, hoje em dia, de maneira trivial, até o grau de precisão desejado, dentro de um critério pré-estabelecido. Para o 
segundo problema, a solução não é trivial mas, atualmente, existem várias aproximações para o funcional de troca e correlação. A aproximação mais comum é a chamada aproximação da densidade local (LDA - Local Density Approximation) [45]. Nesta aproximação supõe-se que a contribuição de troca-correlação de todo o volume infinitesimal dependa apenas da densidade local daquele volume. Apesar de simples, ela fornece resultados satisfatórios para uma grande variedade de sistemas, sendo amplamente utilizada na física da matéria condensada. No entanto, em alguns casos, a aproximação LDA não descreve muito bem os sistemas e o passo seguinte foi fazer com que a contribuição de trocacorrelação de todo o volume infinitesimal não dependesse apenas da densidade local daquele volume, mas também da densidade nos volumes vizinhos, ou seja, incluindo a dependência do gradiente da densidade. Esta aproximação é chamada de aproximação do gradiente generalizado (GGA - Generalized Gradient Approximation) [54]. Aproximações deste tipo vêm sendo amplamente utilizadas na física da matéria condensada e estão descritas brevemente no apêndice A.

\section{Métodos de Pseudopotencial}

As funções de onda para descrever elétrons livres em um cristal periódico podem ser expandidas em ondas planas. Se o potencial devido aos íons for desconsiderado, as ondas planas serão a solução exata. Se o potencial for suave, então ele pode ser tratado como uma pertubação. Entretanto, o potencial devido aos íons está longe de ser suave e por isso uma base de ondas planas é inviável para descrever todos os elétrons em um cristal, principalmente as funções de onda eletrônicas das regiões próximas aos núcleos atômicos, pois seriam necessárias muitas componentes para representar adequadamente as variações rápidas que as funções apresentam. Slater sugeriu uma maneira de solucionar este problema [55], propondo que a expansão em ondas planas fosse aumentada com a solução das funções de onda atômicas nas regiões esféricas próximas aos núcleos, assumindo que o potencial é esfericamente simétrico dentro das esferas atômicas e nulo na região intersticial. Este é conhecido como método APW (Augmented Plane Wave) e o potencial é chamado 
de potencial muffin-tin. Em 1940, Herring [56] propôs um método alternativo com o intuito de superar a aproximação muffin-tin do potencial. Nesta aproximação, as funções de onda dos elétrons de valência são construídas como uma combinação linear de ondas planas com funções atômicas. Com uma escolha apropriada dos coeficientes da expansão, estas funções de onda são então, por construção, ortogonais aos estados de caroço e, por isso, este método é conhecido como OPW (Orthogonalized Plane Wave).

Em um cristal, é difícil descrever convenientemente os estados dos elétrons de caroço enquanto que a descrição dos estados dos elétrons de valência é apropriadamente descrita por uma expansão de ondas planas, pois estão sujeitos a um potencial muito mais suave do que os elétrons do caroço. O passo posterior foi remover completamente os estados de caroço, substituindo sua ação por um pseudopotencial. Entretanto, este pseudopotencial precisa ser construído de maneira a representar adequadamente as propriedades de ligação do potencial verdadeiro. Desse modo, vamos analisar as características essenciais dos estados eletrônicos de um átomo, dividindo-os em três espécies:

ESTADOS DE CAROÇO: altamente localizados e não participam ativamente das ligações químicas.

ESTADOS DE VALÊNCIA: extensos e responsáveis pelas ligações químicas.

ESTADOS DE SEMICAROÇO: localizados e polarizáveis, mas geralmente não contribuem diretamente para as ligações químicas.

Os estados de valência, devido à ortogonalização com os estados de caroço, possuem um comportamento oscilatório característico. O número de nós é $n-\ell-1$, onde $n$ é o número quântico principal e $\ell$ o momentum angular. Quando as funções de base escolhidas são ondas planas, o cálculo dos elementos de matriz da hamiltoniana precisa das componentes de Fourier dessas funções de onda. Fortes picos na função de onda necessitam de um grande número de ondas planas para serem corretamente descritos, com um grande custo computacional.

Como os estados de caroço não são essenciais para a correta descrição das ligações químicas e uma boa descrição das funções de onda de valência 
não são estritamente necessárias, não perdemos nenhuma informação se a solução dentro de um raio específico (raio de cutoff) for substituída por uma função suave, sem nós. Não possuindo nenhum nó, esta função corresponde ao estado fundamental de um problema atômico efetivo, onde o potencial verdadeiro é substituído por um pseudopotencial.

Philips e Kleinman [57] mostraram que é possível construir uma função de onda suave de estados de valência $\tilde{\phi}_{v}$, não ortonormal aos estados de caroço $\phi_{c}$, combinando os estados de caroço com as funções de onda de valência verdadeiras $\phi_{v}$ da seguinte forma

$$
\left|\tilde{\phi}_{v}\right\rangle=\left|\phi_{v}\right\rangle+\sum_{c} \alpha\left|\phi_{c}\right\rangle
$$

em que $\alpha_{c v}=\left\langle\phi_{c} \mid \tilde{\phi}_{v}\right\rangle \neq 0$. Esta pseudofunção de onda satisfaz a equação de Schrödinger modificada

$$
\left[\hat{H}+\sum_{c}\left(\epsilon_{v}-\epsilon_{c}\right)\left|\phi_{c}\right\rangle\left\langle\phi_{c}\right|\right]\left|\tilde{\phi}_{v}\right\rangle=\epsilon_{v}\left|\tilde{\phi}_{v}\right\rangle
$$

em que $\hat{H}=\hat{T}+\hat{V} ; \hat{V}=\left(Z_{c} / r\right) \hat{l}$ é o potencial nuclear e $\hat{I}$ o operador identidade. Assim, é possível construir uma pseudo-hamiltoniana da forma

$$
\hat{H}_{P S}=\hat{H}+\sum_{c}\left(\epsilon_{v}-\epsilon_{c}\right)\left|\phi_{c}\right\rangle\left\langle\phi_{c}\right|
$$

com os mesmos autovalores da hamiltoniana original mas com funções de onda mais suaves e sem nós. O potencial associado a esta pseudo-hamiltoniana é

$$
\hat{V}_{P S}=\frac{Z_{c}}{r} \hat{I}+\sum_{c}\left(\epsilon_{v}-\epsilon_{c}\right)\left|\phi_{c}\right\rangle\left\langle\phi_{c}\right|
$$

e é chamado de pseudopotencial.

Há uma grande liberdade na construção de pseudopotenciais. Este é um problema inverso, dada uma pseudofunção de onda que após alguma distância decai exatamente como a função de onda total; e é um autoestado de uma pseudo-hamiltoniana com os mesmos autovalores da função de onda total, o pseudopotencial é obtido invertendo a equação de Schrödinger radial

$$
\left\{-\frac{\hbar^{2}}{2 m} \frac{d^{2}}{d r^{2}}+\frac{\ell(\ell+1)}{2 r^{2}}+V(r)\right\} r R(\epsilon, r)=\epsilon r R(\epsilon, r)
$$


para a pseudofunção de onda. Esta é uma equação diferencial de segunda ordem. Uma vez fixado $\epsilon$, sua solução é univocamente determinada pelo valor da função de onda $R(\epsilon, r)$ e sua derivada $R^{\prime}(\epsilon, r)$ em qualquer ponto $r_{0}$. Estas duas condições podem ser igualmente realizadas se especificarmos o valor da derivada logarítmica radial da função de onda em $r_{0}$

$$
\cot \eta_{\ell}(\epsilon) \propto\left[\frac{d}{d r} \ln R^{\ell}(\epsilon, r)\right]_{r_{0}}=\frac{1}{R^{\ell}\left(\epsilon, r_{0}\right)}\left[\frac{d R^{\ell}(\epsilon, r)}{d r}\right]_{r_{0}}
$$

junto com uma condição de normalização. Isto pode ser feito para qualquer valor de $\ell$. Portanto, se o potencial total e o pseudopotencial forem os mesmos fora de algum raio $r_{C}$ (raio de cutoff), então estas funções de onda são proporcionais entre si se as derivadas logarítmicas correspondentes são as mesmas, ou seja

$$
\frac{1}{R_{A E}^{\ell}\left(\epsilon, r_{C}\right)}\left[\frac{d R_{A E}^{\ell}(\epsilon, r)}{d r}\right]_{r_{C}}=\frac{1}{R_{P S}^{\ell}\left(\epsilon, r_{C}\right)}\left[\frac{d R_{P S}^{\ell}(\epsilon, r)}{d r}\right]_{r_{C}}
$$

em que $A E$ significa All Electron e PS pseudopotencial. A proporcionalidade se torna uma igualdade apenas quando é requerido que a pseudofunção de onda preserve sua norma dentro do raio de cutoff

$$
\int_{0}^{r_{C}} r^{2}\left[R_{P S}^{\ell}(\epsilon, r]^{2} d r=\int_{0}^{r_{C}} r^{2}\left[R_{A E}^{\ell}(\epsilon, r]^{2} d r .\right.\right.
$$

Estes são chamados de pseudopotenciais de norma conservada [58]. Considerando a regra de soma de Friedel

$$
-\frac{1}{2}\left\{\left[r R^{\ell}(\epsilon, r)\right]^{2} \frac{d}{d \epsilon} \frac{d}{d r} \ln R^{\ell}(\epsilon, r)\right\}_{r_{c}}=\int_{0}^{r_{c}} r^{2}\left[R^{\ell}(\epsilon, r)\right]^{2} d r
$$

a conservação da norma impõe, em primeira ordem nos autovalores, que a derivada logarítmica das funções de onda total e das pseudofunções de onda variam da mesma forma. Ou seja, uma pequena mudança nos autovalores devido à uma alteração no potencial externo produz uma mudança de segunda ordem na derivada logarítmica. Portanto, a condição (2.34), que por construção é válida apenas para o valor de $\epsilon$ usado para obter as funções de onda, se torna aproximadamente válida em uma faixa de autovalores ao redor de $\epsilon$. Por isso, pseudopotenciais derivados de cálculos atômicos podem ser utilizados em 
outros ambientes, o que garante uma alta transferibilidade ao pseudopotencial. Quando um átomo faz parte de uma molécula ou de um cristal, seus elétrons sofrem influência dos outros átomos. Isso implica que os autovalores eletrônicos são deslocados de seus valores atômicos, mas a propriedade de transferibilidade garante que as funções de onda total e as pseudofunções de onda ainda coincidam fora do raio de cutoff. Por isso, a restrição de conservação da norma garante que o pseudopotencial é útil, pelo menos em ambientes tais que os autovalores não sejam significativamente diferentes dos valores usados em sua construção.

Apesar da conservação da norma ser importante para que o pseudopotencial tenha alta transferibilidade, esta restrição o torna "duro" (hard), de tal forma que são necessárias várias ondas planas para a descrição dos estados eletrônicos. Entretanto, independentemente de se respeitar o critério de transferibilidade, embutido na equação (2.36), não é estritamente necessário que a norma da função de onda total e da pseudofunção de onda coincidam. Assim, esforços para se reduzir a quantidade de ondas planas foram feitos na direção de se abrandar a condição de conservação da norma, se generalizando a regra de soma na equação (2.36). Isso foi feito em 1990 por Vanderbilt [52], dando origem aos pseudopotenciais ultrasoft (ultrasuaves).

A essência do método APW original é o fato das funções de onda próximas ao núcleo serem similares às funções atômicas, sendo fortemente variáveis, mas aproximadamente esféricas. Ao contrário, na região intersticial entre os átomos tanto o potencial como as funções de onda são mais suaves. Dessa forma, o espaço é divido em duas regiões e diferentes funções de base são usadas para expandir a função de onda em cada região: soluções da equação de Schrödinger radial dentro de esferas centradas nos átomos e ondas planas na região intersticial remanescente. Um dos problemas deste método é a equação radial de Schrödinger depender de um parâmetro de energia $E_{\ell}$, não conhecido a priori. As APWs são soluções da equação de Schrödinger dentro das esferas apenas na energia $E_{\ell}$, dessa forma as bandas de energia não podem ser obtidas com uma única diagonalização, sendo necessário resolver um determinante secular como função de $E_{\ell}$ e determinar suas raízes, o que demanda alto custo computacional. O método LAPW é uma modificação no APW, 
no qual a função de base dentro das esferas depende não apenas da equação de radial, mas também da sua derivada com relação a $E_{\ell}$. Com isso, as LAPWs possuem uma maior liberdade variacional que as APWs, pois os parâmetros $E_{\ell}$ diferem levemente das bandas de energia. Isto leva a uma enorme simplificação com relação ao método APW, pois todas as bandas de energia podem ser obtidas de maneira precisa com uma única diagonalização, enquanto no APW é necessário uma por banda.

Em 1994, Blochl propôs uma abordagem entre o método LAPW e o de pseudopotenciais [59], chamada Projected Augmented Wave (PAW). Esta abordagem mantém características do LAPW, em que todos os elétrons são considerados (All Electron $\mathrm{AE}$ ), mas usa uma decomposição da função de onda total em termos de uma pseudofunção de onda suave e uma contribuição localizada que varia bruscamente na região do núcleo (as esferas muffin tin, na linguagem do APW). Mostraremos a metodologia PAW da maneria original proposta por Blochl [59].

As funções de onda possuem comportamento diferente em diversas regiões do espaço. Em regiões próximas ao núcleo, há uma rápida oscilação devido à grande atração coulombiana, mas na região de ligação, a função de onda é bem suave. Portanto, consideramos o espaço de Hilbert de todas as funções de onda ortogonais aos estados de caroço. As funções de onda fisicamente relevantes neste espaço de Hilbert possuem um comportamento altamente oscilatório, o que torna o tratamento numérico bem trabalhoso. Uma maneira de se enfrentar este problema é considerar um espaço de Hilbert auxiliar, chamado pseudo-espaço de Hilbert. Mapeamos então as funções de onda de valência da função de onda $A E$ neste novo espaço fictício. Este mapeamento deve ser linear e devem transformar as funções de onda $A E$ em pseudofunções de onda computacionalmente convenientes.

Conhecendo esta transformação $\mathcal{T}$ das pseudofunções de onda para a função de onda $\mathrm{AE}$, qualquer observável, representado pelo valor esperado $\langle\mathcal{O}\rangle$ de algum operador $\mathcal{O}$, das pseudofunções de onda $|\tilde{\phi}\rangle$ pode ser obtido. Isto pode ser feito obtendo-se a função de onda real como $|\phi\rangle=\mathcal{T}|\tilde{\phi}\rangle$ e calculando $\langle\phi|\mathcal{O}| \phi\rangle$. Outra maneira é calcular o valor esperado $\langle\mathcal{O}\rangle=\langle\tilde{\phi}|\tilde{\mathcal{O}}| \tilde{\phi}\rangle$ de um pseudo-operador $\tilde{\mathcal{O}}=\mathcal{T}^{\dagger} \mathcal{O} \mathcal{T}$ no espaço de Hilbert das pseudofunções de onda. 
Da mesma forma, a energia total pode ser calculada diretamente como um funcional das pseudofunções de onda. O estado fundamental das pseudofunções de onda pode ser obtido como

$$
\frac{\partial E[\mathcal{T}|\tilde{\phi}\rangle]}{\partial\langle\tilde{\phi}|}=\epsilon \mathcal{T}^{\dagger} \mathcal{T}|\tilde{\phi}\rangle
$$

É necessário escolher uma forma para a transformação. Como iremos explorar características de tipos atômicos particulares, consideramos apenas transformações que diferem da identidade por uma soma de contribuições $\hat{\mathcal{T}}_{R}$ locais, centrada nos átomos, tais que

$$
\mathcal{T}=1+\sum_{R} \hat{\mathcal{T}}_{R}
$$

Cada contribuição local $\hat{\mathcal{T}}_{R}$ age somente dentro de alguma região aumentada, ao redor de um átomo. Isto implica que a função de onda $A E$ e a pseudofunção de onda coincidem fora desta região. Os termos locais $\hat{\mathcal{T}}_{R}$ são definidos para cada região aumentada individualmente por

$$
\left|\varphi_{i}\right\rangle=\left(1+\hat{\mathcal{T}}_{R}\right)\left|\tilde{\varphi}_{i}\right\rangle
$$

em que se deve especificar a função alvo $\left|\varphi_{i}\right\rangle$ da transformação $\mathcal{T}$, para conjuntos de funções iniciais $\left|\tilde{\varphi}_{i}\right\rangle$. Estas funções são ortogonais aos estados de caroço e completas na região aumentada. Os estados iniciais $\left|\tilde{\varphi}_{i}\right\rangle$ são chamados pseudo-ondas parciais e as correspondentes funções alvo $\left|\varphi_{i}\right\rangle$ ondas parciais AE. Uma escolha natural para as funções das ondas parciais $A E$ são as soluções da equação de Schrödinger radial para o átomo isolado, ortogonalizadas em relação aos estados de caroço, se necessário. $O$ índice $i$ refere-se ao sítio atômico $R$, ao número quântico do momento angular $L=(\ell, m)$ e a um índice adicional $n$ para rotular diferentes ondas parciais no mesmo sítio e momento angular.

Para cada onda parcial AE, escolhe-se uma pseudo-onda parcial denotada por $\tilde{\varphi}_{i}$. Estas pseudo-ondas parciais devem ser idênticas à onda parcial $A E$ correspondente fora da região aumentada e devem elas mesmas constituir um conjunto completo de funções dentro desta região. Os graus de liberdade restantes na escolha das pseudo-ondas parciais são usados para se otimizar as pseudofunções de onda. 
Com estas definições, pode-se construir uma expressão fechada para o operador da transformação $\mathcal{T}$. Dentro da região aumentada, cada pseudofunção de onda parcial pode ser expandida nas pseudo-ondas parciais

$$
|\tilde{\phi}\rangle=\sum_{i}\left|\tilde{\varphi}_{i}\right\rangle c_{i} .
$$

Como $\left|\varphi_{i}\right\rangle=\mathcal{T}\left|\tilde{\varphi}_{i}\right\rangle$, as funções de onda AE correspondentes são da forma

$$
|\phi\rangle=\mathcal{T}|\tilde{\phi}\rangle=\sum_{i}\left|\varphi_{i}\right\rangle c_{i}
$$

com coeficientes $c_{i}$ idênticos nas duas expansões. Assim, podemos expressar a função de onda $A E$ como

$$
|\phi\rangle=|\tilde{\phi}\rangle-\sum_{i}\left|\tilde{\varphi}_{i}\right\rangle c_{i}+\sum_{i}\left|\varphi_{i}\right\rangle c_{i}
$$

em que os coeficientes da expansão das ondas parciais ainda devem ser determinados.

Como esta transformação deve ser linear, os coeficientes $c_{i}$ devem ser funcionais lineares das pseudofunções de onda. Portanto, os coeficientes são produtos escalares

$$
c_{i}=\left\langle\tilde{p}_{i} \mid \tilde{\phi}_{i}\right\rangle
$$

das pseudofunções de onda com alguma função fixa $\left\langle\tilde{p}_{i}\right|$, chamadas funções projetoras. Existe exatamente uma função projetora para cada pseudo-onda parcial. As funções projetoras são localizadas na região aumentada, apesar de, em princípio, funções projetoras mais estendidas possam ser escolhidas. A forma mais geral para a função projetora, segundo Blochl, é

$$
\left\langle\tilde{p}_{i}\right|=\sum_{j}\left(\left\{\left\langle f_{k} \mid \tilde{\phi}_{1}\right\rangle\right\}\right)_{i j}^{-1}\left\langle f_{j}\right|
$$

em que $f_{k}$ forma um conjunto arbitrário e linearmente independente de funções. As funções projetoras são localizadas se as funções $\left|f_{i}\right\rangle$ também o forem. Resumindo, a transformação linear (2.38)

$$
\mathcal{T}=1+\sum_{i}\left(\left|\varphi_{i}\right\rangle-\left|\tilde{\varphi}_{i}\right\rangle\right)\left\langle\tilde{p}_{i}\right|
$$


entre as funções de onda parciais de valência e as pseudofunções de onda foi estabelecida. Usando esta transformação, as funções de onda AE podem ser obtidas das pseudofunções de onda por

$$
|\phi\rangle=|\tilde{\phi}\rangle+\sum_{i}\left(\left|\varphi_{i}\right\rangle-\left|\tilde{\varphi}_{i}\right\rangle\right)\left\langle\tilde{p}_{i} \mid \tilde{\phi}_{i}\right\rangle .
$$

Esta transformação é determinada por três quantidades: as ondas parciais $\mathrm{AE}$ $\left|\varphi_{i}\right\rangle$ obtidas por uma integração radial da equação de Schrödinger de um conjunto de energias atômicas $\epsilon_{i}^{1}$ e ortogonalizadas com os estados de caroço; uma pseudo-onda parcial $\left|\tilde{\varphi}_{i}\right\rangle$, que coincide com a onda parcial AE; e uma função projetora para cada pseudo-onda parcial localizada dentro da região aumentada e que obedeça à relação $\left\langle\tilde{p}_{i} \mid \tilde{\varphi}_{j}\right\rangle=\delta_{i j}$.

As ondas parciais são funções radiais multiplicadas por harmônicos esféricos. Em geral, as pseudofunções de onda são expandidas em ondas planas, mas outras escolhas são igualmente possíveis. As funções projetoras também são radiais multiplicadas por harmônicos esféricos, mas em seguida são transformadas nas mesmas representações das pseudofunções de onda.

Os estados de caroço $\left|\phi_{c}\right\rangle$ são decompostos de uma maneira similar aos de valência. Eles possuem três contribuições: uma pseudofunção de onda de caroço $\left|\phi_{c}\right\rangle$, idênticas aos estados verdadeiros fora da região aumentada e uma continuação suave dentro; uma onda parcial $\mathrm{AE}\left|\varphi_{c}\right\rangle$ que são idênticas aos estados de caroço $A E\left|\phi^{c}\right\rangle$ e são expressas como funções radiais multiplicadas por harmônicos esféricos; e uma pseudo-onda parcial de caroço, que são idênticas aos pseudoestados de caroço $\left|\tilde{\phi}^{c}\right\rangle$, mas representadas também como funções radiais multiplicadas por harmônicos esféricos. Dessa forma, os estados de caroço são expressos na forma

$$
\left|\phi^{c}\right\rangle=\left|\tilde{\phi}^{c}\right\rangle+\left|\varphi^{c}\right\rangle-\left|\tilde{\varphi}^{c}\right\rangle .
$$

Ao contrário dos estados de valência, não são necessárias funções projetoras para os estados de caroço. Além disso, os estados de caroço são importados do átomo isolado.

Portanto, no método PAW também se tem uma divisão do espaço, assim como no LAPW, e a função de onda AE é decomposta em termos de uma pseudofunção de onda suave mais uma contribuição localizada. A função de onda 
AE (verdadeira) e a pseudofunção de onda são relacionadas por uma transformação linear, dada pela equação (2.42). Apesar de não ser estritamente necessário, o método PAW congela os orbitais de caroço em uma configuração de referência, funcionando apenas para os estados de valência, exatamente como no método de pseudopotencial. Por isso, todos os métodos de pseudopotenciais podem ser utilizados no PAW. Até o presente, o método PAW parece ser um dos métodos mais poderosos para os cálculo de estrutura eletrônica de cristais, pois combina a eficiência dos pseudopotenciais com a precisão dos métodos baseados no APW, sendo a metodologia utilizada neste trabalho. O método PAW é uma abordagem geral, possuindo o APW como um caso particular [60] e o método de pseudopotenciais como uma aproximação bem definida [61].

\subsection{Propriedades termodinâmicas}

A metodologia descrita até agora utiliza uma rede estática (aproximação de Born-Oppenheimer) para descrever o cristal. Como os íons estão parados, todas as propriedades calculadas dessa forma são independentes da temperatura. A Terra apresenta um gradiente de temperatura elevado, atingindo milhares de Kelvin no manto superior e inferior, podendo chegar a temperaturas de até $6000 \mathrm{~K}$ no núcleo, de tal forma que a inclusão de efeitos térmicos nas simulações pode influenciar os resultados. Dentro da aproximação adiabática, os graus de liberdade associados ao movimento dos íons são separados dos da parte eletrônica. A metodologia apresentada até o momento trata apenas desta última. Entretanto, para a incorporação de efeitos térmicos, deve-se considerar também o movimento dos núcleos atômicos, descritos pela equação (2.5). Nesta equação, os íons estão sujeitos ao potencial devido aos outros íons $\hat{V}_{N N}$ e ao potencial devido aos elétrons do sistema. Se não há forças agindo sobre os íons, o que corresponde à rede estática, então o cristal está em equilíbrio. Deste modo, pode-se considerar que os íons descrevem um movimento oscilatório ao redor de uma posição de equilíbrio. Isto corresponde a um potencial harmônico agindo sobre os íons.

De acordo com a mecânica estatística, os níveis de energia de um sistema 
determinam completamente suas funções termodinâmicas. Em particular, a energia livre de Helmholtz é dada, de maneira geral, por

$$
F=-k_{B} T \ln Z
$$

em que $k_{B}$ é a constante de Boltzmann, $T$ a temperatura e $Z$ a função de partição, que é a soma de todos os fatores de Boltzmann correspondentes a todos os níveis de energia possíveis do sistema

$$
Z=\sum_{n} \exp \left[-\frac{\epsilon_{n}}{k_{B} T}\right]
$$

sendo $\epsilon_{n}$ os autovalores do operador energia. Os núcleos atômicos, sendo muito mais pesados que os elétrons, realizam um movimento oscilatório ao redor de suas posições de equilíbrio, de tal forma que pode-se aproximar a interação entre os íons por um potencial harmônico. Assim, se considerarmos o sólido como um conjunto de osciladores independentes, os autovalores de energia do sistema são dados por

$$
\epsilon_{n}=\left(n+\frac{1}{2}\right) \hbar \omega
$$

Com a utilização das equações (2.48), (2.49) e (2.50), a energia livre se escreve

$$
F_{i}=\frac{1}{2} \hbar \omega_{i}+k_{B} T \ln \left\{1-\exp \left[-\frac{\hbar \omega_{i}}{k_{B} T}\right]\right\} \text {. }
$$

Para uma rede cristalina com modos normais de vibração $\omega_{i}, \sum_{i} F_{i}$ nos dá a parcela da energia livre associada com a vibração do sistema. A energia livre total inclui também a parcela da energia da rede estática, na qual os íons ocupam sua posição de equilíbrio. Assim, pode-se escrever a energia livre de Helmholtz como

$$
F(V, T)=E(V)+\frac{1}{2} \sum_{q, i} \hbar \omega_{q, i}(V)+k_{B} T \sum_{q, i} \ln \left\{1-\exp \left[-\frac{\hbar \omega_{q, i}(V)}{k_{B} T}\right]\right\}
$$

em que $q$ são vetores do espaço recíproco. Nesta expressão o segundo e o terceiro termos do lado direito são a energia de ponto zero e a energia térmica do sistema, respectivamente, enquanto $E(V)$ é a energia interna estática do sistema, calculada através da DFT e cuja metologia foi descrita na seção anterior. 
Esta maneira de introduzir-se efeitos térmicos é conhecida como aproximação quase-harmônica e possibilita o cálculo da energia livre de Helmholtz do sistema e, assim, a determinação de todas propriedades termodinâmicas, para sistemas em que o acoplamento elétron-fônon é desprezível.

\section{Cálculo de fônons por primeiros princípios}

O cálculo da energia livre de Helmholtz, equação (2.52), dentro da aproximação quase-harmônica, requer o conhecimento da energia interna estática do sistema, $E(V)$, e das frequências de vibração (fônons) do cristal [62]. De acordo com a equação (2.5), o potencial efetivo $V_{e f}$ a que os íns estão sujeitos é dado por

$$
V_{e f}=V_{N N}+E_{n}(\vec{R}) .
$$

Considere, então, um cristal com $n$ átomos por célula unitária e seja $u(\ell k)$ o deslocamento do átomo $k$ na célula $\ell$. Assumindo que o potencial $V_{e f}$ é uma função da posição instantânea de todos os átomos, pode-se expandir $V_{e f}$, em uma série de Taylor, em potências do deslocamento $u_{\alpha}(\ell k)$, do átomo $\alpha$ [62], como

$$
V_{e f}=V_{0}+\left.\sum_{\ell k \alpha} \frac{\partial V_{e f}}{\partial u_{\alpha}(\ell k)}\right|_{0} u_{\alpha}(\ell k)+\frac{1}{2} \sum_{\ell k, \ell^{\prime} k^{\prime}} \sum_{\alpha \beta} \Phi_{\alpha \beta}\left(\ell k, \ell^{\prime} k^{\prime}\right) u_{\alpha}(\ell k) u_{\beta}\left(\ell^{\prime} k^{\prime}\right)+\ldots
$$

em que $V_{0}$ é o valor do potencial na posição de equilíbrio e

$$
\Phi_{\alpha \beta}\left(\ell k, \ell^{\prime} k^{\prime}\right)=\left.\frac{\partial^{2} V_{e f}}{\partial u_{\alpha}(\ell k) \partial u_{\beta}\left(\ell^{\prime} k^{\prime}\right)}\right|_{0} .
$$

O primeiro termo na equação (2.54) é uma constante, podendo ser considerada nula. O segundo termo é a força em cada átomo e, portanto, também nula na configuração de equilíbrio. Na aproximação harmônica, termos de ordem maiores que dois (termos quadráticos) não são considerados na expansão e tem-se

$$
V_{\text {harm }}=\frac{1}{2} \sum_{\ell k, \ell^{\prime} k^{\prime}} \sum_{\alpha \beta} \Phi_{\alpha \beta}\left(\ell k, \ell^{\prime} k^{\prime}\right) u_{\alpha}(\ell k) u_{\beta}\left(\ell^{\prime} k^{\prime}\right) .
$$

Pode-se, então, escrever a equação de movimento para os íons [62]

$$
m_{k} \ddot{u}_{\alpha}(\ell k)=\sum_{\ell^{\prime} k^{\prime} \beta} \Phi_{\alpha \beta}\left(l k, \ell^{\prime} k^{\prime}\right) u_{\beta}\left(\ell^{\prime} k^{\prime}\right)
$$


em que $m_{k}$ é a massa do $k$-ésimo átomo, $\alpha=x, y, z$, e $\Phi$ é a matriz de força interatômica, em que $\Phi_{\alpha \beta}\left(l k, \ell^{\prime} k^{\prime}\right)$ representa a força linear negativa em um átomo $(\ell k)$ na direção $\alpha$, devido a um deslocamento do átomo $\left(\ell^{\prime} k^{\prime}\right)$ na direção $\beta$. Devido à simetria de translação, a matriz de constantes de força pode ser escrita como

$$
\Phi_{\alpha \beta}\left(\ell k, \ell^{\prime} k^{\prime}\right)=\Phi_{\alpha \beta}\left(0 k,\left(\ell^{\prime}-\ell\right) k^{\prime}\right)
$$

e a equação (2.57) pode ser escrita como

$$
m_{k} \ddot{u}_{\alpha}(\ell k)=\sum_{\ell^{\prime} k^{\prime} \beta} \Phi_{\alpha \beta}\left(0 k, \ell^{\prime} k^{\prime}\right) u_{\beta}\left(\ell^{\prime} k^{\prime}\right) .
$$

Para resolver esta equação, supomos uma solução da forma

$$
u_{\alpha}(\ell k)=\frac{1}{\sqrt{m_{k}}} \sum_{q} U_{\alpha}(q, k) \exp [i(q . x(l)-\omega t)],
$$

em que $x(\ell)$ é o vetor posição de equilíbrio da $\ell$-ésima célula unitária e $U_{\alpha}(q, k)$ não depende de $\ell$. Substituindo essa solução na equação (2.59), tem-se

$$
\omega^{2} U_{\alpha}(q, k)=\sum_{k^{\prime} \beta} D_{\alpha \beta}\left(k k^{\prime} \mid q\right) U_{\beta}\left(q, k^{\prime}\right),
$$

cuja solução não trivial é obtida solucionando o determinante

$$
\left|D_{\alpha \beta}\left(k k^{\prime} \mid q\right)-\omega^{2} \delta_{\alpha \beta} \delta_{k k^{\prime}}\right|=0 .
$$

Nesta expressão, $D_{\alpha \beta}$ é a matriz dinâmica do sistema e é dada por

$$
D_{\alpha \beta}\left(k k^{\prime} \mid q\right)=\frac{1}{\sqrt{m_{k} m_{k^{\prime}}}} \sum_{\ell^{\prime}} \Phi_{\alpha \beta}\left(0 k, \ell^{\prime} k^{\prime}\right) \exp \left(i q . x\left(\ell^{\prime}\right)\right) .
$$

A matriz dinâmica é uma matriz hermitiana $3 n \times 3 n$. Por isso, possui $3 n$ autovalores reais, correspondentes aos $3 n$ graus de liberdade da célula unitária com $n$ átomos. Como $D_{\alpha \beta}$ é uma matriz hermitiana, seus autovalores $\omega^{2}$ são reais e esta é uma condição necessária (mas não suficiente) para o cristal ser considerado estável. As frequências de vibração de um cristal, necessárias para se construir a energia livre de Helmholtz na equação (2.52), podem ser obtidas diagonalizando-se a matriz dinâmica, dada pela equação (2.62). Devemos então calcular essa matriz para obter as propriedades termodinâmicas do cristal. 
Dentro do formalismo descrito, o cálculo da matriz dinâmica pode ser feito diretamente, deslocando-se um átomo da célula e calculando as forças que aparecem no sistema através do teorema de Hellman-Feynman. Entretanto, este método requer a utilização de supercélulas grandes o suficiente para que os elementos $\Phi_{\alpha \beta}\left(0 k, \ell^{\prime} k^{\prime}\right)$ sejam pequenos o bastante nas bordas da célula. Além disso, podem ser necessários muitos deslocamentos para cálculos das forças em todos os átomos. Por exemplo, uma estrutura a ser estudada neste trabalho é descrita por uma célula monoclínica de bases centradas, com uma base de 30 átomos. Nesta estrutura são necessários 51 deslocamentos, ou seja, 51 cálculos de estrutura eletrônica, mostrando que este método é inviável para se estudar fônons de cristais que apresentam células com baixa simetria e com uma base com um número grande de átomos. Uma alternativa é o uso da teoria de pertubação do funcional da densidade. Este foi o método usado neste trabalho e que passaremos a expor a seguir.

Considere que o potencial externo dependa de algum parâmetro $\lambda$, tal que

$$
V_{\lambda}(\vec{r}) \approx V(\vec{r})+\lambda \frac{\partial V(\vec{r})}{\partial \lambda}+\frac{1}{2} \lambda^{2} \frac{\partial^{2} V(\vec{r})}{\partial \lambda^{2}}+\ldots
$$

em que todas as derivadas são calculadas em $\lambda=0$. Podemos também expandir, em potências de $\lambda$, a densidade de carga e a energia do sistema, tal que

$$
\begin{aligned}
n_{\lambda}(\vec{r}) & \approx n(\vec{r})+\lambda \frac{\partial n(\vec{r})}{\partial \lambda}+\frac{1}{2} \lambda^{2} \frac{\partial^{2} n(\vec{r})}{\partial \lambda^{2}}+\ldots \\
E_{\lambda} & \approx E+\lambda \frac{\partial E}{\partial \lambda}+\frac{1}{2} \lambda^{2} \frac{\partial^{2} E}{\partial \lambda^{2}}+\ldots
\end{aligned}
$$

Pelo teorema de Hellman-Feynman, a derivada de primeira ordem da energia $(\partial E / \partial \lambda)$ não depende de nenhuma derivada da densidade $n(\vec{r})$, de modo que

$$
\frac{\partial E}{\partial \lambda}=\int n(\vec{r}) \frac{\partial V(\vec{r})}{\partial \lambda} d \vec{r}
$$

Portanto, a derivada de segunda ordem da energia $\left(\partial^{2} E / \partial \lambda^{2}\right)$ depende de derivadas de primeira ordem da densidade como

$$
\frac{\partial^{2} E}{\partial \lambda^{2}}=\int \frac{\partial V(\vec{r})}{\partial \lambda} \frac{\partial n(\vec{r})}{\partial \lambda} d \vec{r}+\int n(\vec{r}) \frac{\partial^{2} V(\vec{r})}{\partial \lambda^{2}} d \vec{r},
$$


resultado este que pode ser generalizado para variáveis mistas, de modo que

$$
\frac{\partial^{2} E}{\partial \lambda \partial \mu}=\int \frac{\partial V(\vec{r})}{\partial \lambda} \frac{\partial n(\vec{r})}{\partial \mu} d \vec{r}+\int n(\vec{r}) \frac{\partial^{2} V(\vec{r})}{\partial \lambda \partial \mu} d \vec{r} .
$$

De maneira geral, a derivada de ordem $(2 n+1)$ da energia depende apenas de derivadas até ordem $n$ da densidade de carga (teorema $(2 n+1)$ ) [63-65]. A derivada de primeira ordem da densidade de carga pode ser obtida de maneira tradicional através da teoria de resposta linear, aplicando a teoria de pertubação na hamiltoniana de Kohn-Sham temos

$$
\frac{\phi_{v}(\vec{r})}{\partial \lambda}=\sum_{c} \phi_{c}(\vec{r}) \frac{1}{\varepsilon_{v}-\varepsilon_{c}}\left\langle\phi_{c}\left|\frac{\partial V_{K S}}{\partial \lambda}\right| \phi_{v}\right\rangle=\frac{1}{\varepsilon_{v}-H_{K S}} P_{c} \frac{\partial V_{K S}(\vec{r})}{\partial \lambda} \phi_{v}(\vec{r}),
$$

em que $v$ denota estados ocupados e $c$ estados vazios e $P_{c}$ é o operador projetor sobre estados vazios. A resposta autoconsistente do potencial

$$
\frac{\partial V_{K S}(\vec{r})}{\partial \lambda}=\frac{\partial V(\vec{r})}{\partial \lambda}+\int \frac{1}{\left|\vec{r}-\vec{r}^{\prime}\right|} \frac{n\left(\vec{r}^{\prime}\right)}{\partial \lambda} d \vec{r}^{\prime}+\int \frac{\delta V_{x c}(\vec{r})}{\delta n\left(\vec{r}^{\prime}\right)} \frac{\partial n\left(\vec{r}^{\prime}\right)}{\partial \lambda} d \vec{r}^{\prime}
$$

depende da variação em primeira ordem da densidade de carga

$$
\frac{\partial n\left(\vec{r}^{\prime}\right)}{\partial \lambda}=2 \operatorname{Re} \sum_{v} \phi_{v}^{\star}(\vec{r}) \frac{\partial \phi_{v}(\vec{r})}{\partial \lambda} .
$$

Assim, $\partial \phi_{v}(\vec{r}) / \partial \lambda$ e todas outras quantidades necessárias podem ser determinadas, de maneira autoconsistente, resolvendo-se um conjunto de equações lineares.

\subsection{Teoria elástica de cristais}

\section{O tensor de deformação}

A teoria da elasticidade trata da relação entre as mudanças no volume e na forma em um material sob ação de forças. Quando forças são aplicadas sobre um sólido, este sofre deformações em alguma extensão. Estas deformações podem ser explicadas matematicamente considerando-se um corpo em um referencial cartesiano em três dimensões. Um ponto do corpo pode ser descrito 
pela coordenada $\left(x_{1}, x_{2}, x_{3}\right)$. Uma transformação linear impõe ao corpo uma rotação e uma mudança tanto de orientação quanto de forma $[66,67]$, de modo que suas coordenadas apresentam a transformação

$$
x_{i}^{\prime}=\chi_{i 0}+\left(\delta_{i j}+\chi_{i j}\right) x_{j},
$$

em que os $x_{i}^{\prime}$ representam as novas coordenadas do ponto originalmente em $x_{i}, \chi_{i 0}$ representa uma translação, $\chi_{i j}$ são os elementos de uma transformação linear e a convenção de soma de Einstein foi utilizada.

Considere um segmento de linha no interior do corpo submetido a uma transformação da forma apresentada na equação (2.73). Impondo a restrição de que o comprimento $\Delta x$ desse elemento de linha permaneça inalterado, devemos ter

$$
\Delta x_{i} \Delta x_{i}=\Delta x_{i}^{\prime} \Delta x_{i}^{\prime}
$$

e substituindo a equação (2.73) na (2.74), obtemos

$$
\begin{aligned}
& \Delta x_{i} \Delta x_{i}= {\left[\left(\delta_{i j}+\chi_{i j}\right) \Delta x_{j}\right]\left[\left(\delta_{i k}+\chi_{i k}\right) \Delta x_{k}\right] } \\
&= \delta_{i j} \delta_{i k} \Delta x_{j} \Delta x_{k}+\delta_{i j} \chi_{i k} \Delta x_{j} \Delta x_{k}+\delta_{i k} \chi_{i j} \Delta x_{j} \Delta x_{k} \\
&= \Delta x_{i} \Delta x_{i}+\chi_{i k} \Delta x_{i} \Delta x_{k}+\chi_{i j} \Delta x_{j} \Delta x_{i} \Longrightarrow \\
& \Longrightarrow x_{i j} \Delta x_{i} \Delta x_{j}=0,
\end{aligned}
$$

ou seja,

$$
\begin{aligned}
\chi_{11}\left(\Delta x_{1}\right)^{2} & +\chi_{22}\left(\Delta x_{2}\right)^{2}+\chi_{33}\left(\Delta x_{3}\right)^{2}+\left(\chi_{23}+\chi_{32}\right) \Delta x_{2} \Delta x_{3}+ \\
& +\left(\chi_{31}+\chi_{13}\right) \Delta x_{3} \Delta x_{1}+\left(\chi_{12}+\chi_{21}\right) \Delta x_{1} \Delta x_{2}=0 .
\end{aligned}
$$

A equação (2.76) só pode ser satisfeita para um elemento arbitrário $\Delta x_{i}$ se

$$
\begin{aligned}
& \chi_{11}=\chi_{22}=\chi_{33}=0 \\
& \chi_{23}+\chi_{32}=0 \Rightarrow \chi_{23}=-\chi_{32} \\
& \chi_{31}+\chi_{13}=0 \Rightarrow \chi_{31}=-\chi_{13} \\
& \chi_{12}+\chi_{21}=0 \Rightarrow \chi_{12}=-\chi_{21}
\end{aligned}
$$

isto é,

$$
\chi_{i j}=-\chi_{j i}
$$


Dessa forma, impondo a restrição de que o comprimento do elemento de linha seja inalterado, a transformação linear representa uma rotação e uma translação do elemento de linha. Considerando todos os possíveis elementos de linha de um corpo e efetuando a transformação (2.73), com a restrição dada em (2.74), e com $\chi_{i 0}$ e $\chi_{i j}$ os mesmos para todos os elementos, então todos os elementos de linha serão transladados e rotacionados de tal forma que o volume $e$ a forma do corpo permanecem inalterados. Isso é idêntico ao deslocamento de um corpo rígido obtido na mecânica clássica. Note que há 3 componentes da translação $\chi_{i 0}$ e 3 da matriz antissimétrica $\chi_{i j}$. Ou seja, 6 graus de liberdade, como na mecânica clássica.

Considere, agora, uma transformação geral, de tal forma que o comprimento do elemento de linha seja alterado. Devemos ter, então, pela equação (2.73), que

$$
\begin{aligned}
\Delta x_{i}^{\prime}= & \left(\delta_{i j}+\chi_{i j}\right) \Delta x_{j}, \\
= & \delta_{i j} \Delta x_{j}+x_{i j} \Delta x_{j} \\
= & \Delta x_{i}+\chi_{i j} \Delta x_{j} \Longrightarrow \\
& \Longrightarrow \Delta x_{i}^{\prime}-\Delta x_{i}=\chi_{i j} \Delta x_{j}
\end{aligned}
$$

A equação (2.79) nos dá a variação de cada elemento de linha, quando o corpo é submetido à transformação (2.73). Podemos também escrever esta equação em termos das partes simétrica e antissimétrica de $\chi_{i j}$

$$
\Delta x_{i}^{\prime}-\Delta x_{i}=\frac{1}{2}\left[\left(\chi_{i j}+\chi_{j i}\right)+\left(\chi_{i j}-\chi_{j i}\right)\right] \Delta x_{j} .
$$

Por esta equação, percebe-se que a restrição (2.74) impõe que a parte simétrica de $\chi_{i j}$ seja nula e podemos identificar a parte antissimétrica com as rotações do corpo

$$
\omega_{i j}=\frac{1}{2}\left(x_{i j}-x_{j i}\right) .
$$

Assim, se montarmos uma expressão para a mudança no quadrado do comprimento, obteremos exatamente o lado esquerdo da equação (2.76)

$$
\Delta x_{i}^{\prime} \Delta x_{i}^{\prime}-\Delta x_{i} \Delta x_{i}=\frac{1}{2}\left(x_{i j}+x_{j i}\right) \Delta x_{i} \Delta x_{j} .
$$


Portanto, a mudança no comprimento de um elemento de linha está relacionada com a parte simétrica de $\chi_{i j}$

$$
e_{i j}=\frac{1}{2}\left(\chi_{i j}+\chi_{j i}\right) .
$$

A quantidade simétrica $e_{i j}$ possui toda a informação sobre as deformações de qualquer elemento de linha de um corpo submetido a uma transformação $\chi_{i j} \mathrm{e}$ é conhecido com tensor de deformação, enquanto que a quantidade antissimétrica $\omega_{i j}$ possui toda a informação pertinente às rotações do corpo rígido.

Considere, agora, que um corpo sofreu uma deformação, de tal forma que o deslocamento de um ponto $\mathcal{P}$ em $x_{i}$ foi $u_{i}\left(x_{j}\right)$. Considere que essa função e suas derivadas são contínuas. Antes da deformação, o comprimento do elemento de linha $d x_{i}$ é

$$
d s^{2}=d x_{i} d x_{i}
$$

depois da deformação

$$
d s^{\prime 2}=\left(d x_{i}+\frac{\partial u_{i}}{\partial x_{j}} d x_{j}\right)\left(d x_{i}+\frac{\partial u_{i}}{\partial x_{k}} d x_{k}\right)=d x_{i} d x_{j}\left[\delta_{i j}+\left(\frac{\partial u_{i}}{\partial x_{j}}+\frac{\partial u_{j}}{\partial x_{i}}\right) \frac{\partial u_{k}}{\partial x_{i}} \frac{\partial u_{k}}{\partial x_{j}}\right] .
$$

Como uma translação e uma rotação não mudam o comprimento de um elemento de linha, é esperado que a mudança em $d s$ seja devido apenas à distorção do material. Assim

$$
d s^{\prime 2}-d s^{2}=d x_{i} d x_{j}\left(\frac{\partial u_{i}}{\partial x_{j}}+\frac{\partial u_{j}}{\partial x_{i}}\right)=2 \epsilon_{i j} d x_{i} d x_{j}
$$

em que $\epsilon_{i j}$ são coeficientes que especificam a deformação do elemento de linha sob o deslocamento $u_{i}$. Assim, tem-se

$$
\epsilon_{i j}=\frac{1}{2}\left(\frac{\partial u_{i}}{\partial x_{j}}+\frac{\partial u_{j}}{\partial x_{i}}\right)+\frac{1}{2} \frac{\partial u_{k}}{\partial x_{i}} \frac{\partial u_{k}}{\partial x_{j}}
$$

Expandindo $\epsilon_{i j}$ obtemos três expressões da forma

$$
\epsilon_{11}=\frac{\partial u_{1}}{\partial x_{1}}+\frac{1}{2}\left[\left(\frac{\partial u_{1}}{\partial x_{1}}\right)^{2}+\left(\frac{\partial u_{2}}{\partial x_{1}}\right)^{2}+\left(\frac{\partial u_{3}}{\partial x_{1}}\right)^{2}\right]
$$

e três da forma

$$
\epsilon_{23}=\frac{1}{2}\left(\frac{\partial u_{2}}{\partial x_{3}}+\frac{\partial u_{3}}{\partial x_{2}}\right)+\frac{1}{2}\left(\frac{\partial u_{1}}{\partial x_{2}} \frac{\partial u_{1}}{\partial x_{3}}+\frac{\partial u_{2}}{\partial x_{2}} \frac{\partial u_{2}}{\partial x_{3}}+\frac{\partial u_{3}}{\partial x_{3}} \frac{\partial u_{3}}{\partial x_{3}}\right) .
$$


Os elementos de $\epsilon_{i j}$, em termos das derivadas dos deslocamentos e em termos das coordenadas, no estado não deformado, são conhecidos como componentes da distorção de Lagrange. Elementos similares escritos em termos das derivadas espaciais com respeito às coordenadas do sistema deformado são definidas por

$$
\eta_{i j}=\frac{1}{2}\left(\frac{\partial u_{i}}{\partial x_{j}}+\frac{\partial u_{j}}{\partial x_{i}}\right)-\frac{1}{2} \frac{\partial u_{k}}{\partial x_{i}} \frac{\partial u_{k}}{\partial x_{j}}
$$

e são conhecidas como componentes Eulerianas da distorção. Em primeira ordem, as distorções de Euler e Lagrange são idênticas e podemos identificar

$$
e_{i j}=\frac{1}{2}\left(\frac{\partial u_{i}}{\partial x_{j}}+\frac{\partial u_{j}}{\partial x_{i}}\right) \text {. }
$$

\section{O tensor de stress}

Quando um corpo não está deformado, o arranjo de suas moléculas correspondem a um estado de equilíbrio térmico, ou seja, todas as partes do corpo estão em equilíbrio mecânico. Se considerarmos qualquer parte do corpo, a força resultante é zero. Sob uma deformação, as moléculas do corpo deixam suas posições de equilíbrio e surgem forças que tendem a retornar o corpo à sua configuração original. Considere uma partícula $\mathcal{P}$ no interior de um corpo e um vetor unitário $\vec{n}$ em $\mathcal{P}$, apontando em qualquer direção. Seja $\Delta S$ um pequeno plano dentro do corpo, contendo $\mathcal{P}$ e normal à $\vec{n}$. Considere agora as forças através de $\Delta S$ de duas porções separadas do corpo, as quais tenham $\triangle S$ como uma fronteira comum. Se considerarmos apenas as forças normais à $\vec{n}$, estas forças formam uma dupla sobre $\Delta S$. Esta força é chamada tração (ou compressão, dependendo do sentido) através de $\Delta S$. Se tomarmos o limite de $\Delta S$ tendendo à zero, a razão entre a tração através de $\Delta S$ e a área $\Delta S$ é o stress em $\mathcal{P}$, correspondendo à direção $\vec{n}$. Isto é [68]

$$
\Sigma^{n}(\mathcal{P}, \vec{n})=\lim _{\Delta S \rightarrow 0} \frac{\Delta T}{\Delta S}
$$

Considere, agora, um sistema cartesiano de coordenadas e um elemento infinitesimal do corpo neste sistema, como mostra a figura 2.1. Se o vetor normal $\vec{n}$ for perpendicular a cada um dos planos $(y x, x z, y z)$, apontando na direção 


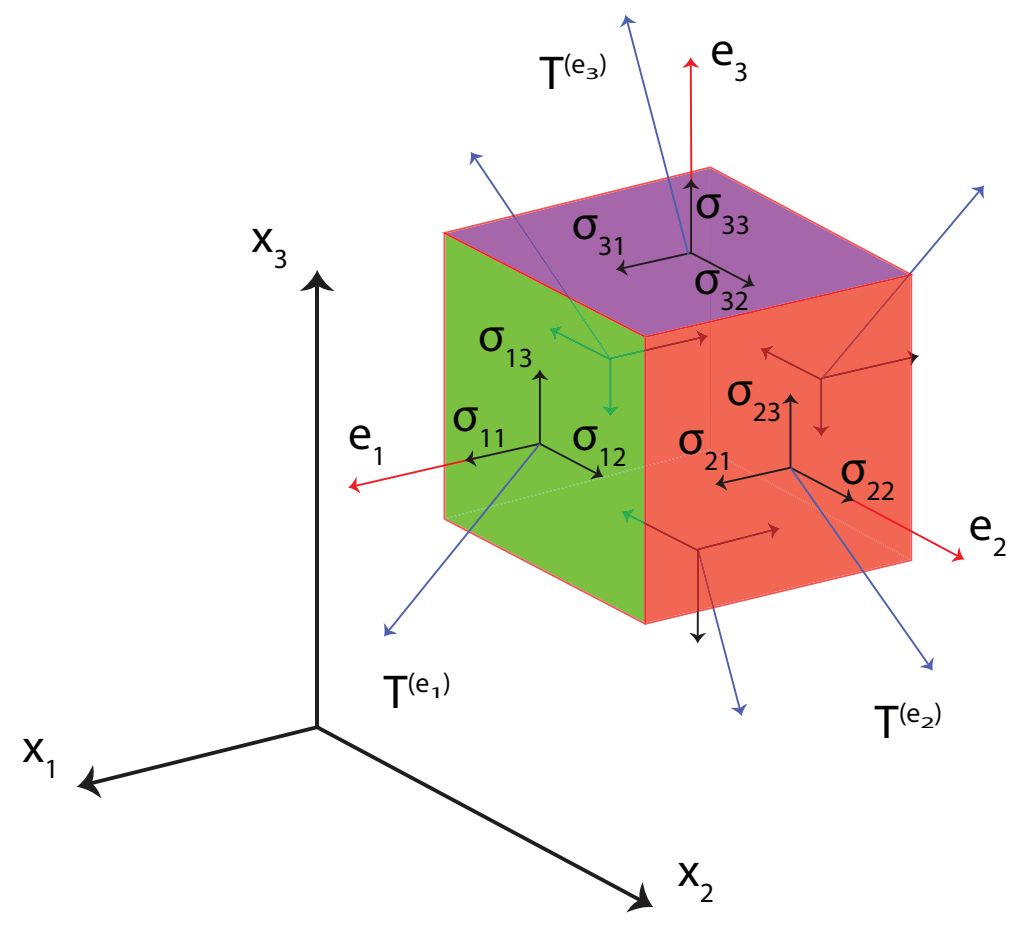

Figura 2.1: Esquema do stress em cada face de um elemento de volume no interior do sólido

positiva do eixo da coordenada, podemos decompor o $\Sigma^{n}$ nas componentes sobre cada um dos eixos

$$
\begin{aligned}
& \Sigma^{n}(\mathcal{P}, \vec{n} \| x)=\sigma_{11} \hat{x}+\sigma_{12} \hat{y}+\sigma_{13} \hat{z} \\
& \Sigma^{n}(\mathcal{P}, \vec{n} \| y)=\sigma_{21} \hat{x}+\sigma_{22} \hat{y}+\sigma_{23} \hat{z} \\
& \Sigma^{n}(\mathcal{P}, \vec{n} \| z)=\sigma_{31} \hat{x}+\sigma_{32} \hat{y}+\sigma_{33} \hat{z} .
\end{aligned}
$$

As nove componentes $\sigma_{i j}$ são as componentes do stress. Elas formam um tensor de segunda ordem, assim como o tensor de distorção. Em geral, se considera como positivo a componente do stress apontando para fora da superfície da figura 2.1. Considere agora a equação

$$
\operatorname{det}\left|\sigma_{i j}-\sigma \delta_{i j}\right|=0,
$$

em que seus autovetores são os eixos principais de stress e seus autovalores $\sigma_{i}$ os stress principais. Pode-se mostrar que

$$
\sigma_{1}+\sigma_{2}+\sigma_{3}=\sigma_{11}+\sigma_{22}+\sigma_{33}=\operatorname{Tr}\left[\sigma_{i i}\right]
$$


e, como traço de um tensor, essa quantidade é invariante para qualquer rotação de coordenadas. Podemos identificá-la como um stress que tem a natureza de uma pressão hidrostática. Podemos então considerar que as componentes do stress como uma componente de pressão hidrostática e cinco componentes de tensões de cisalhamento. O stress normal médio $\sigma$ é

$$
\sigma=\frac{1}{3}\left(\sigma_{1}+\sigma_{2}+\sigma_{3}\right)
$$

e, se um corpo está submetido a um stress hidrostático de compressão, tem-se que a pressão $P$ é dada por

$$
P=-\sigma=-\frac{1}{3} \operatorname{Tr}\left[\sigma_{i i}\right] .
$$

Um material sob stress apresenta certa deformação. Se as componentes do tensor de distorção são determinadas pelas componentes do tensor de stress, o material é considerado perfeitamente elástico. Neste caso, as componentes da distorção são funções lineares homogêneas das componentes do stress. Isso é uma generalização da lei de Hooke e é uma boa aproximação para muitos materiais, inclusive os que compõe o manto terrestre.

\section{Stress Quântico}

Estudos para uma definição do stress dentro da mecânica quântica foram realizados desde o surgimento desta teoria. O próprio Schrödinger [69], seguido por Pauli [70], introduziu o tensor de stress na mecânica quântica. Com esta base, Nielsen e Martin [71] propuseram o que eles chamaram de teorema do stress, que consiste numa generalização do teorema do virial quântico. Este pode ser derivado através do mesmo procedimento proposto por Fock [72] para o teorema do virial quântico. A hamiltoniana geral de um sistema pode ser escrita como

$$
H=\sum_{i} \frac{p_{i}^{2}}{2 m_{i}}+V_{\text {int }}+V_{\text {ext }},
$$

em que $V_{\text {int }}$ e $V_{\text {ext }}$ denotam a energia potencial interna e externa do sistema e são uma função da posição de todas as partículas. $V_{\text {int }}$ considera a contribuição interna dos potenciais interatômicos e $V_{\text {ext }}$ incorpora os potenciais associados 
com influências externas. Assim, e energia total do sistema segue da equação de Schrödinger

$$
E_{\text {tot }}=\left\langle\psi\left|\sum_{i} \frac{p_{i}^{2}}{2 m_{i}}+V_{\text {int }}+V_{\text {ext }}\right| \psi\right\rangle
$$

através de um dimensionamento uniforme das coordenadas de posição, de tal forma que $r_{i \alpha} \rightarrow r_{i \alpha}+\epsilon_{\alpha \beta} r_{i \beta}$ em que $\epsilon_{\alpha \beta}$ é um tensor de deformação simétrico. Com essa transformação, a função de onda se torna

$$
\Psi_{\epsilon}(\vec{r})=\operatorname{det}(I+\epsilon)^{-1 / 2} \Psi\left((I+\epsilon)^{-1} \vec{r}\right),
$$

em que / é a matriz identidade, $\epsilon$ a matriz do tensor de deformação e o fator $\operatorname{det}(I+\epsilon)^{-1 / 2}$ é necessário para preservar a normalização da função de onda. De acordo com o princípio variacional, um funcional da forma

$$
G[|\phi\rangle]=\frac{\langle\phi|g| \phi\rangle}{\langle\phi \mid \phi\rangle}
$$

deve ser estacionário para qualquer variação arbitrária de $|\phi\rangle$ [73]. Em particular, a energia total (que é um funcional da função de onda) deve ser estacionária para qualquer variação da função de onda $\Psi$. Assim, devemos ter

$$
\frac{\partial\langle\Psi|H| \Psi\rangle}{\partial \epsilon_{\alpha \beta}}=\sum_{i}\left\langle\Psi\left|\frac{p_{i \alpha} p_{i \beta}}{m_{i}}-r_{i \beta} \nabla_{i \alpha}\left(V_{i n t}+V_{e x t}\right)\right| \Psi\right\rangle=0 .
$$

De acordo com a termodinâmica clássica, tem-se

$$
\sigma_{i j}=V^{-1} \frac{\partial U}{\partial \epsilon_{i j}}
$$

de forma que podemos identificar

$$
V \sigma_{\alpha \beta}=-\sum_{i}\left\langle\Psi\left|r_{i \beta} \nabla_{i \alpha}\left(V_{e x t}\right)\right| \psi\right\rangle
$$

como o stress exercido pelo ambiente externo ao sólido e

$$
V \sigma_{\alpha \beta}=\sum_{i}\left\langle\psi\left|\frac{p_{i \alpha} p_{i \beta}}{m_{i}}-r_{i \beta} \nabla_{i \alpha}\left(V_{i n t}\right)\right| \psi\right\rangle
$$

como o stress intrínseco ao sistema. Percebemos pela equação (2.88) que o stress interno é balanceado pelo stress externo ao sistema, para que o sistema 
permaneça em equilíbrio. Assim a equação (2.91) é uma generalização da expressão do teorema do virial para a pressão e foi chamada por Nielsen e Martin [71] de teorema do stress.

Posteriormente, Nielsen e Martin [74] aplicaram o teorema do stress no contexto da DFT, considerando a hamiltoniana (2.87) como sendo a hamiltoniana das equaçãoes de Kohn-Sham, e assim obtiveram o stress interno total dentro da DFT e da aproximação de pseudopotenciais como

$$
\begin{aligned}
V \sigma_{\alpha \beta} & =-\frac{\hbar^{2}}{m} \sum_{i=1}^{N} \int \phi^{*}(r) \nabla_{\alpha} \nabla_{\beta} \phi_{i}(r) d r \\
& -\frac{1}{2} \iint \rho(r) \rho\left(r^{\prime}\right) \frac{\left(r-r^{\prime}\right)_{\alpha}\left(r-r^{\prime}\right)_{\beta}}{\left|r-r^{\prime}\right|^{3}} d r d r^{\prime} \\
& -\frac{1}{2} \sum_{s=1}^{N_{s}} \sum_{i=1}^{P_{s}} \int \rho(r)\left(v_{P S}^{\text {loc,s }}\right)^{\prime}\left(\left|r-R_{i}\right|\right) \frac{\left(r-R_{i}\right)_{\alpha}\left(r-R_{i}\right)_{\beta}}{\left|r-R_{i}\right|} d r \\
& -\frac{1}{2} \sum_{i=1}^{P} \sum_{j \neq i}^{P} Z_{i} Z_{j} \frac{\left(R_{i}-R_{j}\right)_{\alpha}\left(R_{i}-R_{j}\right)_{\beta}}{\left|R_{i}-R_{j}\right|^{3}} \\
& +\delta_{\alpha \beta} \int \rho(r) \epsilon_{X C}[\rho(r)]-\mu_{X C}[\rho(r)] d r+T_{\alpha \beta}^{n l}
\end{aligned}
$$

em que, no primeiro termo, a soma é em todos os orbitais de Kohn-Sham ocupados e $T_{\alpha \beta}^{n l}$ é a contribuição não local do pseudopotencial para o stress.

Pode-se então utilizar a expressão (2.92) para se calcular o stress em um material por primeiros princípios. Isto está implementado no código computacional Quantum ESPRESSO [53], utilizado neste trabalho. Dessa forma, pode-se calcular o stress em um material devido a uma distorção aplicada e através da lei de Hooke generalizada, que será apresentada posteriormente neste capítulo, calcular os coeficientes elásticos.

\section{Materiais isotrópicos}

A Terra é formada por rochas, compostas por cristais. As propriedades elásticas de um cristal dependem de sua orientação, mas, se considerarmos um pedaço de rocha grande o suficiente, de tal forma que contenha muitos cristais em diferentes orientações espaciais, é esperado que a variação do comportamento 
elástico em diferentes direções seja anulado, de tal forma que a rocha possa ser considerada um agregado isotrópico $[8,68]$. Assim, o comportamento elástico do material é independente de qualquer direção particular.

Em um material isotrópico, as propriedades são independentes de sua orientação. Em particular, o comportamento elástico é o mesmo em todas as direções. A forma mais geral para as relações entre o stress e a distorção, para um material isotrópico, é

$$
\begin{aligned}
& \sigma_{11}=A e_{11}+B\left(e_{22}+e_{33}\right)+C e_{23}+D\left(e_{31}+e_{12}\right) \\
& \sigma_{23}=E e_{11}+F\left(e_{22}+e_{33}\right)+G e_{23}+H\left(e_{31}+e_{12}\right)
\end{aligned}
$$

em que os coeficientes $A, B, C, D, E, F, G, H$ dependem apenas do material em particular e das condições termodinâmicas. As equações para $\sigma_{22}, \sigma_{33}, \sigma_{31}, \sigma_{12}$ são as mesmas, bastando uma permutação dos índices [66].

Estes coeficientes não podem depender da direção do sistema de coordenadas escolhido. Em particular, se pegarmos um sistema de coordenadas que coincide com os eixos principais da distorção em um ponto $\mathcal{P}$, as equações (2.93) e (2.94) ficam

$$
\begin{array}{r}
\sigma_{11}=A e_{11}+B\left(e_{22}+e_{33}\right) \\
\sigma_{23}=E e_{11}+F\left(e_{22}+e_{33}\right) .
\end{array}
$$

Tome, agora, um segundo eixo de referência $\left(x^{\prime}, y^{\prime}, z^{\prime}\right)$ rotacionado de $90^{\circ}$ do primeiro, em torno do eixo $x$. Dessa forma, o eixo $x$ coincide com $x^{\prime}$, o eixo $y^{\prime}$ coincide com $z$ e o eixo $z^{\prime}$ é oposto ao eixo $y$. Estes novos eixos também coincidem com os eixos principais da distorção e portanto, através da equação (2.94), obtemos

$$
\sigma_{2^{\prime} 3^{\prime}}=E e_{1^{\prime} 1^{\prime}}+F\left(e_{2^{\prime} 2^{\prime}}+e_{3^{\prime} 3^{\prime}}\right)
$$

e assim

$$
-\sigma_{32}=E e_{11}+F\left(e_{22}+e_{33}\right) .
$$

Como o stress é um tensor simétrico, devemos ter que $\sigma_{23}=\sigma_{32}=0$. Analogamente, mostra-se que quando os eixos de coordenadas são os eixos principais da distorção tem-se $\sigma_{13}=\sigma_{31}=0$ e $\sigma_{12}=\sigma_{21}=0$. Isso mostra que os eixos principais da distorção coincidem com os eixos principais de stress. 
Considere agora o tensor

$$
\sigma_{i j}-B \theta \delta_{i j}-(A-B) e_{i j}
$$

em que $\theta$ é a dilatação, definida por

$$
\theta=\frac{\partial u_{1}}{\partial x_{1}}+\frac{\partial u_{2}}{\partial x_{2}}+\frac{\partial u_{3}}{\partial x_{3}}=e_{11}+e_{22}+e_{33}
$$

Se o sistema de coordenadas estiver orientado de acordo com os eixos principais da distorção, suas componentes são nulas, e, portanto, assim também é o stress. Portanto, como a forma de um tensor não depende do sistema de coordenadas, suas componentes são nulas para qualquer sistema. Isso mostra que para um material isotrópico perfeitamente elástico, a relação entre o stress e a distorção pode ser escrita como

$$
\sigma_{i j}=B \theta \delta_{i j}+(A-B) e_{i j}
$$

Assim, os oito coeficientes elásticos das equações (2.93) e (2.94) podem ser expressas em termos de apenas duas constantes elásticas, ou seja, isso mostra que $C=D=E=F=H=0$ e $A-B=G$. Em geral, os dois parâmetros são representados por $\lambda$ e $\mu$, conhecidos como parâmetros de Lamé, em que $\lambda=B$ e $\mu=\frac{1}{2}(A-B)$. Podemos, então, ao invés das equações (2.93) e (2.94), escrever

$$
\begin{gathered}
\sigma_{11}=\lambda \theta+2 \mu e_{11} \\
\sigma_{23}=2 \mu e_{23}
\end{gathered}
$$

e a relação completa entre a distorção e o stress fica

$$
\sigma_{i j}=\lambda \theta \delta_{i j}+2 \mu e_{i j}
$$

O coeficiente elástico $\mu$ possui um significado físico simples, ele é a constante de rigidez do material e mede sua resistência a tensões de cisalhamento, como pode-se perceber pela equação (2.99) tomando $i \neq j$. Já o parâmetro de Lamé $\lambda$ não é tão simples de ser visualizado fisicamente. Por isso, em geral, se trabalha com o bulk modulus $K$ ao invés de $\mu$. Pela equação (2.86) tem-se que a pressão é dada por

$$
P=-\frac{1}{3} \operatorname{Tr}\left[\sigma_{i i}\right]=-\frac{1}{3} \sum_{i=1}^{3} \sigma_{i i}
$$


e, utilizando a equação (2.99) $\operatorname{com} i=j$, temos

$$
P=-\frac{1}{3} \sum_{i=1}^{3}\left(\lambda \theta \delta_{i i}+2 \mu e_{i i}\right)
$$

Lembrando que $\theta=\sum_{i=1}^{3} e_{i i}$, então

$$
P=-\left(\lambda \theta+\frac{2}{3} \mu \theta\right)
$$

Agora, a dilatação está associada com a mudança de volume, por unidade de volume, associada com uma deformação no corpo. Para notar este fato, considere um elemento cúbico de volume infinitesimal orientado de acordo com os eixos de coordenadas. O volume desse elemento é $V=d x_{1} d x_{2} d x_{3}$. Se efetuarmos uma distorção no material ao longo dos eixos de coordenadas tal que $d x_{i}^{\prime}=\left(1+e_{i i}\right) d x_{i}=\left(1+\frac{\partial u_{i}}{\partial x_{i}}\right) d x_{i}$, o elemento final de volume pode ser escrito, em primeira ordem, como

$$
d x_{1}^{\prime} d x_{2}^{\prime} d x_{3}^{\prime}=\left(1+\frac{\partial u_{1}}{\partial x_{1}}+\frac{\partial u_{2}}{\partial x_{2}}+\frac{\partial u_{3}}{\partial x_{3}}\right) d x_{1} d x_{2} d x_{3}=(1+\theta) d x_{1} d x_{2} d x_{3}
$$

e assim temos que

$$
V^{\prime}=V+\Delta V=(1+\theta) V \Longrightarrow \theta=\frac{\Delta V}{V} .
$$

Utilizando as expressões (2.100) e (2.101), tem-se que

$$
P=-\left(\lambda \frac{\Delta V}{V}+\frac{2}{3} \mu \frac{\Delta V}{V}\right)=-\frac{\Delta V}{V}\left(\lambda+\frac{2}{3} \mu\right)
$$

levando à relação

$$
d P=-\frac{d V}{V}\left(\lambda+\frac{2}{3} \mu\right) \Longrightarrow-V \frac{d P}{d V}=\left(\lambda+\frac{2}{3} \mu\right) .
$$

Como temos que o bulk modulus $K$ é dado por

$$
K=-V \frac{d P}{d V}
$$

podemos relacionar o parâmetro de Lamé $\lambda$ com o bulk modulus:

$$
K=\lambda+\frac{2}{3} \mu
$$




\section{Equações de movimento de um sistema isotrópico}

Considere as forças em um elemento infinitesimal de volume, como mostrado na figura 2.1. As forças em cada superfície do cubo podem ser obtidas pelo produto do vetor de tração $T^{e_{i}}$ em cada superfície. Por exemplo, a componente das forças $F$ na direção y pode ser escrita como

$$
F_{2}=\sigma_{22} \delta x_{1} \delta x_{3}+\sigma_{21} \delta x_{1} \delta x_{3}+\sigma_{23} \delta x_{1} \delta x_{3} .
$$

Entretanto, se o stress for homogêneo, não há forças no corpo, pois as trações em faces opostas se cancelam. Por isso, só haverão forças se o gradiente espacial do tensor de stress for diferente de zero. Nesse caso as forças $F_{2}$ podem ser escritas como

$$
F_{2}=\frac{\partial}{\partial x_{2}}\left[\sigma_{22}+\sigma_{21}+\sigma_{23}\right] d x_{1} d x_{2} d x_{3}
$$

e, assim, podemos generalizar e escrever as forças em cada direção como

$$
F_{i}=\frac{\partial \sigma_{i j}}{\partial x_{j}} d x_{1} d x_{2} d x_{3},
$$

lembrando que estamos usando a convenção de soma de Einstein. Além destas, podem existir também forças externas, tais que $F_{i}^{e x t}=f_{i} d x_{1} d x_{2} d x_{3}$, em que $f_{i}$ é uma força por elemento de volume. A massa desse elemento de volume é $m=\rho d x_{1} d x_{2} d x_{3}$, em que $\rho$ é a densidade deste elemento. Assim, podemos usar a segunda lei de Newton e escrever a equação de movimento

$$
\rho a_{i}=\frac{\partial \sigma_{i j}}{\partial x_{j}}+f_{i} .
$$

Substituindo a relação (2.99) na equação (2.103) tem-se

$$
\rho a_{i}=\frac{\partial}{\partial x_{j}}\left(\lambda \theta \delta_{i j}+2 \mu e_{i j}\right)+f_{i}
$$

e, utilizando as expressões (2.84), que relacionam as distorções em termos das derivadas dos deslocamentos, temos que

$$
\rho a_{i}=\frac{\partial}{\partial x_{i}}(\lambda \theta)+\frac{\partial}{\partial x_{j}}\left[\mu\left(\frac{\partial u_{i}}{\partial x_{j}}+\frac{\partial u_{j}}{\partial x_{i}}\right)\right]+f_{i}
$$


e, finalmente, podemos escrever

$$
\rho \frac{d^{2} u_{i}}{d t^{2}}=(\lambda+\mu) \frac{\partial \theta}{\partial x_{i}}+\mu \nabla^{2} u_{i}+f_{i} .
$$

No caso em que o deslocamento e a velocidade $v_{i}$ são sempre pequenos, como é o caso de problemas ordinários em elasticidade e, em particular, para o estudo da Terra, podemos substituir a derivada total no tempo por uma derivada parcial no tempo, já que estamos desprezando termos de segunda ordem, e assim obter as equações de movimento de um sistema isotrópico

$$
\rho \frac{\partial^{2} u_{i}}{\partial t^{2}}=(\lambda+\mu) \frac{\partial \theta}{\partial x_{i}}+\mu \nabla^{2} u_{i}+f_{i}
$$

\section{Ondas elásticas em meios isotrópicos}

A equação (2.105) descreve o movimento de pequenas pertubações em um meio e, se considerarmos que não há forças externas, podemos escrever

$$
\rho \frac{\partial^{2} u_{i}}{\partial t^{2}}=(\lambda+\mu) \frac{\partial \theta}{\partial x_{i}}+\mu \nabla^{2} u_{i}
$$

em que, diferenciando os dois membros da equação (2.106) com relação a $x_{i} \mathrm{e}$ utilizando a equação (2.102), que relaciona o parâmetro de Lamé $\mu$ com o bulk modulus $K$, obtemos

$$
\rho \frac{\partial^{2} \theta}{\partial t^{2}}=(\lambda+2 \mu) \nabla^{2} \theta \Longrightarrow \rho \frac{\partial^{2} \theta}{\partial t^{2}}=\left(K+\frac{4}{3} \mu\right) \nabla^{2} \theta .
$$

Por outro lado, aplicando o rotacional em ambos os membros da equação (2.106), tem-se

$$
\rho \frac{\partial^{2}}{\partial t^{2}}\left(\nabla \times u_{i}\right)=(\lambda+\mu)\left[\nabla \times\left(\frac{\partial \theta}{\partial x_{i}}\right)\right]+\mu \nabla^{2}\left(\nabla \times u_{i}\right) .
$$

Como $\nabla \times\left(\partial \theta / \partial x_{i}\right)=0$, temos que

$$
\rho \frac{\partial^{2}}{\partial t^{2}}\left(\nabla \times u_{i}\right)=\mu \nabla^{2}\left(\nabla \times u_{i}\right) .
$$

As equações (2.107) e (2.108) são ambas equações de onda. Pela expressão (2.107), percebe-se que a dilatação $\theta$ pode ser transmitida pela substância com velocidade $V_{P}$ dada por

$$
V_{P}=\sqrt{\frac{\lambda+2 \mu}{\rho}}=\sqrt{\frac{K+\frac{4}{3} \mu}{\rho}} .
$$


Adicionalmente, pela equação (2.108), percebe-se que uma pertubação rotacional pode ser transmitida com velocidade $V_{S}$ dada por

$$
V_{S}=\sqrt{\frac{\mu}{\rho}} .
$$

Em sismologia, estes dois tipos de onda são chamadas ondas primárias $\mathrm{P}$, ou ondas de pressão, e ondas secundárias $\mathrm{S}$, ou ondas de cisalhamento. Suas velocidades dependem apenas dos coeficientes elásticos e da densidade do material onde se propagam. Pela equação (2.110), percebe-se que em um meio em que $\mu=0$ a velocidade das ondas $S$ é nula, de maneira que ondas rotacionais não se propagam em um meio onde a rigidez seja nula. Assim, as ondas S não se propagam em um meio líquido e é desta forma que se descobriu que a Terra possui um núcleo líquido. Através de dados coletados por sismógrafos, percebeu-se que depois de uma certa latitude, em relação ao epicentro de terremotos, as ondas de cisalhamento não chegavam de volta na crosta, indicando que as ondas sísmicas atravessaram alguma região líquida no interior da Terra.

\section{Materiais anisotrópicos}

Apesar da Terra, em grande escala, ser considerada um material isotrópico, efeitos anisotrópicos podem ser cruciais para a explicação de algumas características [40]. Por exemplo, a explicação usualmente aceita para a descontinuidade $\mathrm{D}^{\prime \prime}$ é uma transição da fase perovskita para uma fase pós-perovskita, recentemente descoberta, e que ocorre para pressões da ordem de grandeza das pressões do manto terrestre inferior [23,75,76]. Entretanto, estudos de ondas acústicas em rochas de $\mathrm{MgSiO}_{3}$ pós-perovskita sob pressão mostraram que o aumento na velocidade das ondas $\mathrm{P}$ e $\mathrm{S}$ é insuficiente para explicar a descontinuidade $\mathrm{D}^{\prime \prime}$ [77]. Inferiu-se que no manto a fase pós-perovskita tenha uma orientação preferencial em seus eixos, o que indicaria que o material nessa região seja anisotrópico. Diversos estudos em $\mathrm{MgSiO}_{3}$ tem tomado essa direção a fim de se calcular a anisotropia do manto $[40,78,79]$.

Para materiais não isotrópicos, mas ainda elásticos, é necessário se consi- 
derar a lei de Hooke generalizada

$$
\sigma_{i j}=C_{i j k l} e_{k l},
$$

em que $\sigma_{i j}$ é o tensor de stress no material, $e_{k l}$ a distorção provocada por este stress e $C_{i j k l}$ o tensor de 81 componentes, que representa os coeficientes elásticos do material. Como visto na seção anterior, tanto o stress como a distorção devem ser uma matriz simétrica, de tal forma que $\sigma_{i j}=\sigma_{j i}$ e $e_{k l}=e_{l k}$. Portanto, o tensor elástico deve obedecer às relações de simetria $C_{i j k l}=C_{j i k l}=C_{i j \mid k}$. Utilizando a conservação da energia é possível mostrar ainda que $C_{i j k l}=C_{k l i j}$. Assim, ficamos com 21 componentes independentes para o tensor elástico em um material anisotrópico.

Cristais, apesar de não serem isotrópicos, apresentam alguma simetria, que reduz o número de componentes do tensor elástico. Estas simetrias sugerem escrever estes tensores de outra forma, reduzindo a ordem dos mesmos. Primeiramente, vamos introduzir a notação de Voigt para especificar as componentes dos tensores de stress e strain, que está mostrada na tabela 2.1.

Tabela 2.1: Notação de Voigt para as componentes dos tensores de stress e strain.

\begin{tabular}{||c|c|c|c|c|c|c||}
\hline \hline$i j$ & 11 & 22 & 33 & 23 e 32 & 13 e 31 & 12 e 21 \\
\hline$\alpha$ & 1 & 2 & 3 & 4 & 5 & 6 \\
\hline \hline
\end{tabular}

Como os tensores de stress e strain são simétricos, eles possuem apenas seis componentes independentes e podem ser escritos como matrizes linha, de maneira que

$$
\begin{aligned}
& \sigma_{i}=\left(\sigma_{1}, \sigma_{2}, \sigma_{3}, \sigma_{4}, \sigma_{5}, \sigma_{6}\right) \\
& e_{j}=\left(e_{1}, e_{2}, e_{3}, e_{4}, e_{5}, e_{6}\right) .
\end{aligned}
$$

Com essa notação, o tensor elástico assume a forma de uma matriz $6 \times 6$ e a lei de Hooke generalizada toma a forma

$$
\sigma_{i}=C_{i j} e_{j} .
$$

Consideremos, como exemplo, um cristal com simetria ortorrômbica, que é o caso da estrutura cristalina tanto do $\mathrm{MgSiO}_{3}$ na fase perovskita como na 
fase pós-perovskita, em que existem nove coeficientes elásticos independentes. Desse modo, o tensor elástico, na notação de Voigt, tem a forma

$$
C=\left(\begin{array}{cccccc}
C_{11} & C_{12} & C_{13} & 0 & 0 & 0 \\
C_{12} & C_{22} & C_{23} & 0 & 0 & 0 \\
C_{13} & C_{23} & C_{33} & 0 & 0 & 0 \\
0 & 0 & 0 & C_{44} & 0 & 0 \\
0 & 0 & 0 & 0 & C_{55} & 0 \\
0 & 0 & 0 & 0 & 0 & C_{66}
\end{array}\right)
$$

Se utilizarmos as relações (2.84), podemos escrever a lei de Hooke generalizada em termos das derivadas dos deslocamentos

$$
\sigma_{i j}=C_{i j k l}\left[\frac{1}{2}\left(\frac{\partial u_{k}}{\partial x_{l}}+\frac{\partial u_{l}}{\partial x_{k}}\right)\right]
$$

e como $C_{i j k l}=C_{i j l k}$, temos

$$
\begin{aligned}
\sigma_{i j} & =\frac{1}{2}\left[C_{i j 11}\left(\frac{\partial u_{1}}{\partial x_{1}}+\frac{\partial u_{1}}{\partial x_{1}}\right)+C_{i j 12}\left(\frac{\partial u_{1}}{\partial x_{2}}+\frac{\partial u_{2}}{\partial x_{1}}\right)+C_{i j 13}\left(\frac{\partial u_{1}}{\partial x_{3}}+\frac{\partial u_{3}}{\partial x_{1}}\right)\right]+ \\
& +\frac{1}{2}\left[C_{i j 12}\left(\frac{\partial u_{2}}{\partial x_{1}}+\frac{\partial u_{1}}{\partial x_{2}}\right)+C_{i j 22}\left(\frac{\partial u_{2}}{\partial x_{2}}+\frac{\partial u_{2}}{\partial x_{2}}\right)+C_{i j 23}\left(\frac{\partial u_{2}}{\partial x_{3}}+\frac{\partial u_{3}}{\partial x_{2}}\right)\right]+ \\
& +\frac{1}{2}\left[C_{i j 13}\left(\frac{\partial u_{3}}{\partial x_{1}}+\frac{\partial u_{1}}{\partial x_{3}}\right)+C_{i j 23}\left(\frac{\partial u_{3}}{\partial x_{2}}+\frac{\partial u_{2}}{\partial x_{3}}\right)+C_{i j 33}\left(\frac{\partial u_{3}}{\partial x_{3}}+\frac{\partial u_{3}}{\partial x_{3}}\right)\right] \\
\sigma_{i j} & =\frac{1}{2}\left[2 C_{i j 11} \frac{\partial u_{1}}{\partial x_{1}}+2 C_{i j 12} \frac{\partial u_{1}}{\partial x_{2}}+2 C_{i j 13} \frac{\partial u_{1}}{\partial x_{3}}+2 C_{i j 12} \frac{\partial u_{2}}{\partial x_{1}}+2 C_{i j 22} \frac{\partial u_{2}}{\partial x_{2}}\right]+ \\
& +\frac{1}{2}\left[2 C_{i j 23} \frac{\partial u_{2}}{\partial x_{3}}+2 C_{i j 13} \frac{\partial u_{3}}{\partial x_{1}}+2 C_{i j 23} \frac{\partial u_{3}}{\partial x_{2}}+2 C_{i j 33} \frac{\partial u_{3}}{\partial x_{3}}\right]
\end{aligned}
$$

e, portanto

$$
\sigma_{i j}=C_{i j k l} \frac{\partial u_{k}}{\partial x_{l}} .
$$

\section{Equações de movimento de um sistema anisotrópico}

Voltando à equação (2.103), tínhamos

$$
\rho a_{i}=\frac{\partial \sigma_{i j}}{\partial x_{j}}+f_{i} .
$$


Como $a_{i}$ é a aceleração do elemento de volume, podemos escrever esta equação em termos do deslocamento $u_{k}$

$$
\rho \frac{\partial^{2} u_{i}}{\partial t^{2}}=\frac{\partial \sigma_{i j}}{\partial x_{j}}+f_{i},
$$

em que estamos usando a notação para soma de Einstein, ou seja

$$
\frac{\partial \sigma_{i j}}{\partial x_{j}}=\frac{\partial \sigma_{i 1}}{\partial x_{1}}+\frac{\partial \sigma_{i 2}}{\partial x_{2}}+\frac{\partial \sigma_{i 3}}{\partial x_{3}} .
$$

Utilizando a lei de Hooke generalizada, em termos do deslocamento (2.115), e lembrando que orientamos os eixos das distorções e do stress de acordo com os eixos de simetria do cristal (ortorrômbica, neste caso), tem-se, excluindo as forças externas,

$$
C_{i j k l} \frac{\partial u_{k}}{\partial x_{\jmath} \partial x_{j}}-\rho \frac{\partial^{2} u_{i}}{\partial t^{2}}=0 .
$$

Adotemos a expressão para descrever os deslocamentos da forma

$$
u_{k}=A p_{k} e^{i\left(k_{r} x_{r}-\omega t\right)},
$$

em que $A$ é a amplitude do deslocamento, $p_{k}$ é um vetor unitário que representa a direção do deslocamento (ou vetor de polarização), $\omega$ é a frequência angular da onda, $x_{r}$ é um vetor espacial e $k_{r}$ é o número de onda. Substituindo a equação (2.117) na equação de movimento (2.116), obtemos as equações

$$
\left(C_{i j k l} n_{j} n_{l}-\rho V^{2} \delta_{i k}\right) p_{k}=0,
$$

em que $n_{k}$ é o versor na direção $k, \rho$ é a densidade, $V$ é a velocidade e $p_{k}$ são os vetores de polarização da onda, obtidos através da equação de autovalores

$$
\operatorname{det}\left|C_{i j k l} n_{j} n_{l}-\rho V^{2} \delta_{i k}\right|=0 .
$$

As equações (2.119) são conhecidas como equações de Christoffel. Os autovalores das equações (2.119) possibilitam o cálculo das velocidades das ondas acústicas em um material, sendo que os autovetores correspondentes fornecem a polarização $p_{k}$ da onda. Assim, sabendo-se os coeficientes elásticos do material, é possível calcular a velocidade de ondas acústicas. Para 
tanto, primeiro se escolhe o versor $\hat{n}=n_{i}$ com $i=1,2,3$, que define a direção de propagação, e depois se diagonaliza a matriz (2.119). Os autovalores são proporcionais às velocidades e os autovetores são a polarização da onda. É interessante notar que, no caso geral, quando se resolve a equação de Christoffel, obtém-se um autovetor na direção de $\hat{n}$ e dois autovetores normais à $\hat{n}$. $O$ vetor de polarização na direção de $\hat{n}$ corresponde à onda $P$ enquanto os vetores de polarização normais à $\hat{n}$ correspondem às ondas $\mathrm{S}$.

Através do teorema do virial e do teorema de Hellman-Feynman é possível, utilizando a energia total, calcular teoricamente o stress sentido por um cristal, de acordo com a distorção aplicada. Cada distorção está relacionada com um conjunto de coeficientes elásticos. Traçando um gráfico do stress $\mathrm{x}$ distorção em determinada direção, esperamos obter uma reta, cujo coeficiente angular é a componente elástica que relaciona esse stress com essa distorção. Com seis distorções, podemos calcular os nove coeficientes elásticos de um cristal com simetria ortorrômbica e, assim, é possível calcular a velocidade das ondas se propagando neste material.

\subsection{Equações de Estado}

O estado termodinâmico de um sistema é, em geral, definido por sua pressão $P$, volume $V$ e temperatura $T$. Estas grandezas estão relacionadas pela equação de estado do sistema. O conhecimento de equações de estado de minerais é muito importante para a geofísica, como, por exemplo, para a construção de modelos para a densidade do planeta. O efeito da temperatura em sólidos é pequeno e, portanto, efeitos térmicos podem ser tratados como uma perturbação em uma equação de estado isotérmica $V=V(P)$. Existem diversas maneiras de se construir uma equação de estado para sólidos. A mais simples é considerar-se que o bulk modulus é constante, tal que

$$
K=-V \frac{\partial P}{\partial V}=\text { constante. }
$$

Resolvendo-se essa equação diferencial obtém-se a relação $V(P)$

$$
V=V_{0} \exp \left(-\frac{P}{K_{0}}\right)
$$


em que $V_{0}$ e $K_{0}$ são o volume e o bulk modulus à pressão nula, respectivamente. Entretanto, esta não é uma boa aproximação, pois a equação de estado não leva em consideração o fato de que é cada vez mais difícil de se comprimir um sólido, conforme a pressão aumenta, ou seja, o bulk modulus deve aumentar com a pressão. Uma maneira de se contornar este problema é supor que o aumento do bulk modulus é linear com a pressão, ou seja

$$
-V \frac{\partial P}{\partial V}=K_{0}+K_{0}^{\prime} P,
$$

obtendo, assim, a equação integral de Murnaghan, conhecida apenas como equação de Murnaghan

$$
P=\frac{K_{0}}{K_{0}^{\prime}}\left[\left(\frac{V_{0}}{V}\right)^{K_{0}^{\prime}}-1\right] .
$$

No entanto, a equação de estado mais utilizada, especialmente no tratamento de dados experimentais, é a de Birch-Murnaghan, obtida expandindo-se a energia livre em função de uma distorção infinitesimal. Se essa expansão for até termos cúbicos, tem-se a equação de Birch-Murnaghan de terceira ordem

$$
P=\frac{3 K_{0}}{2}\left[\left(\frac{V_{0}}{V}\right)^{\frac{7}{3}}-\left(\frac{V_{0}}{V}\right)^{\frac{5}{3}}\right]\left\{1+\frac{3}{4}\left(K_{0}^{\prime}-4\right)\left[\left(\frac{V_{0}}{V}\right)^{\frac{2}{3}}-1\right]\right\},
$$

sendo esta uma das equações mais utilizadas na literatura e por isso a escoIhida neste trabalho. A equação de estado é uma relação entre $P$ e $V$. Sendo estas as grandezas medidas experimentalmente, ela é facilmente usada para se extrair tanto $K_{0}$ como $K_{0}^{\prime}$ de dados experimentais, utilizando o método dos mínimos quadrados para se calcular os parâmetros que melhor ajustam as medidas realizadas. Entretanto, resultados teóricos fornecem a energia $E$ como função de $V$, de tal forma que o ajuste deve ser feito não na equação de estado (2.124), mas sim na relação $E \times V$, obtida integrando-se a equação (2.124)

$$
E(V)=E_{0}+\frac{9 V_{0} K_{0}}{16}\left\{\left[\left(\frac{V_{0}}{V}\right)^{\frac{2}{3}}-1\right]^{3} K_{0}^{\prime}+\left[\left(\frac{V_{0}}{V}\right)^{\frac{2}{3}}-1\right]^{2}\left[6-4\left(\frac{V_{0}}{V}\right)^{\frac{2}{3}}\right]\right\} .
$$

Os valores teóricos de $V_{0}, K_{0}$ e $K_{0}^{\prime}$ são obtidos através do método dos mínimos quadrados, ajustando-se a equação (2.125) aos resultados obtidos por 


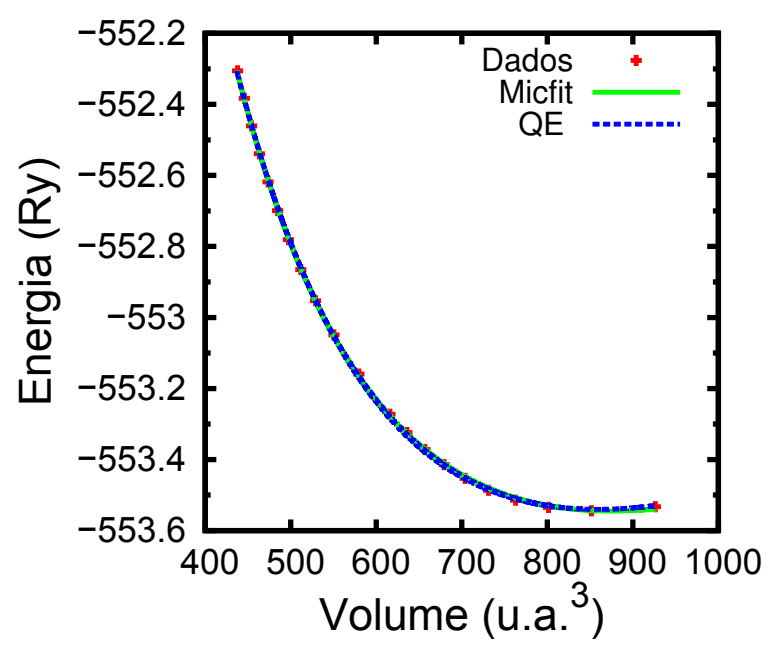

Figura 2.2: Ajuste da energia como função do volume para $\circ \mathrm{CaCO}_{3}$, na estrutura romboédrica, utilizando dois códigos diferentes: QE, que é um código de ajuste fornecido pelo pacote computacional Quantum ESPRESSO, e Micfit, que é um código desenvolvido por nós.

cálculos de primeiros princípios. Entretanto, como este é um ajuste não linear e dependente de três parâmetros, ele é um ajuste complexo. Portanto, é adequado que a comparação entre resultados, todos tenham sido obtidos com a utilização da mesma equação. Além disso, ajustes realizados com códigos computacionais diferentes podem apresentar resultados discrepantes, mesmo com um valor de $\chi$ (qualidade do ajuste) pequeno, devido à utilização de algoritmos diferentes para a minimização dos parâmetros. Como exemplo, apresentamos na figura 2.2 a curva de energia em função do volume para o $\mathrm{CaCO}_{3}$, na estrutura romboédrica, em que ajustou-se a equação de Birch-Murnaghan de terceira ordem com dois códigos diferentes.

Podemos observar que as curvas se sobrepõem de maneira, praticamente, perfeita. Por consequência, podemos concluir que o ajuste realizado pelos dois códigos fornece equações compatíveis com os resultados. Entretanto, os valores dos parâmetros das equações de estado são bem diferentes, como mostra a tabela 2.2.

Nota-se uma diferença pequena no volume, cerca de $2 \%$ entre os valores 
Tabela 2.2: Valores dos parâmetros da equação de estado do $\mathrm{CaCO}_{3}$, na estrutura romboédrica, obtidos utilizando dois códigos diferentes: QE e Micfit. $\chi$ é a qualidade do ajuste.

\begin{tabular}{||c|c|c|c|c||}
\hline \hline Código & $V_{0}$ (u.a. $\left.^{3}\right)$ & $K_{0}(\mathrm{GPa})$ & $K_{0}^{\prime}$ & $\chi$ \\
\hline \hline Micfit & 875,29 & 59,8 & 3,64 & $8,7 \times 10^{-7}$ \\
\hline QE & 859,61 & 68,3 & 3,46 & $1,2 \times 10^{-6}$ \\
\hline \hline
\end{tabular}

obtidos pelo dois ajustes. Entretanto, a diferença nos valores do bulk modulus é de $14 \%$ e a diferença na derivada do bulk modulus $\left(K_{0}^{\prime}\right)$ é de $5 \%$ ! Esta é uma diferença grande, considerando que os ajustes foram realizados para os mesmos resultados e que o $\chi$ é pequeno em ambos os casos. Assim, o ideal é que a comparação dos valores de parâmetros da equação de estado seja realizada com a mesma equação e de preferência utilizando o mesmo código para o ajuste. Neste trabalho utilizamos o código Micfit para os ajustes da equação de estado.

\subsection{Detalhes computacionais}

\section{Parâmetros de convergência}

A metodologia de pseudopotenciais foi utilizada em todos os cálculos realizados neste trabalho, utilizando o pacote computacional Quantum ESPRESSO [53]. Este código utiliza uma base de ondas planas para descrever a função de onda. Infelizmente, não é possível utilizar uma quantidade infinita de ondas planas e é preciso limitar o seu número. Isto é feito considerando apenas os vetores de onda $\vec{k}$ tais que $k<k_{\text {máx. }}$ Ou seja, apenas os vetores $k$ dentro de uma esfera de raio $k_{\text {máx }}$, centrada na origem, no espaço recíproco. Todos os vetores dentro desta esfera são levados em conta na base da função de onda. Ao invés de se usar $k_{\text {máx }}$, utiliza-se como parâmetro a energia de um elétron livre correspondente a $k_{\text {máx }}$ :

$$
E_{\text {cut }}=\frac{\hbar^{2} k_{\text {máx }}^{2}}{2 m_{e}}
$$


chamada de energia de corte. Quanto maior esta energia, uma quantidade maior de ondas planas são utilizadas e, portanto, espera-se que o cálculo seja mais preciso, mas o custo computacional também é maior. Por isso, no início de qualquer cálculo de primeiros princípios, é necessário se estabelecer uma energia de corte ideal, na qual o cálculo seja o mais preciso possível com o menor custo computacional. Estes estudos de convergência dos resultados com o número de ondas planas utilizadas na base foram efetuados para todos os sistemas. A figura 2.3 mostra, como exemplo, o gráfico da energia total do $\mathrm{MgSiO}_{3}$, na estrutura romboédrica, como função da energia de corte. Percebese que a variação na energia total do sistema passa a ser muito pequena para valores de $E_{c u t}$ entre 90 e 100 Ry. Assim, utilizou-se 90 Ry para a energia de corte no $\mathrm{MgSiO}_{3}$. Além da energia de corte, também é importante realizar um estudo da convergência com relação à quantidade de pontos $\mathbf{k}$ utilizados para efetuar a integração na primeira zona de Brillouin. Estas análises foram feitas para todos os compostos e estruturas estudados neste trabalho, não apenas para a energia total, mas também para as forças e para o stress, já que estes

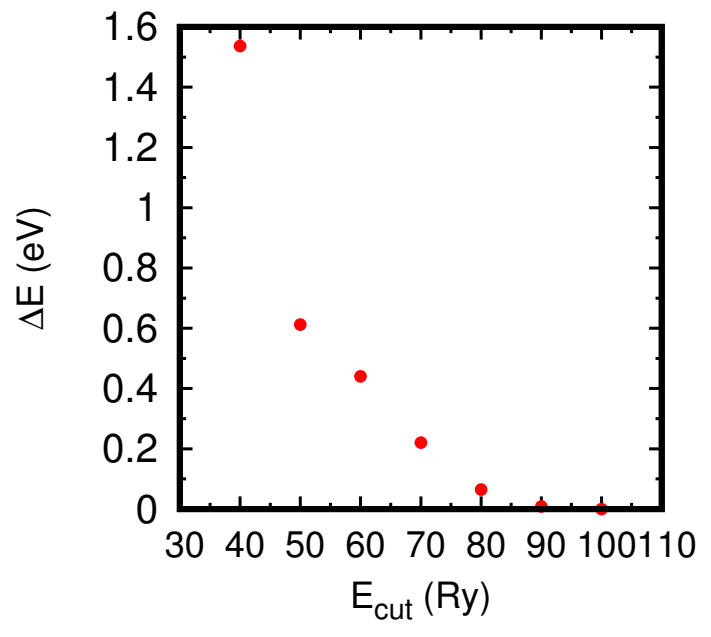

Figura 2.3: Energia total relativa $(\Delta E)$ em função do valor da energia de corte $\left(E_{c u t}\right)$, com respeito àquela de valor mais baixo, que foi deslocado para o zero de energia. 
últimos possuem uma convergência mais lenta do que a energia. A tabela 2.3 mostra os valores de energia de corte e da rede de pontos $\mathbf{k}$ utilizados para cada estrutura de cada material estudado.

Tabela 2.3: Valores de energia de corte $\left(E_{c u t}\right)$, em unidades de Ry, e da rede de pontos $\mathbf{k}$ utilizados para cada sistema, em suas respectivas estruturas.

\begin{tabular}{||l|l|c|c|}
\hline \hline Sistema & Estrutura & $E_{\text {cut }}$ & pontos k \\
\hline \hline $\mathrm{MgSiO}_{3}$ & Pmna & 90 & $6 \times 6 \times 6$ \\
$\mathrm{MgSiO}_{3}$ & $\mathrm{Cmcm}$ & 90 & $6 \times 6 \times 6$ \\
$\mathrm{MgCO}_{3}$ & $\mathrm{R} \overline{3} \mathrm{c}$ & 80 & $4 \times 4 \times 4$ \\
$\mathrm{MgCO}_{3}$ & $\mathrm{C} 2 / \mathrm{m}$ & 80 & $4 \times 4 \times 4$ \\
$\mathrm{CaCO}_{3}$ & $\mathrm{R} \overline{3} \mathrm{c}$ & 80 & $4 \times 4 \times 4$ \\
$\mathrm{CaCO}_{3}$ & $\mathrm{Pmcn}$ & 80 & $4 \times 4 \times 4$ \\
$\mathrm{CaCO}_{3}$ & $\mathrm{Pmmn}$ & 80 & $4 \times 4 \times 4$ \\
$\mathrm{CO}_{2}$ & $\overline{4} 2 \mathrm{~d}$ & 80 & $6 \times 6 \times 6$ \\
$\mathrm{CO}_{2}$ & $\mathrm{P} \overline{\mathrm{m}} 2$ & 80 & $6 \times 6 \times 6$ \\
$\mathrm{CO}_{2}$ & $\mathrm{P} 42 / \mathrm{mnm}$ & 80 & $6 \times 6 \times 6$ \\
$\mathrm{O}_{2}$ & $\mathrm{C} 2 / \mathrm{m}$ & 90 & $4 \times 4 \times 4$ \\
\hline \hline
\end{tabular}

\section{Minimização estrutural}

Para se obter os parâmetros de rede teóricos do cristal otimizou-se a célula do cristal em várias pressões utilizando métodos de dinâmica molecular de célula variável [80]. O método utilizado foi aquele proposto por Wentzcovitch [81], no qual o tensor de stress é utilizado como variável. Com isto pode-se otimizar a estrutura em qualquer pressão desejada já que a pressão do sistema pode ser calculada com o tensor de stress [67] e este é facilmente calculado com o método de pseudopotencial [74]. Entretanto, a pressão calculada desta forma não é exata, pois incorpora as aproximações utilizadas nos cálculos de primeiros princípios. Assim, a real pressão do sistema é obtida da maneira usual, utilizando alguma equação de estado. Para todas as estruturas, utilizou-se a 
equação de Birch-Murnaghan de segunda ordem. Com esse procedimento obtivemos os valores dos parâmetros de rede, volume à pressão nula $V_{0}$ e bulk modulus de todos os minerais.

\section{Propriedades elásticas}

Os coeficientes elásticos podem ser descritos como a segunda derivada da energia ${ }^{1}$ como função da deformação do sistema, tal que

$$
C_{i j k l}=\frac{1}{V} \frac{\partial^{2} E}{\partial e_{i j} \partial e_{k l}} .
$$

Este método é muito utilizado para o cálculo dos coeficientes elásticos de materiais. Entretanto, ele requer uma correção para a contribuição da pressão nos $C_{i j k l}$, de tal forma que necessita de distorções que conservem o volume [40]. Dentro da metodologia da teoria do funcional da densidade, com aproximação de pseudopotenciais, o tensor de stress de um material é facilmente calculado, através da equação (2.92). Com isso pode-se utilizar a lei de Hooke generalizada (2.111) e obter os coeficientes elásticos associados com a deformação $e_{k l}$. Este método é mais conveniente do que utilizar a relação entre a energia e a distorção, pois como o stress é um tensor, uma menor quantidade de distorções é necessária para a caracterização completa do tensor elástico.

Observando a lei de Hooke generalizada na equação (2.111), vê-se que os coeficientes elásticos $C_{i j k l}$ são uma constante de proporcionalidade entre a distorção $e_{k l}$ no cristal e o stress $\sigma_{i j}$ provocado por esta deformação. Portanto, se aplicarmos uma distorção no cristal, cálculos de primeiros princípios fornecem o tensor de stress provocado e pode-se facilmente calcular $C_{i j k l}$. Para tanto, lembramos que, como demonstrado no capítulo 2, a parte simétrica de uma matriz de transformação representa as distorções em uma estrutura. Os vetores primitivos $\vec{a}_{1}, \vec{a}_{2}, \vec{a}_{3}$ da rede podem ser escritos como uma matriz $\vec{R}$ :

$$
\vec{R}=\left(\begin{array}{l}
\vec{a}_{1} \\
\vec{a}_{2} \\
\vec{a}_{3}
\end{array}\right) .
$$

\footnotetext{
${ }^{1} \mathrm{O}$ coeficiente elástico é a segunda derivada da energia livre de Gibbs. Para cálculos estáticos à pressão nula, ela se resume à energia interna do sistema.
} 
Dessa forma, pode-se definir uma distorção na rede como uma transformação nesses vetores de rede como

$$
\vec{R}^{\prime}=\mathcal{T} \vec{R},
$$

em que $\vec{R}^{\prime}$ é uma matriz com os vetores de rede distorcidos e

$$
\mathcal{T}=\left(\mathcal{I}+e_{i j}\right),
$$

em que $e_{i j}$ é a matriz de deformação e $\mathcal{I}$ é a matriz identidade. Com as equações (2.127) e (2.128) pode-se calcular vetores primitivos correspondentes à qualquer distorção desejada. Com estes vetores, o tensor de stress é calculado e os coeficientes elásticos extraídos através da equação (2.111). Como cada estrutura possui um tensor elástico com diferentes quantidades de componentes, é necessário um tensor de deformação para cada classe cristalina [67]. As distorções utilizadas para cada estrutura são mostradas no apêndice B.

Para cada uma das matrizes de distorção $e_{k l}$, mostradas nas equações (B.1), (B.2) e (B.3), consideramos valores de distorções de $\pm 1 \%(\delta= \pm 0,01)$ e, através do método dos mínimos quadrados, ajustamos uma reta. A constante elástica é o coeficiente angular desta reta. 


\section{Propriedades do $\mathrm{MgSiO}_{3}$}

We have to remember that what we observe is not nature herself, but nature exposed to our method of questioning.

- Werner Heisenberg, Physics and Philosophy: The revolution in modern science.

\subsection{Introdução}

$\mathrm{O} \mathrm{MgSiO}_{3}$ (silicato de magnésio) é o material mais abundante no planeta Terra. Estimativas indicam que o $\mathrm{Mg}_{1-x} \mathrm{Fe}_{x} \mathrm{SiO}_{3}$ perovskita compõe cerca de $85 \%$ do manto inferior da Terra [82]. Essa região corresponde a cerca de 55\% do volume de nosso planeta e é a maior região pura existente [18]. O manto inferior é uma região de temperaturas e pressões extremas e conhecer o comportamento de seus constituintes é fundamental para se compreender diversas propriedades geofísicas. Diversos modelos geofísicos, principalmente sismológicos, dependem de um conhecimento preciso de diversas propriedades do manto. Como a única fonte direta de informação sobre o interior da Terra são as ondas sísmicas que atravessam seu interior, a determinação das contantes elásticas é de especial importância, pois são empregadas no cálculo das velocidades de ondas acústicas no material.

Como a maior parte do manto inferior é composta por $\mathrm{MgSiO}_{3}$ perovskita, apresentamos, neste capítulo, os resultados do nosso estudo sobre este mineral. Estes resultados servirão como molde do manto inferior e também irão cumprir com a finalidade de servir como referência ou padrão, validando o es- 
tudo dos carbonatos que serão apresentados nos próximos capítulos.

Neste capítulo apresentamos os resultados dos estudos das propriedades estruturais, eletrônicas e elásticas do $\mathrm{MgSiO}_{3}$, onde utilizamos a teoria do funcional da densidade (DFT) com aproximações LDA e GGA para o termo de troca e correlação. Iniciamos as simulações à pressão nula e posteriormente incluímos efeitos báricos.

\subsection{Propriedades estruturais}

A célula primitiva do $\mathrm{MgSiO}_{3}$ pertence ao grupo 62 na tabela internacional de cristalografia, cujo arranjo convencional corresponde ao grupo Pnma. A célula primitiva deste cristal é ortorrômbica com uma base de 20 (vinte) átomos. Os vetores primitivos da rede são: $(a, 0,0) ;(0, b, 0)$ e $(0,0, c)$, em que $a, b$ e $c$ são os parâmetros da rede. Por se tratar de uma estrutura ortorrômbica, é possível orientar os eixos da célula de seis maneiras distintas, dando origem a outros cinco grupos não convencionais: Pbnm, Pmcn, Pmnb, Pcmn e Pnam. Para todos eles, a base possui quatro unidades de $\mathrm{MgSiO}_{3}$, ou seja quatro átomos de magnésio, quatro átomos de silício e 12 átomos de oxigênio.

Escolhemos o grupo Pbnm para a orientação dos eixos do cristal de $\mathrm{MgSiO}_{3}$ perovskita, já que esta é a orientação mais utilizada na literatura. Nesta fase, os átomos de silício e de magnésio estão nas posições de Wyckoff 4b e 4c, respectivamente. Os átomos de oxigênio se dividem em duas espécies, uma com quatro átomos (posição de Wyckoff $4 \mathrm{c}-\mathrm{O}_{1}$ ) e outra com oito átomos (posição de Wyckoff $8 \mathrm{~d}-\mathrm{O}_{2}$ ). Nesta estrutura perovskita ortorrômbica, cada um dos quatro átomos de silício possui seis átomos de oxigênio como primeiros vizinhos, divididos em três esferas de coordenação, e cada um dos quatro átomos de magnésio possui oito átomos de oxigênio como primeiros vizinhos, divididos em cinco esferas de coordenação. Cada átomo de oxigênio possui dois átomos de silício como primeiros vizinhos. Uma representação do arranjo dos átomos da estrutura ortorrômbica do $\mathrm{MgSiO}_{3}$ está mostrada na figura 3.1. Para se obter os parâmetros de rede teóricos do cristal otimizou-se a célula do cristal para diferentes valores de pressão através da utilização de métodos de dinâmica 
Figura 3.1: Estrutura cristalina do $\mathrm{MgSiO}_{3}$ perovskita. As esferas azuis representam os átomos de silício, as vermelhas os átomos de oxigênio e as amarelas os átomos de magnésio.

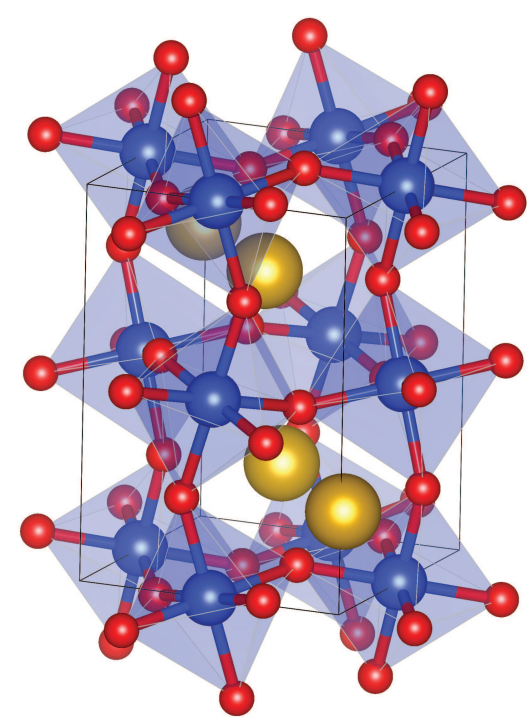

molecular de célula variável [80]. O método utilizado neste trabalho foi aquele proposto por Wentzcovitch [81], no qual o tensor de stress é utilizado como variável. Com isto pode-se otimizar a estrutura em qualquer pressão desejada já que a pressão do sistema pode ser calculada com o tensor de stress [67] e este é facilmente calculado dentro do método de pseudopotencial [74]. Entretanto, a pressão calculada desta forma não é exata, pois incorpora as aproximações utilizadas nos cálculos de primeiros princípios. Assim, a real pressão do sistema é obtida da maneira usual, utilizando alguma equação de estado. A equação de estado mais utilizada é a de Birch-Murnaghan de segunda ordem, por isso esta foi utilizada neste trabalho. Com esse procedimento obtivemos os valores dos parâmetros de rede, que estão apresentados na tabela 3.1, juntamente com dados experimentais.

Tabela 3.1: Propriedades estruturais do $\mathrm{MgSiO}_{3}$ perovskita ortorrômbico, em que $a, b, c$ são os parâmetros de rede e $K_{0}$ é o bulk modulus.

\begin{tabular}{||c|c|c|c|c|c||}
\hline \hline & $a(\AA)$ & $b(\AA)$ & $c(\AA)$ & $V_{0}\left(\AA^{3}\right)$ & $K_{0}(\mathrm{GPa})$ \\
\hline \hline Teórico & 4,74 & 4,90 & 6,85 & 159,01 & 261 \\
\hline Experimental & $4,78^{(a)}$ & $4,94^{(a)}$ & $6,91^{(a)}$ & 163,17 & $264^{(b)}$ \\
\hline \hline
\end{tabular}

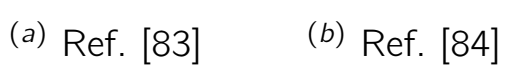


Percebe-se que os valores teóricos e experimentais estão em bom acordo. Os valores das constantes de rede são menores do que os dados experimentais, resultado compatível com o fato de que a utilização do funcional LDA subestima os parâmetros de rede. A tabela 3.2 mostra os valores dos parâmetros internos da estrutura perovskita do $\mathrm{MgSiO}_{3}$, os quais estão em excelente acordo com os valores experimentais.

Tabela 3.2: Posições dos átomos de $\mathrm{Si}, \mathrm{Mg}$ e $\mathrm{O}$ em relação aos parâmetros de rede $a, b, c$ da célula primitiva ortorrômbica do $\mathrm{MgSiO}_{3}$, estrutura perovskita $(\mathrm{Pbnm})$. Resultados experimentais são da referência [84].

\begin{tabular}{||c|c||c|c|c||c|c|c||}
\hline \hline \multicolumn{1}{||c||}{} & \multicolumn{3}{c||}{ Teórico } & \multicolumn{3}{c||}{ Experimental } \\
\hline Átomo & Posição de Wyckoff & $x$ & $y$ & $z$ & $x$ & $y$ & $z$ \\
\hline \hline $\mathrm{Si}$ & 4b & 0,5 & 0 & 0 & 0,5 & 0 & 0 \\
\hline $\mathrm{Mg}$ & 4c & 0,985 & 0,058 & 0,250 & 0,986 & 0,056 & 0,250 \\
\hline $\mathrm{O}_{1}$ & 4c & 0,104 & 0,466 & 0,250 & 0,102 & 0.467 & 0,250 \\
\hline $\mathrm{O}_{2}$ & 8d & 0,696 & 0,299 & 0,054 & 0,696 & 0,298 & 0,052 \\
\hline \hline
\end{tabular}

\subsection{Propriedades eletrônicas}

A primeira zona de Brillouin do cristal de $\mathrm{MgSiO}_{3}$ perovskita ortorrômbico é um paralelepípedo, conforme mostra a figura 3.2, em que estão destacados os pon-

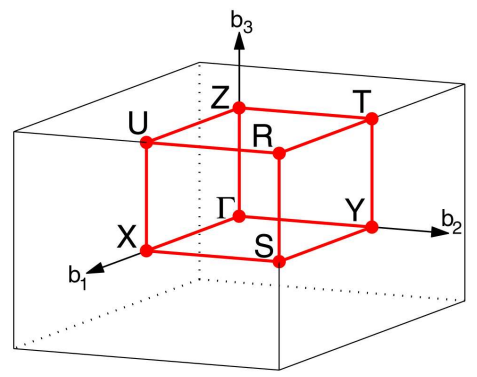

Figura 3.2: Primeira zona de Brillouin da rede ortorrômbica primitiva do $\mathrm{MgSiO}_{3}$, mostrando os pontos e as direções de alta simetria. Ref. [85]. 
tos e as direções de alta simetria.

Com os valores otimizados das constantes de rede, calculou-se a estrutura de bandas do material nas direções de alta simetria da primeira zona de Brillouin. A estrutura de bandas e as densidades de estados (DOS) projetadas nos átomos de magnésio, silício e oxigênio estão mostradas na figura 3.3, onde o zero de energia foi deslocado para o topo da banda de valência $\left(E_{v}\right)$.

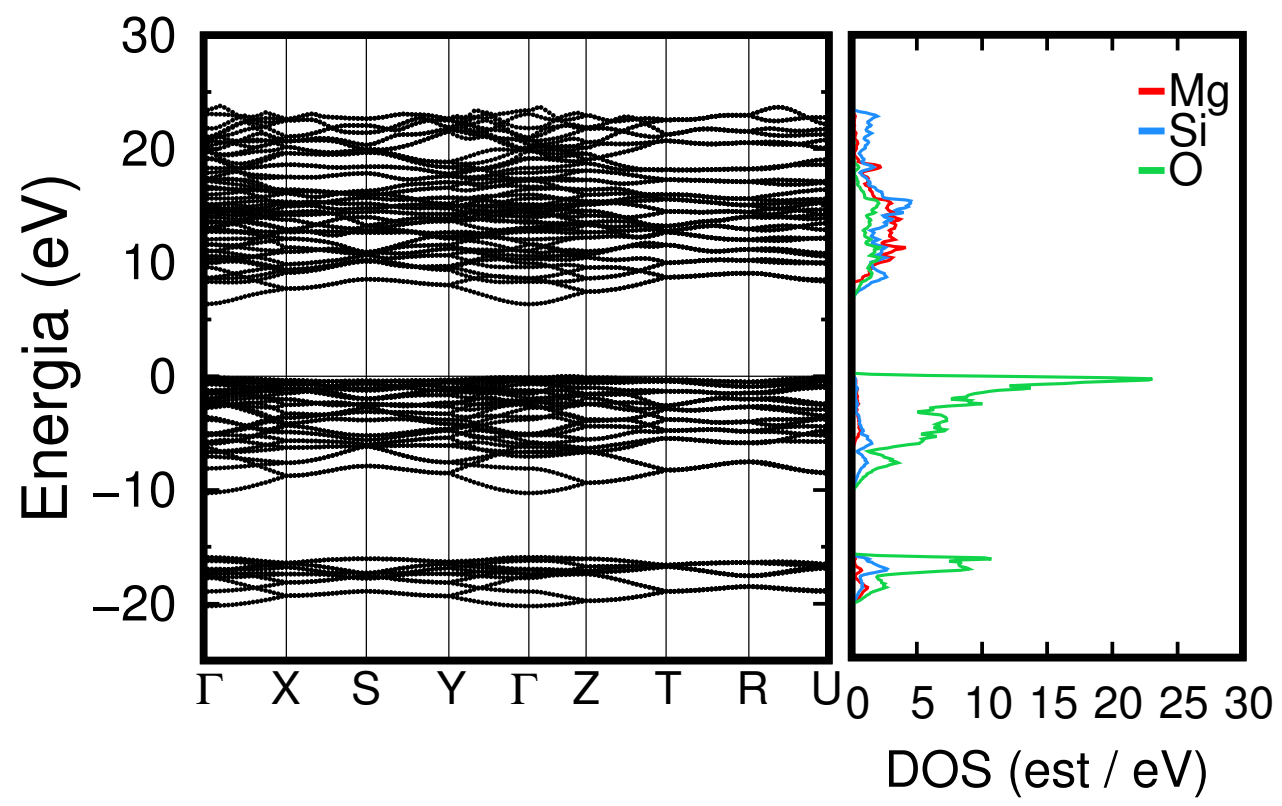

Figura 3.3: Estrutura de bandas e densidades de estados (DOS) projetadas nos átomos de magnésio, silício e oxigênio do $\mathrm{MgSiO}_{3}$ na estrutura perovskita.

A largura da faixa de energia proibida fundamental, definida como a diferença de energia entre o estado mais alto ocupado e mais baixo desocupado, é de transição indireta e seu valor é $E_{g}=6,34 \mathrm{eV}$. O topo da banda de valência se posiciona na direção $\Gamma-Z$ e o fundo da banda de condução é no ponto $\Gamma$. Este resultado é somente $4 \%$ menor do que o valor experimental estimado de 6,6 eV [86], consistente com o fato de que o valor do gap de energia de um material é geralmente subestimado por simulações baseadas no formalismo DFT, uma vez que esta metodologia descreve bem os estados eletrônicos ocupados (estado fundamental) e não os desocupados (estado excitado).

A banda formada na região de energia de aproximadamente $-17 \mathrm{eV}$ é ma- 
joritariamente composta pelos orbitais $2 s$ dos átomos de oxigênio, enquanto seus estados $2 p$ compõem, prioritariamente, a banda de valência do mineral, que apresenta largura de cerca de $10 \mathrm{eV}$. O fundo da banda de condução é formado por estados dos átomos de magnésio e silício. Podemos analisar a composição do sistema cristalino do ponto de vista dos estados de oxidação dos átomos constituintes, sabendo que a camada de valência do $\mathrm{Mg}$ é $3 s^{2}$, do $\mathrm{Si}$ é $3 s^{2} 3 p^{2}$ e a do O é $2 s^{2} 2 p^{4}$. Neste modelo, na formação da unidade $\mathrm{MgSiO}_{3}$ do mineral, cada par $(\mathrm{Mg}, \mathrm{Si})$ da unidade primitiva doa seis elétrons para os 3 (três) átomos de $\mathrm{O}$. Assim, os átomos de magnésio encontram-se no estado de oxidação +2 , os átomos de silício encontram-se no estado de oxidação +4 e os de oxigênio no estado de oxidação -2. Os estados s e $p$ dos íons de $\mathrm{Mg}$ e Si, eletronicamente desocupados, contribuem para a formação do fundo da banda de condução enquanto que os estados $p$ dos íons de $\mathrm{O}$, eletronicamente ocupados, contribuem para a formação da banda de valência. A densidade eletrônica do sistema, mostrada na figura 3.4 para o plano (200) do cristal, demonstra o caráter parcialmente iônico deste mineral.

Nossos resultados teóricos para as propriedades estruturais e eletrônicas do $\mathrm{MgSiO}_{3}$, mostraram boa concordância com os dados experimentais disponíveis, indicando que o método utilizado descreve bem este cristal.

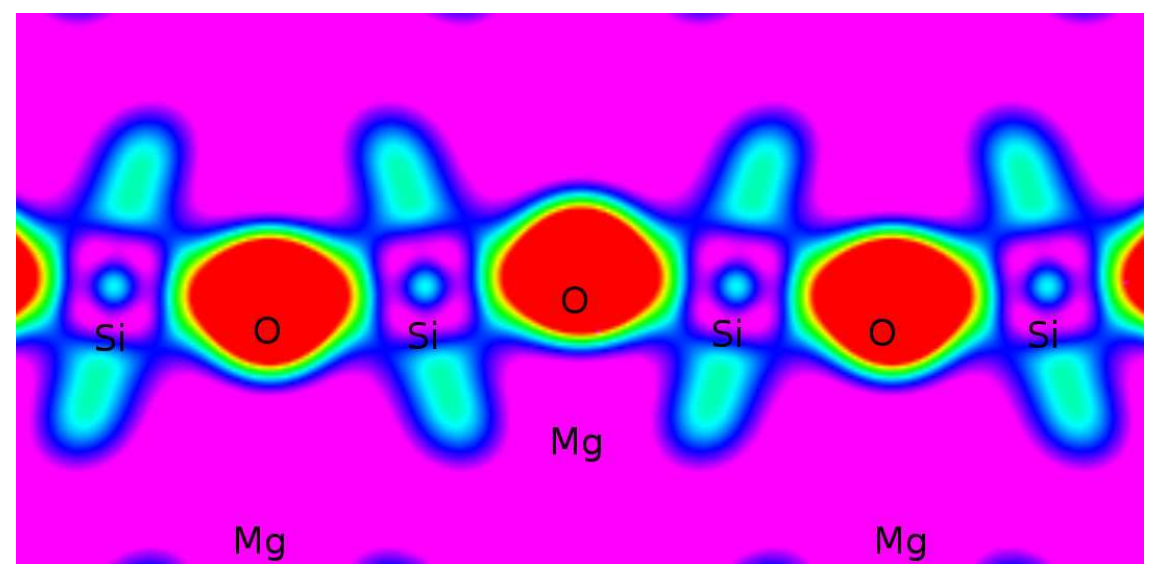

Figura 3.4: Densidade eletrônica do $\mathrm{MgSiO}_{3}$ ortorrômbico no plano (200). O esquema de cores segue o arco íris, variando do violeta (baixa densidade) para o vermelho (alta densidade). 


\subsection{Propriedades elásticas}

O tensor elástico do $\mathrm{MgSiO}_{3}$ perovskita foi calculado utilizando a metodologia apresentada no capítulo 2 e os valores de suas componentes estão mostrados na tabela 3.3, juntamente com os resultados de outros cálculos teóricos e com dados experimentais disponíveis na literatura.

Tabela 3.3: Componentes do tensor elástico $C_{i j}$, em $\mathrm{GPa}$, do $\mathrm{MgSiO}_{3}$ perovskita.

\begin{tabular}{||c|c|c|c||}
\hline \hline$C_{i j}$ & Este trabalho & Teórico $^{(a)}$ & Exp. $^{(b)}$ \\
\hline \hline$C_{11}$ & 479 & 485 & 482 \\
$C_{22}$ & 544 & 560 & 537 \\
$C_{33}$ & 474 & 474 & 485 \\
$C_{44}$ & 202 & 200 & 204 \\
$C_{55}$ & 173 & 176 & 186 \\
$C_{66}$ & 156 & 155 & 147 \\
$C_{12}$ & 136 & 130 & 144 \\
$C_{13}$ & 136 & 136 & 147 \\
$C_{23}$ & 153 & 144 & 146 \\
\hline \hline
\end{tabular}
(a) Ref. [40]
(b) Ref. [87]

As pequenas discrepâncias entre os resultados teóricos e experimentais são esperadas uma vez que os resultados teóricos são obtidos para $T=0 \mathrm{~K}$. Encontramos que $C_{22}>C_{11}>C_{33}$ e que $C_{44}>C_{55}>C_{66}$. Isso indica que o eixo na direção do parâmetro de rede $b$ é o menos compressível, enquanto a compressibilidade nas direções dos eixos a e $c$ são da mesma ordem.

O bulk modulus (módulo de compressibilidade), obtido pelas equações de estado, é uma medida isotrópica da elasticidade do material. Ele também pode ser obtido como uma média dos coeficientes elásticos em diversas direções [67]. Existem diversas formas de se efetuar esta média, algumas mais precisas do que outras. Uma das mais utilizadas, e que fornece bons resultados quando comparados com resultados experimentais, é a média de Voig-ReussHill. A média de Voigt [88] é obtida considerando-se que o stress é uniforme no 
material e as expressões para os módulos elásticos ficam

$$
\begin{aligned}
& K_{V}=\frac{1}{9}\left[\left(C_{11}+C_{22}+C_{33}\right)+2\left(C_{12}+C_{23}+C_{13}\right)\right] \\
& \mu_{V}=\frac{1}{15}\left[\left(C_{11}+C_{22}+C_{33}\right)-\left(C_{12}+C_{23}+C_{13}\right)+3\left(C_{44}+C_{55}+C_{66}\right)\right],
\end{aligned}
$$

enquanto a média de Reuss considera que o strain é uniforme [89]

$$
\begin{aligned}
& \frac{1}{K_{R}}=\left(S_{11}+S_{22}+S_{33}\right)+2\left(S_{12}+S_{23}+S_{13}\right) \\
& \frac{15}{\mu_{R}}=4\left(S_{11}+S_{22}+S_{33}\right)-4\left(S_{12}+S_{23}+S_{13}\right)+3\left(S_{44}+S_{55}+S_{66}\right)
\end{aligned}
$$

em que $S_{\alpha \beta}$ é o tensor de compliance, o inverso do tensor elástico $\mathbf{S}=\mathbf{C}^{-1}$. A média de Voig-Reuss-Hill é obtida pela média aritmética da média de Voigt com a de Reuss [90]:

$$
\begin{gathered}
K=\frac{K_{V}+K_{R}}{2} \\
\mu=\frac{\mu_{V}+\mu_{R}}{2} .
\end{gathered}
$$

A tabela 3.4 apresenta os valores dos módulos de elasticidade isotrópicos obtidos através dos coeficientes elásticos e através da equação de estado, assim como dados experimentais [87], mostrando que os valores dos módulos elásticos calculados com os coeficientes elásticos estão em excelente acordo com resultados experimentais.

Tabela 3.4: Módulos de elasticidade isotrópicos $\left(K_{0}\right.$ e $\mu$ ) do $\mathrm{MgSiO}_{3}$ perovskita obtidos através dos coeficientes elásticos $\left(C_{i j k l}\right)$ e através da equação de estado (EoS). Resultados experimentais são da referência [87].

\begin{tabular}{||l|c|c|}
\hline \hline & $K_{0}(\mathrm{GPa})$ & $\mu(\mathrm{GPa})$ \\
\hline \hline$C_{i j k l}$ & 264,2 & 181,1 \\
EoS & 261,0 & - \\
Exp. & 264,0 & 184,9 \\
\hline \hline
\end{tabular}


A anisotropia do $\mathrm{MgSiO}_{3}$ pode acarretar importantes efeitos geofísicos e tem sido amplamente investigada $[68,78,79]$. Para estudarmos a anisotropia do $\mathrm{MgSiO}_{3}$ à $P=0 \mathrm{GPa}$, resolvemos a equação de Christoffel (2.119) para determinar a velocidade de propagação das ondas acústicas no material em diferentes direções do cristal. A figura 3.5 mostra os resultados obtidos para a velocidade de propagação das ondas acústicas $\mathrm{P}$ e $\mathrm{S}$.

Analisando os resultados apresentados na figura, conclui-se que tanto a direção como a polarização da onda influenciam nos valores das velocidades de propagação das ondas acústicas no $\mathrm{MgSiO}_{3}$. Existem diversas formas de se medir a anisotropia destas velocidades e uma das mais utilizadas é dada pelas relações [40]

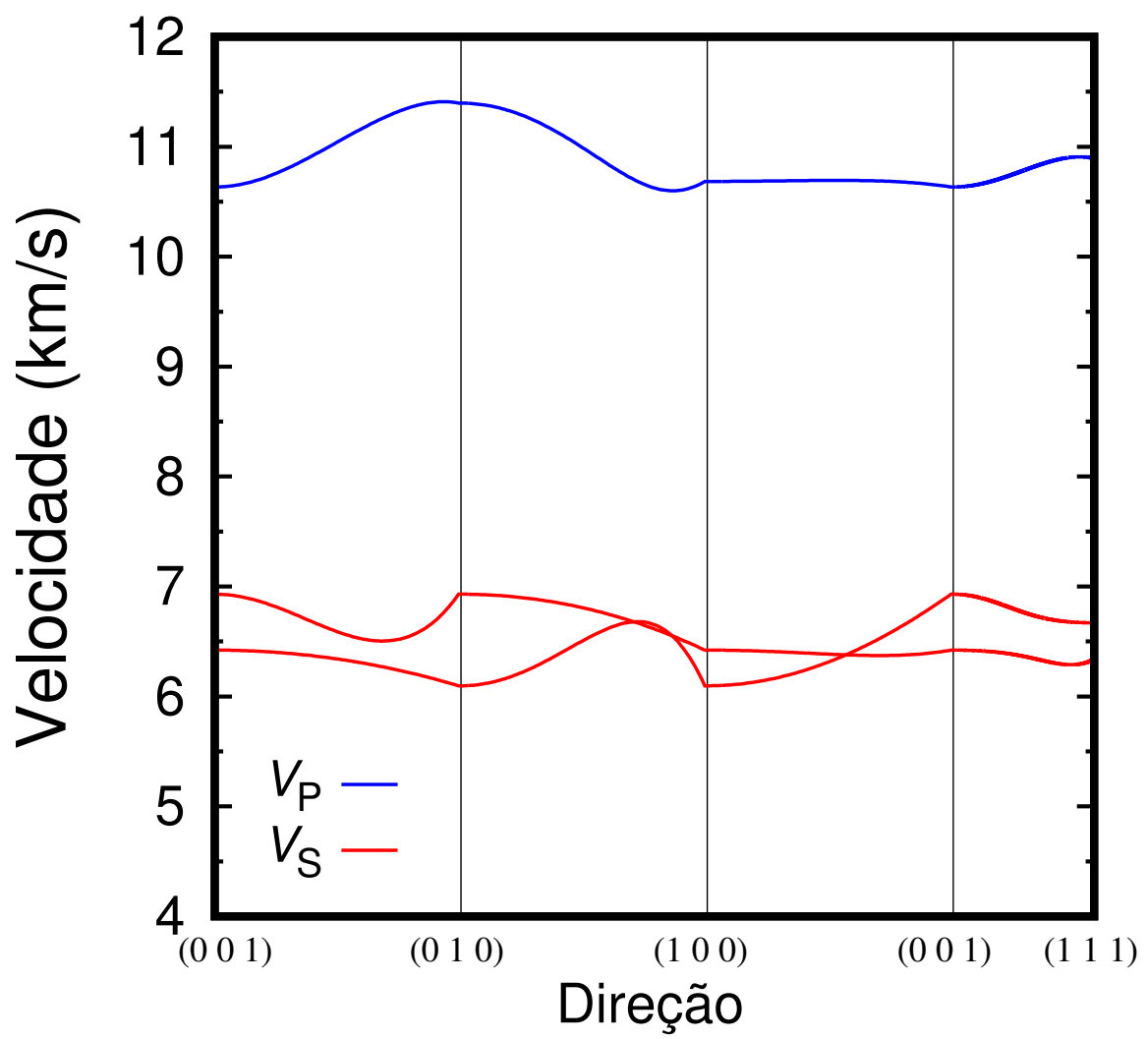

Figura 3.5: Velocidade de propagação das ondas acústicas $P\left(V_{P}\right)$ e $S\left(V_{S}\right)$ no $\mathrm{MgSiO}_{3}$ ortorrômbico, na estrutura perovskita, em diferentes direções do cristal. 


$$
\begin{aligned}
& A_{P}=\frac{V_{P_{\text {max }}}-V_{P_{\text {min }}}}{\left\langle V_{P}\right\rangle} \times 100, \text { com }\left\langle V_{P}\right\rangle=\sqrt{\frac{K+\frac{4}{3} \mu}{\rho}} \\
& A_{S}=\frac{V_{S_{\text {max }}}-V_{S_{\text {min }}}}{\left\langle V_{S}\right\rangle} \times 100, \text { com }\left\langle V_{S}\right\rangle=\sqrt{\frac{\mu}{\rho}}
\end{aligned}
$$

em que $\left\langle V_{P}\right\rangle$ e $\left\langle V_{S}\right\rangle$ são as velocidades em agregados isotrópicos do cristal e $\rho$ é a densidade do material. O bulk modulus $K$ foi calculado com as expressões (3.1), (3.3) e (3.5). O módulo de cisalhamento $\mu$ foi obtido pelas relações (3.2), (3.4) e (3.6). Utiliza-se o bulk modulus obtido pela média de Voigt-Reuss-Hill, pois este é o único método de se calcular o módulo de cisalhamento. Calculamos, então, a anisotropia da velocidade de propagação das ondas acústicas $\mathrm{P}$ e S, obtendo: $A_{P}=8,34 \%, A_{S_{1}}=13,58 \%, A_{S_{2}}=12,03 \%$.

Analisando os resultados podemos observar que a velocidade de propagação das ondas $S$ apresenta uma maior anisotropia do que a das ondas P. Estes resultados são consistentes com outros encontrados na literatura [40, 76, 91]. Como a variação da direção influencia a velocidade da onda no material, uma orientação preferencial dos eixos do cristal, nas rochas que compõem o planeta, pode ocasionar mudanças bruscas nas velocidades de propagação. Para se verificar este efeito é preciso estudar as velocidades das ondas no cristal sob condições de altas pressões.

\section{5 $\quad \mathrm{MgSiO}_{3}$ sob pressão}

Para o estudo de propriedades de materiais com interesse geofísico, é imprescindível incorporar efeitos de altas pressões, já que estas influenciam diretamente diversas propriedades, principalmente elásticas, pois os minerais tendem a ficar mais duros quando pressionados. Para incluir efeitos báricos em nossos cálculos, utilizamos a metodologia apresentada no capítulo 2 para o cálculo do tensor de stress. Como mostrado no capítulo anterior, a pressão hidrostática pode ser definida pela equação (2.86)

$$
P=-\frac{1}{3} \operatorname{Tr}\left(\sigma_{i j}\right)
$$


de tal forma que podemos otimizar a estrutura em qualquer pressão desejada.

\section{Propriedades estruturais}

Na seção anterior apresentamos os resultados encontrados para os parâmetros de rede que foram otimizados para a condição de pressão nula. Podemos, então, para um valor pré-determinado da pressão, encontrar os parâmetros de rede, ajustando a equação de estado. Assim, através da relação $P \times V$, podemos obter a pressão para qualquer volume calculado. A tabela 3.5 apresenta os valores dos parâmetros de rede $a, b, c$ e do bulk modulus $(K)$ para diferentes pressões, no intervalo de pressões $0 \leq P \leq 150 \mathrm{GPa}$.

Tabela 3.5: Parâmetros de rede $a, b, c$ e bulk modulus $K$ do $\mathrm{MgSiO}_{3}$ ortorrômbico, para alguns valores selecionados de pressão, no intervalo $0 \leq P \leq 150 \mathrm{GPa}$.

\begin{tabular}{||c|c|c|c|c||}
\hline \hline$P(\mathrm{GPa})$ & $a(\AA)$ & $b(\AA)$ & $c(\AA)$ & $K(\mathrm{GPa})$ \\
\hline \hline 0 & 4,74 & 4,90 & 6,85 & 265 \\
\hline 30 & 4,58 & 4,77 & 6,62 & 387 \\
\hline 60 & 4,45 & 4,68 & 6,47 & 499 \\
\hline 100 & 4,32 & 4,59 & 6,31 & 642 \\
\hline 150 & 4,19 & 4,51 & 6,16 & 812 \\
\hline \hline
\end{tabular}

Pode-se observar dos valores da tabela que as constantes de rede $a, b$ e $c$ diminuem conforme a pressão aumenta, mas as relações $b / a$ e $c / a$ permanecem aproximadamente constantes. Para o valor de pressão de $150 \mathrm{GPa}$ as constantes a e $c$ diminuem $11 \%$ e $10 \%$, respectivamente, enquanto a constante $b$ diminui $8 \%$, corroborando a análise feita anteriormente de que a compressibilidade na direção do eixo do parâmetro $b$ é a menor, enquanto que na direção dos eixos dos parâmetros $a$ e $c$ são semelhantes.

Apresentamos na figura 3.6 os resultados da equação de estado do $\mathrm{MgSiO}_{3}$ na estrutura ortorrômbica perovskita, obtida utilizando-se os funcionais LDA (linhas tracejadas) e GGA (linhas contínuas), e dados experimentais, que apresentam valores intermediários em relação aos resultados teóricos. Como os 


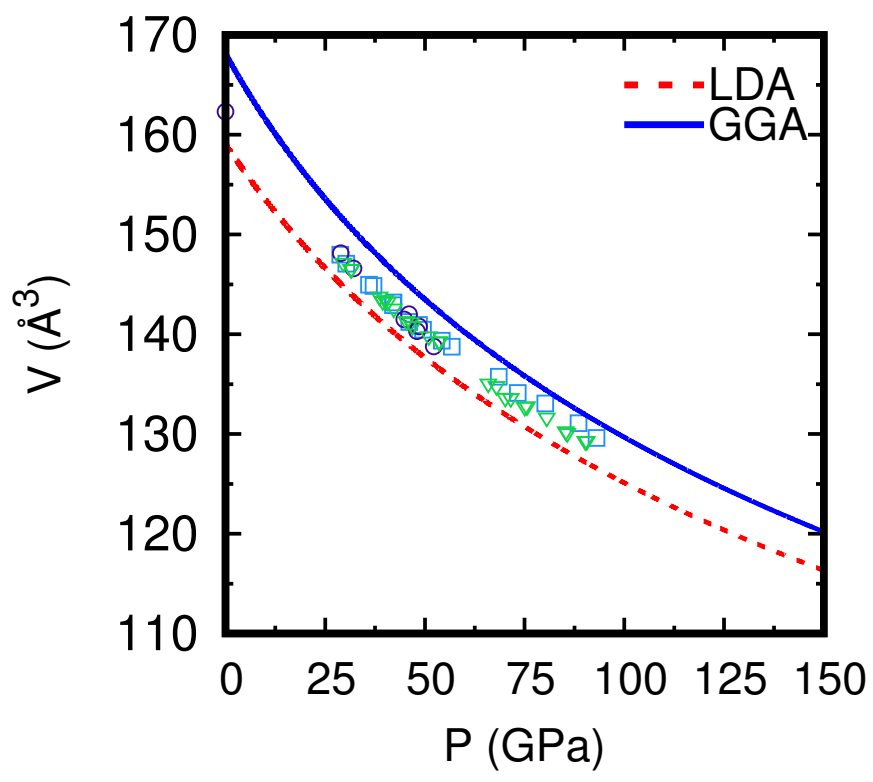

Figura 3.6: Equação de estado do $\mathrm{MgSiO}_{3}$ na estrutura ortorrômbica perovskita, obtida utilizando-se o funcional LDA (linhas tracejadas) e o GGA (linhas contínuas). Os dados experimentais são das referências [92] ( $\square)$, [93] $(\bigcirc)$ e [94] $(\nabla)$.

dados experimentais foram obtidos à temperatura ambiente, então, se efeitos térmicos forem introduzidos na simulação, os valores dos parâmetros de rede, obtidos com a utilização do funcional LDA, aumentariam, aproximando-se dos valores experimentais. Por outro lado, como os valores dos parâmetros de rede, obtidos com a utilização do funcional GGA, estão superestimados, a introdução de efeitos térmicos fariam com que os valores aumentassem, distanciando-se dos valores experimentais. Assim, podemos concluir que a utilização do funcional LDA é mais apropriada para a descrição da equação de estado do material, fato também observado em outros estudos [39].

A tabela 3.6 apresenta as posições dos átomos de magnésio e oxigênio, em relação aos parâmetros de rede $a, b, c$ da célula primitiva do $\mathrm{MgSiO}_{3}$, para algumas pressões selecionadas, mostrando que posições atômicas relativas não são consideravelmente afetadas pelo aumento da pressão. 
Tabela 3.6: Posições dos átomos de magnésio $(\mathrm{Mg})$ e de oxigênio $\left(\mathrm{O}_{1}\right.$ e $\left.\mathrm{O}_{2}\right)$, em relação aos parâmetros de rede $a, b, c$ da célula primitiva do $\mathrm{MgSiO}_{3}$, estrutura perovskita, para algumas pressões selecionadas $(P)$, em unidades de GPa.

\begin{tabular}{||c||c|c|c||c|c|c||c|c|c||}
\hline \hline \multirow{2}{*}{} & \multicolumn{3}{c||}{$\mathrm{Mg}(4 \mathrm{c})$} & \multicolumn{3}{c||}{$\mathrm{O}_{1}(4 \mathrm{c})$} & \multicolumn{3}{c||}{$\mathrm{O}_{2}(8 \mathrm{~d})$} \\
\cline { 2 - 10 } & $\mathrm{x}$ & $\mathrm{y}$ & $\mathrm{z}$ & $\mathrm{x}$ & $\mathrm{y}$ & $\mathrm{z}$ & $\mathrm{x}$ & $\mathrm{y}$ & $\mathrm{z}$ \\
\hline \hline 0 & 0,9856 & 0,0539 & 0,250 & 0,0986 & 0,4690 & 0,250 & 0,6990 & 0,2964 & 0,0512 \\
\hline 30 & 0,9840 & 0,0593 & 0,250 & 0,1013 & 0,4700 & 0,250 & 0,6951 & 0,2996 & 0,0519 \\
\hline 60 & 0,9818 & 0,0640 & 0,250 & 0,1036 & 0,4713 & 0,250 & 0,6922 & 0,3015 & 0,0525 \\
\hline 100 & 0,9793 & 0,0691 & 0,250 & 0,1060 & 0,4722 & 0,250 & 0,6887 & 0,3037 & 0,0531 \\
\hline 150 & 0,9758 & 0,0746 & 0,250 & 0,1086 & 0,4733 & 0,250 & 0,6847 & 0,3059 & 0,0536 \\
\hline \hline
\end{tabular}

\section{Propriedades eletrônicas}

Calculamos as propriedades eletrônicas do sistema sob diferentes pressões, obtendo a estrutura eletrônica do $\mathrm{MgSiO}_{3}$ perovskita. Conforme a pressão aumenta, o gap de energia também aumenta, como pode ser observado na figura 3.7.

Apesar do gap aumentar com a pressão, ele continua sendo de transição indireta, onde o topo da banda de valência continua sendo na direção $\Gamma-Z$ mas o

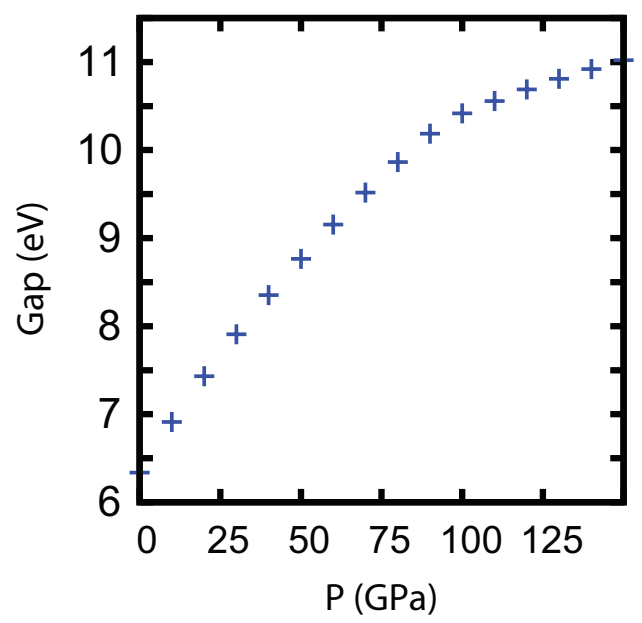

Figura 3.7: Gap de energia, em função da pressão, do $\mathrm{MgSiO}_{3}$ perovskita. 
fundo da banda de condução deixa de ser no ponto $\Gamma$ e passa a ser na direção $X-S$. A forma da estrutura de bandas do material permanece aproximadamente a mesma, mas é possível observar um pequeno aumento nas larguras das bandas de energia. Por exemplo, para $P=150 \mathrm{GPa}$, a banda de valência se alarga da ordem de $1 \mathrm{eV}$, como mostra a figura 3.8.
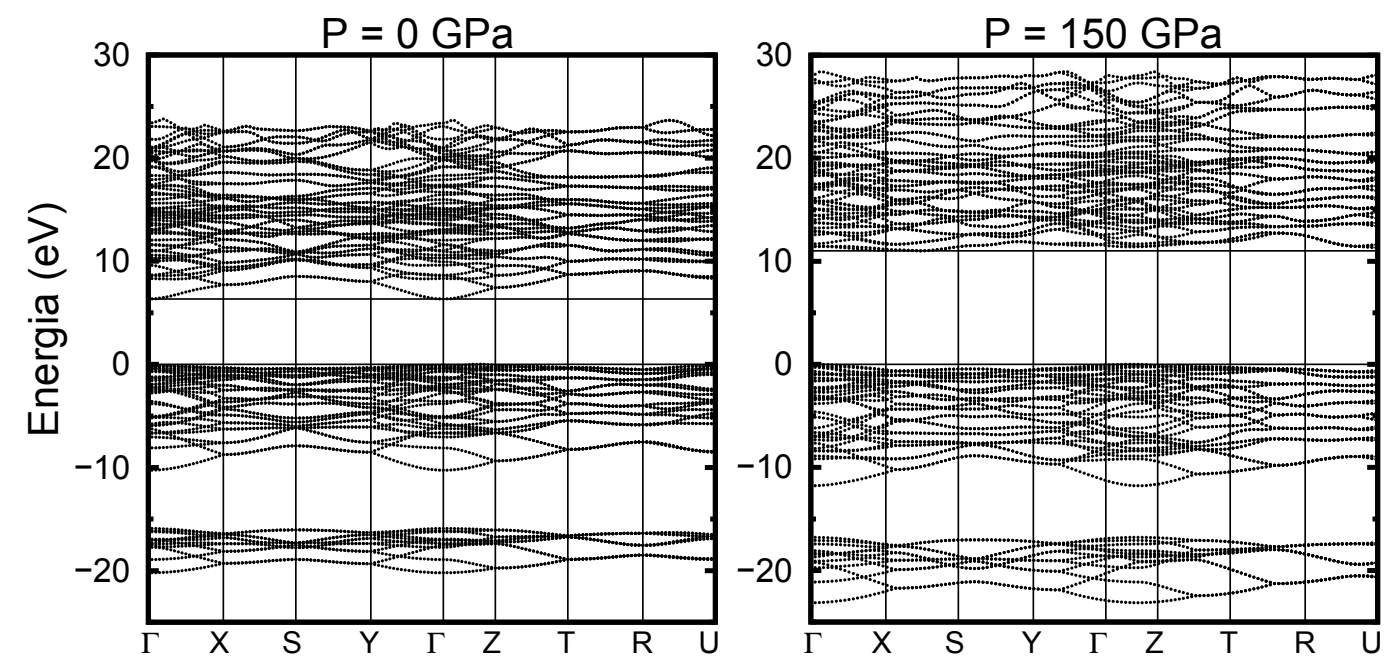

Figura 3.8: Estrutura de bandas do $\mathrm{MgSiO}_{3}$ perovskita a $P=0$ e $P=150 \mathrm{GPa}$.

As características gerais das bandas mantém-se com o aumento da pressão, mostrando que o fundo da banda de condução é formado por estados dos átomos de magnésio e silício, enquanto que a banda de valência do mineral é , primordialmente, formada pelos orbitais dos átomos de oxigênio. A figura 3.9 apresenta as densidades de estados do $\mathrm{MgSiO}_{3}$ perovskita em diferentes pressões, mostrando que na medida que a pressão aumenta a densidade de estados na região do topo da banda de valência do material diminui e aumenta a dispersão dos estados eletrônicos. Assim, a largura das bandas de energia aumenta, e a largura da faixa de energia que separa os níveis de energia ligantes (banda de valência) daqueles anti-ligantes (banda de condução) também aumenta. 


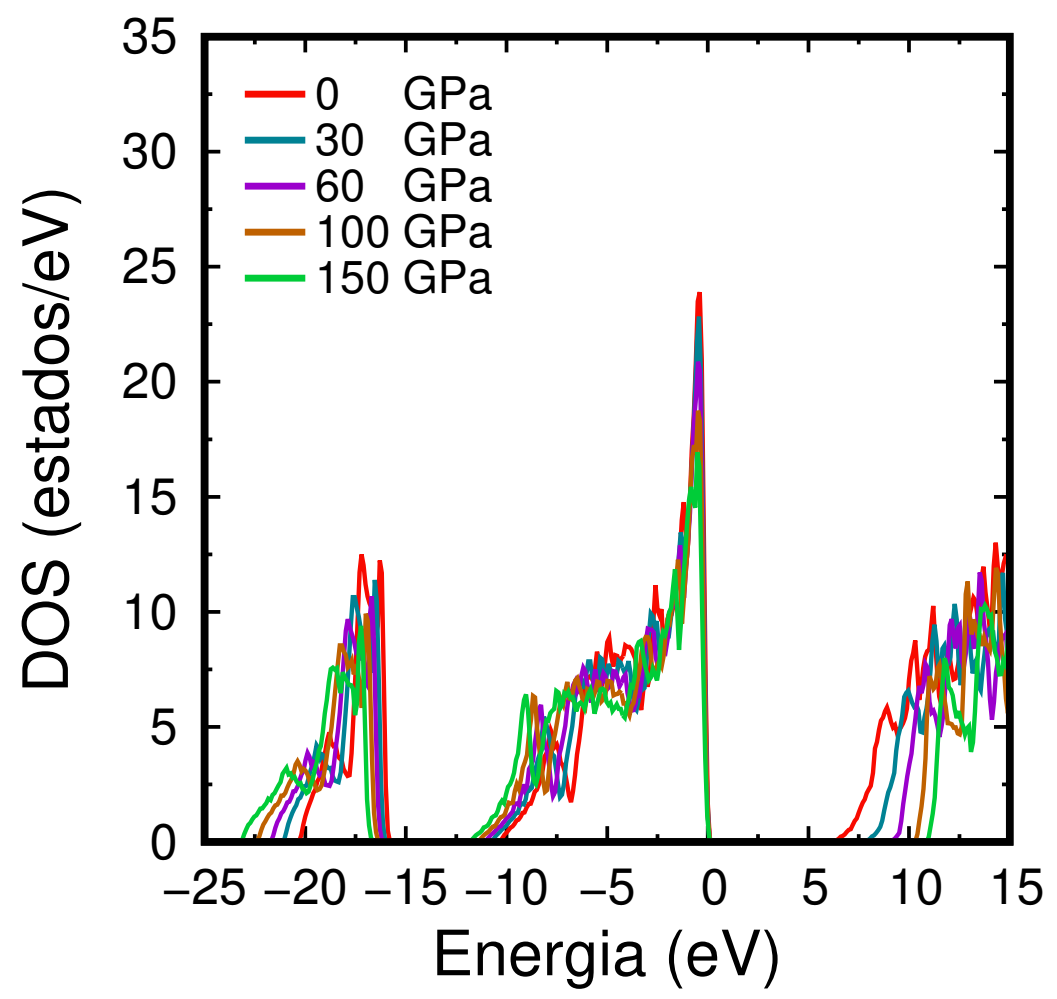

Figura 3.9: Densidade de estados do $\mathrm{MgSiO}_{3}$ perovskita em diferentes pressões.

\section{Propriedades elásticas}

Para cada uma das pressões consideradas, calculamos as componentes do tensor elástico, mostrados na tabela 3.7. Como havíamos mostrado na seção

Tabela 3.7: Coeficientes elásticos, em $\mathrm{GPa}$, do $\mathrm{MgSiO}_{3}$ perovskita sob pressão $P$.

\begin{tabular}{||c|c|c|c|c|c|c|c|c|c||}
\hline \hline$P(\mathrm{GPa})$ & $\mathrm{C}_{11}$ & $\mathrm{C}_{22}$ & $\mathrm{C}_{33}$ & $\mathrm{C}_{44}$ & $\mathrm{C}_{55}$ & $\mathrm{C}_{66}$ & $\mathrm{C}_{12}$ & $\mathrm{C}_{13}$ & $\mathrm{C}_{23}$ \\
\hline \hline 0 & 479 & 544 & 474 & 202 & 173 & 156 & 136 & 136 & 153 \\
\hline 30 & 622 & 738 & 672 & 253 & 211 & 215 & 240 & 208 & 230 \\
\hline 60 & 734 & 909 & 849 & 298 & 234 & 267 & 344 & 279 & 302 \\
\hline 100 & 866 & 1124 & 1065 & 354 & 265 & 327 & 478 & 372 & 401 \\
\hline 150 & 1026 & 1381 & 1310 & 423 & 300 & 398 & 633 & 489 & 517 \\
\hline \hline
\end{tabular}


anterior, para $P=0$ tem-se que $C_{22}>C_{11}>C_{33} ; C_{44}>C_{55}>C_{66}$ e $C_{23}>C_{13}>C_{12}$. Estas relações se mantém até valores de pressão da ordem de $30 \mathrm{GPa}$ e, a partir deste valor, elas se alteram mostrando as seguintes relações: $C_{22}>C_{33}>$ $C_{11} ; C_{44}>C_{66}>C_{55}$ e $C_{12}>C_{23}>C_{13}$. Apesar disto, notamos que o eixo na direção do parâmetro de rede $b$ continua sendo o menos compressível e que a compressibilidade nas direções dos parâmetros a e $c$ altera-se e, para altas pressões, o eixo a se torna mais compressível que o eixo $c$. Também temos que os coeficientes elásticos associados a tensões de cisalhamento mudam diferentemente com a pressão. Para altas pressões $C_{55}$ é menor que $C_{44}$ e $C_{66}$, indicando o favorecimento do cisalhamento no plano (010) em comparação aos planos (100) e (001). Esta tendência está ilustrada na figura 3.10 e está de acordo com outros resultados teóricos disponíveis na literatura [40].

Estudamos a anisotropia do $\mathrm{MgSiO}_{3}$ com o aumento da pressão. Usando a mesma metodologia apresentada na seção anterior, calculamos a velocidade das ondas acústicas no material, em diferentes direções, para várias pressões. Estes resultados estão mostrados na figura 3.11.

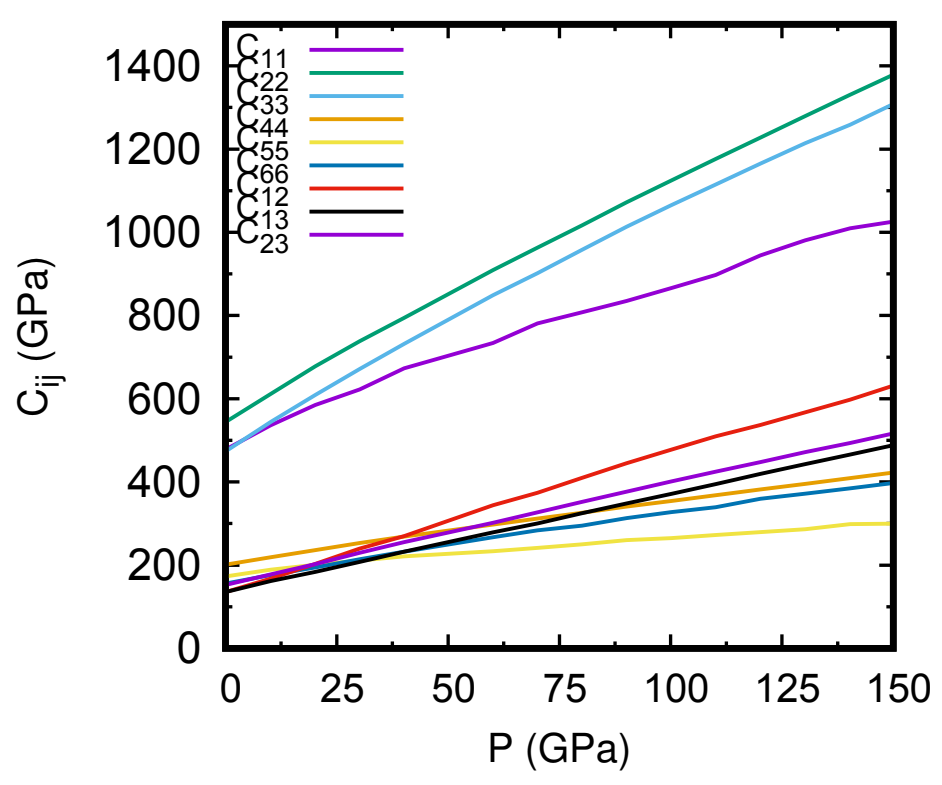

Figura 3.10: Coeficientes elásticos $\left(C_{i j}\right)$ do $\mathrm{MgSiO}_{3}$ perovskita em função da pressão. 


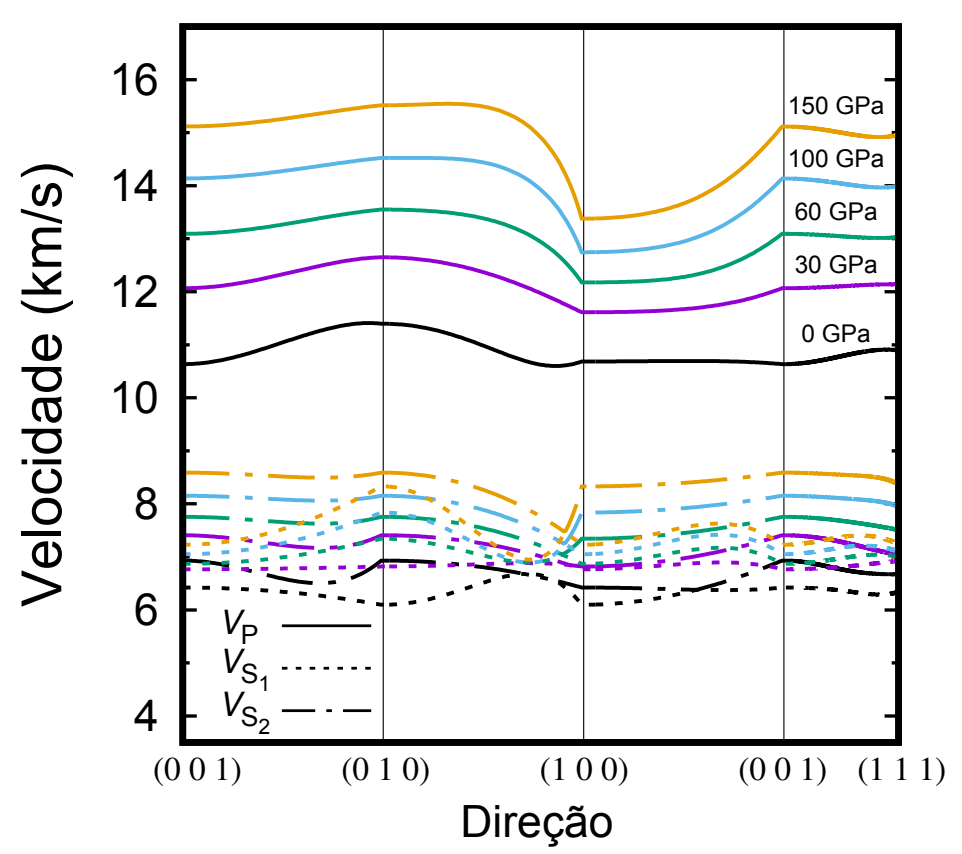

Figura 3.11: Velocidade das ondas acústicas $P\left(V_{P}\right)$ e $S\left(V_{S_{1}}\right.$ e $\left.V_{S_{2}}\right)$, em diferentes direções, no $\mathrm{MgSiO}_{3}$ ortorrômbico, na estrutura perovskita, em função da pressão.

O aspecto das curvas das velocidades como função da direção não variam significativamente com o aumento da pressão. Entretanto, a diferença entre as velocidades máxima e mínima aumenta e é mais acentuada nas ondas acústicas $\mathrm{P}$ em comparação com as ondas $\mathrm{S}$. Assim, a anisotropia deste sistema tende a aumentar com o aumento da pressão. Na direção (100) e para pressões mais altas há uma diminuição brusca no valor das velocidades, que pode chegar a ser de até $1,4 \%(15,5 \mathrm{~km} / \mathrm{s}$ para $13,3 \mathrm{~km} / \mathrm{s})$. Este comportamento é consistente com a variação na velocidade de ondas sísmicas na região da descontinuidade $\mathrm{D}^{\prime \prime}$. Entretanto, o modelo aceito para explicar esta variação na velocidade de ondas sísmicas, neste intervalo de pressões, baseia-se na ocorrência de uma transição de fase do $\mathrm{MgSiO}_{3}$, passando da estrutura perovskita (Pv) para a estrutura pós-perovskita (Ppv) [76, 95-97]. A estrutura Ppv é mais dura que a $P v$ e as velocidades das ondas sísmicas são maiores nesta fase. 
Entretanto, o aumento da velocidade das ondas devido apenas à mudança estrutural não explica completamente a descontinuidade D". Se a estrutura Ppv mantiver este comportamento com a pressão, a mudança de fase juntamente com uma orientação preferencial dos eixos pode ser suficiente para explicar esta descontinuidade na velocidade das ondas sísmicas. De qualquer forma, podemos concluir que mesmo em regiões onde não há a transição para a fase pós-perovskita, uma direção preferencial da estrutura, em altas pressões, pode acarretar numa mudança brusca nas velocidades de propagação das ondas acústicas no cristal.

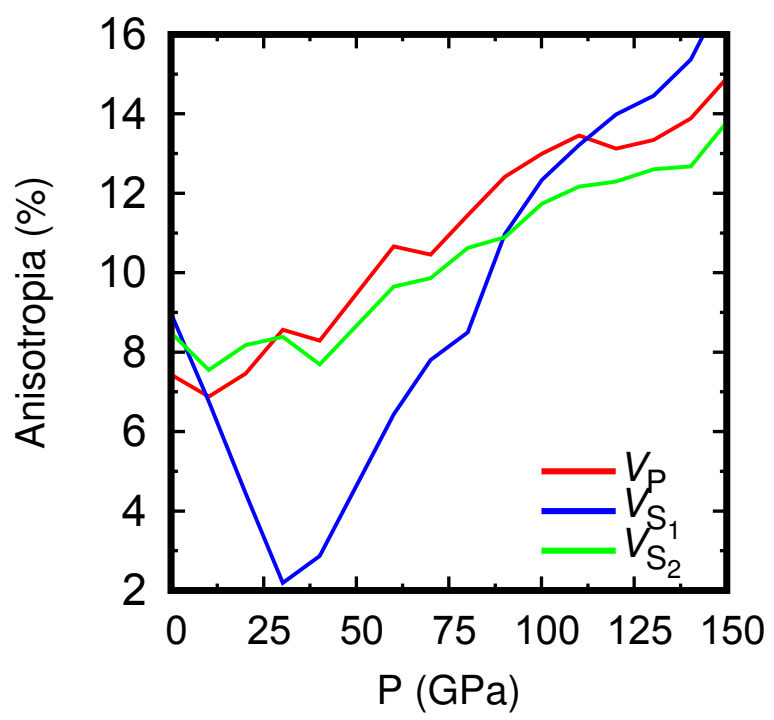

Figura 3.12: Anisotropia da velocidade como função da pressão para as ondas acústicas $P\left(V_{P}\right)$ e $S\left(V_{S_{1}}\right.$ e $\left.V_{S_{2}}\right)$ no MgSiO3 perovskita.

A figura 3.12 apresenta a anisotropia das ondas acústicas $\mathrm{P}$ e S no $\mathrm{MgSiO}_{3}$ perovskita, em função da pressão. $\mathrm{A}$ anisotropia das ondas $\mathrm{P}$ cresce quase que linearmente com o aumento da pressão. O comportamento da anisotropia das ondas $S$ é peculiar, pois enquanto as ondas $S_{2}$ apresentam um comportamento similar ao das ondas $P$, a anisotropia das ondas $S_{1}$ apresenta uma relação particular com a pressão. Ela diminui com o aumento da pressão, para valores de pressão pouco menores que $30 \mathrm{GPa}$ e, a partir deste valor, a anisotropia das ondas $S_{1}$ aumenta quase linearmente com a pressão. Este estudo da anisotropia 
é importante pois nos dá um limite superior para a anisotropia dos agregados isotrópicos da matéria. Alguns agregados cristalinos possuem uma direção preferencial para os eixos dos cristais e, nesses casos, a anisotropia é da ordem de 2 a 3 vezes menor que a do cristal perfeitamente orientado, mas maior do que aquela de agregados isotrópicos. Atualmente, a melhor explicação para a descontinuidade $D^{\prime \prime}$ é a transição de fase da estrutura perovskita para uma fase pós-perovskita, que ocorre no $\mathrm{MgSiO}_{3}$ em valores de pressão da ordem de magnitude dos da região entre o manto inferior e o núcleo terrestre. Entretanto, experimentos recentes efetuados em agregados de $\mathrm{MgSiO}_{3}$ pós-perovskita sob pressões de até 172 GPa mostraram que, apesar da velocidade de ondas acústicas nesta fase ser maior do que a na fase perovskita, a transição de fase não é suficiente para explicar o súbito aumento na velocidade das ondas sísmicas na região $D^{\prime \prime}$ [77]. Isso indica que uma orientação preferencial da estrutura pode ser importante para explicar a descontinuidade $\mathrm{D}^{\prime \prime}$.

\subsection{Transição de fase estrutural do $\mathrm{MgSiO}_{3}$}

Apesar do $\mathrm{MgSiO}_{3}$ ser o material dominante na maior parte do manto inferior terrestre, ele não conserva a estrutura perovskita por toda a extensão do manto. Já foi mostrado experimentalmente que sob pressões de $120 \mathrm{GPa}$ e temperaturas de $2100 \mathrm{~K}$ [96] o $\mathrm{MgSiO}_{3}$ passa da estrutura perovskita (Pv) para a estrutura pós-perovskita (Ppv). Esta transição de fase é tida como responsável pela descontinuidade na região $D^{\prime \prime}$.

$\mathrm{Na}$ estrutura pós-perovskita a célula primitiva também é ortorrômbica, mas de bases centradas, pertencente ao grupo espacial $\mathrm{Cmcm}$. Os vetores primitivos da rede são: $(a / 2 ; b / 2 ; 0),(-a / 2 ; b / 2 ; 0)$ e $(0 ; 0 ; c)$. A figura 3.13 mostra uma representação do arranjo dos átomos na célula deste cristal.

Assim como na estrutura Pv, na estrutura Ppv cada átomo de silício está cercado por oito átomos de oxigênio, formando um octaedro. Comparando as figuras 3.13 e 3.1 , percebe-se que os octaedros apresentam diferentes orientações, fazendo com que a célula primitiva da fase Ppv apresente duas unidades de $\mathrm{MgSiO}_{3}$, ou seja, uma base de dez átomos, sendo dois átomos de mag- 


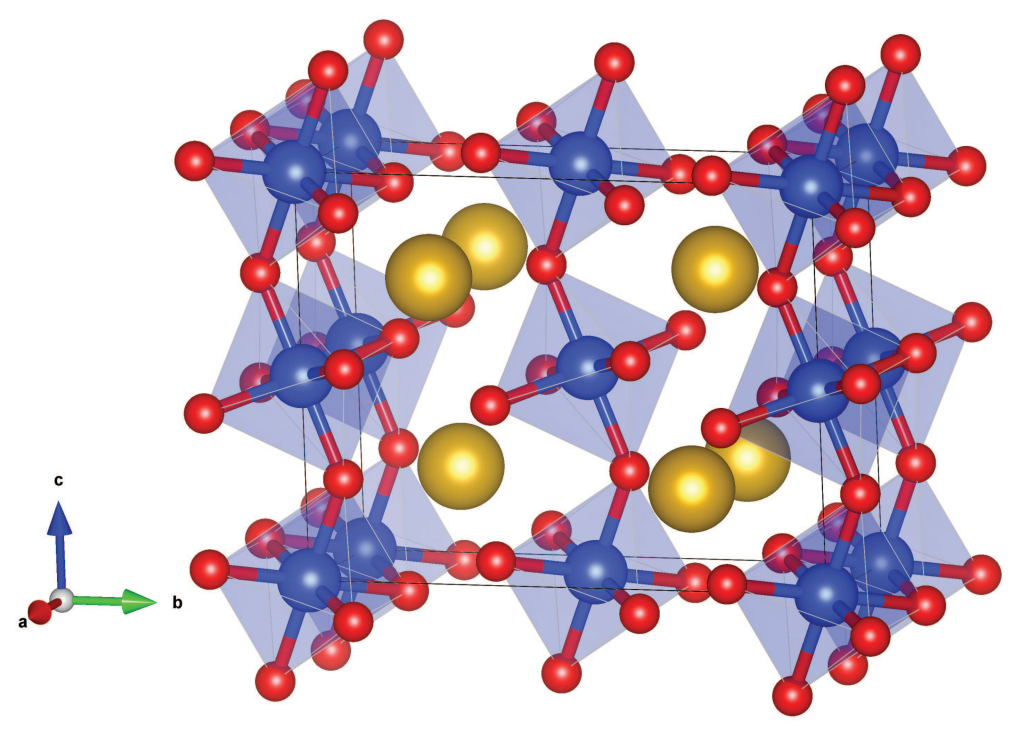

Figura 3.13: Estrutura cristalina do $\mathrm{MgSiO}_{3}$ na fase pós-perovskita. As esferas azuis representam os átomos de silício, as vermelhas os átomos de oxigênio e as amarelas os átomos de magnésio.

nésio, dois átomos de silício e seis átomos de oxigênio. Utilizando o mesmo procedimento já descrito para estudar a estrutura perovskita, foram obtidos os parâmetros de rede para a estrutura pós-perovskita à pressão de $120 \mathrm{GPa}$, utilizando o funcional LDA, que estão mostrados na tabela 3.8. Como esta estrutura só é estável a altas pressões, comparamos nossos resultados com medidas experimentais feitas a $P=120 \mathrm{GPa}$.

O valor do volume está em excelente acordo com os dados experimentais [96]. Esta concordância corrobora a afirmação de que para pressões bem altas os funcionais LDA e GGA descrevem melhor a energia de troca e corre-

Tabela 3.8: Parâmetros de rede $a, b, c$ do $\mathrm{MgSiO}_{3}$ na estrutura pós-perovskita. Os valores experimentais são da referência [96].

\begin{tabular}{||c|c|c|c|c||}
\hline \hline & $a(\AA)$ & $b(\AA)$ & $c(\AA)$ & $\vee\left(\AA^{3}\right)$ \\
\hline \hline Teórico & 2,451 & 8,012 & 6,083 & 119,46 \\
\hline Experimental & 2,456 & 8,042 & 6,093 & 120,39 \\
\hline \hline
\end{tabular}


lação, de forma que cálculos de primeiros princípios, baseados na DFT, conseguem descrever muito bem os cristais [98]. A tabela 3.9 apresenta as posições dos átomos na estrutura pós-perovskita, obtidas através de simulações à pressão de $120 \mathrm{GPa}$, mostrando que os parâmetros estruturais estão, também, em excelente acordo com dados experimentais [96]

Tabela 3.9: Posições dos átomos de $\mathrm{Si}, \mathrm{Mg}$ e $\mathrm{O}$ em relação aos parâmetros de rede $a, b, c$ da célula primitiva ortorrômbica de bases centradas do $\mathrm{MgSiO}_{3}$, estrutura pós-perovskita, para $P=120 \mathrm{GPa}$. Resultados experimentais, também obtidos a $P=120 \mathrm{GPa}$, são da referência [96].

\begin{tabular}{||c|c||c|c|c||c|c|c||}
\hline \hline \multicolumn{2}{||c||}{} & \multicolumn{3}{c||}{ Teórico } & \multicolumn{3}{c||}{ Experimental } \\
\hline Átomo & Posição de Wyckoff & $x$ & $y$ & $z$ & $x$ & $y$ & $z$ \\
\hline \hline $\mathrm{Si}$ & $4 a$ & 0 & 0 & 0 & 0 & 0 & 0 \\
\hline $\mathrm{Mg}$ & $4 \mathrm{c}$ & 0 & 0,253 & 0,250 & 0 & 0,253 & 0,250 \\
\hline $\mathrm{O}_{1}$ & $4 \mathrm{c}$ & 0 & 0,927 & 0,250 & 0 & 0,923 & 0,250 \\
\hline $\mathrm{O}_{2}$ & 8f & 0 & 0,635 & 0,440 & 0 & 0,631 & 0,436 \\
\hline \hline
\end{tabular}

A otimização do $\mathrm{MgSiO}_{3}$ na estrutura Ppv foi efetuada para diversos valores de pressão, permitindo a obtenção dos parâmetros da equação de estado. Com esses valores foi obtida a entalpia do sistema como função da pressão. A figura 3.14 apresenta a entalpia relativa do silicato de magnésio, por átomo, na fase $P p v$ com respeito àquela na fase $P v$.

A transição de fase $\mathrm{Pv} \Rightarrow \mathrm{Ppv}$ ocorre em $P=100 \mathrm{GPa}$, em concordância com outros resultados teóricos, que obtiveram esta transição em $P=98 \mathrm{GPa}$ [99]. Essa transição também foi detectada experimentalmente, só que em $125 \mathrm{GPa}$, mas em temperaturas de $2100 \mathrm{~K}$. Como nossos resultados são para uma rede estática na qual a temperatura não é considerada, exceto por efeitos de ponto zero, podemos concluir que nosso resultado está em bom acordo com os resultados experimentais. Para estudar o efeito desta transição nas velocidades de propagação de ondas acústicas, calculamos o tensor elástico do $\mathrm{MgSiO}_{3}$ na estrutura pós-perovskita para $P=100 \mathrm{GPa}$ e a partir deste foram determinadas as velocidades das ondas em diferentes direções do material, que estão 


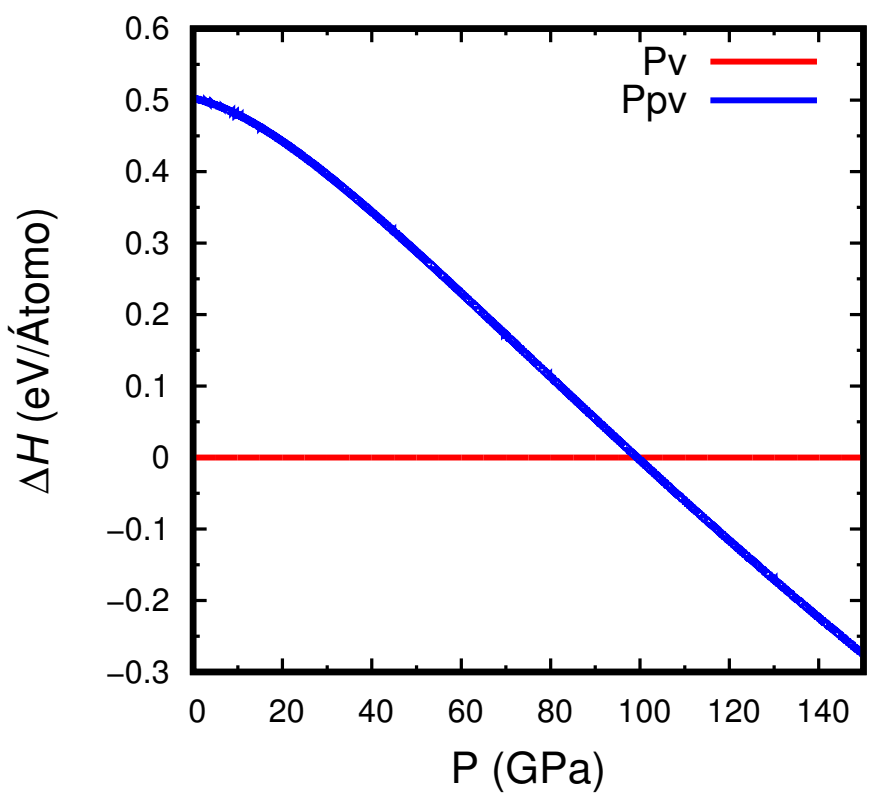

Figura 3.14: Entalpia relativa do $\mathrm{MgSiO}_{3}$ na estrutura pós-perovskita (Ppv) com respeito à entalpia na estrutura perovskita $(P \vee)$. Os valores estão normalizados por fórmula.

mostradas na figura 3.15.

Para a maior parte das direções consideradas, verifica-se que de fato as velocidades de propagação das ondas são maiores na estrutura pós-perovskita do que na perovskita. Entretanto, existem algumas regiões em certas direções onde as velocidades das ondas é maior na estrutura perovskita. Para obter uma melhor compreensão do que ocorre nas condições termodinâmicas do manto inferior, calculamos as velocidades das ondas acústicas em agregados isotrópicos de $\mathrm{MgSiO}_{3}$, cujos resultados estão mostrados na figura 3.16.

Nossos resultados mostram que as velocidades das ondas acústicas apresentam comportamentos muito similares em ambos agregados isotrópicos. A velocidade das ondas $\mathrm{P}$ é cerca de $1 \%$ maior, à $P=110 \mathrm{GPa}$, na estrutura pósperovskita do que na perovskita e a velocidade das ondas S é cerca de $2 \%$ maior nesta mesma pressão. Estas mudanças tão pequenas nos valores das velocidades das ondas acústicas devido à transição de fase $P \vee \Rightarrow P p \vee$ está de acordo com dados experimentais, os quais afirmam que apenas esta transição da fase 


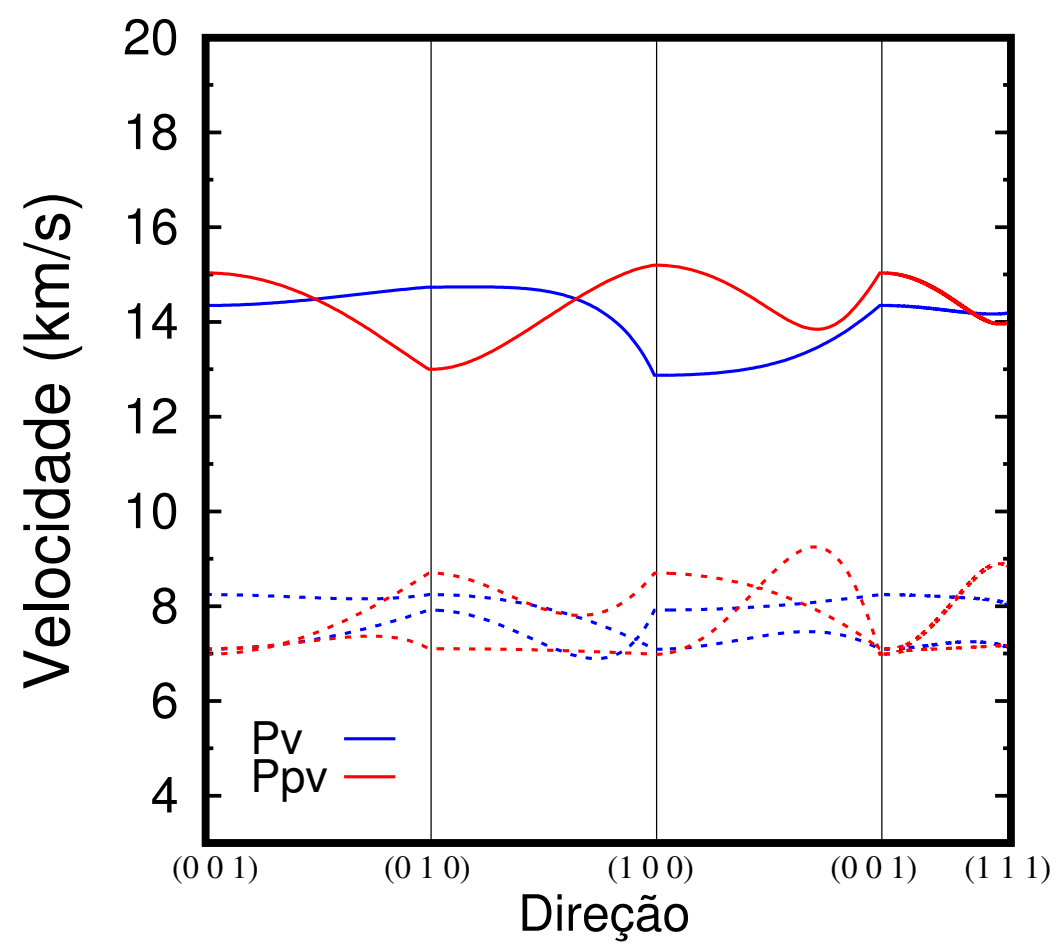

Figura 3.15: Velocidades das ondas acústicas no $\mathrm{MgSiO}_{3}$, em diferentes direções do cristal, nas estruturas Pv (linhas azuis) e Ppv (linhas vermelhas) à pressão de 100 $\mathrm{GPa}$. As linhas sólidas são as velocidades das ondas acústicas $\mathrm{P}$ e as pontilhadas as velocidades das ondas acústicas $\mathrm{S}$.

estrutural não é suficiente para explicar a descontinuidade $D^{\prime \prime}$. Entretanto, sabese também que impurezas de ferro no $\mathrm{MgSiO}_{3}$ apresentam uma transição associada ao estado magnético do sistema, passando de um estado de alto spin para um de baixo spin em pressões equivalente àquelas do manto inferior. Essa transição reduz o volume do material, aumentando os coeficientes elásticos e, portanto, a velocidade de propagação das ondas sísmicas [42, 43, 100]. Este fenômeno também é um modelo viável para descrever a descontinuidade $D^{\prime \prime}$ e tem sido alvo de inúmeras investigações [100-107]. Diferentemente desta tendência, estudaremos neste trabalho a presença de carbono no manto inferior e as consequências desta presença nas velocidades das ondas sísmicas. 


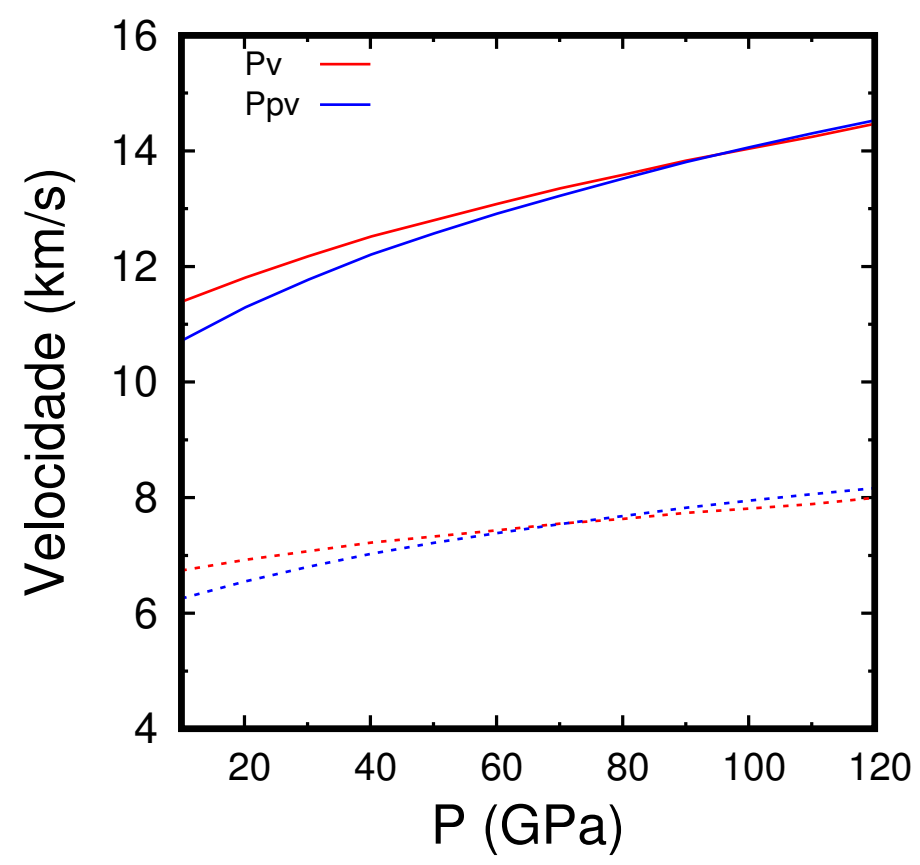

Figura 3.16: Velocidades das ondas acústicas em agregados isotrópicos de $\mathrm{MgSiO}_{3}$ nas estruturas perovskita ( $P v)$ e pós-perovskita (Ppv). As linhas sólidas são as velocidades das ondas acústicas $\mathrm{P}$ e as pontilhadas das ondas acústicas $\mathrm{S}$.

\subsection{Conclusões}

Neste capítulo estudamos as propriedades estruturais, eletrônicas e elásticas do $\mathrm{MgSiO}_{3}$, nas estruturas perovskita e pós-perovskita. Nossos resultados teóricos para as propriedades estruturais e eletrônicas do $\mathrm{MgSiO}_{3}$ perovskita mostraram boa concordância com os dados experimentais disponíveis, indicando que o método utilizado descreve bem este material. Estes cálculos foram realizados primeiramente para pressão nula e em seguida incluiu-se efeitos báricos. As constantes de rede diminuem com a pressão, mas as relações $b / a$ e $c / a$ permanecem aproximadamente constantes, sendo que o eixo y deste material é o menos compressível, enquanto que a compressibilidade dos eixos $x$ e $z$ são da mesma ordem. A equação de estado foi calculada com os funcionais LDA e GGA, sendo que o primeiro subestima enquanto que o segundo superestima os volumes, em relação aos dados experimentais. Como os dados experimentais 
foram obtidos à temperatura ambiente, então, se efeitos térmicos forem introduzidos na simulação, os parâmetros de rede obtidos com o funcional LDA aumentariam, aproximando-se dos valores experimentais. Assim, o funcional LDA é mais adequado para a descrição da equação de estado deste material. Apesar da grande mudança dos parâmetros de rede, as posições atômicas relativas não são significativamente alteradas.

As características gerais das bandas mantém-se com o aumento da pressão. O gap de energia aumenta, mas continua sendo de transição indireta e a forma da estrutura de bandas permanece aproximadamente a mesma, sendo que a largura das bandas de energia aumenta. As características gerais das bandas de energia mantém-se as mesmas com o aumento da pressão, assim o fundo da banda de condução continua sendo formado por estados dos átomos de magnésio e silício, enquanto que a banda de valência é primordialmente formada pelos orbitais dos átomos de oxigênio.

Calculamos também as propriedades elásticas deste material como função da pressão. O eixo y é o mais compressível em todas as pressões calculadas. A compressibilidade dos eixos $x$ e $z$ é parecida, sendo que a do eixo $z$ é ligeiramente maior em pressões mais baixas, mas menor em altas pressões. Com estes coeficientes elásticos resolvemos a equação de Christoffel e calculamos as velocidades como função da direção. $O$ aspecto das curvas das velocidades não é significativamente alterado com o aumento da pressão. Entretanto, a diferença entre as velocidades máximas e mínimas aumenta e é mais acentuada nas ondas $P$ em comparação com as ondas S. Na direção (100) e para altas pressões há uma diminuição brusca no valor das velocidades, que pode chegar a 1,4\%. Este comportamento é consistente com a variação da velocidade de ondas sísmicas na região da descontinuidade $\mathrm{D}^{\prime \prime}$. O modelo aceito para esta descontinuidade é uma transição da estrutura perovskita para a pós-perovskita. Esta última é mais dura que a perovskita, resultando em maiores velocidades. Entretanto, apenas esta transição não é capaz de explicar completamente este aumento de velocidades na descontinuidade $\mathrm{D}^{\prime \prime}$. Assim, uma orientação preferencial dos eixos no $\mathrm{MgSiO}_{3}$ pode explicar esta região.

$\mathrm{O} \mathrm{MgSiO}_{3}$ apresenta uma transição para uma estrutura pós-perovskita. Esta também é uma estrutura ortorrômbica, mas de base centrada. Comparando a 
entalpia como função da pressão, nossos resultados indicam que a transição ocorre a $P=100 \mathrm{GPa}$, o que está de acordo com outros resultados. As propriedades eletrônicas e estruturais do $\mathrm{MgSiO}_{3}$ pós-perovskita também mostraram boa concordância com os dados experimentais disponíveis. As velocidades acústicas na estrutura Ppv são ligeiramente maiores do que na estrutura Pv. Entretanto, nossos resultados mostram que esta diferença não é suficiente para explicar a descontinuidade $\mathrm{D}^{\prime \prime}$ 


\section{Compostos de carbono em altas}

pressões

Therefore the problem is not so much, to see what nobody has yet seen, but rather to think concerning that which everybody sees, what nobody has yet thought.

- Arthur Schopenhauer, Parerga and Paralipornena

\subsection{Introdução}

O carbono possui um papel fundamental para a compreensão do planeta, sendo o elemento principal de todas biomoléculas. Nenhum outro elemento é tão importante para a sustentabilidade da vida na Terra, incluindo a humana. O ciclo do carbono próximo à superfície afeta o clima, a saúde de ecossistemas, a disponibilidade de energia barata etc. $\mathrm{O}$ estudo do carbono tem se concentrado principalmente em seu efeito na superfície e atmosfera e muito se sabe sobre o papel do carbono nessas regiões [35]. Entretanto, muito pouco é conhecido sobre o comportamento do carbono em regiões profundas do planeta. A presença de $\mathrm{CO}_{2}$ em magmas e gases vulcânicos indicam uma presença significativa de carbono no interior da Terra [108-110]. Além disso, alguns diamantes apresentam inclusões de materiais provenientes do manto inferior. Como estas inclusões são incorporadas na formação do cristal, elas indicam a presença de carbono nessa região [37]. Com isso, estima-se que as regiões profundas da Terra possam conter até $90 \%$ de todo o carbono do planeta [36]. Contudo, nosso conhecimento do carbono nessas condições é limitado e diversas questões permanecem em aberto, tais como, por exemplo, quanto carbono é armazenado no 
interior do planeta? Quais são os reservatórios de carbono? Como o carbono é armazenado no interior do planeta? Entre outras.

Como a solubilidade do carbono nos silicatos componentes do manto é baixa, acredita-se que a maior parte do carbono oxidado no planeta esteja na forma de carbonatos. Dessa forma, carbonatos de cálcio $\left(\mathrm{CaCO}_{3}\right)$ e magnésio $\left(\mathrm{MgCO}_{3}\right)$ seriam as principais fontes de $\mathrm{CO}_{2}$ no interior do planeta [108], existindo evidências experimentais de sua formação nas condições do manto terrestre [111]. No entanto, detalhes de como o carbono é armazenado no interior do planeta ainda não estão claros. Tanto o $\mathrm{CaCO}_{3}$ como o $\mathrm{MgCO}_{3}$ desempenham um papel fundamental no ciclo do carbono global e no clima do planeta. O conhecimento de propriedades estruturais e energéticas desses carbonatos é vital para a compreensão do manto terrestre, especialmente do ciclo profundo do carbono. Vários estudos têm se concentrado nas propriedades estruturais desses carbonatos $[108,112,113]$, mas poucos tem se preocupado com as propriedades eletrônicas e elásticas destes materiais.

Neste capítulo, primeiramente, será apresentada uma revisão das estruturas propostas na literatura para estes dois carbonatos. Em seguida, calcularemos suas propriedades eletrônicas e seu tensor elástico, de tal forma a calcular a velocidade de ondas sísmicas. Sabendo a velocidade das ondas acústicas nestes minerais, pode-se comparar com os resultados apresentados na seção anterior das velocidades acústicas no $\mathrm{MgSiO}_{3}$ e inferir a influência do carbono na propagação de ondas sísmicas no manto inferior. Isto pode ajudar a melhorar e incrementar modelos geofísicos para descrever a estrutura terrestre.

\subsection{Cristal de $\mathrm{MgCO}_{3}$}

A pressões e temperaturas ambientes, a magnesita possui uma estrutura romboédrica, grupo espacial $R \overline{3} \mathrm{c}$. Este grupo pode ser representado com os vetores de uma rede romboédrica ou de uma rede hexagonal. No caso de vetores unitários romboédricos, a estrutura possui uma base com dez átomos, sendo dois átomos de magnésio, dois átomos de carbono e seis átomos de oxigênio. A rede hexagonal possui uma base com 30 átomos, sendo seis de magnésio, 
Tabela 4.1: Posições de Wyckoff dos átomos na célula do $\mathrm{MgCO}_{3}$ magnesita, grupo espacial $\mathrm{R} \overline{3} \mathrm{c}$, em função dos vetores unitários de uma rede romboédrica e de uma hexagonal.

\begin{tabular}{||c||c|c|c|c||c|c|c|c||}
\hline \hline \multirow{2}{*}{ Átomo } & \multicolumn{4}{c||}{ Romboédrica } & \multicolumn{4}{c||}{ Hexagonal } \\
\cline { 2 - 9 } & Wyckoff & $\mathrm{x}$ & $\mathrm{y}$ & $\mathrm{z}$ & Wyckoff & $\mathrm{x}$ & $\mathrm{y}$ & $\mathrm{z}$ \\
\hline \hline $\mathrm{Mg}$ & $2 \mathrm{~b}$ & 0 & 0 & 0 & $6 \mathrm{~b}$ & 0 & 0 & 0 \\
$\mathrm{C}$ & $2 \mathrm{a}$ & 0,25 & 0,25 & 0,25 & $6 \mathrm{a}$ & 0 & 0 & 0,25 \\
$\mathrm{O}$ & $6 \mathrm{e}$ & $\mathrm{x}$ & $-\mathrm{x}+0,5$ & 0,25 & $18 \mathrm{e}$ & $\mathrm{x}$ & 0 & 0,25 \\
\hline \hline
\end{tabular}

seis de carbono e 18 de oxigênio. As posições de Wyckoff das posições atômicas destas duas redes estão mostradas na tabela 4.1.

Como os vetores unitários da rede hexagonal guardam uma relação mais simples com os eixos cartesianos, ela é utilizada, em geral, para analisar resultados experimentais. Por outro lado, a rede romboédrica, ou trigonal, é a rede primitiva da magnesita e, portanto, a que possui a menor base de átomos, o que a torna mais adequada para a realização de simulações computacionais. A relação entre as coordenadas internas dos átomos de uma rede com as da outra é dada pela transformação:

$$
\vec{X}_{\text {romb }}=\vec{X}_{h e x}\left(\begin{array}{rrr}
-1 & 1 & 0 \\
1 & 0 & -1 \\
1 & 1 & 1
\end{array}\right)
$$

em que $\vec{X}_{\text {romb }}$ representa as posições com relação aos vetores de uma rede romboédrica e $\vec{X}_{\text {hex }}$ as posições com relação aos vetores de uma rede hexagonal. A figura 4.1 mostra a estrutura cristalina do $\mathrm{MgCO}_{3}$ na fase estrutural $\mathrm{R} \overline{3} \mathrm{c}$, nas redes romboédrica e hexagonal. Cada átomo de magnésio possui seis átomos de oxigênio como primeiros vizinhos, enquanto cada átomo de carbono possui três átomos de oxigênio.

Para obter os parâmetros estruturais, otimizou-se a célula do cristal para diferentes valores de pressão, de $-15 \mathrm{GPa}$ a $150 \mathrm{GPa}$, através da utilização de métodos de dinâmica molecular de célula variável, e os funcionais LDA e GGA. A seguir, utilizou-se a equação de Birch-Murnaghan de segunda ordem 

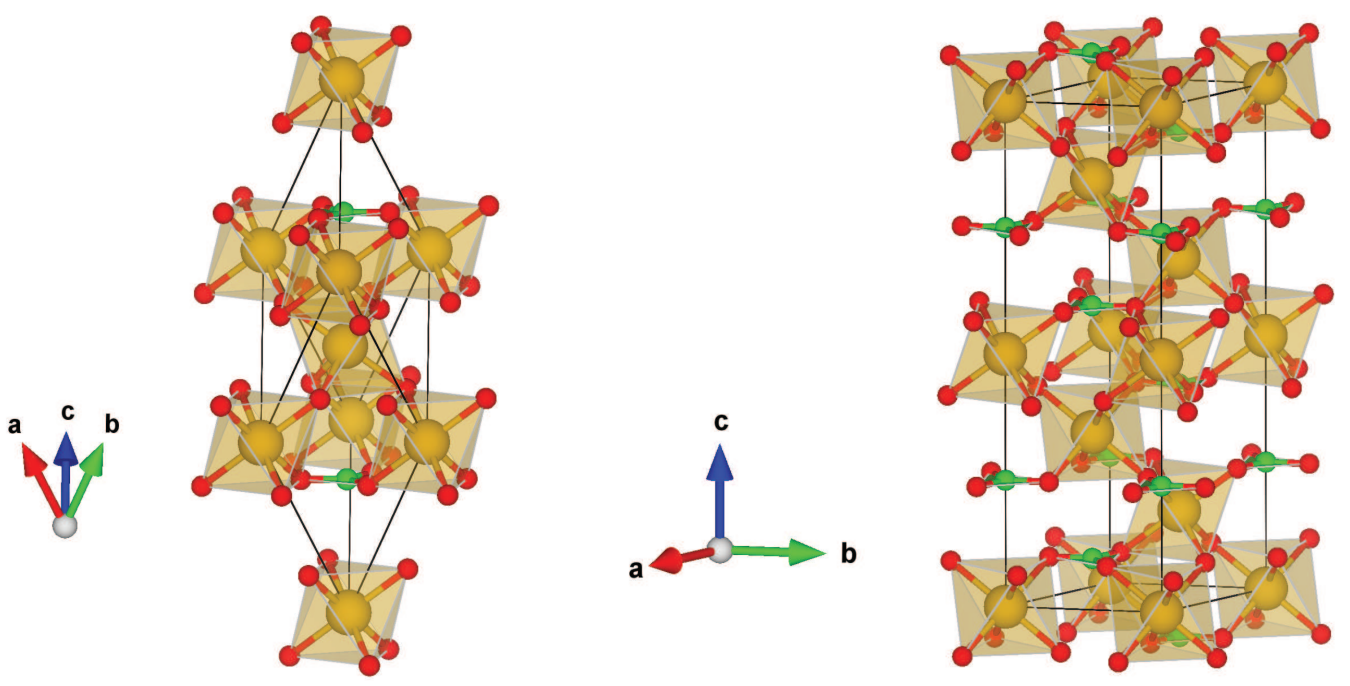

Figura 4.1: Estrutura cristalina do $\mathrm{MgCO}_{3}$ na fase estrutural $\mathrm{R} \overline{3} \mathrm{c}$, na rede romboédrica (esquerda) e hexagonal (direita). As esferas amarelas representam os átomos de magnésio, as verdes os átomos de carbono e as vermelhas os átomos de oxigênio.

para se calcular os parâmetros da equação de estado e, consequentemente, os parâmetros de rede do $\mathrm{MgCO}_{3}$ na rede romboédrica. Utilizando a relação (4.1), obtivemos os parâmetros estruturais da rede hexagonal, para comparação com dados experimentais. Estes valores estão mostrados na tabela 4.2.

De acordo com a tabela, quando comparados com dados experimentais disponíveis, os parâmetros de rede são subestimados quando do uso do funcio-

Tabela 4.2: Parâmetros estruturais do $\mathrm{MgCO}_{3}$, obtidos da equação de estado, na estrutura $\mathrm{R} \overline{3} \mathrm{c}$, para uma rede hexagonal. O bulk modulus $\left(K_{0}\right)$ é dado em GPa e a derivada do bulk modulus $\left(K_{0}^{\prime}\right)$ é adimensional. Resultados experimentais da referência [114].

\begin{tabular}{||c||c|c|c|c|c||}
\hline \hline & $\mathrm{a}(\AA)$ & $\mathrm{c}(\AA)$ & $V_{0}\left(\AA^{3}\right)$ & $K_{0}$ & $K_{0}^{\prime}$ \\
\hline \hline GGA & 4,70 & 15,20 & 290,77 & 100 & 4,48 \\
LDA & 4,61 & 14,58 & 268,34 & 122 & 4,44 \\
Exp. & 4,63 & 15,02 & 279,28 & 119 & 4,02 \\
\hline \hline
\end{tabular}


nal LDA, por cerca de 1-2\%, e superestimados pelo funcional GGA, por cerca de 1-3\%. Devemos salientar que os valores teóricos foram obtidos a partir de cálculos estáticos, representando a condição $T=0 \mathrm{~K}$, exceto pelo efeito de ponto zero. Por outro lado, os dados experimentais foram obtidos à temperatura ambiente. No entanto, considerando que a utilização da LDA subestima os parâmetros de rede, esta parece ser uma melhor aproximação para descrever este material, em comparação com a GGA, uma vez que a inclusão de efeitos térmicos aumentariam os valores dos parâmetros de rede, aproximando-os dos valores experimentais. Em termos do bulk modulus, observa-se um comportamento inverso dos resultados com a utilização da LDA e GGA, quando comparados com os dados experimentais. Novamente, os resultados estáticos obtidos com o funcional LDA acarretam em uma melhor comparação com dados experimentais, obtidos à temperatura ambiente, uma vez que efeitos térmicos tendem a amolecer o material, o que reduziria o valor do bulk modulus, levando os resultados com a LDA mais próximos dos valores experimentais.

\section{Propriedades eletrônicas}

Com os valores otimizados das constantes de rede, calculou-se a estrutura de faixas de energia do material nas direções de alta simetria da primeira zona de Brillouin da estrutura hexagonal. A figura 4.2 apresenta a estrutura de bandas e as densidades de estados projetadas nos átomos ( $\mathrm{Mg}, \mathrm{C}$ e $\mathrm{O}$ ), à pressão nula, para $0 \mathrm{MgCO}_{3}$ obtida utilizando o funcional LDA, onde o zero de energia foi deslocado para o topo da banda de valência. A largura da faixa de energia proibida fundamental é de transição indireta $M \rightarrow \Gamma$, e tanto com o uso do funcional LDA como o GGA, seu valor é de 5,0 eV, valor este subestimado em relação ao valor experimental de $6,00 \mathrm{eV}$.

A banda de valência do mineral é formada essencialmente pelos estados ligantes $2 p$ dos átomos de $\mathrm{O}$, que apresenta largura de cerca de $8 \mathrm{eV}$, sendo composta por duas sub-bandas, separadas por aproximadamente 1,5 eV. O fundo da banda de condução é formado, prioritariamente, pelos estados $s$ e $p$ antiligantes dos átomos de magnésio e carbono. Do ponto de vista puramente iônico, na formação da unidade $\mathrm{MgCO}_{3}$ do mineral, os átomos de oxigênio, pos- 


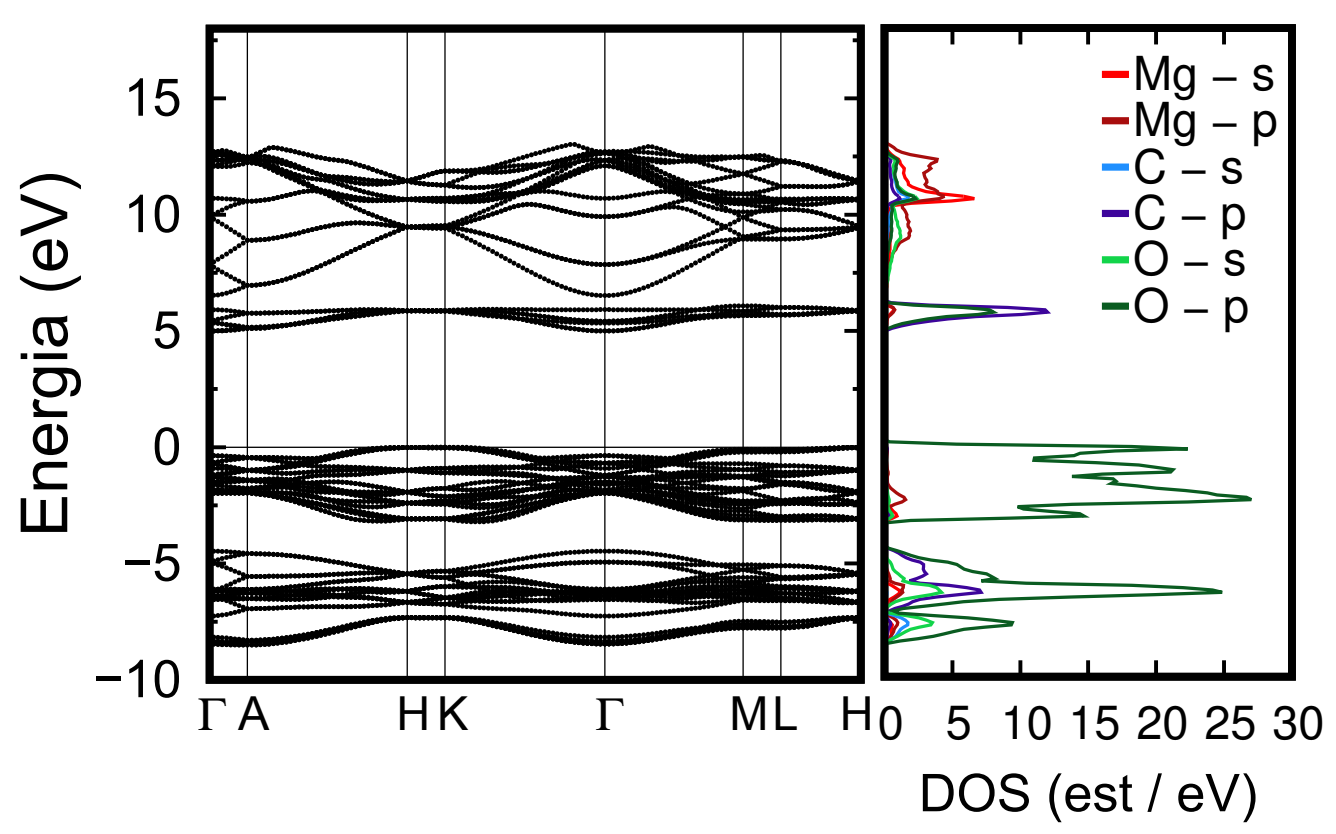

Figura 4.2: Estrutura de bandas e densidades de estados (DOS) do $\mathrm{MgCO}_{3}(\mathrm{R} \overline{\mathrm{C}} \mathrm{c}$ ) projetadas nos átomos de $\mathrm{Mg}, \mathrm{C}$ e O, obtidas com a utilização do funcional LDA.

suindo uma configuração eletrônica de valência $2 s^{2} 2 p^{4}$, passam para a configuração iônica $\mathrm{O}^{2-}$, recebendo seis elétrons dos átomos de magnésio e carbono. Por outro lado, os átomos de magnésio e carbono, respectivamente, que possuem configurações eletrônicas de valência $3 s^{2}$ e $2 s^{2} 2 p^{2}$, doam dois e quatro elétrons, respectivamente, para os átomos de oxigênio, adquirindo as configurações iônicas $\mathrm{Mg}^{2+}$ e $\mathrm{C}^{4+}$. Os estados s e $p$ dos íons de $\mathrm{Mg} \mathrm{e} \mathrm{C}$, eletronicamente desocupados, contribuem para a formação do fundo da banda de condução enquanto que os estados $p$ dos íons de $\mathrm{O}$, eletronicamente ocupados, contribuem para a formação da banda de valência.

\section{Propriedades elásticas}

As rochas que compõem o planeta são formadas por cristais, orientados em diversas direções, de tal forma que, na média, o planeta pode ser considerado isotrópico [68], possuindo apenas dois coeficientes elásticos, como, por exemplo, o módulo de compressibilidade $(K)$ e o módulo de cisalhamento $(\mu)$. O módulo de 
compressibilidade é um parâmetro que pode ser obtido diretamente da equação de estado. O módulo de cisalhamento, por sua vez, é mais complexo de ser calculado, sendo que seu valor deve ser extraído através de valores médios dos coeficientes elásticos, como visto no capítulo 3. Os coeficientes elásticos foram calculados utilizando os métodos descritos no capítulo 2 e já utilizados no capítulo 3 para o cálculo do tensor elástico do $\mathrm{MgSiO}_{3} . \mathrm{O} \mathrm{MgCO}_{3}$, por pertencer à classe cristalina $\overline{3} \mathrm{~m}$, possui seis coeficientes elásticos independentes [67]. $\mathrm{O}$ tensor elástico completo, na notação de Voigt, escreve-se:

$$
\begin{gathered}
C_{i j}=\left(\begin{array}{cccccc}
C_{11} & C_{12} & C_{13} & C_{14} & 0 & 0 \\
C_{12} & C_{11} & C_{13} & -C_{14} & 0 & 0 \\
C_{13} & C_{13} & C_{33} & 0 & 0 & 0 \\
C_{14} & -C_{14} & 0 & C_{44} & 0 & 0 \\
0 & 0 & 0 & 0 & C_{44} & -2 C_{14} \\
0 & 0 & 0 & 0 & -2 C_{14} & C_{66}^{\dagger}
\end{array}\right) . \\
{ }^{\dagger} C_{66}=\frac{1}{2}\left(C_{11}-C_{12}\right)
\end{gathered}
$$

Os valores destes coeficientes elásticos podem ser obtidos efetuando-se três distorções no sistema, como apresentadas no apêndice B. Utilizando a relação entre stress e strain, calculamos as componetes do tensor para o $\mathrm{MgCO}_{3}$ na estrutura $\mathrm{R} \overline{3} \mathrm{c}$, para pressão nula, obtidos com o funcional LDA, apresentadas na tabela 4.3. Nesta tabela também estão apresentos dados experimentais obtidos através de medidas de espectroscopia de Brillouin e difração de raios$X$ [115]. Nossos resultados são para uma rede estática na qual a temperatura não é considerada, enquanto os dados experimentais foram obtidos à temperatura ambiente. A inclusão de efeitos térmicos tende a deixar os materiais mais "moles", fazendo com que nossos resultados se tornem mais consistentes com os dados experimentais. Além disso, há uma correlação inversa entre o volume e a compressibilidade [98]. Assim, é esperado que resultados obtidos com o funcional LDA superestimem os coeficientes elásticos.

Como nosso principal objetivo é entender a influência do carbono na propagação de ondas sísmicas no manto inferior, é interessante, neste ponto, elaborar uma comparação entre os valores das componentes do tensor elástico do 
Tabela 4.3: Componentes do tensor elástico $\left(C_{i j}\right)$, em $\mathrm{GPa}$, do $\mathrm{MgCO}_{3}$ na estrutura $\mathrm{R} \overline{3} \mathrm{c}$. Resultados experimentais da referência [115].

\begin{tabular}{||c||c|c||}
\hline \hline$C_{i j}$ & Teórico & Exp. \\
\hline \hline$C_{11}$ & 283 & 261 \\
$C_{33}$ & 166 & 158 \\
$C_{44}$ & 64 & 58 \\
$C_{12}$ & 85 & 74 \\
$C_{13}$ & 71 & 60 \\
$C_{14}$ & 25 & 20 \\
\hline \hline
\end{tabular}

$\mathrm{MgCO}_{3}$ e do $\mathrm{MgSiO}_{3}$, mostrados na tabela 4.4.

$\mathrm{O} \mathrm{MgSiO}_{3}$ possui nove coeficientes elásticos independentes, enquanto que - $\mathrm{MgCO}_{3}$ possui seis. Apesar do tensor elástico do $\mathrm{MgSiO}_{3}$ possuir um maior número de componentes independentes, sua matriz é bloco diagonalizada, apesar deste cristal ser menos simétrico do que o $\mathrm{MgCO}_{3}$. Adicionalmente, podemos notar que os coeficientes elásticos do $\mathrm{MgCO}_{3}$ são significativamente me-

Tabela 4.4: Coeficientes elásticos $C_{i j}$, em $\mathrm{GPa}$, do $\mathrm{MgSiO}_{3}$, na estrutura perovskita, e do $\mathrm{MgCO}_{3}$, na estrutura $\mathrm{R} \overline{3} \mathrm{C}$, à pressão nula.

\begin{tabular}{||c||c|c||}
\hline \hline$C_{i j}$ & $\mathrm{MgCO}_{3}$ & $\mathrm{MgSiO}_{3}$ \\
\hline \hline $\mathrm{C}_{11}$ & 283 & 479 \\
$\mathrm{C}_{22}$ & 283 & 544 \\
$\mathrm{C}_{33}$ & 166 & 474 \\
$\mathrm{C}_{44}$ & 64 & 202 \\
$\mathrm{C}_{55}$ & 64 & 173 \\
$\mathrm{C}_{66}$ & 99 & 156 \\
$\mathrm{C}_{12}$ & 85 & 136 \\
$\mathrm{C}_{13}$ & 71 & 136 \\
$\mathrm{C}_{23}$ & 71 & 153 \\
$\mathrm{C}_{14}$ & 25 & 0 \\
\hline \hline
\end{tabular}


nores do que os do $\mathrm{MgSiO}_{3}$. Desta forma, podemos afirmar que a magnesita é mais "mole" do que o $\mathrm{MgSiO}_{3}$ perovskita, principal formador do manto terrestre. Como a velocidade de propagação de ondas acústicas é diretamente proporcional aos coeficientes elásticos, isto é um indicativo de que a velocidade destas ondas poderá ser menor na magnesita do que na perovskita ${ }^{1}$.

A anisotropia de ondas sísmicas é um efeito observado em diversos estudos de sismologia e pode nos dizer muito sobre o interior do planeta. Utilizamos o tensor elástico para calcular a velocidade das ondas acústicas em diferentes direções do material. Para tanto resolvemos a equação de Christoffel [67]:

$$
\left[C_{i j k l} n_{j} n_{l}-\rho V^{2} \delta_{i k}\right] p_{k}=0
$$

em que $C_{i j k l}$ são as componentes do tensor elástico, $n_{i}$ são versores que indicam a direção considerada, $\rho$ é a densidade, $V$ é a velocidade e $p_{k}$ é o vetor de polarização da onda. Esta equação mostra que a velocidade de propagação é proporcional ao valor das componentes do tensor elástico, mas inversamente proporcional à densidade. A densidade do $\mathrm{MgCO}_{3}$ é menor que a do $\mathrm{MgSiO}_{3}$ enquanto que os coeficientes elásticos são bem menores na magnesita, como mostra a tabela 4.4. Isso faz com que a velocidade de propagação de ondas sísmicas seja significativamente menor na magnesita, em todas as direções consideradas, do que no $\mathrm{MgSiO}_{3}$, perovskita, como mostra a figura 4.3.

Podemos notar, também, que a magnesita apresenta uma maior variação nas velocidades com relação à direção considerada, quando comparamos com o $\mathrm{MgSiO}_{3}$, implicando que a magnesita é mais anisotrópica. Seguindo o mesmo procedimento apresentado no capítulo 3 para o $\mathrm{MgSiO}_{3}$, equações 3.8, determinamos a anisotropia do $\mathrm{MgCO}_{3}$. A tabela 4.5 apresenta a anisotropia da velocidade de propagação das ondas acústicas $\mathrm{P}$ e $\mathrm{S}$ destes dois materiais.

A magnesita é muito mais anisotrópica do que $0 \mathrm{MgSiO}_{3}$, o que pode ter implicações importantes para regiões do manto com alta concentração de carbono, onde a formação de magnesita pode ser favorável. Como a velocidade das ondas na magnesita é menor que no $\mathrm{MgSiO}_{3}$, uma alta concentração de

\footnotetext{
${ }^{1} \mathrm{~A}$ velocidade de ondas acústicas depende não apenas dos módulos de elasticidade, mas também da densidade do material. Por isso, apenas o fato dos coeficientes elásticos serem menores não implica, necessariamente, que as velocidades também serão.
} 


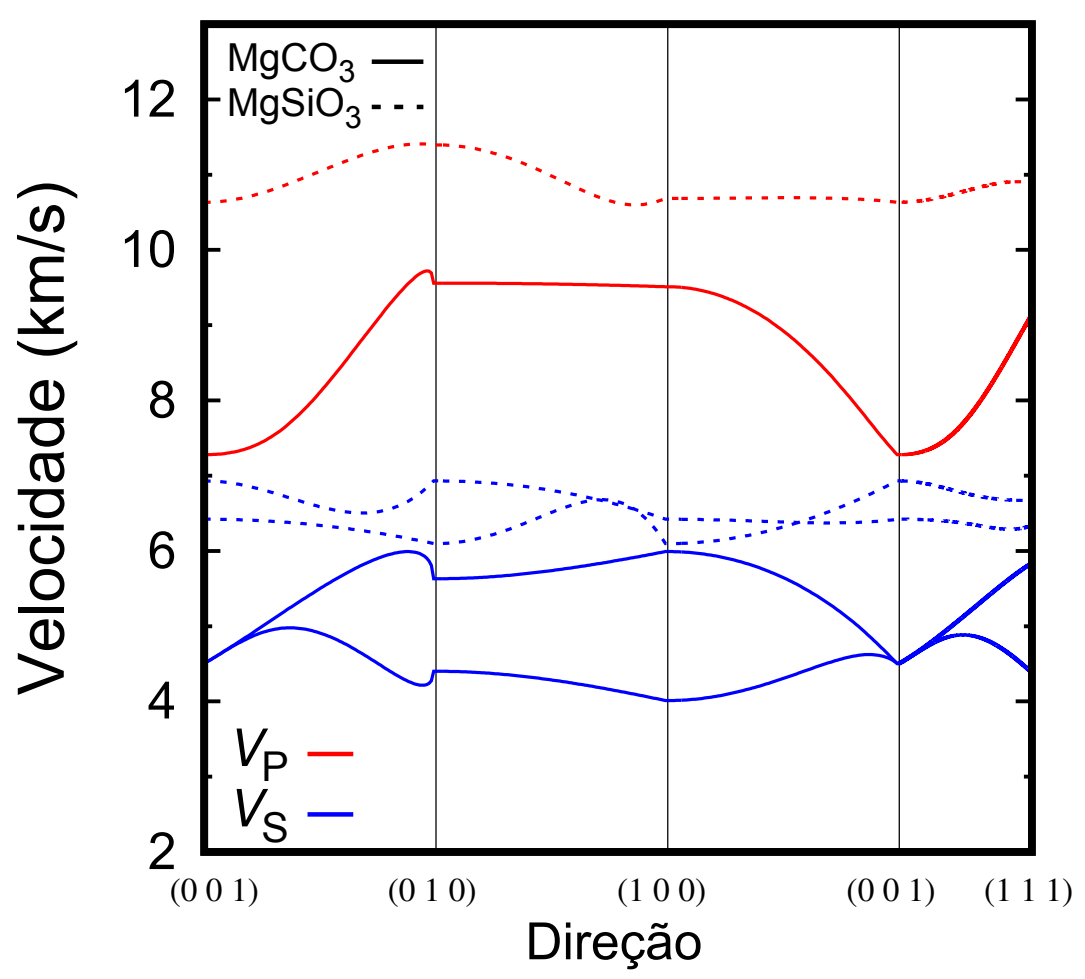

Figura 4.3: Velocidade de propagação de ondas acústicas $P\left(V_{P}\right)$ e $S\left(V_{S}\right)$, em diferentes direções do cristal, no $\mathrm{MgCO}_{3}$ na estrutura $\mathrm{R} \overline{\mathrm{C}}$ (magnesita) e no $\mathrm{MgSiO}_{3}$ perovskita.

Tabela 4.5: Anisotropia da velocidade de propagação das ondas acústicas $\mathrm{P}$ e $\mathrm{S}$ do $\mathrm{MgSiO}_{3}$ perovskita e do $\mathrm{MgCO}_{3}$ na estrutura $\mathrm{R} \overline{3} \mathrm{c}$.

\begin{tabular}{||c||c|c||}
\hline \hline Anisotropia & $\mathrm{MgCO}_{3}$ & $\mathrm{MgSiO}_{3}$ \\
\hline \hline $\mathrm{A}_{\mathrm{P}}$ & 28,06 & 8,34 \\
$\mathrm{~A}_{\mathrm{S}_{1}}$ & 19,25 & 13,58 \\
$\mathrm{~A}_{\mathrm{S}_{2}}$ & 29,62 & 12,03 \\
\hline \hline
\end{tabular}

carbono, favorável à formação de $\mathrm{MgCO}_{3}$, ocasionará uma diminuição na velocidade das ondas sísmicas. Assim, a presença de átomos de carbono pode ser a causa da existência de zonas de baixa velocidade no planeta. Entretanto, es- 
tes resultados são para pressão nula. É preciso considerar efeitos báricos para que tais resultados sejam aplicáveis ao interior da Terra. Na próxima seção são apresentados resultados para altas pressões.

\section{Comportamento do $\mathrm{MgCO}_{3}$ sob altas pressões}

$\mathrm{O} \mathrm{MgCO}_{3}$ apresenta diversas formas cristalinas. Vários experimentos [116,117] mostram que a estrutura $\mathrm{R} \overline{3} \mathrm{c}$ é estável até pressões de cerca de $80 \mathrm{GPa}$. Entretanto, Isshiki et al., em experimentos de difração de raios- $X$, detectaram uma transição de fase em pressões da ordem de $115 \mathrm{GPa}$ e temperaturas entre 2100 e $2200 \mathrm{~K}$ [118]. Apesar dos autores terem proposto uma estrutura ortorrômbica, eles não foram capazes de obter informações mais refinadas para esta estrutura. Diversas outras estruturas foram propostas para a magnesita a altas pressões $[108,119,120]$ e todas elas são energeticamente muito próximas entre si. De qualquer forma, atualmente, a estrutura mais estável a altas pressões, do ponto de vista energético, é aquela proposta por Oganov et al. [113] que, utilizando métodos baseados em algoritmos genéticos, previu uma transição da fase $R \overline{3} c$ para uma fase monoclínica, grupo espacial $C 2 / m$, à pressão de 91 GPa [113]. Recentemente, Pickard e Needs [108] estudaram diversas estruturas e verificaram uma possível fase triclínica estável, em um pequeno intervalo de pressão, entre a romboédrica $(R \overline{3} c)$ e a monoclínica $(\mathrm{C} 2 / \mathrm{m})$ [108]. Como ela aparenta ser estável apenas em um intervalo muito pequeno de pressão, ela não será investigada neste trabalho. De qualquer modo, na faixa de valores de pressão de interesse geofísico ( $P \leq 140 \mathrm{GPa}$ ), os resultados de todas essas investigações concordam que, em baixas pressões, $\mathrm{O} \mathrm{MgCO}_{3}$ permanece na fase $\mathrm{R} \overline{3} \mathrm{c}$ e, a pressões mais elevadas, na fase $\mathrm{C} 2 / \mathrm{m}$.

\section{Estrutura monoclínica}

A estrutura monoclínica do $\mathrm{MgCO}_{3}$, grupo espacial $\mathrm{C} 2 / \mathrm{m}$, possui uma base com 30 átomos, sendo seis átomos de magnésio, divididos em três espécies, seis átomos de carbono, também divididos em duas espécies, e 18 átomos de oxigênio, divididos em seis espécies. As posições internas dos átomos em relação aos parâmetros de rede da estrutura monoclínica, também designada como 
Tabela 4.6: Posições de Wyckoff dos átomos na rede do $\mathrm{MgCO}_{3}$ na estrutura monoclínica, grupo espacial $\mathrm{C} 2 / \mathrm{m}$ à $P=100 \mathrm{GPa}$.

\begin{tabular}{||c||c||c|c|c||}
\hline \hline Átomo & Wyckoff & $x$ & $y$ & $z$ \\
\hline \hline $\mathrm{Mg}_{1}$ & $4 \mathrm{~g}$ & 0,00000 & 0,75372 & 0,00000 \\
$\mathrm{Mg}_{2}$ & $4 \mathrm{i}$ & 0,32302 & 0,50000 & 0,69732 \\
$\mathrm{Mg}_{3}$ & $4 \mathrm{i}$ & 0,93518 & 0,50000 & 0,65431 \\
$\mathrm{C}_{1}$ & $8 \mathrm{j}$ & 0,37049 & 0,32106 & 0,32672 \\
$\mathrm{C}_{2}$ & $4 \mathrm{i}$ & 0,23155 & 0,50000 & 0,03550 \\
$\mathrm{O}_{1}$ & $4 \mathrm{i}$ & 0,09256 & 0,50000 & 0,89611 \\
$\mathrm{O}_{2}$ & $8 \mathrm{j}$ & 0,34903 & 0,16655 & 0,42869 \\
$\mathrm{O}_{3}$ & $8 \mathrm{j}$ & 0,50806 & 0,30973 & 0,26729 \\
$\mathrm{O}_{4}$ & $4 \mathrm{i}$ & 0,36582 & 0,50000 & 0,97246 \\
$\mathrm{O}_{5}$ & $4 \mathrm{i}$ & 0,35178 & 0,50000 & 0,42732 \\
$\mathrm{O}_{6}$ & $8 \mathrm{j}$ & 0,22500 & 0,33201 & 0,15891 \\
\hline \hline
\end{tabular}

magnesita-II, foram otimizadas à pressão de $100 \mathrm{GPa}$ e estão mostradas na tabela 4.6, onde está utilizada a nomenclatura de Wyckoff.

Uma representação do arranjo dos átomos do $\mathrm{MgCO}_{3}$ na estrutura monoclínica está apresentada na figura 4.4, em que os átomos de oxigênio formam tetraedros ao redor dos átomos de carbono, enquanto os átomos de magnésio possuem coordenação 8 e 10.

O estudo da estabilidade destes sistemas, em função da pressão, pode ser efetuado através da energia livre de Gibbs $(G(P, T)=H-T S)$ ou pela entalpia $(H)$, se à temperatura nula. Assim, desprezando efeitos térmicos, estudamos a estabilidade destes sistemas obtendo suas respectivas entalpias em função da pressão. A figura 4.5 apresenta as entalpias relativas, com respeito àquela da estrutura na fase $R \overline{3} \mathrm{c}$, da fase $\mathrm{C} 2 / \mathrm{m}$, assim como de duas outras fases adicionais, C2/c e C222 1 , que foram propostas como possíveis estruturas para o $\mathrm{MgCO}_{3}$ a altas pressões [108,119-121].

Pelos resultados apresentados na figura, percebe-se que as fases $\mathrm{C} 2 / \mathrm{c} \mathrm{e}$ C222 ${ }_{1}$ não são estáveis no intervalo de pressões considerado. Adicionalmente, 

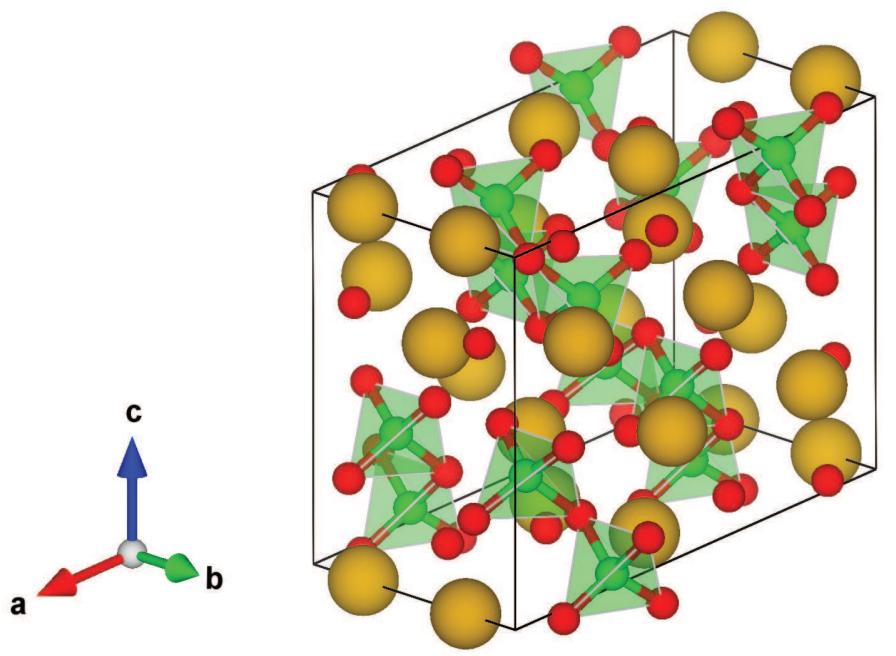

Figura 4.4: Estrutura cristalina do $\mathrm{MgCO}_{3}$ na fase monoclínica ( $\left.\mathrm{C} 2 / \mathrm{m}\right)$. As esferas amarelas representam os átomos de magnésio, as verdes os átomos de carbono e as vermelhas os átomos de oxigênio.

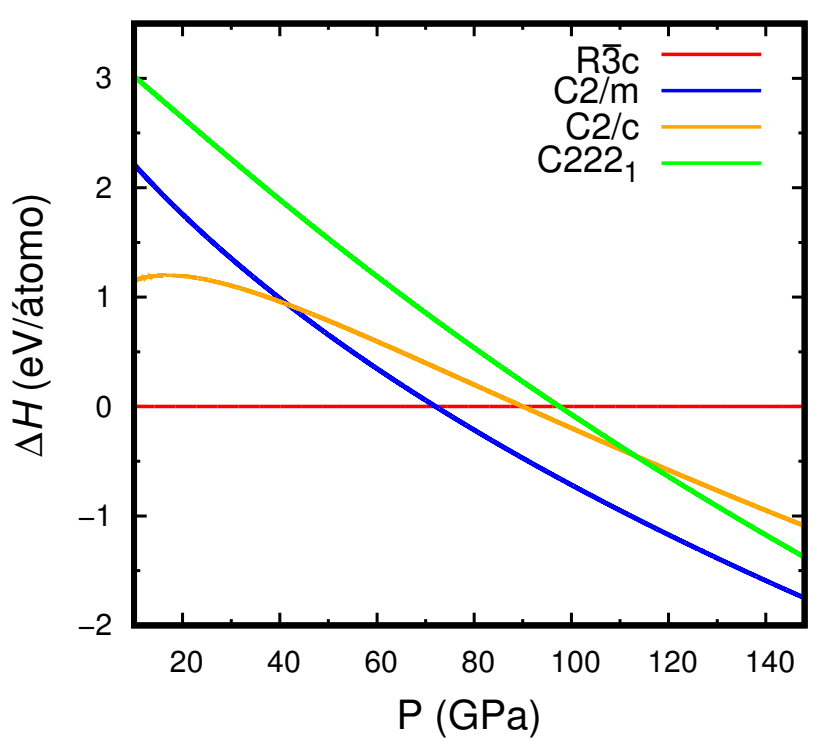

Figura 4.5: Entalpias relativas $(\Delta H)$ do $\mathrm{MgCO}_{3}$, calculadas com o funcional LDA, para as fases C2/m (linha azul), C2/c (linha laranja) e C222 (linha verde), com respeito à fase $\mathrm{R} \overline{3} \mathrm{c}$ (linha vermelha). 
para valores de pressão até $150 \mathrm{GPa}$, as únicas estruturas estáveis são de fato as fases $\mathrm{R} \overline{3} \mathrm{c}$ e $\mathrm{C} 2 / \mathrm{m}$. Encontramos que a pressão da transição de fase da estrutura $\mathrm{R} \overline{3} \mathrm{c}$ para a $\mathrm{C} 2 / \mathrm{m}$ é $P=76 \mathrm{GPa}$, valor este em boa concordância com valores experimentais $[116,117]$ e com aquele previsto por cálculos utilizando o funcional GGA, onde a pressão de transição foi $P=91$ GPa [113].

Apresentamos na figura 4.6 os resultados da equação de estado do $\mathrm{MgCO}_{3}$ nas estruturas $R \overline{3} c$ e $C 2 / m$, obtidas utilizando-se os funcionais LDA e GGA. Para este material, também, podemos concluir que a utilização do funcional LDA é mais apropriada para a descrição da equação de estado, uma vez que os dados experimentais foram obtidos à temperatura ambiente, e introdução de efeitos térmicos nas simulações aproximariam os resultados LDA dos valores experimentais.

Como esperado, os resultados obtidos com o funcional GGA superestimam o volume, quando comparados com dados experimentais, enquanto aqueles

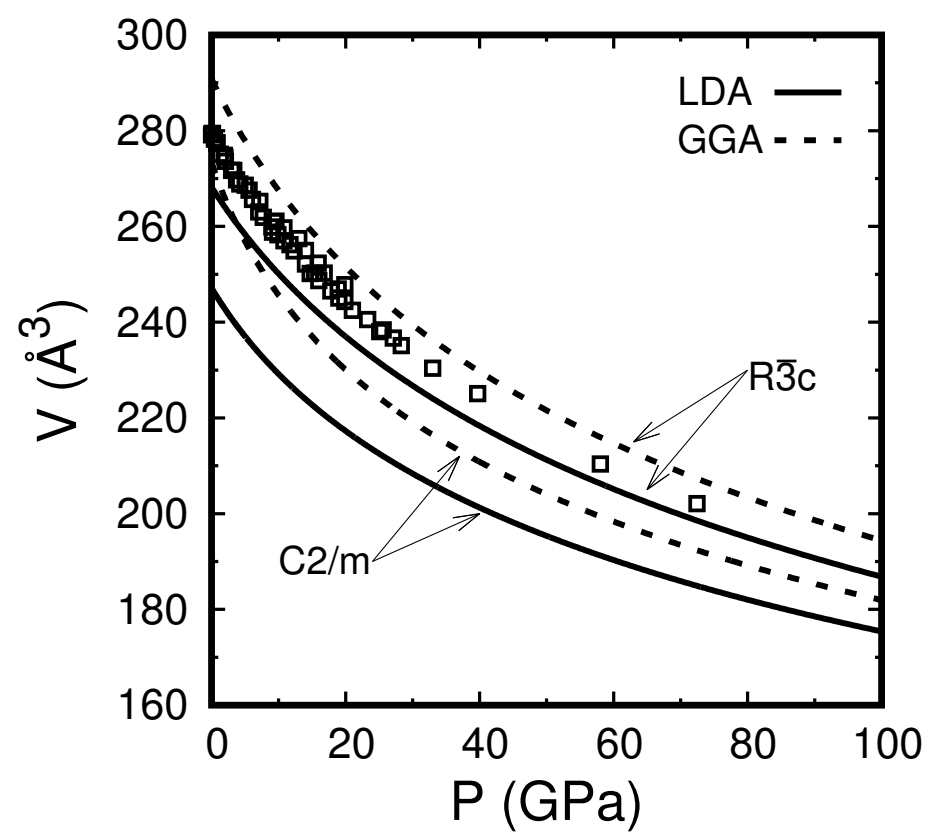

Figura 4.6: Resultados da equação de estado do $\mathrm{MgCO}_{3}$ nas fases $\mathrm{R} \overline{3} \mathrm{c}$ e $\mathrm{C} 2 / \mathrm{m}$ calculadas com o funcional LDA (linhas contínuas) e GGA (linhas tracejadas). Dados experimentais são da referência [116]. 
obtidos com o funcional LDA subestimam. A transição de fase da estrutura romboédrica $(\mathrm{R} \overline{\mathrm{C}} \mathrm{c})$ para a estrutura monoclínica $(\mathrm{C} 2 / \mathrm{m})$, acontece para $P=76 \mathrm{GPa}$, utilizando o LDA, e para $P=90 \mathrm{GPa}$, para o GGA. Podemos notar que nesses valores de pressão, há uma grande redução no volume da célula primitiva. Lembrando que o bulk modulus $K$ é uma medida do quão difícil é se comprimir um corpo, e como há uma relação inversa entre $K$ e o volume, então volumes menores representam que o mineral apresenta $K$ maiores. A velocidade das ondas acústicas depende diretamente do valor de $K$, de tal forma que esta redução no volume, na região de transição de fase estrutural, pode acarretar uma mudança drástica nas velocidades sísmicas.

Calculamos as propriedades eletrônicas do $\mathrm{MgCO}_{3}$ nas estruturas romboédrica $(R \overline{3} c)$ e monoclínica $(C 2 / m)$, na pressão de transição de fase estrutural, $P=76 \mathrm{GPa}$, utilizando o funcional LDA. A figura 4.7 apresenta as densidades de estados (DOS) destas duas fases.

Inicialmente, comparando a DOS da fase romboédrica $(\mathrm{R} \overline{3} \mathrm{c})$ à $P=76 \mathrm{GPa}$ com aquela obtida à $P=0$ (figura 4.2) podemos observar que a aplicação da pressão causa um pequeno alargamento nas bandas de energia do $\mathrm{MgCO}_{3}$, pois com a diminuição do volume o sistema passa a apresentar maior dispersão nos estados $p$ dos átomos de oxigênio que compõem a banda de valência, cuja largura era de $8 \mathrm{eV}$ e passa a ser de aproximadamente $10 \mathrm{eV}$. Além disso, o gap aumenta um pouco, pois a energia que separa os estados ligantes (banda de valência) daqueles antiligantes (banda de condução) aumenta com a diminuição do volume.

Comparando as $\mathrm{DOS}$ do $\mathrm{MgCO}_{3}$ nas fases $\mathrm{R} \overline{3} \mathrm{c}$ e $\mathrm{C} 2 / \mathrm{m}$, à $P=76 \mathrm{GPa}$, figura 4.7, observa-se que a grande redução no volume na pressão da transição $\mathrm{R} \overline{3} c \Rightarrow C 2 / \mathrm{m}$ (figura 4.6) causa um aumento substancial na dispersão dos estados que compõem a banda de valência, de modo que para a fase $\mathrm{C} 2 / \mathrm{m}$, em relação à $R \overline{3} c$, o aumento desta banda é de cerca de $3 \mathrm{eV}$. Adicionalmente, observa-se que a largura do gap, também, apresenta um grande aumento, passando de $\approx 5 \mathrm{eV}$ para $\approx 7 \mathrm{eV}$. Em ambas fases, a composição das bandas é essencialmente a mesma, ou seja, a banda de valência do mineral é, especialmente, formada pelos orbitais (ocupados) dos átomos de oxigênio no estado de oxidação -2 , enquanto o fundo da banda de condução é formado por estados 


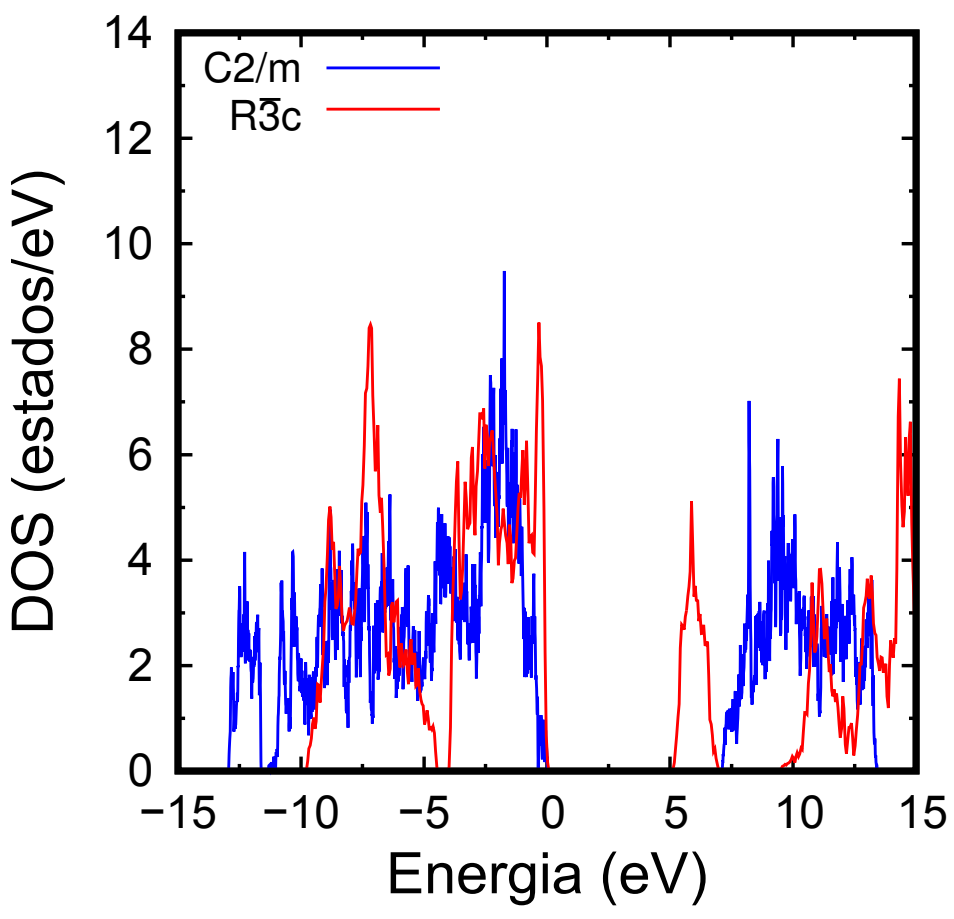

Figura 4.7: Densidade de estados (DOS) do $\mathrm{MgCO}_{3}$ nas estruturas romboédrica ( $R \overline{3} \mathrm{c}$ - linhas azuis) e monoclínica ( $C 2 / \mathrm{m}$ - linhas vermelhas) na pressão de transição de fase estrutural $P=76 \mathrm{GPa}$ ).

(desocupados) dos átomos de magnésio e carbono nos estados de oxidação $+2 \mathrm{e}+4$, respectivamente.

\section{Propriedades elásticas - Estrutura $\mathrm{R} \overline{3} \mathrm{c}$}

Utilizando a metodologia descrita anteriormente para o cálculo do tensor elástico à pressão nula, calculou-se as componentes deste tensor para a estrutura $\mathrm{R} \overline{3} \mathrm{c}$ do $\mathrm{MgCO}_{3}$, para valores da pressão entre 0 e $150 \mathrm{GPa}$, cujos valores estão dados na tabela 4.7. Conforme esperado, os valores dos coeficientes elásticos aumentam com o aumento da pressão.

Na figura 4.8 apresentamos o gráfico das componentes do tensor elástico $C_{i j}$ em função da pressão para evidenciar o efeito e o grau da influência da pressão nestas componentes. Percebe-se que os valores de todas as componentes do 
Tabela 4.7: Componentes do tensor elástico $\left(C_{i j}\right)$ do $\mathrm{MgCO}_{3}$ na estrutura $\mathrm{R} \overline{3} \mathrm{c}$, em função da pressão aplicada $(P)$. As unidades estão em $\mathrm{GPa}$.

\begin{tabular}{||c||c|c|c|c|c|c|c|c|c|c|c|c||}
\hline \hline$P$ & 0,1 & 5,2 & 10,3 & 15,4 & 20,4 & 25,4 & 30,3 & 40,4 & 50,3 & 75,4 & 100,5 & 150,6 \\
\hline \hline$C_{11}$ & 283 & 320 & 354 & 387 & 418 & 447 & 476 & 531 & 584 & 709 & 826 & 1041 \\
$C_{33}$ & 166 & 189 & 212 & 234 & 256 & 279 & 300 & 341 & 381 & 478 & 571 & 747 \\
$C_{44}$ & 64 & 73 & 81 & 89 & 96 & 103 & 110 & 123 & 135 & 162 & 186 & 228 \\
$C_{12}$ & 85 & 103 & 121 & 138 & 156 & 173 & 191 & 225 & 259 & 343 & 425 & 583 \\
$C_{13}$ & 71 & 91 & 110 & 129 & 147 & 165 & 182 & 217 & 251 & 333 & 413 & 565 \\
$C_{14}$ & 25 & 31 & 37 & 42 & 46 & 50 & 55 & 63 & 69 & 86 & 101 & 124 \\
\hline \hline
\end{tabular}

tensor aumentam com o aumento da pressão. Percebe-se que a pressão tem um maior efeito nas componentes diagonais $\mathrm{C}_{11}$ e $\mathrm{C}_{33}$, enquanto a componente $\mathrm{C}_{44}$ é pouco afetada. Este comportamento também é observado para os outros coeficientes, em que as componentes $\mathrm{C}_{12}$ e $\mathrm{C}_{13}$ são mais afetadas do que a $\mathrm{C}_{14}$. Esta tendência evidencia a anisotropia da magnesita. A partir do tensor elástico,

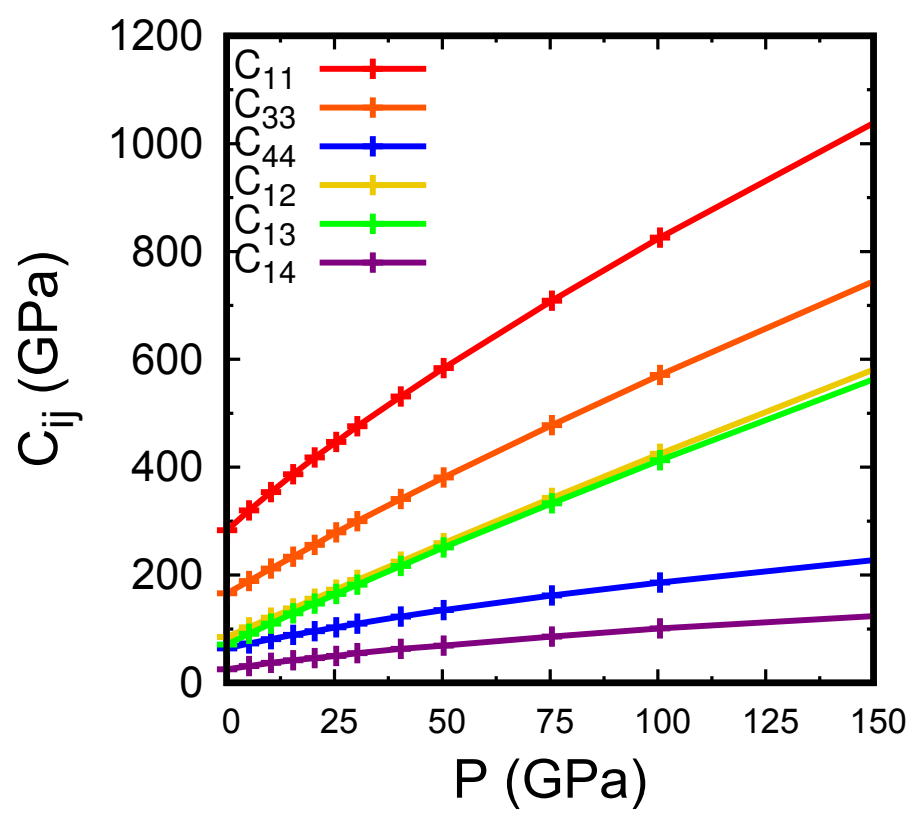

Figura 4.8: Coeficientes elásticos $C_{i j}$ do $\mathrm{MgCO}_{3}$ na estrutura $\mathrm{R} \overline{3} \mathrm{c}$, em função da pressão aplicada $(P)$. 
obtivemos as velocidades de propagação das ondas acústicas em função da pressão. A figura 4.9 mostra, para diferentes direções do cristal $\mathrm{MgCO}_{3}(\mathrm{R} \overline{3} \mathrm{c})$, as velocidades das ondas às pressões $P=0$ e $P=76 \mathrm{GPa}$, pressão na qual a magnesita sofre uma transição de fase para a estrutura monoclínica $(\mathrm{C} 2 / \mathrm{m})$.

Comparando-se os resultados obtidos para as pressões $P=0$ e $P=76 \mathrm{GPa}$, observa-se um aumento das velocidades, tanto das ondas $P$, como das ondas $S$, com o aumento da pressão. A forma das curvas das velocidades das ondas $P$ se mantém aproximadamente inalterada, e a velocidade máxima destas ondas apresenta um aumento de 39\%, enquanto que para a velocidade mínima ele é de $44 \%$. Portanto, a diferença entre as velocidades máxima e mínima diminui, o que implica numa menor anisotropia na propagação das ondas P. Para as ondas acústicas $\mathrm{S}$, obtivemos que para uma delas a velocidade máxima aumenta $30 \%$ e a mínima 12\%, intensificando a anisotropia desta onda. A figura 4.10 mostra a variação da anisotropia, como função da pressão, das velocidades

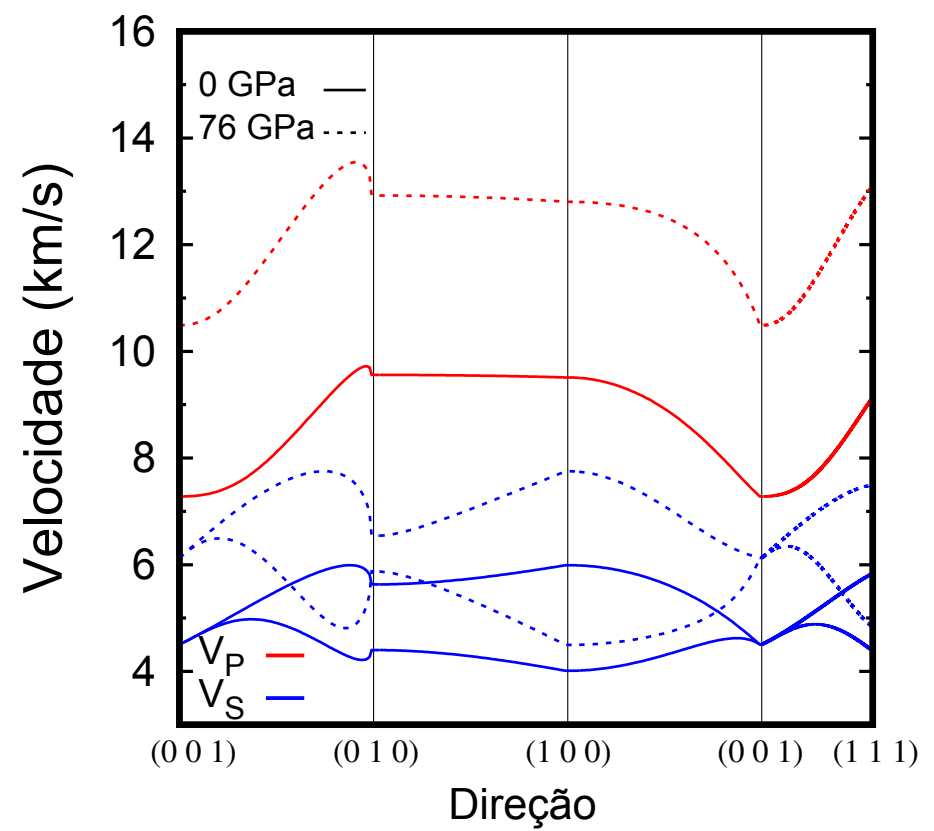

Figura 4.9: Velocidade de propagação das ondas acústicas $P\left(V_{P}\right)$ e $S\left(V_{S}\right)$, em diferentes direções do material, no $\mathrm{MgCO}_{3}$ na estrutura $\mathrm{R} \overline{3} \mathrm{c}$, à pressão nula e na pressão de transição de fase $(P=76 \mathrm{GPa})$. 


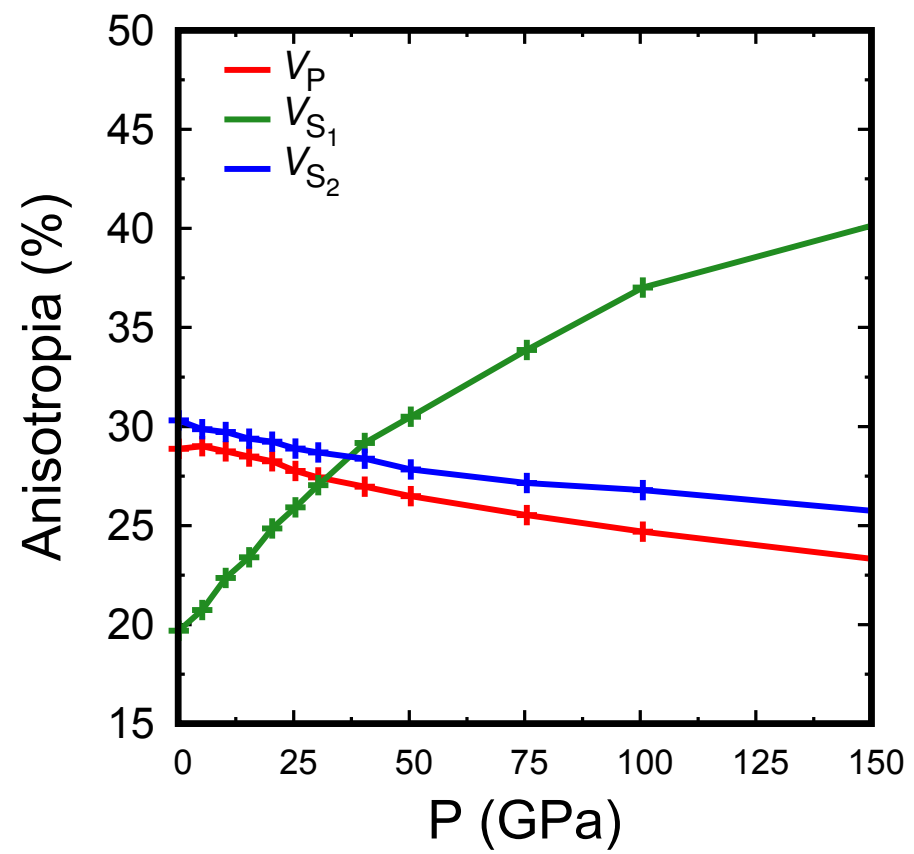

Figura 4.10: Anisotropia, em função da pressão, das velocidades de propagação das ondas acústicas $\mathrm{P}\left(V_{\mathrm{P}}\right)$ e $\mathrm{S}\left(V_{\mathrm{S}_{1}}\right.$ e $\left.V_{\mathrm{S}_{2}}\right)$ no $\mathrm{MgCO}_{3}$, na estrutura $\mathrm{R} \overline{\mathrm{C}} \mathrm{C}$.

das ondas acústicas $\mathrm{P}$ e S. Pode-se observar que o comportamento da anisotropia das velocidades das ondas $P\left(V_{P}\right)$ e $S_{2}\left(V_{S_{2}}\right)$, é semelhante, variando de forma aproximadamente linear, diminuindo com a pressão, sendo que a onda $\mathrm{S}_{2}$ é um pouco mais anisotrópica que a onda $\mathrm{P}$. Entretanto, a anisotropia da velocidade das ondas $S_{1}\left(V_{S_{1}}\right)$, tem um aumento significativo com o aumento da pressão, chegando a ser duas vezes maior a pressões de $150 \mathrm{GPa}$ do que à $P=0$. Mesmo na pressão em que ocorre a transição para a estrutura $\mathrm{C} 2 / \mathrm{m}$ (em torno de $76 \mathrm{GPa}$ ), a anisotropia é cerca de $50 \%$ maior. Isso pode ter importantes consequências geofísicas, já que é um fato bem conhecido que rochas sedimentares podem apresentar anisotropia sísmica $[40,122]$. Isto implica que há uma grande variação da velocidade das ondas $S$ com a direção do cristal. Como a anisotropia da velocidade de apenas uma das ondas $\mathrm{S}$ aumenta, enquanto a da outra diminui, caso este cristal tenha uma orientação preferencial, esta anisotropia poderia, em princípio, ser detectada em ondas sísmicas liberadas por terremotos, pois os tempos de chegada das duas ondas $\mathrm{S}$ seriam 
diferentes. Este tipo de medida pode ser feito e poderia ter como consequência informações da composição do manto, como a formação de outros minerais, com anisotropias maiores que a apresentada pelo $\mathrm{MgSiO}_{3}$, como é o caso do $\mathrm{MgCO}_{3}$. Isto pode ser usado para restringir (ou ampliar) os possíveis minerais utilizados em modelos geofísicos.

\section{Propriedades elásticas - Estrutura C2/m}

A estrutura $\mathrm{C} 2 / \mathrm{m}$, como mostra a figura 4.4 , é monoclínica de base centrada. Dessa forma, por pertencer à classe cristalina $2 / \mathrm{m}$, possui 13 coeficientes elásticos independentes [67]. Utilizando a relação entre o stress e o strain, este tensor elástico pode ser calculado com seis distorções no sistema, mostradas no apêndice B. A tabela 4.8 mostra os coeficientes elásticos obtidos como função da pressão.

Tabela 4.8: Coeficientes elásticos $\left(\mathrm{C}_{i j}\right)$ para $\mathrm{O} \mathrm{MgCO}_{3}$ na estrutura $\mathrm{C} 2 / \mathrm{m}$ como função da pressão $(P)$. As unidades estão em $\mathrm{GPa}$.

\begin{tabular}{||c||c|c|c|c|c|c|c|c|c|c|c|c|c||}
\hline \hline$P$ & $C_{11}$ & $C_{22}$ & $C_{33}$ & $C_{44}$ & $C_{55}$ & $C_{66}$ & $C_{12}$ & $C_{13}$ & $C_{15}$ & $C_{23}$ & $C_{25}$ & $C_{35}$ & $C_{46}$ \\
\hline \hline 20,7 & 393 & 497 & 408 & 32 & 109 & 131 & 187 & 113 & 34 & 163 & 43 & 14 & 1 \\
31,2 & 469 & 557 & 493 & 77 & 122 & 150 & 214 & 157 & 31 & 200 & 49 & 17 & 10 \\
41,3 & 533 & 616 & 567 & 102 & 134 & 167 & 238 & 194 & 29 & 232 & 54 & 21 & 14 \\
51,3 & 591 & 672 & 634 & 121 & 144 & 182 & 262 & 228 & 28 & 262 & 59 & 25 & 19 \\
61,4 & 644 & 732 & 688 & 137 & 157 & 196 & 287 & 260 & 26 & 292 & 65 & 42 & 22 \\
71,0 & 713 & 777 & 756 & 149 & 162 & 208 & 306 & 274 & 31 & 314 & 65 & 32 & 26 \\
80,8 & 741 & 827 & 814 & 160 & 169 & 221 & 335 & 319 & 24 & 346 & 72 & 37 & 30 \\
90,7 & 788 & 876 & 869 & 171 & 177 & 232 & 359 & 349 & 24 & 373 & 77 & 42 & 34 \\
100,6 & 833 & 923 & 922 & 180 & 184 & 242 & 383 & 378 & 23 & 399 & 80 & 46 & 38 \\
110,5 & 877 & 969 & 975 & 188 & 191 & 252 & 408 & 406 & 23 & 426 & 83 & 51 & 42 \\
120,4 & 920 & 1014 & 1025 & 196 & 198 & 261 & 432 & 434 & 23 & 452 & 86 & 56 & 46 \\
130,3 & 962 & 1058 & 1076 & 203 & 205 & 269 & 456 & 462 & 24 & 478 & 88 & 61 & 50 \\
140,3 & 1004 & 1102 & 1125 & 210 & 213 & 278 & 480 & 489 & 25 & 503 & 91 & 68 & 54 \\
150,2 & 1045 & 1145 & 1173 & 217 & 221 & 285 & 505 & 516 & 27 & 528 & 93 & 73 & 57 \\
\hline \hline
\end{tabular}

Novamente, como verificado para $\mathrm{O} \mathrm{MgCO}_{3}$ na estrutura $\mathrm{R} \overline{3} \mathrm{c}$ (tabela 4.7), há um aumento nos valores dos coeficientes elásticos conforme a pressão au- 
menta. Também nota-se que a baixas pressões, o eixo y é o menos compressível, mas conforme a pressão aumenta, a menor compressibilidade passa a ser a do eixo z. Comparando a tabela $4.8 \mathrm{com}$ a 4.7 vê-se que os valores dos coeficientes elásticos, respectivos, não variam muito de uma estrutura para a outra. Comparando ainda estas com a tabela 3.7, do capítulo 3, vê-se que os coeficientes elásticos do $\mathrm{MgCO}_{3}$ são consideravelmente menores do que os respectivos valores de $C_{i j}$ do $\mathrm{MgSiO}_{3}$. Este resultado sugere que a substituição dos radicais silicato pelos carbonato amolece o material resultante e poderia ser um processo favorável em condições de alta pressão. Assim, a incorporação de carbono em agregados de $\mathrm{MgSiO}_{3}$ seria energicamente favorável no manto inferior e o carbono estaria dissociado da matriz de $\mathrm{MgSiO}_{3}$.

Na figura 4.11 apresentamos o gráfico das componentes $C_{i j}$ do tensor elástico, em função da pressão, para evidenciar o efeito e o grau da influência da pressão nestas componentes.

Podemos observar que a partir de $100 \mathrm{GPa}$, o eixo y passa a ser o mais compressível. Nota-se também que as componentes $C_{55}$ e $C_{44}$ passam a ser

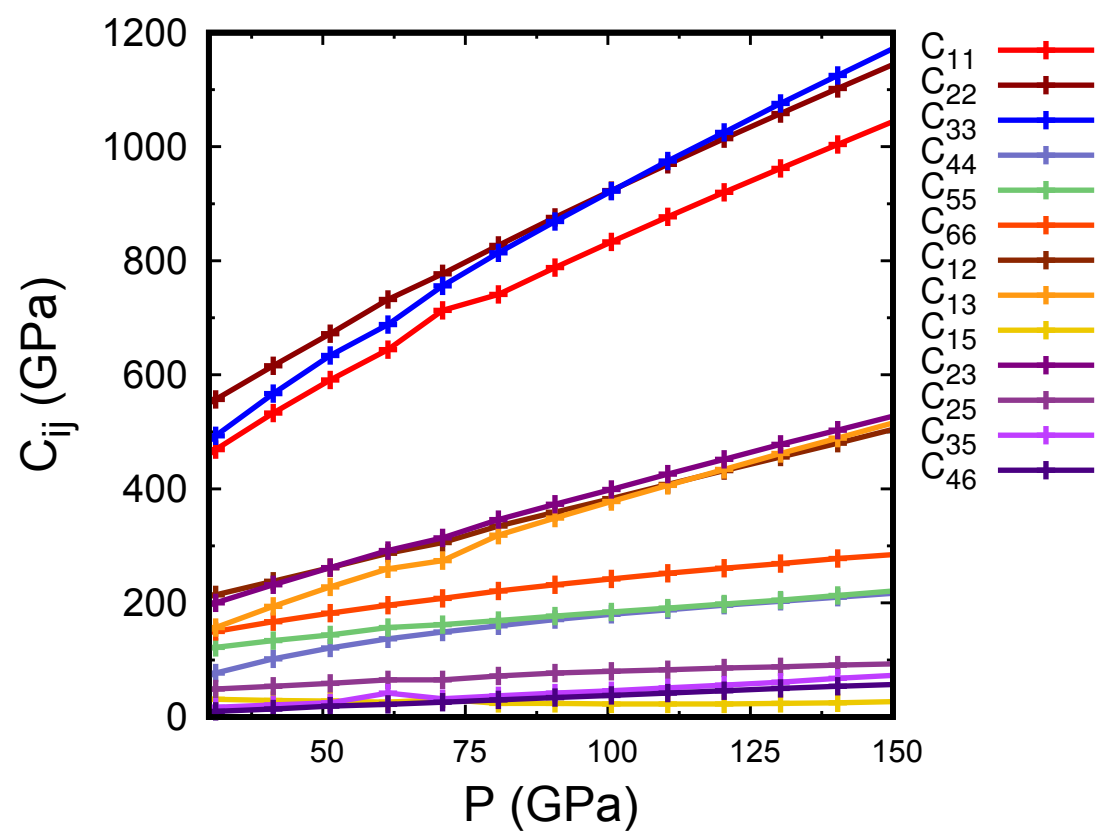

Figura 4.11: Coeficientes elásticos $\left(\mathrm{C}_{i j}\right)$, como função da pressão, para o $\mathrm{MgCO}_{3}$ na estrutura $\mathrm{C} 2 / \mathrm{m}$. 
praticamente iguais a partir de $100 \mathrm{GPa}$. A partir do tensor elástico, obtivemos as velocidades acústicas, em função da pressão. Assim, da mesma forma que mostramos para a estrutura $\mathrm{R} \overline{3} \mathrm{c}$, obtivemos as velocidades das ondas acústicas $\mathrm{P}$ e $\mathrm{S}$ em diversas direções do cristal. Os cálculos foram feitos na pressão de transição de fase $\mathrm{R} \overline{3} \mathrm{c} \Rightarrow \mathrm{C} 2 / \mathrm{m}$ de $76 \mathrm{GPa}$. Assim, apresentamos na figura 4.12 as velocidades de propagação das ondas acústicas, no $\mathrm{MgCO}_{3}$ para diversas direções do cristal, nas fases $\mathrm{R} \overline{3} \mathrm{c}$ e $\mathrm{C} 2 / \mathrm{m}$, na pressão de transição.

Em determinadas direções, as alterações na velocidade são praticamente desprezíveis, enquanto que em outras direções, como na (001) para as ondas $P$, a velocidade das ondas acústicas varia drasticamente. A velocidade máxima das ondas $P$ não sofre variação significativa entre as duas estruturas, variando cerca de $2 \%$. Entretanto a velocidade mínima é bem menor na estrutura $R \overline{3} c$,

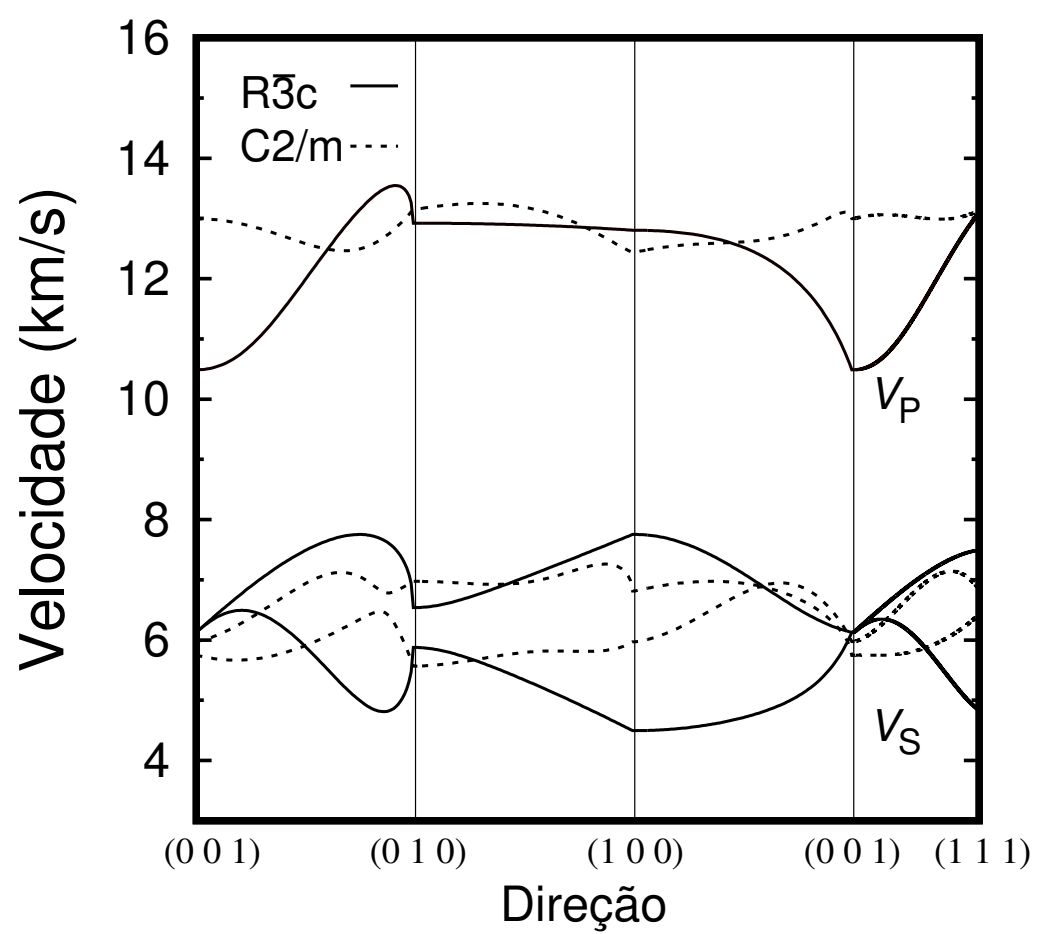

Figura 4.12: Velocidade de propagação das ondas acústicas $P\left(V_{P}\right)$ e $S\left(V_{S}\right)$, na pressão de transição $(P=76 \mathrm{GPa})$, no $\mathrm{MgCO}_{3}$ em diversas direções do cristal, nas estruturas $\mathrm{R} \overline{3} \mathrm{c}$ e $\mathrm{C} 2 / \mathrm{m}$. 
apesar dela ser mais simétrica que a C2/m. O mesmo ocorre, em menor escala, para as duas ondas S. Isso é uma evidência de que a anisotropia na estrutura $\mathrm{C} 2 / \mathrm{m}$ é menor, como pode ser verificado na figura 4.13, que apresenta a anisotropia das velocidades das ondas $\mathrm{P}$ e $\mathrm{S}$, com a pressão, no $\mathrm{MgCO}_{3}$ nas estruturas $\mathrm{R} \overline{3} \mathrm{c}$ e $\mathrm{C} 2 / \mathrm{m}$.

A baixas pressões, a anisotropia das velocidades das ondas $P\left(V_{P}\right)$ na estrutura $\mathrm{C} 2 / \mathrm{m}$ é menor que na estrutura $\mathrm{R} \overline{3} \mathrm{c}$, enquanto a anisotropia das ondas $V_{\mathrm{S}_{1}}$ é muito maior, chegando a $55 \%$. Com o aumento da pressão percebe-se um comportamento inverso, em que a anisotropia das ondas $V_{\mathrm{S}_{1}}$ na estrutura $\mathrm{C} 2 / \mathrm{m}$ é significativamente reduzida, chegando a ter valores equivalentes aos da onda $V_{S_{2}}$, sendo que na estrutura $R \overline{3} c$ ela aumenta para quase o dobro em pressões de $150 \mathrm{GPa}$. Portanto, para pressões em que ocorre a transição de fase da estrutura $\mathrm{R} \overline{3} \mathrm{c}$ para a $\mathrm{C} 2 / \mathrm{m}$, é esperado uma redução na anisotropia de tal forma que orientações preferenciais dos cristais não influenciam significativamente as

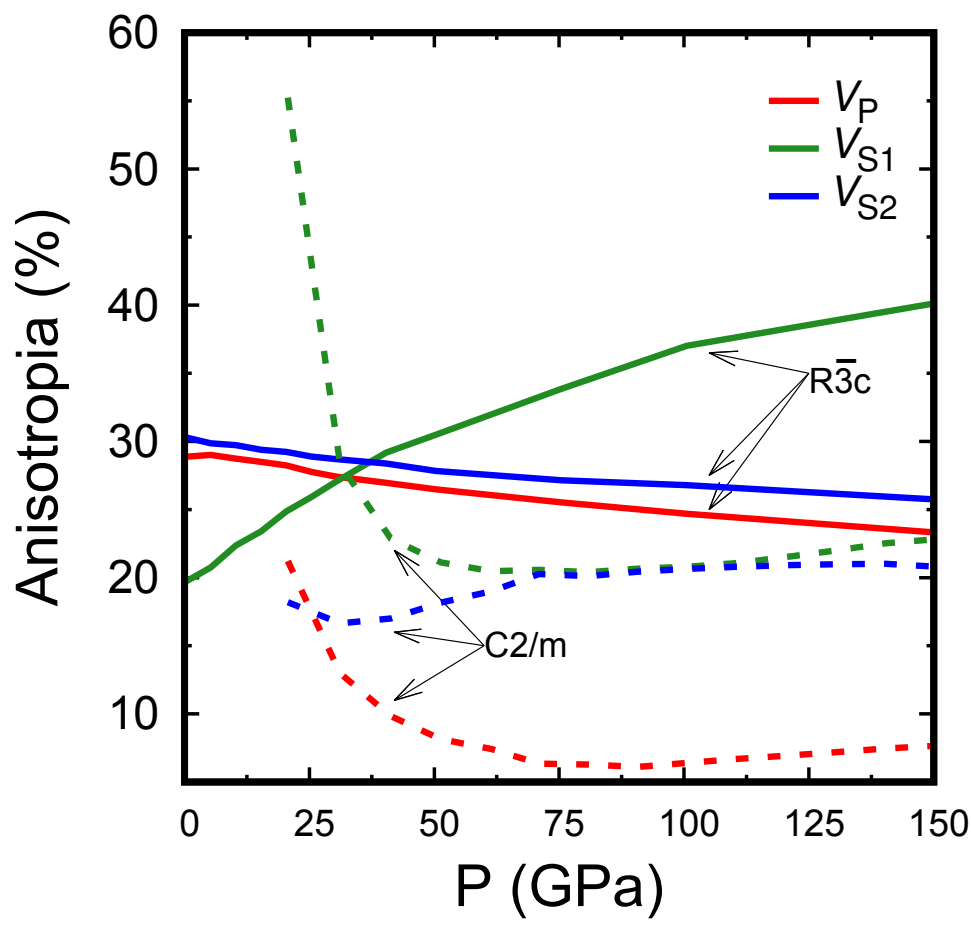

Figura 4.13: Anisotropia das velocidades das ondas acústicas $P\left(V_{P}\right)$ e $S\left(V_{S_{1}}\right.$ e $\left.V_{S_{2}}\right)$ como função da pressão no $\mathrm{MgCO}_{3}$, nas estruturas $\mathrm{R} \overline{3} \mathrm{c}$ e $\mathrm{C} 2 / \mathrm{m}$. 
velocidades de propagação.

\section{Agregados isotrópicos}

Conforme mencionado no capítulo 2, como as rochas que formam os planetas estão orientadas em diversas direções aleatoriamente, pode-se considerálo aproximadamente isotrópico. Para se calcular as propriedades elásticas de agregados isotrópicos destes cristais, utilizamos as médias de Voigt-Reuss-Hill, já utilizadas para descrever agregados de $\mathrm{MgSiO}_{3}$ no capítulo 3. Estas médias nos proporcionam os módulos de compressibilidade e de cisalhamento destes materiais, com os quais é possível calcular as velocidades $V_{P}$ e $V_{S}$ destes agregados. A figura 4.14 mostra a velocidade de propagação das ondas acústicas $\mathrm{P}$ e S em agregados isotrópicos de $\mathrm{MgCO}_{3}$ e $\mathrm{MgSiO}_{3}$.

Estão mostradas as velocidades em agregados compostos pela estrutura mais estável na pressão considerada, sendo que a mudança da linha contínua para tracejada marca a mudança de fase estrutural. Para o $\mathrm{MgCO}_{3}$, na pressão de transição, devido à mudança de fase da estrutura $R \overline{3} c$ para a $\mathrm{C} 2 / \mathrm{m}$, há um aumento de cerca de $1,5 \%$ na velocidade das ondas $P$ e de $4,0 \%$ na velocidade das ondas S. Como a concentração de carbono no interior do planeta é baixa, quando comparada à de outros elementos, em uma região rica em magnesita a descontinuidade nas velocidades de ondas sísmicas devido a essa transição de fase não deve ter nenhum efeito em medidas de tempos de chegada. A linha preta na figura 4.14 mostra as velocidades de agregados isotrópicos de MgSiO3 nas estrutura perovskita (linha contínua) e pós-perovskita (linha tracejada), apresentadas no capítulo 3. Percebe-se que as velocidades na magnesita são cerca de $10 \%$ menores do que no $\mathrm{MgSiO}_{3}$. É interessante notar que a variação das velocidades das ondas na estrutura perovskita são similares às das velocidades na estrutura pós-perovskita, e que na pressão de transição a descontinuidade é desprezível para as ondas $\mathrm{P}$ e muito pequena para as ondas S. Esta transição algumas vezes é considerada a causa de algumas descontinuidades nas velocidades de ondas sísmicas, principalmente na região $\mathrm{D}^{\prime \prime}$ do manto. Nossos resultados indicam que apenas esta transição de fase estrutural é insuficiente para explicar tais descontinuidades e corroboram trabalhos 


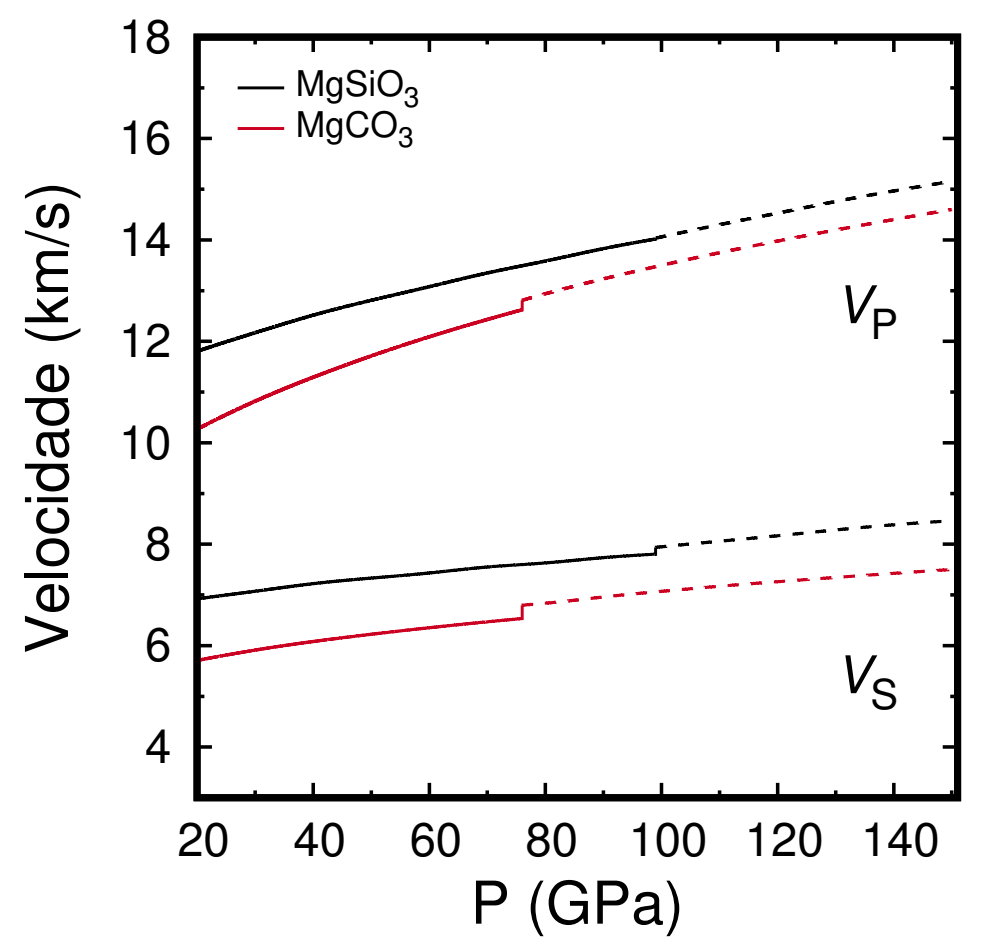

Figura 4.14: Velocidade de propagação das ondas acústicas $P\left(V_{P}\right)$ e $S\left(V_{S}\right)$ em agregados isotrópicos de $\mathrm{MgCO}_{3}$ e de $\mathrm{MgSiO}_{3}$. A mudança de linha contínua para tracejada marca a mudança de fase estrutural. No caso do $\mathrm{MgCO}_{3}$, da estrutura $\mathrm{R} \overline{3} \mathrm{c}$ para a $\mathrm{C} 2 / \mathrm{m}$ e no caso do $\mathrm{MgSiO}_{3}$ da estrutura perovskita ( $\mathrm{Pv}$ ) para a pósperovskita (Ppv).

anteriores nesta direção [77], sendo que outras causas também devem ser consideradas, tais como uma orientação preferencial dos eixos do cristal ou uma diferenciação química.

Uma comparação entre as velocidades de agregados isotrópicos de $\mathrm{MgSiO}_{3}$ e de $\mathrm{MgCO}_{3}$ pode fornecer alguma luz sobre as propriedades físicas e químicas de camadas profundas do manto inferior. Nestas regiões, a fase estável do $\mathrm{MgCO}_{3}$ é a $\mathrm{C} 2 / \mathrm{m}$, enquanto que o $\mathrm{MgSiO}_{3}$ está na fase perovskita ou pósperovskita, dependendo da pressão [18,96,123]. Já está bem consolidado na literatura que existem regiões no manto inferior nas quais são observadas ondas acústicas mais lentas $[18,124,125]$. Estas regiões possuem propriedades 
distintas e são rotuladas como Zona de Baixa Velocidade (Low Velocity Zone, LVZ), Zona de Ultra-Baixa Velocidade (Ultra-Low Velocity Zone, ULVZ) e Larga Província de Ondas Secundárias de Baixa Velocidade (Large Low Shear Velocity Provinces, LLSVP). As LVZ ocorrem no topo do mando superior e têm como característica principal uma redução de cerca de 5\% nas ondas S. Já as ULVZ ocorrem no manto inferior, próxima à fronteira com o núcleo e nelas há uma redução grande tanto na velocidade das ondas $S$ como na das ondas $P[19,125]$. Diversos modelos já foram propostos para explicar as propriedades dessas regiões, como fusão parcial dos minerais, alta concentração de ferro, presença de água e até a presença da fase pós-perovskita no manto inferior [18]. Estas regiões têm natureza distinta, com diferentes origens química e física e até mesmo perfis de temperatura díspares. Considerando o perfil destas zonas de baixa velocidade, particularmente seus contornos nítidos, está claro que apenas propriedades termodinâmicas não podem explicar estas zonas. Além disso, se a fronteira entre o manto e o núcleo possui uma composição homogênea, então esse tipo de explicação requer que a ULVZ seja global. Entretanto, em várias regiões da fronteira do manto com o núcleo faltam evidências da presença dessas ULVZ ou até não possuem tal redução na velocidade [17,126]. Portanto, alguma diferenciação química deve ser considerada para explicar essas propriedades [17,21].

Baseado em nossos resultados, investigamos a possibilidade de que algumas dessas zonas de baixa velocidade possam estar associadas com a presença de carbonatos próximos à fronteira entre o núcleo e o manto. Estas regiões profundas possuem pressões entre 100 e $130 \mathrm{GPa}$. De acordo com os resultados mostrados na figura 4.14 para estas pressões, as velocidades sísmicas em agregados de $\mathrm{MgCO}_{3}$ são consideravelmente menores que àquelas do $\mathrm{MgSiO}_{3}$ em mais de $5 \%$ nas ondas $\mathrm{P}$ e $10 \%$ nas ondas S. Portanto, estes resultados sugerem que o $\mathrm{MgCO}_{3}$ possa estar presente no manto inferior e ser o mineral responsável pelas zonas de baixa velocidade observadas nestas profundidades. Adicionalmente, estes resultados determinam que o carbono pode estar armazenado no manto inferior na forma deste carbonato. 


\subsection{Cristal de $\mathrm{CaCO}_{3}$}

Junto com o $\mathrm{MgSiO}_{3}$ e o $\mathrm{MgO}$, o $\mathrm{CaSiO}_{3}$ é um dos principais minerais no manto inferior. Assim, a evidência de presença de carbono no manto levanta a questão de como ocorre sua incorporação nesses minerais dominantes na composição do manto. Enquanto a seção anterior discutiu o $\mathrm{MgCO}_{3}$, nesta seção discutiremos as propriedades físicas do $\mathrm{CaCO}_{3}$, outro mineral no qual o carbono pode estar incorporado. $\mathrm{O}$ cristal de $\mathrm{CaCO}_{3}$ é bem mais complexo do que a magnesita, possuindo diversos polimorfos. A fase mais estável, à temperatura e pressão ambiente, é a calcita; a aragonita é uma fase que pode ser estabilizada em condições ambientes, mas é mais estável em altas pressões, e a vaterita, que é a fase menos comum. A forma mais estável à temperatura e pressão ambientes é a calcita, cuja estrutura romboédrica está mostrada na figura 4.15. Ela é pertencente ao grupo espacial $\mathrm{R} \overline{3} \mathrm{c}$, sendo isoestrutural ao $\mathrm{MgCO}_{3}$.

Da mesma forma que na magnesita, na calcita cada átomo de cálcio possui seis átomos de oxigênio como primeiros vizinhos e cada átomo de carbono
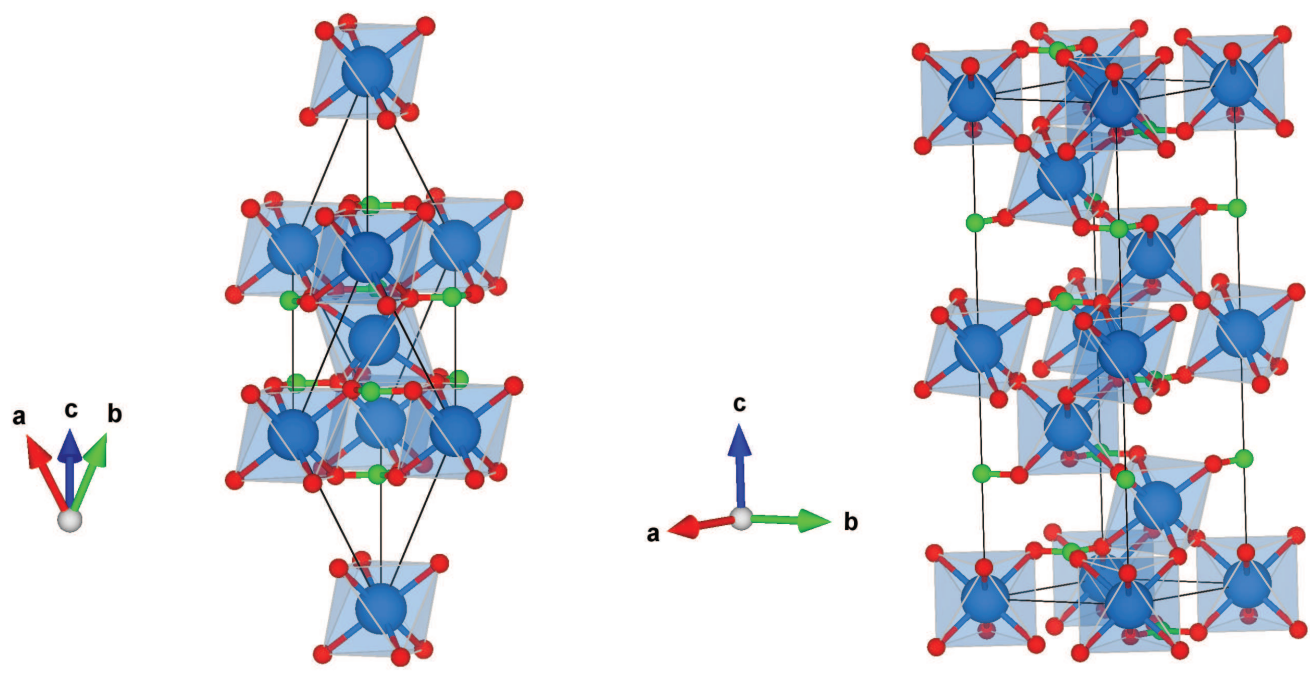

Figura 4.15: Estrutura cristalina do $\mathrm{CaCO}_{3}$ com grupo espacial $\mathrm{R} \overline{\mathrm{C}} \mathrm{c}$, na rede romboédrica (esquerda) e hexagonal (direita). As esferas azuis representam os átomos de cálcio, as verdes os átomos de carbono e as vermelhas os átomos de oxigênio. 
possui três átomos de oxigênio. Utilizando os métodos já descritos, calculouse as propriedades estruturais a pressão nula, primeiro efetuando-se cálculos para uma faixa de pressão de -15 GPa a 150 GPa e, em seguida, utilizando-se a equação de Birch-Murnaghan de segunda ordem para calcular os parâmetros da equação de estado. Este procedimento foi feito utilizando-se os funcionais LDA e GGA e os resultados estão mostrados na tabela 4.9.

Tabela 4.9: Parâmetros da equação de estado do $\mathrm{CaCO}_{3}$ calcita ( $\mathrm{R} \overline{3} \mathrm{c}$ ). Resultados experimentais são das referências $[127,128]$. Os resultados obtidos estão relacionados com a célula hexagonal para facilitar a comparação com dados experimentais. O bulk modulus $\left(K_{0}\right)$ é dado em GPa e a derivada do bulk modulus $\left(K_{0}^{\prime}\right)$ é adimensional.

\begin{tabular}{||c||c|c|c|c|c||}
\hline \hline & a $(\AA)$ & $\mathrm{c}(\AA)$ & $V_{0}\left(\AA^{3}\right)$ & $K_{0}$ & $K_{0}^{\prime}$ \\
\hline \hline GGA & 5,05 & 17,29 & 381,19 & 70 & 3,43 \\
LDA & 4,96 & 16,53 & 352,45 & 72 & 3,93 \\
Exp. & 4,99 & 17,07 & 368,11 & 73 & 4,00 \\
\hline \hline
\end{tabular}

De acordo com a tabela, quando comparados com dados experimentais disponíveis, os parâmetros de rede são subestimados quando do uso do funcional LDA e superestimados pelo funcional GGA. Devemos salientar que os valores teóricos foram obtidos a partir de cálculos estáticos, representando a condição $T=0 \mathrm{~K}$, exceto pelo efeito de ponto zero, enquanto os dados experimentais foram obtidos à temperatura ambiente. Assim, a utilização da LDA parece ser uma melhor aproximação para descrever este material, em comparação com a GGA, uma vez que a inclusão de efeitos térmicos aumentariam os valores dos parâmetros de rede, aproximando-os dos valores experimentais. Em termos do bulk modulus, observa-se um comportamento inverso dos resultados com a utilização da LDA e GGA, quando comparados com os dados experimentais. O funcional LDA apresenta valores de volume menores e o GGA maiores que o valor experimental. Nota-se que o funcional LDA apresenta erros de 4,3\% e $1,99 \%$ no volume e no bulk modulus, respectivamente, enquanto o GGA apresenta erros de $3,7 \%$ e $4,53 \%$. Assim, o erro no volume é da mesma ordem nos 
dois funcionais, mas o erro em $K_{0}$ é significativamente menor no LDA. Comparando estes resultados dos parâmetros estruturais com os apresentados na tabela 4.2, vê-se que a calcita ocupa um volume maior do que a magnesita. Isso se deve ao fato do átomo de cálcio ser maior do que o de magnésio. Por esse motivo, a calcita é mais "mole" do que a magnesita, possuindo módulos de compressibilidade bem menores. A influência disso na propagação de ondas acústicas nestes materiais será discutida em maiores detalhes em seções posteriores.

\section{Propriedades eletrônicas}

Com os valores otimizados das constantes de rede, calculou-se a estrutura de bandas de energia do material nas direções de alta simetria da primeira zona de Brillouin da estrutura hexagonal. A figura 4.16 apresenta a estrutura de bandas e as densidades de estados projetadas nos átomos ( $\mathrm{Ca}, \mathrm{C} \mathrm{e} \mathrm{O}$ ), à pressão nula, para o $\mathrm{CaCO}_{3}$ obtida utilizando o funcional LDA, em que o zero de energia foi

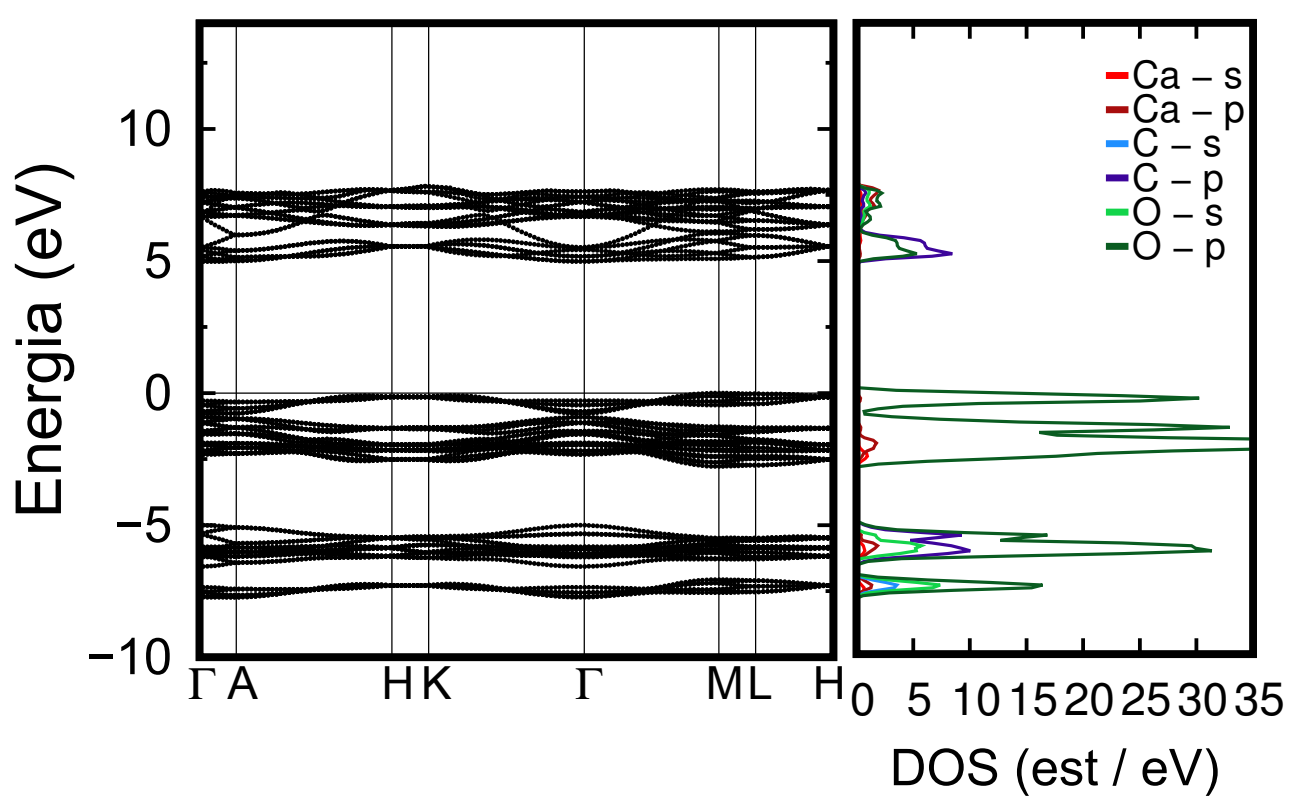

Figura 4.16: Estrutura de bandas e densidades de estados (DOS) do $\mathrm{CaCO}_{3}(\mathrm{R} \overline{\mathrm{z}} \mathrm{c}$ ) projetadas nos átomos de $\mathrm{Ca}, \mathrm{C}$ e $\mathrm{O}$, obtidas com a utilização do funcional LDA. 
deslocado para o topo da banda de valência. Assim como mostrado para a magnesita, a largura da faixa de energia proibida fundamental é de transição indireta $\mathrm{M} \rightarrow \Gamma$, com valor de 4,99 eV com o uso do funcional LDA e de 5,05 eV com o GGA, praticamente os mesmos valores que os obtidos para a magnesita.

A banda de valência do mineral é formada essencialmente pelos estados ligantes dos átomos de $\mathrm{O}$, assim como na magnesita, sendo que esta possui uma largura também de cerca de $8 \mathrm{eV}$. Nos dois casos a banda de valência pode ser divida em duas sub-bandas, sendo que a separação entre estas é cerca de 2,5 eV, $\approx 1 \mathrm{eV}$ maior que na magnesita, mostrando uma menor dispersão das bandas. O fundo da banda de condução é formado, prioritariamente, pelos estados $s$ e $p$ antiligantes dos átomos de cálcio e carbono. A formação desta estrutura de faixas de energia também pode ser compreendida do ponto de vista puramente iônico. Assim, na formação da unidade $\mathrm{CaCO}_{3}$, os três átomos de oxigênio, que em estado neutro apresentam, cada um, uma configuração eletrônica de valência $2 s^{2} 2 p^{4}$, passam para a configuração iônica $\mathrm{O}^{2-}$, recebendo seis elétrons (dois elétrons cada átomo de 0 ) dos átomos de cálcio e carbono. Por outro lado, os átomos neutros de cálcio e carbono, respectivamente, que possuem configurações eletrônicas de valência $4 s^{2}$ e $2 s^{2} 2 p^{2}$, doam dois e quatro elétrons, respectivamente, para os átomos de oxigênio, adquirindo

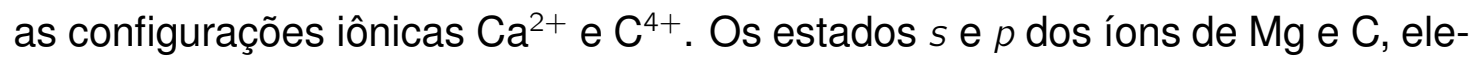
tronicamente desocupados, contribuem para a formação do fundo da banda de condução enquanto que os estados $p$ dos íons de $O$, eletronicamente ocupados, contribuem para a formação da banda de valência. As interações cristalinas ligantes e antiligantes ficam separadas pela região proibida de energia.

\section{Propriedades elásticas}

A calcita, por pertencer ao mesmo grupo espacial da magnesita, também possui seis coeficientes elásticos, sendo que as componentes $C_{i j}$ do tensor são dadas pela equação (4.2). Com as mesmas distorções utilizadas para a magnesita, calculou-se o tensor elástico da calcita, primeiramente à pressão nula. A tabela 4.10 apresenta os resultados para os coeficientes elásticos, assim como dados experimentais obtidos através da espectroscopia de Brillouin [129]. 
Tabela 4.10: Coeficientes elásticos $\left(C_{i j}\right)$, em unidades de $\mathrm{GPa}$, do $\mathrm{CaCO}_{3}$ na estrutura $\mathrm{R} \overline{3} \mathrm{c}$ (calcita). Resultados experimentais são da referência [129].

\begin{tabular}{||c||c|c||}
\hline \hline$C_{i j}$ & Teórico & Exp. \\
\hline \hline$C_{11}$ & 177 & 148 \\
$C_{33}$ & 95 & 85 \\
$C_{44}$ & 39 & 34 \\
$C_{12}$ & 78 & 58 \\
$C_{13}$ & 72 & 54 \\
$C_{14}$ & 25 & 25 \\
\hline \hline
\end{tabular}

Nota-se que, assim como nos resultados obtidos para os outros minerais estudados neste trabalho, os coeficientes elásticos estão superestimados quando comparados com dados experimentais, como esperado quando usa-se o funcional LDA, mas como nossos resultados são para uma rede estática na qual a temperatura não é considerada, exceto pelo efeito de ponto zero, e a inclusão de efeitos térmicos tende a deixar os materiais mais "moles", estes resultados se tornem mais consistentes com os dados experimentais.

Como a estrutura da calcita é igual à estrutura da magnesita, espera-se que ela apresente propriedades similares às da magnesita, levando apenas em conta a diferença entre seus raios covalentes, $R_{M g}=150 \mathrm{pm}$ e $R_{C_{a}}=180 \mathrm{pm}$. Como o principal objetivo deste trabalho é entender como a introdução do carbono influencia na propagação de ondas sísmicas no manto inferior, é interessante, neste ponto, elaborar uma comparação entre as propriedades elásticas da calcita com as da magnesita e as do $\mathrm{MgSiO}_{3}$ perovskita. A tabela 4.11 mostra os valores dos coeficientes elásticos destes três materiais, à pressão nula.

Comparando, então, os resultados da calcita com os coeficientes elásticos da magnesita, vê-se que os coeficientes elásticos da calcita são ainda menores que os da magnesita, que são menores que do $\mathrm{MgSiO}_{3}$ (perovskita). Como o átomo de cálcio é maior que o de magnésio, o volume ocupado pela célula primitiva da calcita é maior do que o da magnesita e, portanto, é mais fácil comprimi-la, explicando assim porque seu tensor elástico é consistentemente 
Tabela 4.11: Valores dos coeficientes do tensor elástico $\left(C_{i j}\right)$ da calcita $\left(\mathrm{CaCO}_{3}-\right.$ $\mathrm{R} \overline{\mathrm{C}} \mathrm{c}$ ), da magnesita $\left(\mathrm{MgCO}_{3}-\mathrm{R} \overline{3} \mathrm{c}\right)$ e do $\mathrm{MgSiO}_{3}$ (perovskita), à pressão nula. As unidades estão em GPa.

\begin{tabular}{||c||c|c|c||}
\hline \hline$C_{i j}$ & $\mathrm{CaCO}_{3}$ & $\mathrm{MgCO}_{3}$ & $\mathrm{MgSiO}_{3}$ \\
\hline \hline $\mathrm{C}_{11}$ & 177 & 283 & 479 \\
$\mathrm{C}_{22}$ & 177 & 283 & 544 \\
$\mathrm{C}_{33}$ & 95 & 166 & 474 \\
$\mathrm{C}_{44}$ & 39 & 64 & 202 \\
$\mathrm{C}_{55}$ & 39 & 64 & 173 \\
$\mathrm{C}_{66}$ & 49 & 99 & 156 \\
$\mathrm{C}_{12}$ & 78 & 85 & 136 \\
$\mathrm{C}_{13}$ & 72 & 71 & 136 \\
$\mathrm{C}_{23}$ & 72 & 71 & 153 \\
$\mathrm{C}_{14}$ & 25 & 25 & 0 \\
\hline \hline
\end{tabular}

menor do que o da magnesita, especialmente nas direções $x, y$ e $z$.

A anisotropia de ondas sísmicas é um efeito observado em diversos estudos de sismologia e pode nos dizer muito sobre o interior do planeta. Utilizamos o tensor elástico para calcular a velocidade das ondas acústicas em diferentes direções do material. Para tanto, com os resultados dos valores dos coeficientes elásticos resolvemos a equação de Christoffel (4.3) a fim de se calcular as velocidades de propagação das ondas acústicas $\mathrm{P}$ e $\mathrm{S}$ em diferentes direções do cristal. Estes resultados, juntamente com aqueles obtidos para o $\mathrm{MgCO}_{3}(\mathrm{R} \overline{\mathrm{C}} \mathrm{c})$ e para o $\mathrm{MgSiO}_{3}$ perovskita, estão exibidos na figura 4.17.

As velocidades de propagação de ondas acústicas são bem menores na calcita do que na magnesita, resultado dos valores dos coeficientes elásticos que na calcita são significativamente menores que os da magnesita. Pode-se notar, inclusive, que em certas direções a velocidade das ondas P, na calcita, são menores que as das ondas $\mathrm{S}$ na magnesita e no $\mathrm{MgSiO}_{3}$ perovskita, indicando que regiões ricas em cálcio e carbono, onde a formação da calcita é favorável, podem apresentar reduções drásticas nas velocidades de ondas sísmicas. $O$ 
caráter destas ondas pode ser determinado em medidas de tempos de chegada de ondas sísmicas provenientes de terremotos, de tal forma que este tipo de informação poderia contribuir para modelos sobre a composição do manto terrestre. Entretanto, a estrutura trigonal do $\mathrm{CaCO}_{3}$ só é estável até pressões da ordem de $2 \mathrm{GPa}$, dessa forma descontinuidades associadas a esta transição ocorrerão em regiões no topo do manto superior terrestre e não no manto inferior. Na próxima seção apresentamos os resultados de cálculos para altas pressões.

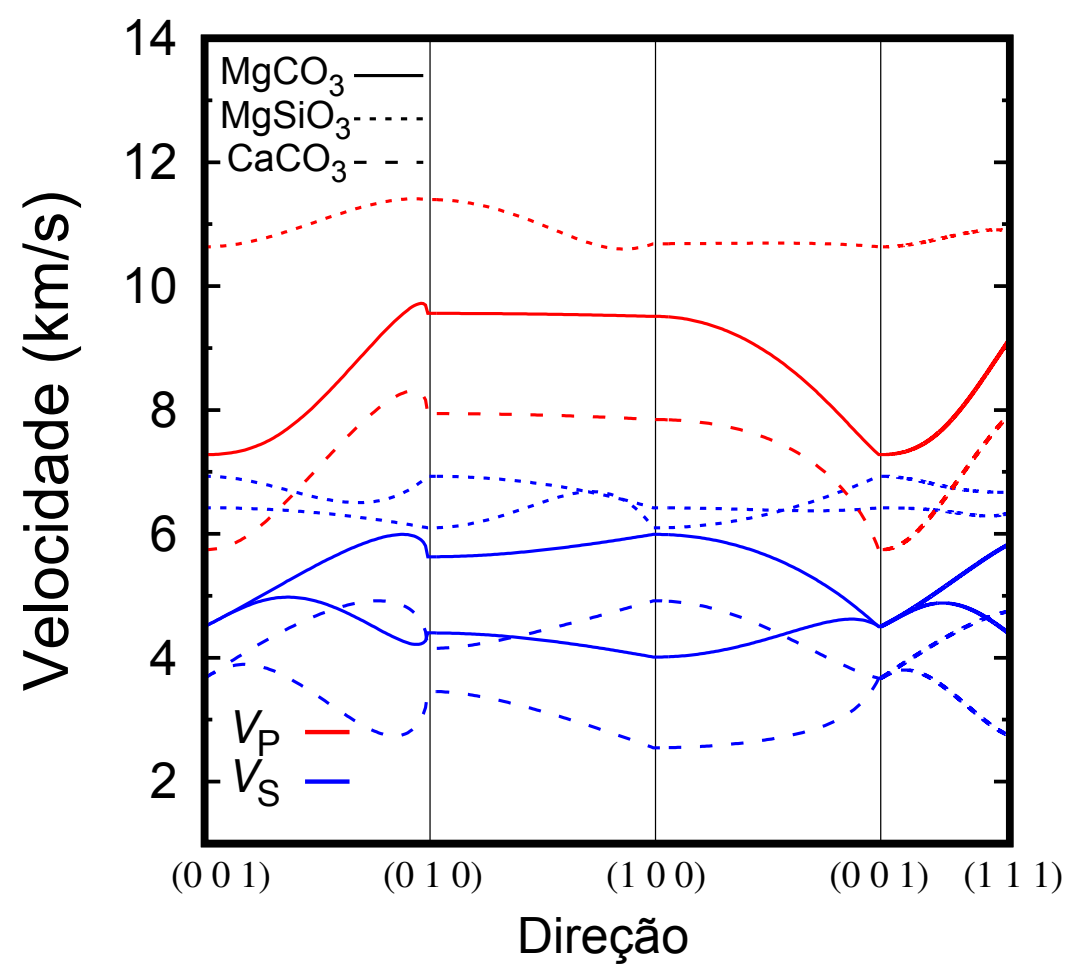

Figura 4.17: Velocidades de propagação de ondas acústicas $P\left(V_{P}\right)$ e $S\left(V_{S}\right)$ no de $\mathrm{CaCO}_{3}(\mathrm{R} \overline{\mathrm{C}} \mathrm{c})$, no $\mathrm{MgCO}_{3}\left(\mathrm{R} \overline{3} \mathrm{c}\right.$ ) e no $\mathrm{MgSiO}_{3}$ (perovskita), ao longo de diferentes direções dos cristais. 


\section{Comportamento do cristal sob altas pressões}

\section{Aragonita e pós-aragonita}

Para pressões acima de $2 \mathrm{GPa}$, $\circ \mathrm{CaCO}_{3}$ calcita se transforma na aragonita, com uma estrutura ortorrômbica primitiva, grupo espacial Pmcn. Uma representação do arranjo dos átomos da estrutura ortorrômbica primitiva da aragonita é mostrada na figura 4.18. Nesta estrutura cada átomo de cálcio possui nove átomos de oxigênio como primeiros vizinhos, divididos em cinco esferas de coordenação, enquanto cada átomo de carbono possui três átomos de oxigênio, divididos em duas esferas de coordenação. Este é o mesmo grupo espacial
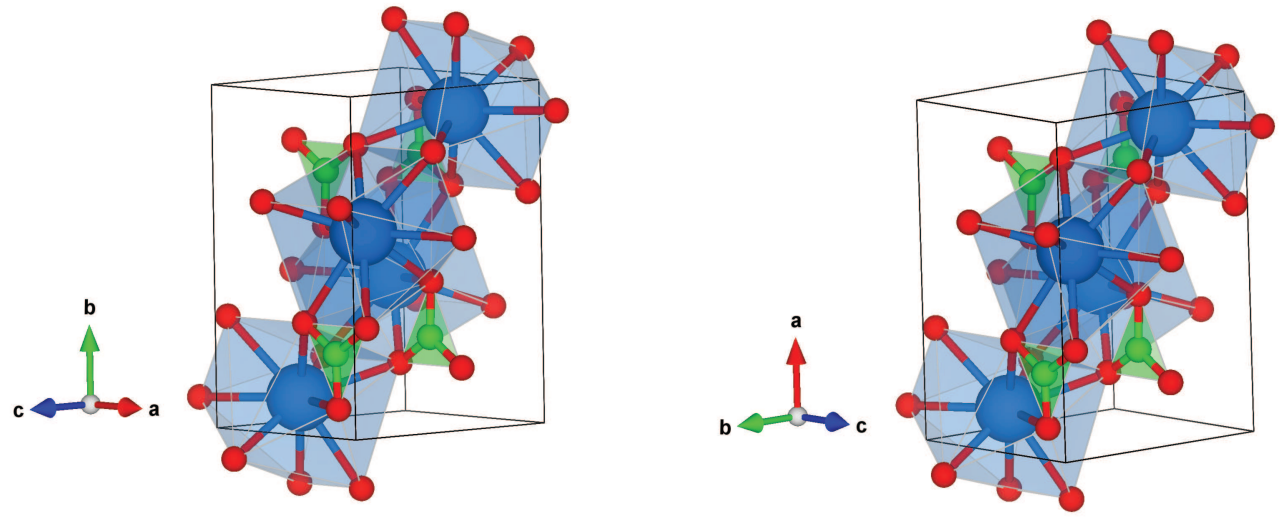

Figura 4.18: Estrutura cristalina do $\mathrm{CaCO}_{3}$ na forma da aragonita, grupo espacial 62, na estrutura Pmcn (esquerda) e Pbnm (direita). As esferas azuis representam os átomos de cálcio, as esferas verdes os átomos de carbono e as esferas vermelhas os átomos de oxigênio.

da perovskita apresentada no capítulo anterior, mas a orientação dos eixos é feita de maneira diferente e as posições atômicas internas são outras. Como a aragonita pode também ser estabilizada à pressão ambiente, calculamos os parâmetros da equação de estado para $P=0$ e comparamos com dados experimentais [130] na tabela 4.12.

De acordo com os resultados da tabela, os valores dos parâmetros de rede teóricos estão consistentes com os dados experimentais disponíveis, sendo que o funcional LDA subestima enquanto o GGA superestima as constantes de rede. 
Tabela 4.12: Propriedades estruturais do $\mathrm{CaCO}_{3}$ aragonita, obtidas através da equação de estado, na estrutura Pmcn. O bulk modulus $\left(K_{0}\right)$ é dado em GPa e a derivada do bulk modulus $\left(K_{0}^{\prime}\right)$ é adimensional. Resultados experimentais são da referência [130].

\begin{tabular}{||c||c|c|c|c|c|c||}
\hline \hline & $\mathrm{a}(\AA)$ & $\mathrm{b}(\AA)$ & $\mathrm{c}(\AA)$ & $V_{0}\left(\AA^{3}\right)$ & $K_{0}$ & $K_{0}^{\prime}$ \\
\hline \hline GGA & 5,01 & 8,02 & 5,80 & 232,89 & 74 & 3,74 \\
LDA & 4,88 & 7,83 & 5,72 & 211,90 & 85 & 3,91 \\
Exp. & 4,96 & 7,97 & 5,74 & 226,71 & 71 & 4,63 \\
\hline \hline
\end{tabular}

Devemos salientar, de novo, que os valores teóricos foram obtidos a partir de cálculos estáticos, representando a condição $T=0 \mathrm{~K}$, exceto pelo efeito de ponto zero. Já foi mostrado, tanto teoricamente [112,113,131] como experimentalmente [132], que a aragonita é estável até pressões de cerca de $40 \mathrm{GPa}$ e a pressões maiores ocorre uma transição para a fase pós-aragonita, também ortorrômbica, mas de grupo espacial Pmmn. O arranjo de átomos na estrutura pós-aragonita está mostrado na figura 4.19.

Para estudar a estabilidade relativa destes três sistemas, desprezando efei-

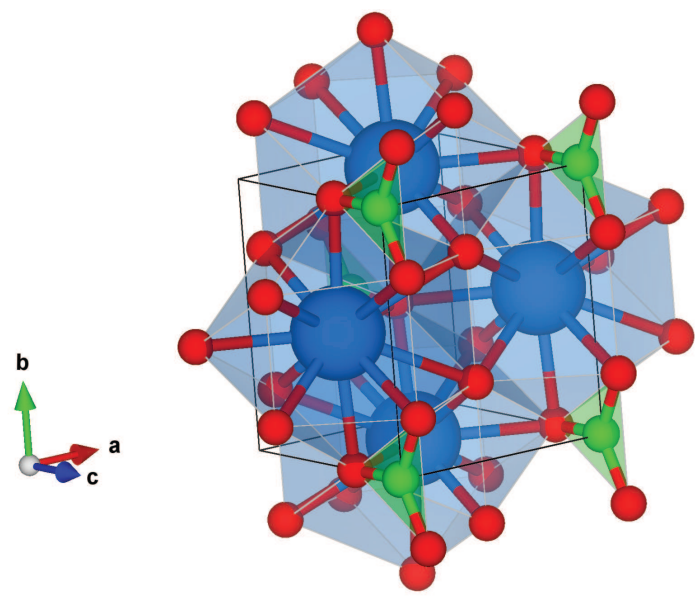

Figura 4.19: Estrutura cristalina do $\mathrm{CaCO}_{3}$ na fase pós-aragonita, com grupo espacial Pmmn. As esferas azuis representam os átomos de cálcio, as esferas verdes os átomos de carbono e as vermelhas os átomos de oxigênio. 
tos térmicos, obtivemos as entalpias do $\mathrm{CaCO}_{3}$ nas estruturas calcita $(\mathrm{R} \overline{\mathrm{C}} \mathrm{c})$, aragonita (Pmcn) e pós-aragonita (Pmmn), utilizando os funcionais LDA e GGA, para valores de pressão de até $150 \mathrm{GPa}$. A figura 4.20 apresenta as entalpias relativas destas três fases do $\mathrm{CaCO}_{3}$, tomando como referência a entalpia da estrutura $\mathrm{R} \overline{3} \mathrm{c}$. Nossos resultados, utilizando o funcional LDA, indicam que a aragonita (Pmcn) já é realmente estável em $P=0$. De fato, o funcional LDA prevê uma transição de fase da estrutura calcita $(\mathrm{R} \overline{\mathrm{C}} \mathrm{c})$ para aragonita (Pmcn) em $P=-2 \mathrm{GPa}$, enquanto os dados experimentais indicam que esta transição ocorre em $P=2,4 \mathrm{GPa}$ [133]. Além disso, este funcional prevê uma transição da fase aragonita (Pmcn) para a pós-aragonita $(\mathrm{Pmmn})$ à $P=38 \mathrm{GPa}$, que está em boa concordância com resultados experimentais [132]. Por outro lado, o funcional GGA prevê essas transições, respectivamente, em $P=4$ GPa e $P=40$ GPa, também em boa concordância com os dados experimentais.
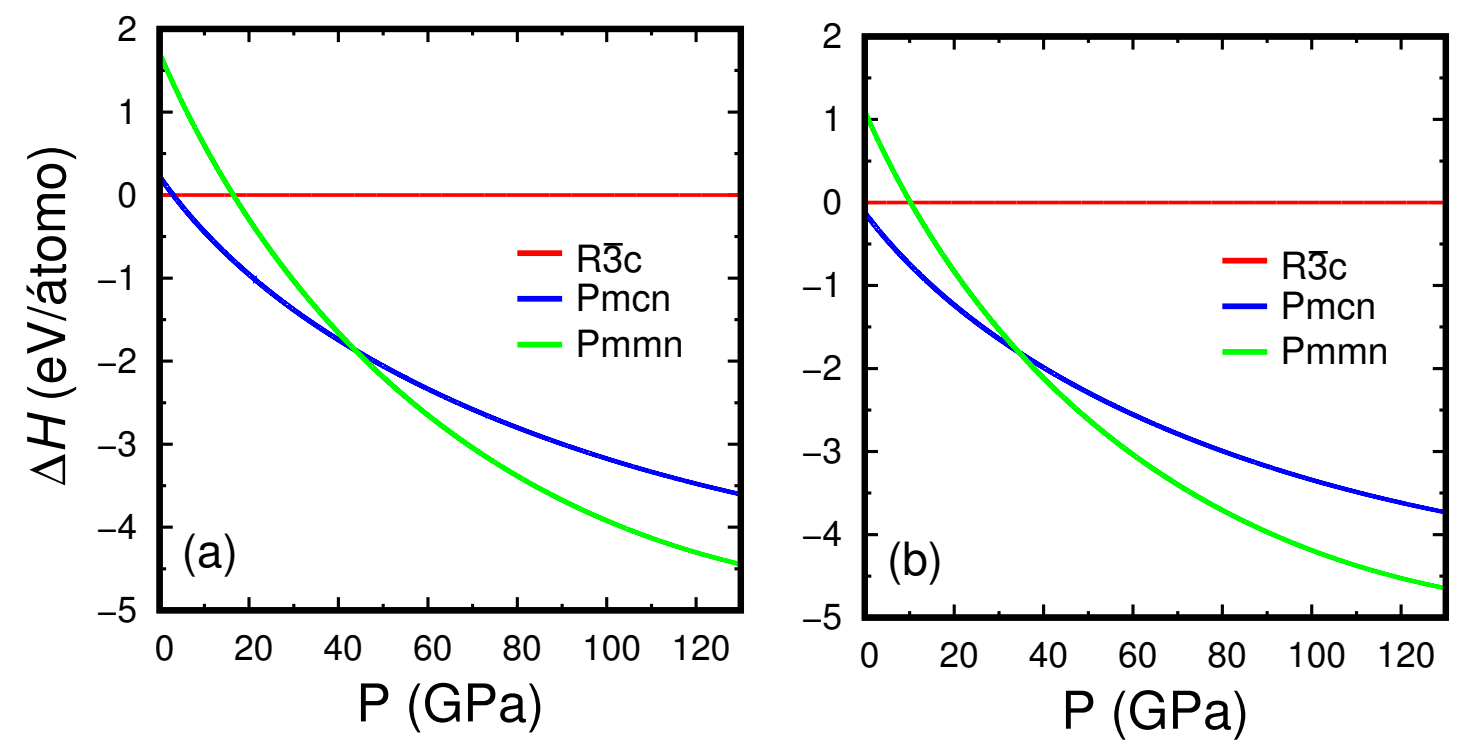

Figura 4.20: Entalpia relativa $(\Delta H)$ do $\mathrm{CaCO}_{3}$, obtidos com o uso dos funcionais (a) GGA e (b) LDA, para as fases aragonita (Pmcn - linha azul) e pós-aragonita (Pmmn - linha verde), com relação à fase calcita ( $R \overline{3} c$ - linha vermelha). 


\section{Propriedades elásticas - Aragonita}

A aragonita possui uma estrutura ortorrômbica, pertencente ao mesmo grupo espacial do $\mathrm{MgSiO}_{3}$. Dessa forma, possui também nove componentes elásticas independentes. Estes coeficientes elásticos podem ser calculados com as mesmas seis distorções usadas para o $\mathrm{MgSiO}_{3}$, mostradas no apêndice $\mathrm{B}$. Os coeficientes elásticos, assim calculados para a aragonita, estão apresentados na tabela 4.13, juntamente com resultados experimentais obtidos através de espectroscopia de Brillouin [134].

Tabela 4.13: Coeficientes elásticos $C_{i j}$, em GPa, do $\mathrm{CaCO}_{3}$ na estrutura aragonita (Pmcn). Valores experimentais da referência [134]. Coeficientes elásticos do $\mathrm{MgSiO}_{3}$, na fase perovskita, também estão mostrados.

\begin{tabular}{||c||c|c|c||}
\hline \hline$C_{i j}$ & Teórico & Exp. & $\mathrm{MgSiO}_{3}$ \\
\hline \hline$C_{11}$ & 210 & 171 & 499 \\
$C_{22}$ & 134 & 110 & 541 \\
$C_{33}$ & 120 & 98 & 472 \\
$C_{44}$ & 47 & 39 & 216 \\
$C_{55}$ & 28 & 24 & 192 \\
$C_{66}$ & 49 & 40 & 147 \\
$C_{12}$ & 75 & 60 & 130 \\
$C_{13}$ & 39 & 28 & 148 \\
$C_{23}$ & 61 & 42 & 156 \\
\hline \hline
\end{tabular}

Nota-se, de novo, assim como nos resultados obtidos para os outros minerais estudados neste trabalho, que os coeficientes elásticos estão superestimados quando comparados com dados experimentais, como esperado quando usa-se o funcional LDA. Entretanto, os dados experimentais foram obtidos em temperatura ambiente e nossos resultados são para uma rede estática na qual a temperatura não é considerada, exceto pelo efeito de ponto zero. Compa- 


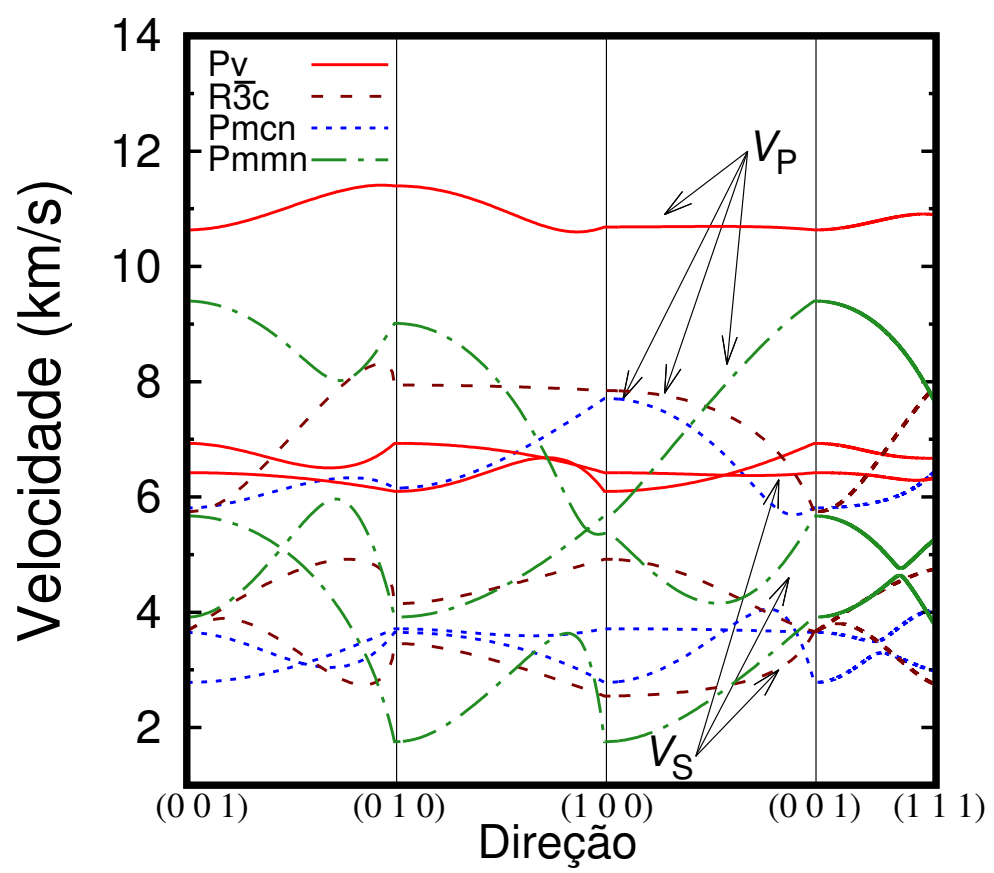

Figura 4.21: Velocidades de propagação de ondas acústicas $P\left(V_{P}\right)$ e $S\left(V_{S}\right)$, ao longo de diferentes direções do cristal, para os polimorfos $\mathrm{R} \overline{3} c$, Pmcn e Pmmn do $\mathrm{CaCO}_{3}$, juntamente com as obtidas para o $\mathrm{MgSiO}_{3}$ na estrutura perovskita ( $\mathrm{Pv}$ ).

rando o tensor elástico da aragonita ${ }^{2}$ com o do $\mathrm{MgSiO}_{3}$ vemos que os valores são significativamente menores. Assim, espera-se que a velocidade das ondas acústicas também seja menor na aragonita quando comparada com o $\mathrm{MgSiO}_{3}$ perovskita.

Utilizamos o tensor elástico e resolvemos a equação de Christoffel (4.3) para calcular as velocidades de propagação das ondas acústicas $\mathrm{P}$ e $\mathrm{S}$ ao longo de diferentes direções da aragonita e da pós-aragonita. Estes resultados, juntamente com aqueles obtidos para a calcita e para o $\mathrm{MgSiO}_{3}$ perovskita, estão exibidos na figura 4.21 .

\footnotetext{
${ }^{2}$ Tanto a aragonita quanto $\mathrm{OMgSiO}_{3}$ pertencem ao grupo espacial 62. Entretanto, a estrutura da aragonita utilizada neste trabalho (e encontrada em boa parte da literatura) está orientada no grupo espacial Pmcn, enquanto $\mathrm{MgSiO}_{3}$ no Pbnm. Isso significa que a orientação dos eixos está trocada. Isto não influencia na análise feita neste trabalho, mas caso seja necessário uma análise termo a termo, deve-se converter as estruturas para a mesma orientação dos eixos.
} 
Na direção (001), pode-se perceber que não há diferenças significativas entre os valores da velocidade na aragonita e na calcita. Entretanto, conforme a direção varia, a velocidade na aragonita se torna bem menor. O comportamento da velocidade como função da direção na aragonita é bem parecido com o no $\mathrm{MgSiO}_{3}$. As velocidades das duas ondas $\mathrm{S}$, na aragonita, são bem próximas entre si, para praticamente todas as direções consideradas, comportamento bem diferente do observado para os outros cristais.

As velocidades das ondas acústicas na estrutura pós-aragonita apresentam um comportamento peculiar. Elas são bem maiores do que nos outros cristais de $\mathrm{CaCO}_{3}$, sendo que as velocidades das ondas $\mathrm{S}$ são comparáveis às das ondas $P$ das outras estruturas. Adicionalmente, além de a fase pós-aragonita possuir altas velocidades de propagação em determinadas direções, elas também apresentam uma grande variação de valor em função da direção. Na direção (100) as ondas P e S possuem velocidades similares. Isso implica numa grande anisotropia deste cristal, referente à propagação de ondas acústicas. Entretanto, estes cálculos foram realizados para pressão nula, de tal forma que a fase pós-aragonita não é estável nestas condições. Como já observado, pressões maiores implicam maiores coeficientes elásticos, assim, as velocidades também serão maiores. Portanto, uma transição para a estrutura pós-aragonita pode acarretar descontinuidades em velocidades acústicas em regiões nas quais sua formação seja favorável.

Para verificarmos a anisotropia destes cristais de $\mathrm{CaCO}_{3}$ nas três fases estruturais, em relação à propagação de ondas, obtivemos a variação da anisotropia, como função da pressão, das velocidades das ondas acústicas $\mathrm{P}$ e $\mathrm{S}$, a qual está mostrada na figura 4.22, onde está mostrada, também, a anisotropia das velocidades das ondas $\mathrm{P}$ e S para $0 \mathrm{MgCO}_{3}$, para comparação entre os carbonatos. De uma maneira geral, os minerais de $\mathrm{CaCO}_{3}$ são muito mais anisotrópicos do que os de $\mathrm{MgCO}_{3}$, sendo que ocorre um pico na anisotropia dos carbonatos de cálcio em valores de pressão pouco maiores do que $25 \mathrm{GPa}$. Com o aumento da pressão, a anisotropia do $\mathrm{CaCO}_{3}$ diminui, mas ainda apresenta valores maiores do que os do $\mathrm{MgCO}_{3}$. A anisotropia da pós-aragonita (Pmmn) chega a valores de até $120 \%$ para as ondas S, mas esta estrutura não é a mais estável nas condições de pressão em que isso ocorre. De qualquer 

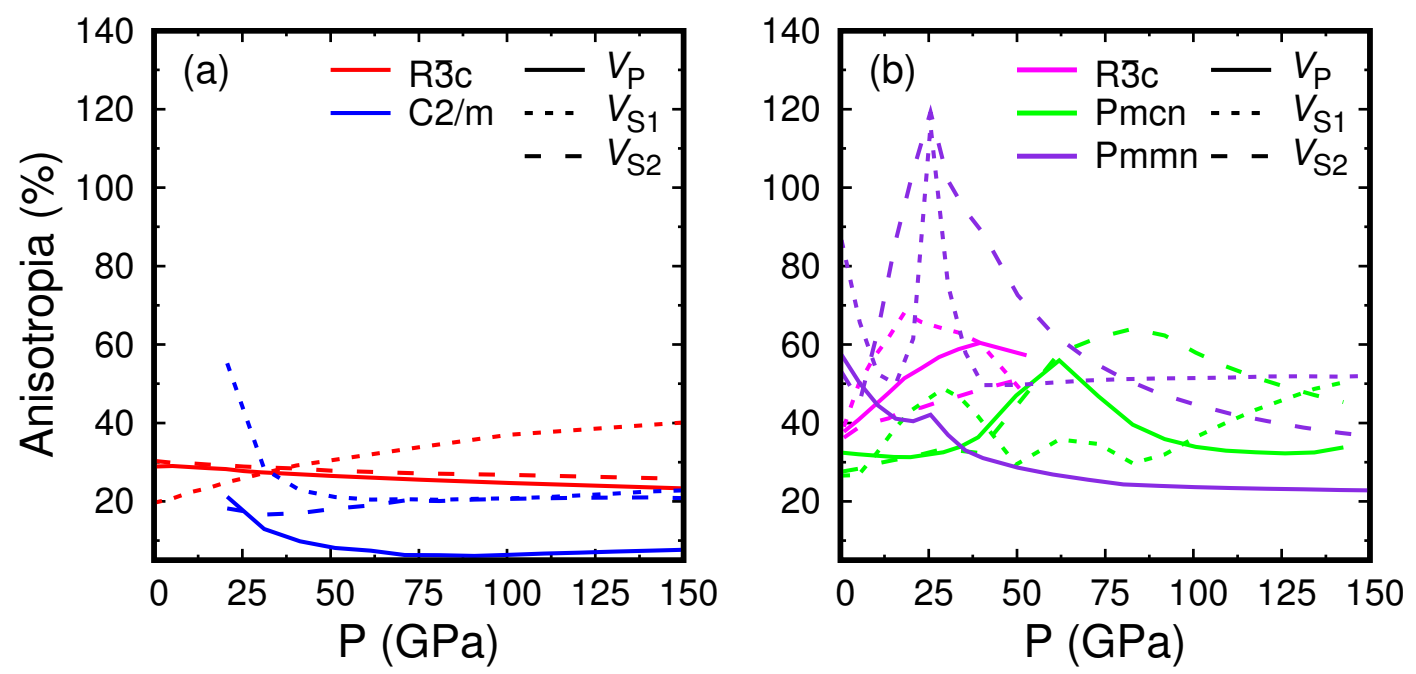

Figura 4.22: Anisotropia das velocidades de ondas acústicas $\left(V_{\mathrm{P}}, V_{\mathrm{S} 1}\right.$, e $\left.V_{\mathrm{S} 2}\right)$ : (a) $\mathrm{MgCO}_{3}$ nas fases $\mathrm{R} \overline{3} \mathrm{c}$ (linhas vermelhas) e $\mathrm{C} 2 / \mathrm{m}$ (linhas azuis); (b) $\mathrm{CaCO}_{3}$ nas fases calcita ( $\mathrm{R} \overline{3} c$ - linhas rosas), aragonita (Pmcn - linhas verdes) e pós-aragonita (Pmmn - linhas violetas).

forma, a anisotropia de regiões do manto ricas em carbonatos de cálcio pode ser significativamente alterada caso a formação da fase pós-aragonita seja favorável.

\section{Agregados isotrópicos}

Para calcular as propriedades elásticas de agregados isotrópicos dos carbonatos de cálcio, utilizamos as médias de Voigt-Reuss-Hill, já utilizadas para descrever outros agregados. Obtivemos, então, os módulos de compressibilidade e de cisalhamento destes materiais, com os quais calculamos as velocidades de propagação das ondas $P$ e das ondas $S$ destes agregados. A figura 4.23 mostra a velocidade de propagação das ondas acústicas $P\left(V_{P}\right)$ e $S\left(V_{S}\right)$ em agregados isotrópicos de aragonita e pós-aragonita, assim como em agregados isotrópicos de $\mathrm{MgCO}_{3}$ e $\mathrm{MgSiO}_{3}$. Mostramos apenas as velocidades das estruturas mais estáveis em cada intervalo de pressão. Como a calcita só é estável até valores de pressão de $\approx 2 \mathrm{GPa}$, as velocidades de seus agregados não estão 


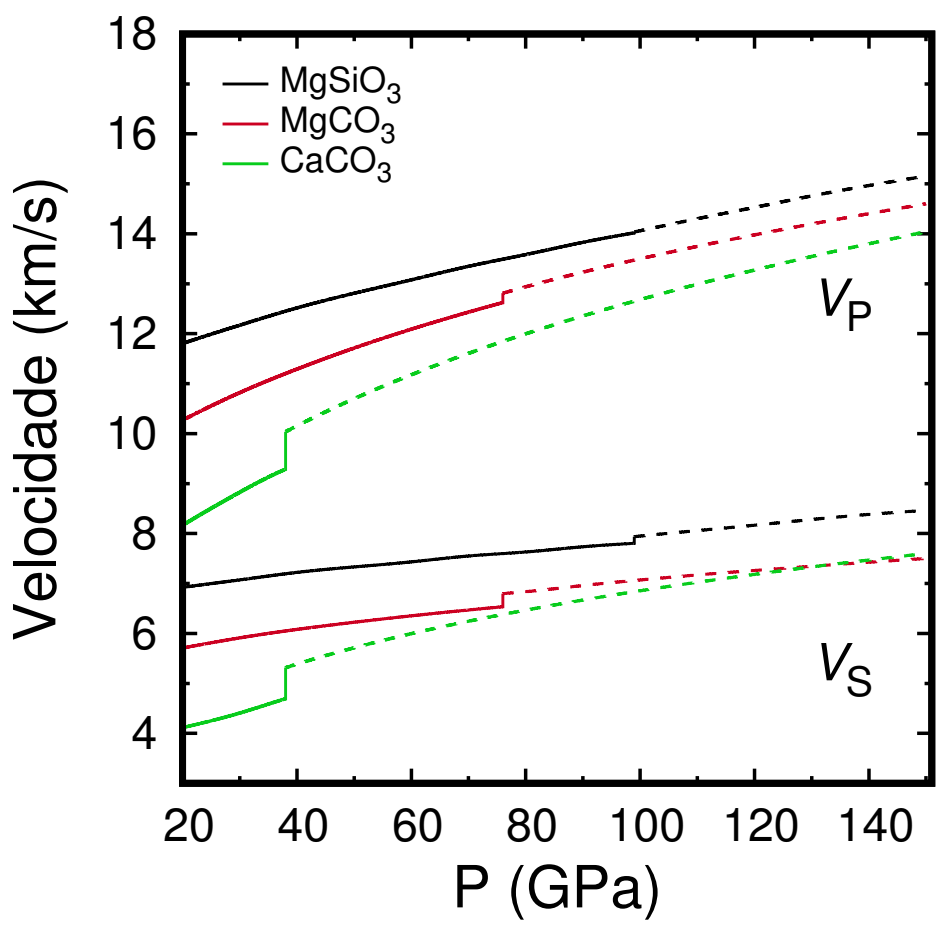

Figura 4.23: Velocidades de propagação das ondas acústicas $P\left(V_{P}\right)$ e $S\left(V_{S}\right)$ em agregados isotrópicos de $\mathrm{CaCO}_{3}$ (linhas verdes), de $\mathrm{MgCO}_{3}$ (linhas vermelhas) e de $\mathrm{MgSiO}_{3}$ (linhas pretas) também estão mostradas. A mudança de linha contínua para tracejada marca a mudança de fase estrutural. No caso do $\mathrm{CaCO}_{3}$ da estrutura Pmcn (aragonita) para a Pmmn (pós-aragonita). No caso do $\mathrm{MgCO}_{3}$ da estrutura $\mathrm{R} \overline{3} \mathrm{c}$ para a $\mathrm{C} 2 / \mathrm{m}$ e no caso do $\mathrm{MgSiO}_{3}$ da estrutura perovskita ( $\mathrm{Pv}$ ) para a pósperovskita (Ppv).

mostradas na figura.

Primeiramente, observa-se que no agregado isotrópico de $\mathrm{CaCO}_{3}$ (linhas verdes), na pressão de transição de fase da estrutura Pmcn (aragonita) para a Pmmn (pós-aragonita), em $P=38 \mathrm{GPa}$, há um grande aumento nas velocidades $V_{P}$ e $V_{S}$ das ondas acústicas. Além disso, as velocidades das ondas acústicas são consideravelmente menores nos agregados de $\mathrm{CaCO}_{3}$ do que nos agregados de $\mathrm{MgCO}_{3}$ e de $\mathrm{MgSiO}_{3}$, consequência dos valores menores dos seus coeficientes elásticos. Estes resultados são particularmente importantes para o intervalo de valores de pressão de 100 a 120 GPa, que corresponde à parte 
inferior do manto inferior. O agregado isotrópico de $\mathrm{CaCO}_{3}$, que seria estável na fase pós-aragonita (Pmmn) neste intervalo de pressões, têm velocidades de propagação $V_{P}$ e $V_{S}$ das ondas acústicas que são muito menores do que as no agregado de $\mathrm{MgSiO}_{3}$, principal constituinte do manto inferior. Portanto, a presença de agregados de $\mathrm{CaCO}_{3}$ poderia também explicar a existência de regiões de baixa velocidade na parte inferior do manto inferior.

\subsection{Cristal de $\mathrm{MgCa}\left(\mathrm{CO}_{3}\right)_{2}$}

Ao se estudar os minerais que podem estar presentes no manto terrestre, percebemos que há uma fase de carbonato adicional que merece atenção. Prestando atenção nas estruturas cristalinas, com células primitivas romboédricas, da magnesita e da calcita, figuras 4.1 e 4.15, respectivamente, nota-se que no $\mathrm{MgCO}_{3}\left(\mathrm{CaCO}_{3}\right)$ existem dois "tipos" de sítios para a localização do átomo de Mg (Ca). Um no centro da célula primitiva e outro nas bordas. Fato este evidenciado também pelas posições de Wyckoff na tabela 4.1. Podemos substituir um dos átomos de $\mathrm{Mg}(\mathrm{Ca})$ por um de $\mathrm{Ca}(\mathrm{Mg})$, na estrutura da magnesita (calcita), obtendo o mineral $\mathrm{MgCa}\left(\mathrm{CO}_{3}\right)_{2}$, conhecido como dolomita. Sendo uma mistura da calcita e da magnesita, também é um cristal importante para a compreensão dos efeitos do carbono no interior da Terra. Já foi mostrado experimentalmente que sob altas pressões a dolomita se decompõe em aragonita + magnesita [135-138], na reação:

$$
\mathrm{MgCa}\left(\mathrm{CO}_{3}\right)_{2} \rightarrow \mathrm{MgCO}_{2}+\mathrm{CaCO}_{2}
$$

Entretanto, dependendo da concentração de cálcio, em regiões mais rasas do planeta, a dolomita coexiste com outros carbonatos, como a magnesita, a calcita ou a aragonita. Tem sido apontado que carbonatos duplos, como a dolomita, podem se transformar em uma estrutura bem mais densa a altas pressões [139], competindo energeticamente com a mistura magnesita + aragonita. Adicionalmente, foi mostrado que este cristal pode ser estável, principalmente em regiões do manto superior [135, 136, 138]. Dessa forma, o estudo de suas propriedades elásticas pode ser importante para uma melhor compreensão da 

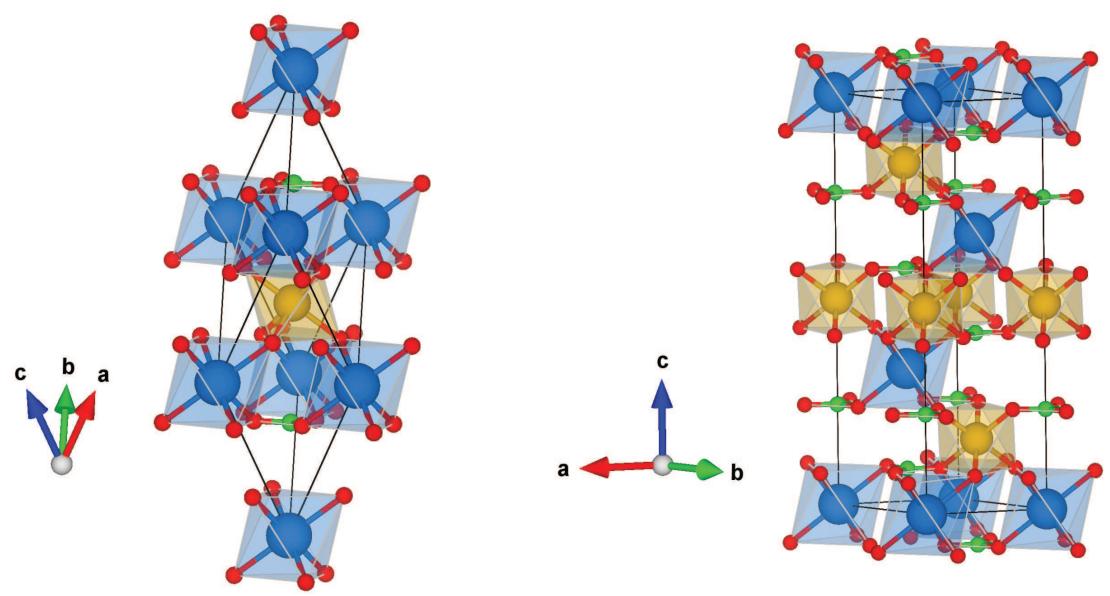

Figura 4.24: Estrutura cristalina do $\mathrm{MgCa}\left(\mathrm{CO}_{3}\right)_{2}$ com grupo espacial $\mathrm{R} \overline{3}$, onde as esferas azuis representam os átomos de cálcio, as amarelas os átomos de magnésio, as esferas verdes os átomos de carbono e as vermelhas os átomos de oxigênio.

influência do carbono no interior do planeta.

A figura 4.24 mostra a estrutura cristalina da dolomita. Percebe-se que o átomo de magnésio ocupa o lugar do átomo de cálcio central na estrutura da calcita. Dessa forma, assim como na magnesita e na calcita, a estrutura cristalina é romboédrica. A presença deste átomo de magnésio no centro da estrutura mantém invariante quase todas as simetrias, exceto a glide translation que a $R \overline{3}$ c possui. Assim a dolomita pertence ao grupo espacial $R \overline{3}$. Nesta estrutura, cada átomo de cálcio, assim como cada átomo de magnésio, possui seis átomos de oxigênio como primeiros vizinhos e cada átomo de carbono possui três átomos de oxigênio, tal qual na magnesita e na calcita. Para obter os parâmetros estruturais, otimizou-se a célula do cristal para diferentes valores de pressão, de $-15 \mathrm{GPa}$ a $150 \mathrm{GPa}$, através da utilização de métodos de dinâmica molecular de célula variável, e os funcionais LDA e GGA. A seguir, utilizou-se a equação de Birch-Murnaghan de segunda ordem para se calcular os parâmetros da equação de estado e, consequentemente, os parâmetros de rede do $\mathrm{MgCa}\left(\mathrm{CO}_{3}\right)_{2}$. Os parâmetros estruturais, obtidos da equação de estado, estão apresentados na tabela 4.14.

Da mesma forma do que para os outros cristais apresentados até o mo- 
Tabela 4.14: Parâmetros estruturais, obtidos da equação de estado, da dolomita $\left(\mathrm{MgCa}\left(\mathrm{CO}_{3}\right)_{2}-\mathrm{R} \overline{3}\right)$. O bulk modulus $\left(K_{0}\right)$ é dado em $\mathrm{GPa}$ e a derivada do bulk modulus $\left(K_{0}^{\prime}\right)$ é adimensional. Resultados experimentais são das referências [127, 128]. Apresentamos os resultados para uma célula hexagonal.

\begin{tabular}{||c||c|c|c|c|c||}
\hline \hline & $\mathrm{a}(\AA)$ & $\mathrm{c}(\AA)$ & $V_{0}\left(\AA^{3}\right)$ & $K_{0}$ & $K_{0}^{\prime}$ \\
\hline \hline GGA & 4,87 & 16,21 & 332,59 & 86,3 & 4,08 \\
LDA & 4,77 & 15,51 & 305,18 & 107,4 & 4,01 \\
Exp. & 4,81 & 16,00 & 320,25 & 101,5 & 3,94 \\
\hline \hline
\end{tabular}

mento, o uso do funcional GGA superestima os valores dos parâmetros de rede, enquanto o LDA os subestima, o oposto ocorrendo para os valores dos bulk moduli. As constantes de rede e os parâmetros da equação de estado estão em bom acordo com os resultados experimentais. Comparando os resultados dos valores dos parâmetros de rede e do bulk modulus do $\mathrm{MgCa}\left(\mathrm{CO}_{3}\right)_{2}$, mostrados na tabela 4.14, com aqueles obtidos para o $\mathrm{MgCO}_{2}$ (magnesita) e o $\mathrm{CaCO}_{2}$ (calcita), apresentados nas tabelas 4.2 e 4.9, respectivamente, vê-se que eles se encontram entre os respectivos valores dos carbonatos de magnésio e de cálcio, consistente com o fato da dolomita ser um carbonato duplo de magnésio e cálcio.

\section{Propriedades eletrônicas}

Com os valores otimizados das constantes de rede, calculou-se a estrutura de faixas de energia do material nas direções de alta simetria da primeira zona de Brillouin da estrutura hexagonal. A figura 4.25 apresenta a estrutura de bandas e as densidades de estados projetadas nos átomos ( $\mathrm{Mg}, \mathrm{Ca}, \mathrm{C}$ e $\mathrm{O}$ ), à pressão nula, para o $\mathrm{MgCa}\left(\mathrm{CO}_{3}\right)_{2}$, obtida utilizando o funcional LDA, em que o zero de energia foi deslocado para o topo da banda de valência. Assim como na magnesita e na calcita, a largura da faixa de energia proibida fundamental é de transição indireta $M \rightarrow \Gamma$, e apresenta valor de $5,4 \mathrm{eV}$ se o funcional LDA é usado.

As características gerais, tanto na forma como na distribuição das bandas, 


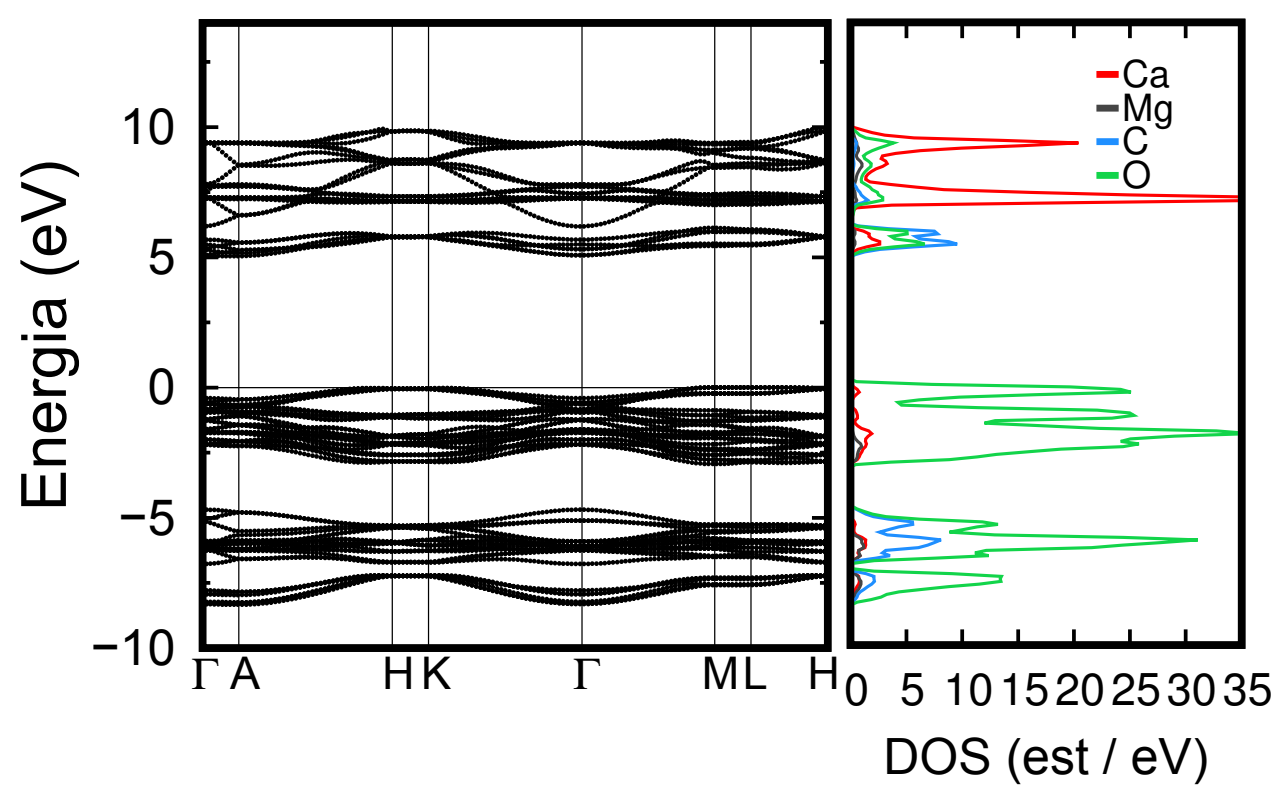

Figura 4.25: Estrutura de bandas de energia e densidades de estados (DOS) da dolomita $\left(\mathrm{MgCa}\left(\mathrm{CO}_{3}\right)_{2}\right.$ - estrutura $\left.\mathrm{R} \overline{3}\right)$ projetadas nos átomos de $\mathrm{Mg}, \mathrm{Ca}, \mathrm{C}$ e $\mathrm{O}$, obtidas com a utilização do funcional LDA.

apresentadas na figura 4.25, para a dolomita, são semelhantes com aquelas das figuras 4.2 e 4.16, para a magnesita e a calcita, respectivamente. A banda de valência do mineral é formada essencialmente pelos estados ligantes $p$ dos átomos de $\mathrm{O}$, que apresenta largura de cerca de $8 \mathrm{eV}$, sendo composta por duas sub-bandas, separadas por aproximadamente 2,0 eV. O fundo da banda de condução é formado, principalmente, pelos estados $s$ e $p$ antiligantes dos átomos de magnésio, cálcio e carbono. Na formação da unidade $\mathrm{MgCa}\left(\mathrm{CO}_{3}\right)_{2}$ do mineral, dentro de um modelo puramente iônico, os átomos de oxigênio apresentam o estado de oxidação -2 e os átomos de magnésio e cálcio adquirem os estados de oxidação +2 e o carbono +4 . Os estados s e $p$ dos íons de $\mathrm{Mg}, \mathrm{Ca}$ e C, eletronicamente desocupados, contribuem para a formação do fundo da banda de condução enquanto que os estados $p$ dos íons de $\mathrm{O}$, eletronicamente ocupados, contribuem para a formação da banda de valência. Estes aspectos nos permitem constatar que a dolomita, a magnesita e a calcita têm propriedades eletrônicas muito parecidas. Entretanto, apesar dessa semelhança, suas pro- 
priedades estruturais são muito diferentes, cada uma apresentando diferentes estruturas com o aumento da pressão.

\section{Propriedades elásticas}

Apesar da dolomita possuir a mesma estrutura da magnesita e da calcita, ela possui uma classe cristalina diferente. A substituição de um dos átomos antes equivalentes, quebra a simetria do sistema, de tal forma que ele agora pertence à classe cristalina $\overline{3}$ e não à $\overline{3} \mathrm{~m}$, como no caso da magnesita e da calcita. Isto faz com que o cristal possua sete coeficientes elásticos independentes, ao invés de seis [67]. Nesta estrutura, o tensor elástico na forma matricial é dado por

$$
\begin{gathered}
C_{i j}=\left(\begin{array}{cccccc}
C_{11} & C_{12} & C_{13} & C_{14} & -C_{15} & 0 \\
C_{12} & C_{11} & C_{13} & -C_{14} & C_{15} & 0 \\
C_{13} & C_{13} & C_{33} & 0 & 0 & 0 \\
C_{14} & -C_{14} & 0 & C_{44} & 0 & 2 C_{15} \\
0 & 0 & 0 & 0 & C_{44} & -2 C_{14} \\
0 & 0 & 0 & 0 & -2 C_{14} & C_{66}^{\dagger}
\end{array}\right) . \\
{ }^{\dagger} C_{66}=\frac{1}{2}\left(C_{11}-C_{12}\right)
\end{gathered}
$$

Apesar desta estrutura cristalina possuir uma componente elástica a mais do que a calcita e a magnesita, é possível calculá-las com as mesmas distorções ${ }^{3}$. Assim, os coeficientes elásticos da dolomita foram obtidos e seus valores estão apresentados na tabela 4.15. Nota-se, novamente, que os valores dos coeficientes elásticos obtidos para a dolomita, assim como aqueles obtidos para os outros minerais estudados neste trabalho, estão superestimados quando comparados com dados experimentais, como esperado quando se usa o funcional LDA. Devemos salientar que os valores teóricos foram obtidos a partir de cálculos estáticos, representando a condição $T=0 \mathrm{~K}$, e os dados experimentais foram obtidos em temperatura ambiente. Como a inclusão de efeitos térmicos tende a deixar os materiais mais "moles", nossos resultados se tornariam mais consistentes com os dados experimentais, quando da introdução de efeitos térmicos.

\footnotetext{
${ }^{3}$ Isto é possível pois componentes do stress que eram nulas passam a ser diferentes de zero.
} 
Tabela 4.15: Coeficientes elásticos da dolomita $\left(\mathrm{MgCa}\left(\mathrm{CO}_{3}\right)_{2}\right)$, estrutura R⿳亠丷厂 . Resultados experimentais são das referências $[140,141]$.

\begin{tabular}{||c||c|c||}
\hline \hline$C_{i j}$ & Teórico & Exp. \\
\hline \hline$C_{11}$ & 228 & 205 \\
$C_{33}$ & 121 & 113 \\
$C_{44}$ & 46 & 40 \\
$C_{12}$ & 82 & 71 \\
$C_{13}$ & 73 & 58 \\
$C_{14}$ & 24 & 20 \\
$C_{15}$ & 14 & 14 \\
\hline \hline
\end{tabular}

$\mathrm{Na}$ tabela 4.16 estão dados os valores dos coeficientes elásticos da magnesita, da calcita e da dolomita, para analisar e comparar os valores destas componentes nestes materiais, objetivando estudar a influência do carbono na propagação de ondas sísmicas no manto inferior

Os coeficientes elásticos da dolomita $\left(\mathrm{MgCa}\left(\mathrm{CO}_{3}\right)_{2}\right)$ apresentam valores intermediários ou semelhantes àqueles da magnesita e da calcita. Isto já era esperado, uma vez que a dolomita é um carbonato duplo de magnésio e cál-

Tabela 4.16: Coeficientes elásticos $C_{i j}$, em GPa, do $\mathrm{MgCO}_{3}$ (magnesita, $\mathrm{R} \overline{3} \mathrm{c}$ ), do $\mathrm{CaCO}_{3}$ (calcita, $\mathrm{R} \overline{3} \mathrm{c}$ ) e do $\mathrm{MgCa}\left(\mathrm{CO}_{3}\right)_{2}$ (dolomita, $\mathrm{R} \overline{3}$ ), todos valores obtidos utilizando-se o funcional LDA.

\begin{tabular}{||c||c|c|c||}
\hline \hline $\mathrm{C}_{i j}$ & $\mathrm{MgCa}\left(\mathrm{CO}_{3}\right)_{2}$ & $\mathrm{CaCO}_{3}$ & $\mathrm{MgCO}_{3}$ \\
\hline \hline $\mathrm{C}_{11}$ & 228 & 177 & 283 \\
$\mathrm{C}_{33}$ & 121 & 95 & 166 \\
$\mathrm{C}_{44}$ & 46 & 39 & 64 \\
$\mathrm{C}_{12}$ & 82 & 78 & 85 \\
$\mathrm{C}_{13}$ & 73 & 72 & 71 \\
$\mathrm{C}_{14}$ & 24 & 25 & 25 \\
$\mathrm{C}_{15}$ & 14 & 0 & 0 \\
\hline \hline
\end{tabular}


cio. Entretanto, como a dolomita apresenta um coeficiente elástico a mais $\left(\mathrm{C}_{15}\right)$ que a calcita e a magnesita, podemos esperar que este fato possa interferir nas propriedades de propagação de ondas acústicas no material. Assim, para averiguarmos esta hipótese, determinamos as velocidades de propagação das ondas acústicas ao longo de diferentes direções do cristal, resolvendo a equação de Christoffel (4.3). A figura 4.26 mostra estes valores na dolomita, juntamente com os obtidos na magnesita, na calcita e no $\mathrm{MgSiO}_{3}$ perovskita. As velocidades de propagação das ondas acústicas na dolomita estão entre os valores das velocidades na magnesita e na calcita. O coeficiente elástico adicional $\left(C_{15}\right)$ não tem efeito perceptível sobre a velocidade de propagação das ondas $\mathrm{P}$, sendo que a variação desta velocidade é a mesma nos três cristais.

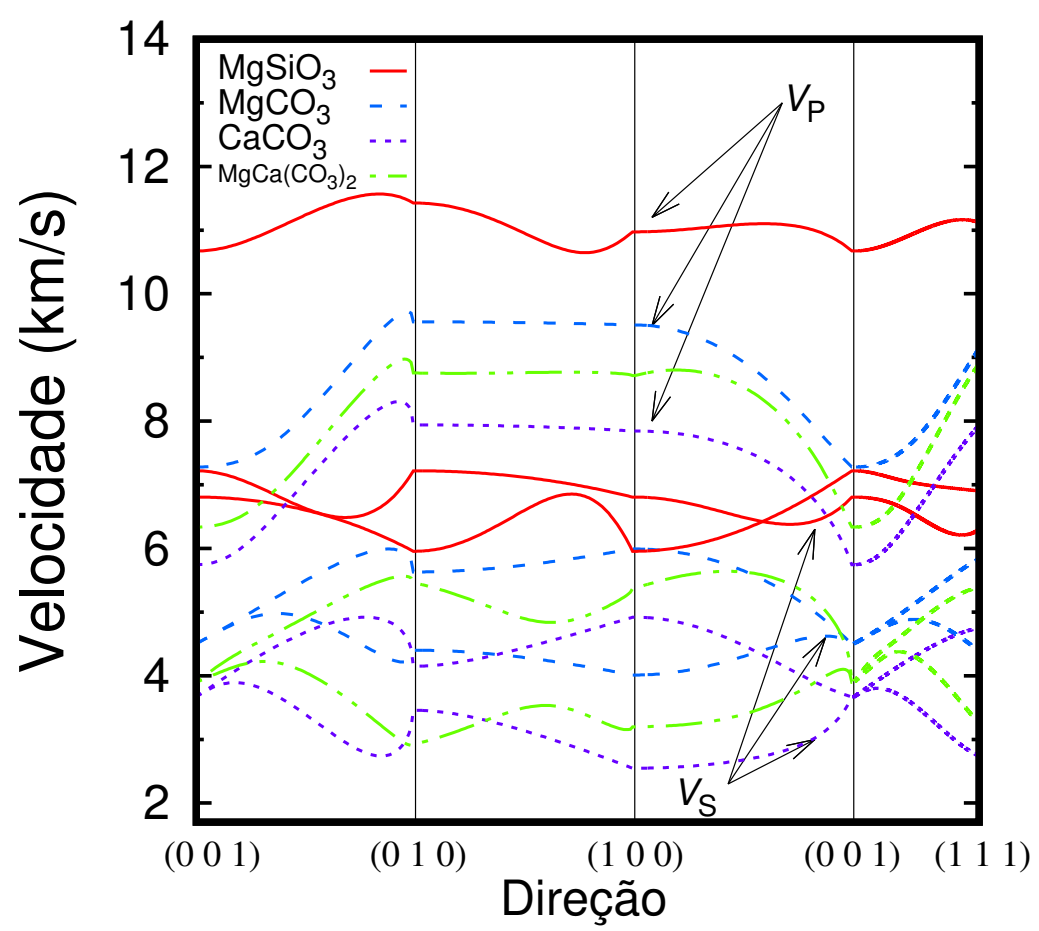

Figura 4.26: Velocidades de propagação de ondas acústicas $P\left(V_{P}\right)$ e $S\left(V_{S}\right)$ na dolomita $\left(\mathrm{MgCaCO}_{3}\right)_{2}$, estrutura $\left.\mathrm{R} \overline{3}\right)$, na calcita $\left(\mathrm{CaCO}_{3}\right.$ estrutura $\left.\mathrm{R} \overline{3} \mathrm{c}\right)$, na magnesita $\left(\mathrm{MgCO}_{3}\right.$, estrutura $\mathrm{R} \overline{3} \mathrm{c}$ ) e no $\mathrm{MgSiO}_{3}$ (perovskita), ao longo de diferentes direções dos cristais. 
Entretanto, percebe-se que as velocidades das ondas $S$ apresentam um perfil diferente para cada um dos cristais. Isso mostra que a anisotropia das ondas $P$ não seria detectada em medidas de tempos de viagem de ondas sísmicas, caso se tenha uma mistura de magnesita + calcita + dolomita na região observada. Para este tipo de análise, é preferível o estudo das ondas $\mathrm{S}$, que além de apresentarem uma grande anisotropia, ainda possuem uma variação diferente, em função da direção, nos três cristais.

Para estudar as propriedades elásticas de agregados isotrópicos do carbonato duplo de cálcio e magnésio, utilizamos as médias de Voigt-Reuss-Hill, já utilizadas para descrever outros agregados. Obtivemos, então, os módulos de compressibilidade e de cisalhamento destes materiais, com os quais calculamos as velocidades de propagação das ondas $\mathrm{P}$ e das ondas $\mathrm{S}$ destes agregados, permitindo sumarizar os resultados para as velocidades das ondas acústicas nos três carbonatos estudados nesta seção, comparando-as com o $\mathrm{MgSiO}_{3}$, o principal constituinte do manto inferior. A figura 4.27 mostra a velocidade de propagação das ondas acústicas $\mathrm{P}$ e $\mathrm{S}$ em agregados isotrópicos de dolomita, assim como de $\mathrm{CaCO}_{3}$, de $\mathrm{MgCO}_{3}$ e de $\mathrm{MgSiO}_{3}$.

A baixas pressões, os valores das velocidades das ondas $\mathrm{P}$ e $\mathrm{S}$ nos agregados de $\mathrm{MgCa}\left(\mathrm{CO}_{3}\right)_{2}$ estão entre os valores daquelas nos agregados de $\mathrm{MgCO}_{3}$ e de $\mathrm{CaCO}_{3}$, conforme esperado. Entretanto, com o aumento da pressão, o $\mathrm{CaCO}_{3}$, sofre uma transição de fase e, à $P=38$ GPa passa para a fase pósaragonita, estrutura na qual as velocidades acústicas têm um aumento drástico. Este aumento já é suficiente para que as velocidades das ondas $\mathrm{S}$ passem a ser maiores no $\mathrm{CaCO}_{3}$ do que na dolomita, mas não para as ondas P. Entretanto, o $\mathrm{CaCO}_{3}$ na fase pós-aragonita possui uma taxa maior de variação da velocidade $V_{\mathrm{P}}$ com a pressão, de modo que para valores de pressão em torno de $80 \mathrm{GPa}$ as velocidades das ondas $P$ também são maiores que na dolomita. De qualquer maneira, todos os carbonatos apresentam velocidades significativamente menores que o $\mathrm{MgSiO}_{3}$ em ambas fases. Portanto, se a formação destes carbonatos for energeticamente favorável, a presença de carbono no manto inferior pode de fato reduzir o valor das velocidades de propagação tanto das ondas $P$ como das ondas $\mathrm{S}$. 


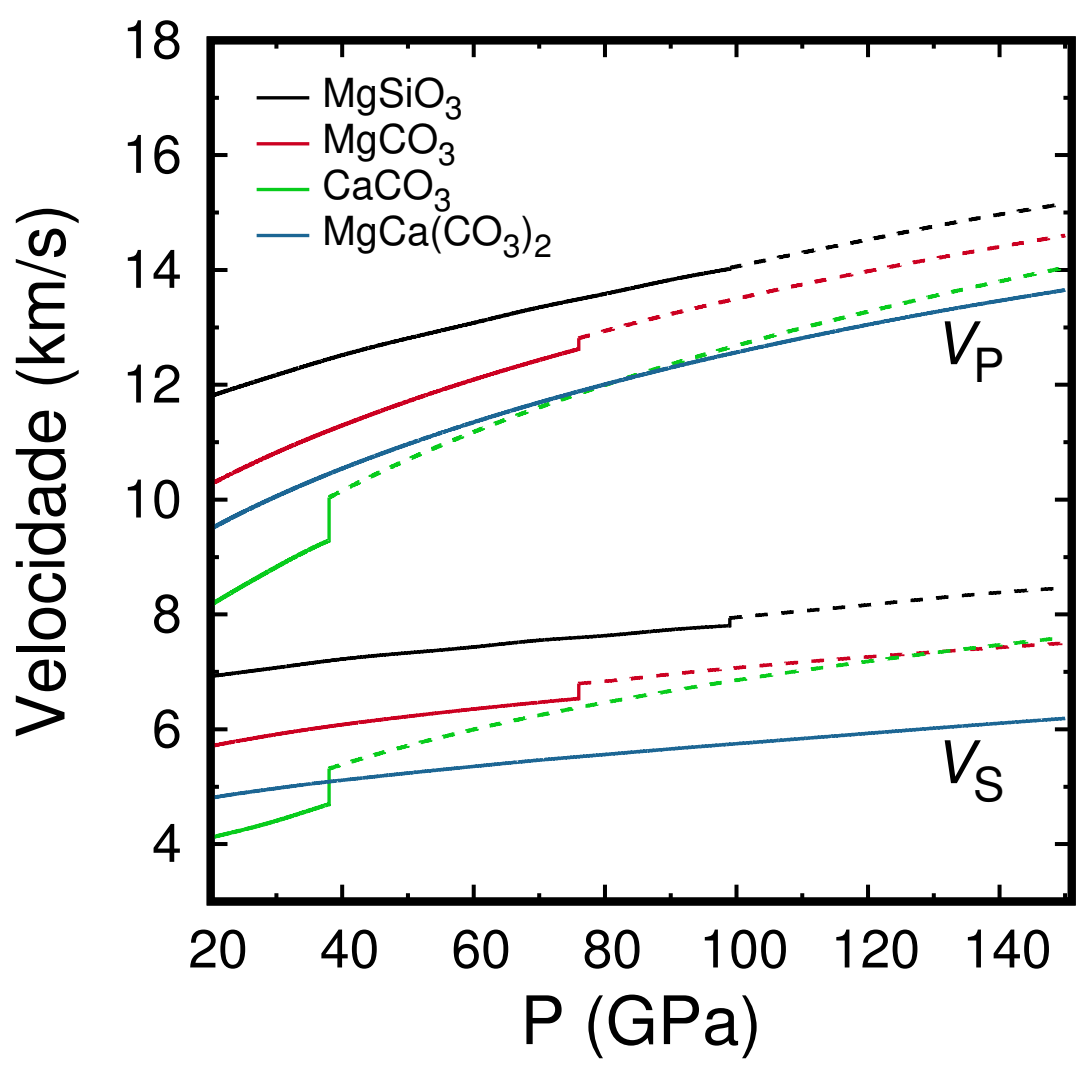

Figura 4.27: Velocidades de propagação das ondas acústicas $P\left(V_{P}\right)$ e $S\left(V_{S}\right)$ em agregados isotrópicos de dolomita $\left(\mathrm{MgCa}\left(\mathrm{CO}_{3}\right)_{2}\right.$ - linhas azuis), de $\mathrm{CaCO}_{3}$ (linhas verdes), de $\mathrm{MgCO}_{3}$ (linhas vermelhas) e de $\mathrm{MgSiO}_{3}$ (linhas pretas). A mudança de linha contínua para tracejada marca a mudança de fase estrutural do mineral. No caso do $\mathrm{CaCO}_{3}$ da estrutura Pmcn (aragonita) para a Pmmn (pós-aragonita). No caso do $\mathrm{MgCO}_{3}$ da estrutura $\mathrm{R} \overline{3} \mathrm{c}$ para a $\mathrm{C} 2 / \mathrm{m}$ e no caso do $\mathrm{MgSiO}_{3}$ da estrutura perovskita $(\mathrm{Pv})$ para a pós-perovskita (Ppv).

\section{Estabilidade da dolomita}

A dolomita é um carbonato duplo, ou seja, um cristal intermediário entre a calcita e a magnesita. Dessa forma, é interessante estudar sua estabilidade energética, com relação à estabilidade dos outros dois minerais. A figura 4.28 mostra a entalpia relativa, em função da pressão, obtida com o funcional LDA, da dolomita e de misturas de $\mathrm{MgCO}_{3}+\mathrm{CaCO}_{3}$. 

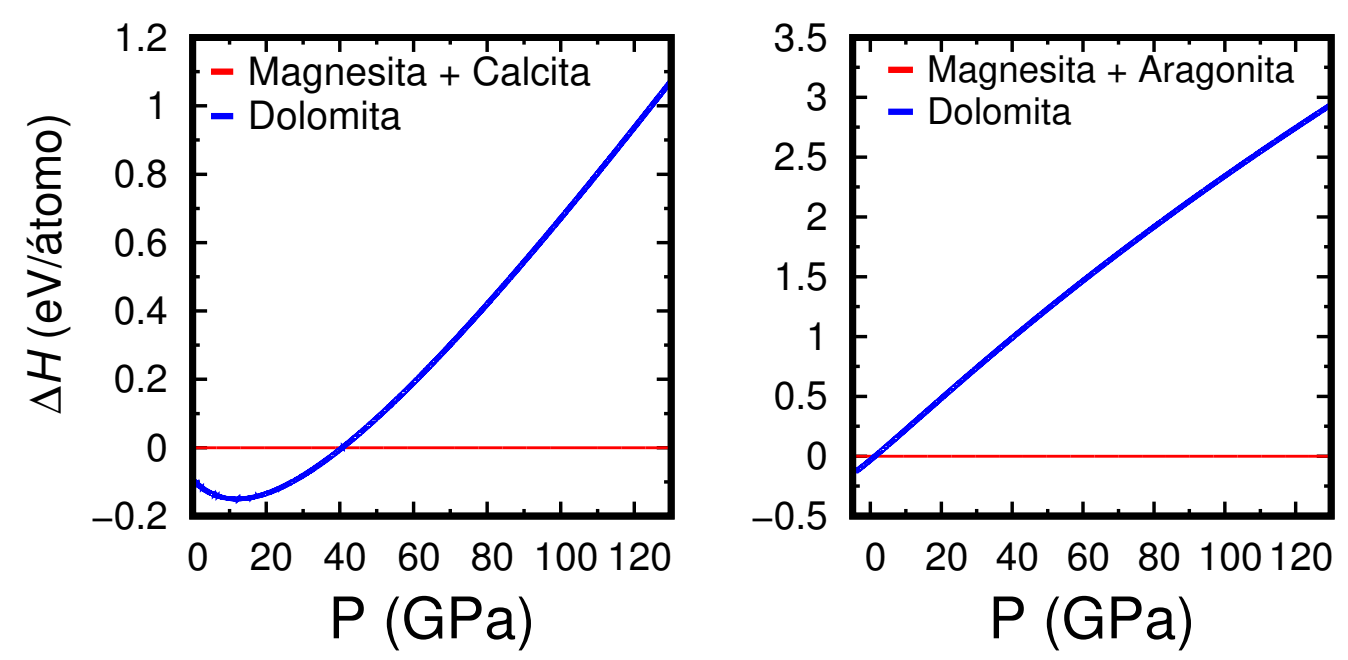

Figura 4.28: Entalpia relativa $(\Delta H)$, em função da pressão, da dolomita em relação à da mistura magnesita + calcita (esquerda); da dolomita em relação à mistura magnesita + aragonita (direita).

Nossos resultados mostram que a dolomita é energicamente mais estável a baixas pressões, quando comparada com as misturas. Como mostrado anteriormente, os resultados que obtivemos, utilizando o funcional LDA, que a transição estrutural do $\mathrm{CaCO}_{3}$, da fase calcita para a fase aragonita, se dá a uma pressão mais baixa que os valores experimentais [133]. Assim, podemos concluir que de fato a dolomita é mais estável a pressão ambiente. Entretanto, sob altas pressões a mistura aragonita + magnesita passa a ser mais estável, de tal forma que sob altas pressões deve haver dissociação do $\mathrm{MgCa}\left(\mathrm{CO}_{3}\right)_{2}$ em $\mathrm{MgCO}_{3}+\mathrm{CaCO}_{3}$. Estes são resultados para as estruturas do $\mathrm{MgCO}_{3}$ a pressão nula. Como já demonstrado, sob altas pressões há uma transição estrutural. Entretanto, como estas fases são mais estáveis que a estrutura trigonal, os resultados aqui apresentados continuam válidos, pois a diferença de entalpia seria ainda maior. Dessa forma, podemos dizer que o carbonato duplo de cálcio e magnésio deve ser estável na estrutura $R \overline{3}$ para valores de pressão de até cerca de $20 \mathrm{GPa}$. Entretanto, nas condições de valores de pressão do interior da Terra, é pouco provável a presença de dolomita nessa estrutura. Como já dito no início desta seção, há indícios de que a dolomita apresente uma transi- 
ção de fase para uma estrutura cristalina monoclínica mais densa. Entretanto, os parâmetros estruturais não foram identificados através de resultados nem experimentais e nem teóricos. A presença de ferro, como por exemplo na forma do mineral siderita $\left(\mathrm{FeCO}_{3}\right)$, pode alterar a estabilidade de carbonatos [142, 143], pois já foram constatadas estruturas triclínicas que podem ser estáveis em altas pressões, entretanto estas estruturas foram identificadas serem estáveis com a presença de ferro na dolomita [144]. De qualquer forma, pode-se inferir que em pressões encontradas no manto inferior (> $100 \mathrm{GPa}$ ) a diferença de entalpia entre uma hipotética nova estrutura do $\mathrm{MgCa}\left(\mathrm{CO}_{3}\right)_{2}$ deve ser pelo menos 2,4 eV menor que na dolomita, de tal forma que este cristal possa ser estável nessas regiões do planeta.

\subsection{Impurezas de carbono no $\mathrm{MgSiO}_{3}$}

Nas rochas que compõem o manto terrestre, o carbono está imerso junto com outros materiais que compõem o interior da Terra. Por isso, é importante saber se carbonatos serão de fato formados, ou se o carbono será incorporado como impureza nos materiais constituintes do manto inferior, ou ainda participando na formação de ligas. Utilizando o $\mathrm{MgSiO}_{3} \mathrm{como}$ material hospedeiro, podemos imaginar a formação de sistemas do tipo $\mathrm{MgSiO}_{3}: \mathrm{C}_{\mathrm{Si}}$ ou ligas do tipo $\mathrm{MgSi}_{1-x} \mathrm{C}_{x} \mathrm{O}_{3}$. Para estudar estes tipos de sistemas iniciamos substituindo na célula primitiva do $\mathrm{MgSiO}_{3}$ um átomo de silício por um átomo de carbono, como mostra a figura 4.29.

Esta célula primitiva, ideal, simula uma liga cristalina ordenada representada pela fórmula $\mathrm{MgSi}_{1-x} \mathrm{C}_{x} \mathrm{O}_{3}$, com $x=0,25$, significando que um quarto dos radicais silicato, no $\mathrm{MgSiO}_{3}$, foram substituídos por radicais carbonato, levando a uma liga com $25 \%$ de concentração de carbono. Para obter-se os parâmetros estruturais desta liga, otimizou-se a célula primitiva para diferentes valores de pressão, de 0 a $150 \mathrm{GPa}$, através da utilização de métodos de dinâmica molecular de célula variável, e o funcional LDA. Iniciando-se com a célula primitiva perovskita do $\mathrm{MgSiO}_{3}$, efetuou-se a substituição de um átomo de Si por um de C, nesta célula. Levando-se em conta o valor da razão entre os raios atômicos 

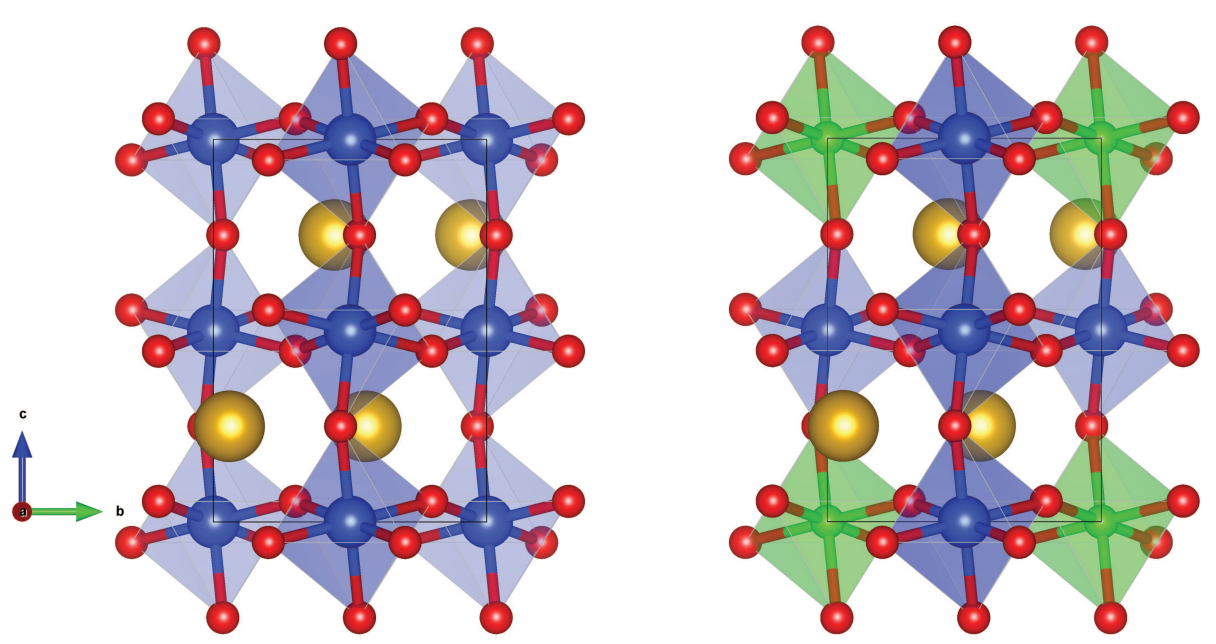

Figura 4.29: Representação da célula primitiva do $\mathrm{MgSiO}_{3}$ (esquerda), onde as esferas azuis representam os átomos de silício, as amarelas os de magnésio e as vermelhas os de oxigênio. Representação da substituição de um átomo de silício por um de carbono na célula primitiva do $\mathrm{MgSiO}_{3}$ (direita), onde os octaedros verdes representam as posições dos átomos de carbono.

do Si e do C, que varia de 1,4 (raios iônicos valência IV) até 1,8 (raios covalentes), espera-se que esta substituição leve a uma redução no volume da célula primitiva. Entretanto, a substituição provoca uma grande distorção na célula primitiva, alterando-a drasticamente, pois são geradas tensões de cisalhamento que a distorcem, fazendo com que ela passe de uma rede ortorrômbica para uma triclínica, com expansão do volume da célula primitiva. A seguir, utilizou-se a equação de Birch-Murnaghan de segunda ordem para se calcular os parâmetros da equação de estado e, consequentemente, os parâmetros estruturais da célula triclínica. A tabela 4.17 apresenta os parâmetros da equação de estado do $\mathrm{MgSi}_{0,75} \mathrm{C}_{0,25} \mathrm{O}_{3}$, juntamente com os do $\mathrm{MgSiO}_{3}$ perovskita.

Pode-se observar que os parâmetros estruturais da equação de estado do $\mathrm{MgSiO}_{3}$ perovskita são drasticamente alterados com a substituição de um dos átomos de Si para a formação da liga $\mathrm{MgSi}_{0,75} \mathrm{C}_{0,25} \mathrm{O}_{3}$. É interessante notar que o bulk modulus apresenta uma enorme redução e o volume uma grande expansão, reduzindo a compressibilidade da liga e fazendo com que fique mais "mole". É interessante notar que o valor de $K_{0}^{\prime}$ é muito maior do que 4, o que é 
Tabela 4.17: Parâmetros da equação de estado da liga $\mathrm{MgSi}_{0,75} \mathrm{C}_{0,25} \mathrm{O}_{3}$ e do $\mathrm{MgSiO}_{3}$ perovskita, obtidos com o funcional LDA. O bulk modulus $\left(K_{0}\right)$ é dado em GPa e a derivada do bulk modulus ( $\left.K_{0}^{\prime}\right)$ é adimensional.

\begin{tabular}{||c||c|c|c||}
\hline \hline Mineral & $\mathrm{V}_{0}\left(\AA^{3}\right)$ & $K_{0}$ & $K_{0}^{\prime}$ \\
\hline \hline $\mathrm{MgSiO}_{3}$ & 159,08 & 261,0 & 3,88 \\
$\mathrm{MgSi}_{0,75} \mathrm{C}_{0,25} \mathrm{O}_{3}$ & 175,37 & 49,7 & 11,24 \\
\hline \hline
\end{tabular}

um indicativo de que poderia ser necessário considerar, na equação de estado de Birch-Murnaghan, termos de ordens superiores na extrapolação dos dados para pressões mais altas. Comparamos então a estabilidade desta liga com relação a uma mistura de $\mathrm{MgSiO}_{3}$ e $\mathrm{MgCO}_{3}$, ambos na estrutura $\mathrm{R} \overline{3} \mathrm{c}$. A figura 4.30 mostra as entalpias, obtidas com o funcional LDA, da liga $\mathrm{MgSi}_{0,75} \mathrm{C}_{0,25} \mathrm{O}_{3}$ e da mistura de $\mathrm{MgCO}_{3}$ com $\mathrm{MgSiO}_{3}$.

Nossos resultados mostram que a liga $\mathrm{MgSi}_{0,75} \mathrm{C}_{0,25} \mathrm{O}_{3}$ é energicamente menos estável quando comparada com a mistura. De outro modo, podemos con-

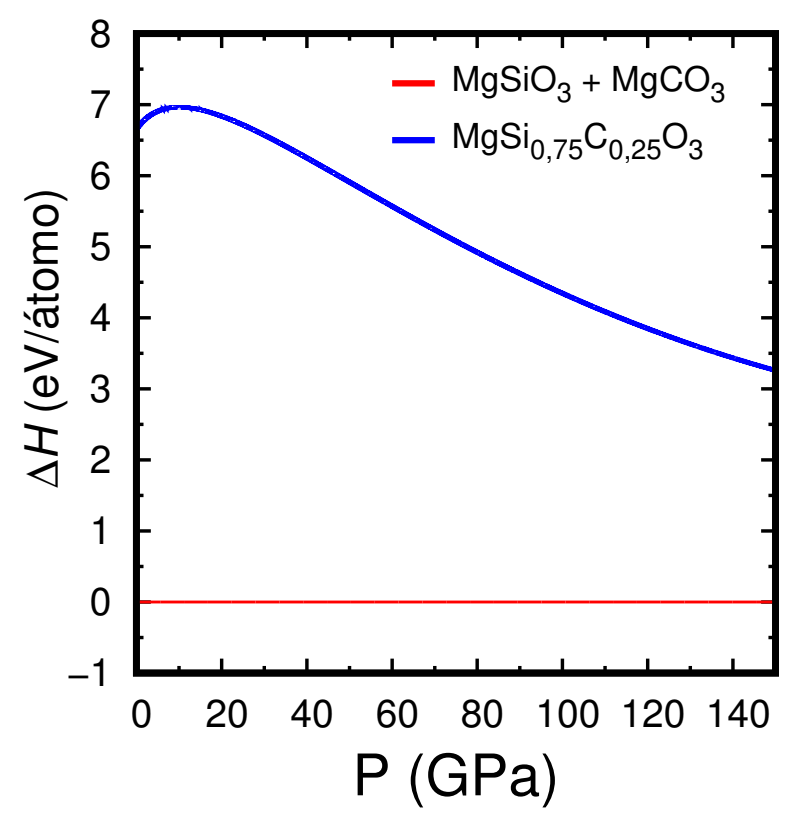

Figura 4.30: Entalpia relativa $(\Delta H)$, em função da pressão, da liga $\mathrm{MgSi}_{0,75} \mathrm{C}_{0,25} \mathrm{O}_{3}$ em relação à da mistura $\left(\mathrm{MgCO}_{3}+3 \mathrm{MgSiO}_{3}\right) / 4$. 
cluir que é energicamente mais estável os dois minerais, $\mathrm{MgSiO}_{3}$ (perovskita) e $\mathrm{MgCO}_{3}$ (magnesita), coexistirem separadamente do que formando a liga. Um fato interessante a ser observado é que a diferença de entalpia diminui com o aumento da pressão. Entretanto, por extrapolação, verifica-se que a pressão necessária para a liga ser mais estável é muito maior do que aquelas encontradas no interior da Terra, se essa tendência permanecer em pressões maiores que as consideradas ${ }^{4}$.

Apesar de se considerar que a maioria do carbono terrestre está concentrada no manto, sua concentração ainda é baixa, comparando-se com outros elementos presentes no interior da Terra. Estima-se que a concentração de carbono no manto seja da ordem de $3 \%$. Sabe-se que cerca de $80 \%$ do manto inferior é formado por $\mathrm{MgSiO}_{3}$, dessa forma, é importante considerar a influência de baixas concentrações de carbono em regiões ricas em magnésio, silício e oxigênio. Dessa forma, os átomos de carbono podem ser incorporados como impurezas no cristal de $\mathrm{MgSiO}_{3}$, ou formar uma liga ordenada com concentrações muito baixas de carbono.

O esquema mais adequado para o estudo deste tipo de sistema é o de supercélula. A correta utilização deste esquema requer que a supercélula gerada represente corretamente o material, para ser usada como referência no estudo de impurezas e ligas. Construiu-se primeiramente uma supercélula do cristal de $\mathrm{MgSiO}_{3}$ ortorrômbico com parâmetros de rede $2 a, 2 b$ e $2 c$, onde $a$, b e c são os parâmetros de rede da célula primitiva. Dessa forma, esta célula possui 160 átomos, sendo 32 de magnésio, 32 de silício e 98 de oxigênio. Para obter os parâmetros estruturais desta supercélula, otimizou-se a célula para diferentes valores de pressão, através da utilização de métodos de dinâmica molecular de célula variável, e o funcional LDA. Calculou-se novamente os parâmetros da equação de estado, mostrados na tabela 4.18, juntamente com os valores da célula primitiva. A tabela mostra que os parâmetros da equação de estado são os mesmos tanto para a supercélula quanto para a célula primitiva ${ }^{5}$.

\footnotetext{
${ }^{4}$ Como o valor de $K_{0}^{\prime}$ obtido é muito alto, é preciso cuidado para se fazer esta extrapolação. Como não estamos interessados em pressões maiores que $150 \mathrm{GPa}$, este fato não altera nossas conclusões.

${ }^{5} A$ supercélula é 8 vezes maior que a célula primitiva, portanto espera-se que seu volume $V_{0}$ seja 8 vezes maior: $8 V_{0}=1272,64 \AA^{3}$.
} 
Tabela 4.18: Parâmetros estruturais, obtidos da equação de estado, da supercélula e da célula primitiva do $\mathrm{MgSiO}_{3}$ perovskita. O bulk modulus $\left(K_{0}\right)$ é dado em GPa e a derivada do bulk modulus $\left(K_{0}^{\prime}\right)$ é adimensional.

\begin{tabular}{||l||c|c|c||}
\hline \hline & $V_{0}\left(\AA^{3}\right)$ & $K_{0}$ & $K_{0}^{\prime}$ \\
\hline \hline $\mathrm{MgSiO}_{3}$ primitiva & 159,08 & 261,0 & 3,88 \\
$\mathrm{MgSiO}_{3}$ supercélula & 1272,48 & 261,6 & 3,87 \\
\hline \hline
\end{tabular}

Com os valores otimizados das constantes de rede, calculou-se a estrutura de faixas de energia, mostrada na figura 4.31, do material descrito pela supercélula, nas direções de alta simetria da primeira zona de Brillouin da estrutura ortorrômbica. A largura da faixa de energia proibida fundamental não se altera, apresentando o valor de 6,34 eV. Os estados s e $p$ dos íons de Mg e Si, ele-

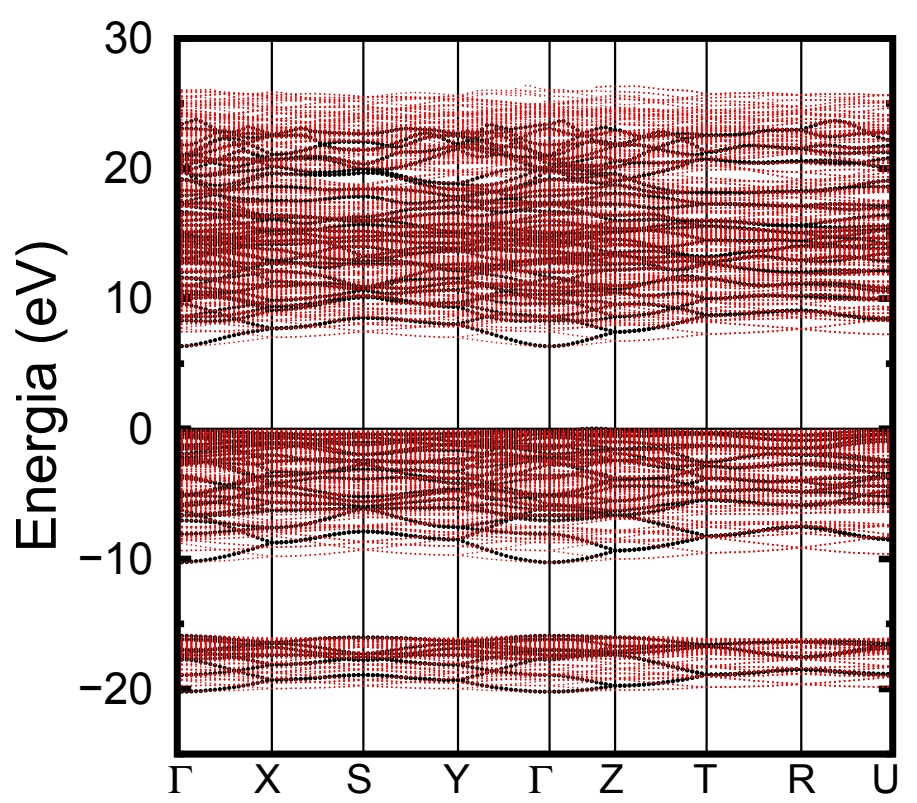

Figura 4.31: Estrutura de bandas, à pressão nula, do $\mathrm{MgSiO}_{3}$ na estrutura perovskita, obtida utilizando-se a célula primitiva (linhas pretas) e uma supercélula de 160 átomos (linhas vermelhas). 
tronicamente desocupados, contribuem para a formação do fundo da banda de condução enquanto que os estados $p$ dos íons de $O$, eletronicamente ocupados, contribuem para a formação da banda de valência, que apresenta largura de cerca de $10 \mathrm{eV}$.

A propriedades eletrônicas e estruturais estão adequadamente descritas pela supercélula construída para simular $0 \mathrm{MgSiO}_{3}$ perovskita. Portanto, podemos concluir que esta supercélula representa corretamente o material e pode ser utilizada para o estudo de defeitos e impurezas ou ligas. A substituição de um átomo de silício, da supercélula, por um átomo de carbono, pode ser utilizada para estudar o carbono como impureza no $\mathrm{MgSiO}_{3}\left(\mathrm{MgSiO}_{3}: \mathrm{C}_{\mathrm{Si}}\right)$ ou uma liga com concentração de 3,125\% de carbono, pois existem 32 átomos de Si na supercélula ( $\left.\mathrm{MgSi}_{0,97} \mathrm{C}_{0,03} \mathrm{O}_{3}\right)$. Iniciamos a simulação computacional do sistema substituindo um átomo de silício da posição $(3 / 4 ; 1 / 2 ; 1 / 2)$ por um átomo de carbono. A figura 4.32 mostra a configuração da supercélula hospedeira e a configuração inicial (ideal) da supercélula com a impureza de carbono.
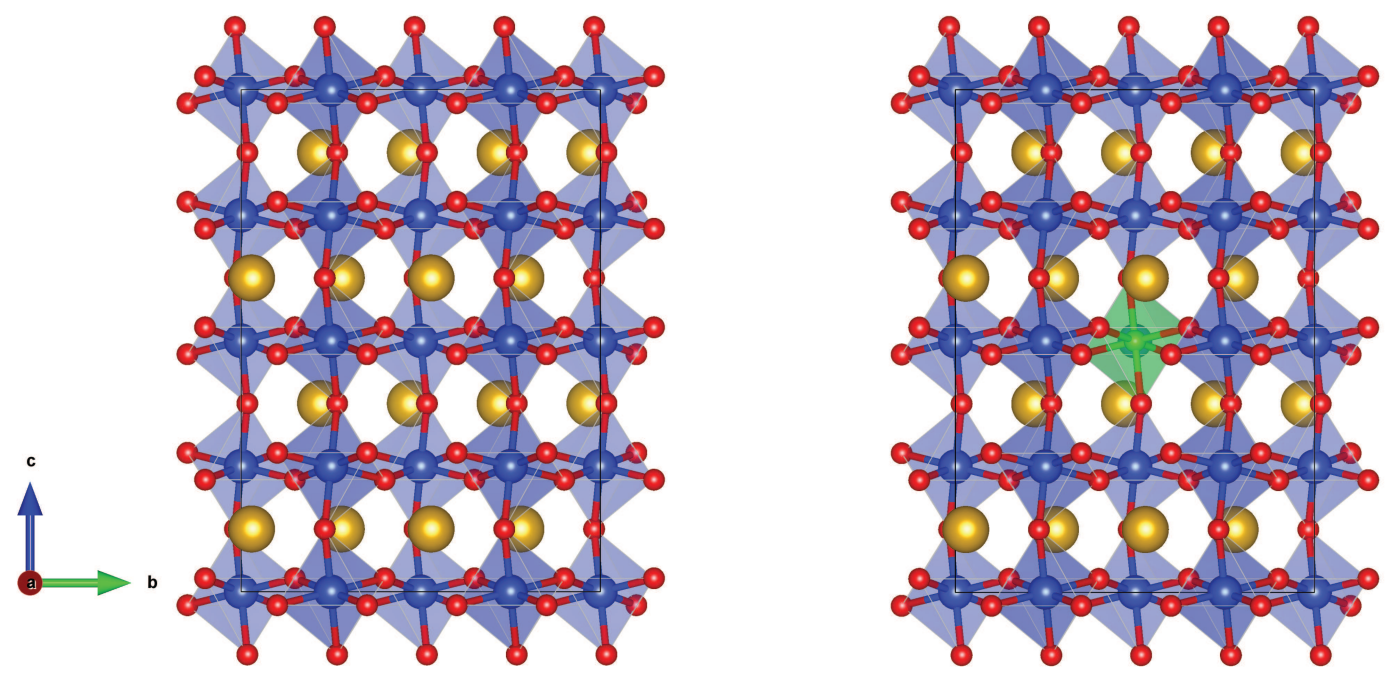

Figura 4.32: Representação da supercélula hospedeira do $\mathrm{MgSiO}_{3}$ (esquerda), onde as esferas azuis representam os átomos de silício, as amarelas os de magnésio e as vermelhas os de oxigênio. Representação da supercélula com a substituição de um átomo de silício por um de carbono (direita), onde a esfera verde representa a posição do átomo de carbono. 
Tabela 4.19: Parâmetros estruturais, obtidos através da equação de estado, para a supercélula perfeita do $\mathrm{MgSiO}_{3}$ e para o sistema $\mathrm{MgSiO}_{3}: \mathrm{C}_{\mathrm{Si}}$, ambos na estrutura perovskita. O bulk modulus ( $\left.K_{0}\right)$ é dado em GPa e a derivada do bulk modulus $\left(K_{0}^{\prime}\right)$ é adimensional.

\begin{tabular}{||c||c|c|c||}
\hline \hline & $V_{0}\left(\AA^{3}\right)$ & $K_{0}$ & $K_{0}^{\prime}$ \\
\hline \hline $\mathrm{MgSiO}_{3}$ & 1272,48 & 262 & 3,88 \\
$\mathrm{MgSiO}_{3}: \mathrm{C}_{\mathrm{Si}}$ & 1286,54 & 207 & 4,96 \\
\hline \hline
\end{tabular}

Para obter os parâmetros estruturais do sistema $\mathrm{MgSiO}_{3}: \mathrm{C}_{\mathrm{Si}}$, otimizou-se a supercélula para diferentes valores de pressão, de 0 a $150 \mathrm{GPa}$, através da utilização de métodos de dinâmica molecular de célula variável, e o funcional LDA. Para cada uma das pressões, a supercélula foi relaxada a fim de se minimizar as forças em cada átomo. Calculou-se então, estaticamente, os parâmetros da equação de estado para a supercélula com a impureza, mostrados na tabela 4.19.

Percebe-se que há uma leve expansão no volume da célula do sistema defeituoso. A introdução da impureza substitucional de $C$ no sítio do Si perturba o sistema localmente, acarretando em uma pequena relaxação, para fora, dos átomos de oxigênio vizinhos da impureza, levando a um pequeno aumento do volume da célula. Se assumirmos que este sistema simula uma liga ordenada $\mathrm{MgSi}_{0,97} \mathrm{C}_{0,03} \mathrm{O}_{3}$, podemos concluir que mesmo com concentrações de $\mathrm{C}$ tão baixas quanto $3,125 \%$, a perturbação causada já é suficiente para aumentar o volume da célula. Entretanto, a perturbação não é grande o suficiente para modificar o tipo de rede cristalina, que permanece ortorrômbica, contrariamente ao que observamos para o sistema com $25 \%$ de concentração de C. Observa-se, também, que o valor do bulk modulus do sistema $\mathrm{MgSiO}_{3}: \mathrm{C}_{\mathrm{Si}}$ é um pouco menor do que o sistema perfeito. Isto implica em velocidades sísmicas menores no sistema em que há a presença de carbono. Já foi demonstrado neste trabalho que a velocidade de ondas em agregados isotrópicos na magnesita é menor que na $\mathrm{MgSiO}_{3}$. Como o bulk modulus é também menor na liga, podemos concluir que as velocidades sísmicas serão também menores no material com a impureza, 
apesar do carbono ser mais leve e levar a uma menor densidade. Podemos inferir que a presença de carbono, mesmo em pequenas quantidades, pode indicar velocidades sísmicas menores e pode ajudar a explicar as zonas de baixa velocidade.

Para estudar a estabilidade energética deste sistema com relação à uma mistura de $\mathrm{MgSiO}_{3}$ e $\mathrm{MgCO}_{3}$, calculamos a entalpia em função da pressão, da impureza de $\mathrm{C}$ em $\mathrm{MgSiO}_{3}$ perovskita. Para obter estes resultados consideramos a seguinte transformação:

$$
32 \mathrm{MgSiO}_{3}: \mathrm{C}_{\mathrm{Si}}=31 \mathrm{MgSiO}_{3}+\mathrm{MgCO}_{3}
$$

Com esta relação, o estudo da entalpia do sistema pode fornecer a informação sobre se é energeticamente favorável que átomos de carbono, em baixas concentrações, formem o mineral $\mathrm{MgCO}_{3}$ ou se é mais favorável o carbono ser incorporado como impureza no $\mathrm{MgSiO}_{3}$. A figura 4.33 mostra a entalpia, em função da pressão, da liga $\mathrm{MgSi}_{0,97} \mathrm{C}_{0,03} \mathrm{O}_{3}$ (ou do sistema $\mathrm{MgSiO}_{3}: \mathrm{C}_{\mathrm{Si}}$ ) e da mistura dos minerais $\mathrm{MgCO}_{3}$ e $\mathrm{MgSiO}_{3}$.

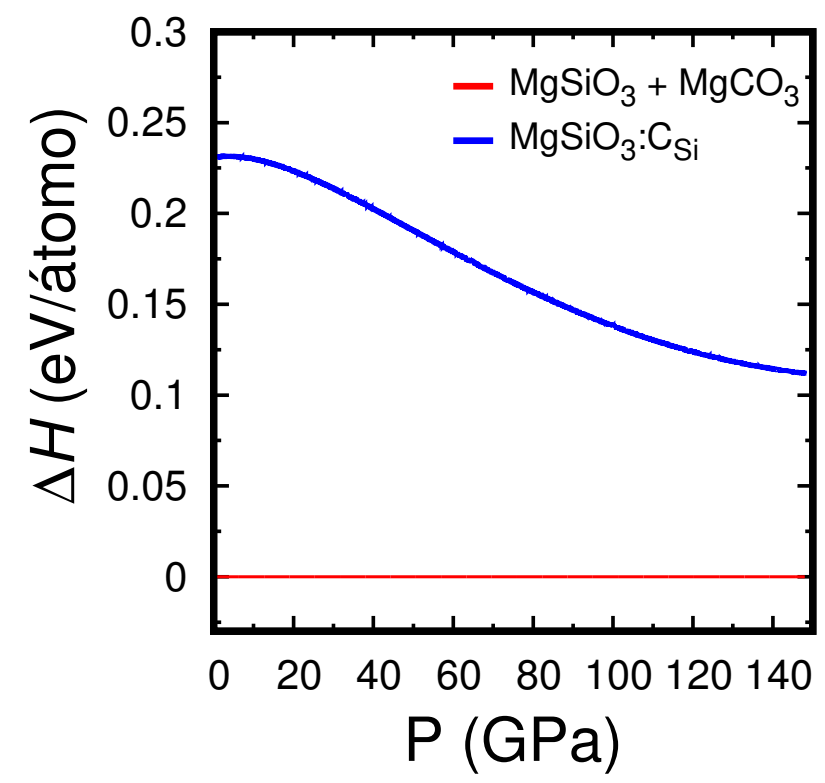

Figura 4.33: Entalpia relativa $(\Delta H)$, em função da pressão, do sistema $\mathrm{MgSiO}_{3}: \mathrm{C}_{\mathrm{Si}}$ (ou da liga $\mathrm{MgSi}_{0,97} \mathrm{C}_{0,03} \mathrm{O}_{3}$ ) em relação à da mistura $\mathrm{MgCO}_{3}+\mathrm{MgSiO}_{3}$. 
A diferença nos valores da entalpia entre a mistura $\mathrm{MgCO}_{3}+\mathrm{MgSiO}_{3}$ e $\mathrm{O}$ sistema $\mathrm{MgSiO}_{3}: \mathrm{C}_{\mathrm{Si}}$ é muito pequena, sendo que a mistura $\mathrm{MgSiO}_{3}+\mathrm{MgCO}_{3}$ é ligeiramente mais estável do que o sistema em que o átomo de carbono está incorporado na matriz de $\mathrm{MgSiO}_{3}$, com concentração de 3,125\%. Percebe-se nitidamente que esta diferença diminui com o aumento da pressão, mas em altas pressões ainda é energeticamente favorável a formação de magnesita + $\mathrm{MgSiO}_{3}$ perovskita. Entretanto, o valor da diferença das entalpias, para valores de pressão em torno de $100 \mathrm{GPa}$, é de cerca de 0,15 eV. Por outro lado, o manto terrestre pode chegar a temperaturas da ordem de $2000 \mathrm{~K}$, cerca de 0,172 eV. Assim, nesta região do manto a energia térmica é mais que suficiente para estabilizar e favorecer o carbono como estando incorporado como impureza no $\mathrm{MgSiO}_{3}$. Este é um importante resultado, pois mostra que a energia térmica do manto inferior pode favorecer a incorporação de impurezas em um dos principais minerais que formam o manto. Impurezas deste tipo fazem parte de uma das hipóteses para explicar as zonas de baixa velocidade de ondas sísmicas no manto inferior. Como já demonstrado neste capítulo, o carbono é mais leve que o silício, fazendo com que a magnesita seja menos densa. Entretanto, o carbono deixa o material mais "mole", diminuindo os coeficientes elásticos numa taxa muito maior que a densidade, de tal forma que as velocidades de ondas acústicas são bem menores. Dessa forma, é esperado que impurezas de carbono no $\mathrm{MgSiO}_{3}$ também diminuam os seus coeficientes elásticos e façam com que as ondas se propaguem de forma mais lenta.

\subsection{Conclusões}

Neste capítulo, calculamos as propriedades dos carbonatos $\mathrm{MgCO}_{3}$ e $\mathrm{CaCO}_{3}$ nas estruturas que assumem sob altas pressões. $\mathrm{O} \mathrm{MgCO}_{3}$ é o carbonato equivalente ao silicato $\mathrm{MgSiO}_{3}$, que forma a maior parte do manto inferior. Como mostrado na última parte deste capítulo, o carbonato de magnésio é mais estável que a presença de carbono como impureza ou como liga no $\mathrm{MgSiO}_{3}$. Portanto, a presença deste elemento no manto inferior implica na presença do mineral $\mathrm{MgCO}_{3}$. A fase mais estável sob baixas pressões é a $\mathrm{R} \overline{3} \mathrm{c}$, cujo tensor 
elástico é menos simétrico que o da simetria ortorrômbica. Assim, há uma maior variação da velocidade das ondas acústicas no $\mathrm{MgCO}_{3}$, quando comparado com as velocidades no $\mathrm{MgSiO}_{3}$ e, portanto, a anisotropia neste mineral é maior, indicando que a presença de carbono aumentaria a anisotropia local no manto inferior. Isto pode ser usado para restringir (ou ampliar) os possíveis minerais utilizados em modelos geofísicos.

Em altas pressões, já foi comprovado experimentalmente que o $\mathrm{MgCO}_{3}$ sofre uma transição estrutural. Ainda não foi possível refinar os dados de difração de raios- $X$, mas cálculos teóricos mostraram que esta é uma estrutura monoclínica de base centrada $\mathrm{C} 2 / \mathrm{m}$. Comparando a entalpia das duas estruturas do $\mathrm{MgCO}_{3}$, encontramos a pressão de transição de $76 \mathrm{GPa}$. A variação da velocidade com a direção de propagação, tanto das ondas $\mathrm{P}$ como das ondas $\mathrm{S}$, é menor na estrutura $\mathrm{C} 2 / \mathrm{m}$, apesar desta ser menos simétrica. Isso faz com que a anisotropia desta nova estrutura seja menor, tanto para as ondas $\mathrm{P}$ como para as ondas $\mathrm{S}$.

$\mathrm{O} \mathrm{CaCO}_{3}$ é um cristal bem mais complexo, apresentando diversos polimorfos. A estrutura mais estável à pressão ambiente é a $R \overline{3} c$, isoestrutural à magnesita, com os átomos nas mesmas posições, com o cálcio ocupando o lugar do magnésio. A calcita possui coeficientes elásticos maiores que $0 \mathrm{MgCO}_{3}$, indicando velocidades acústicas maiores, mas ainda assim são bem menores que as velocidades no $\mathrm{MgSiO}_{3}$. Em altas pressões, o $\mathrm{CaCO}_{3}$ assume primeiramente a estrutura aragonita, com a pressão de transição em torno de 2 GPa e posteriormente a estrutura pós-aragonita. As velocidades acústicas nestes minerais possuem uma grande anisotropia, mas que diminui com a pressão. Ainda assim, os carbonatos $\mathrm{CaCO}_{3}$ são bem mais anisotrópicos que os $\mathrm{MgCO}_{3}$, tanto se levarmos em consideração as ondas $\mathrm{P}$ como as ondas $\mathrm{S}$. As velocidades nos agregados isotrópicos de todos os carbonatos estudados neste capítulo, assim como na liga de silicato de magnésio com concentração de 3,125\% de carbono, são menores que as velocidades no $\mathrm{MgSiO}_{3}$, principal mineral na composição do manto inferior, como mostrado na figura 4.27. Estes resultados são particularmente importantes para o intervalo de valores de pressão no manto inferior, principalmente na região próxima à fronteira do manto com o núcleo, onde se encontram as zonas de ultra-baixa velocidades (ULVZ). A comparação efetuada 

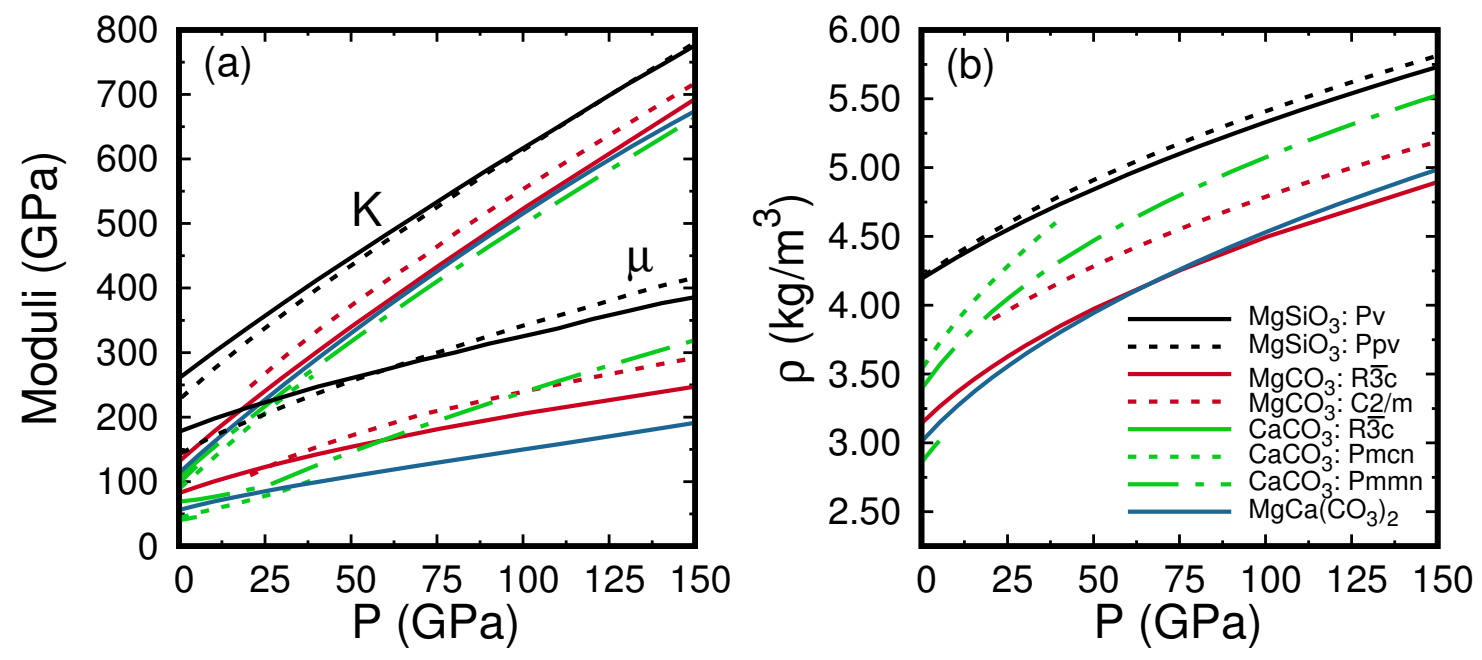

Figura 4.34: (a) Módulos elásticos isotrópicos $K$ e $\mu$ e (b) densidade $(\rho)$, em função da pressão, de agregados isotrópicos de $\mathrm{MgCO}_{3}$ (linhas vermelhas), $\mathrm{CaCO}_{3}$ (linhas verdes), $\mathrm{MgCa}\left(\mathrm{CO}_{3}\right)_{2}$ (linhas azuis) e $\mathrm{MgSiO}_{3}$ (linhas pretas), em várias fases estruturais estáveis.

neste trabalho, entre as velocidades de propagação das ondas acústicas nos agregados de carbonatos e de silicatos pode indicar que se a formação destes carbonatos for energeticamente favorável, a presença de carbono no manto inferior pode, de fato, reduzir o valor das velocidades de propagação tanto das ondas $\mathrm{P}$ como das ondas $\mathrm{S}$.

A figura 4.34 mostra os módulos elásticos isotrópicos e a densidade de agregados isotrópicos, em várias fases estruturais, dos minerais $\mathrm{MgCO}_{3}, \mathrm{CaCO}_{3}$, $\mathrm{MgCa}\left(\mathrm{CO}_{3}\right)_{2}$ e $\mathrm{MgSiO}_{3}$. Destes resultados podemos perceber que tanto a densidade como os módulos elásticos dos agregados de $\mathrm{MgSiO}_{3}$ são maiores que a dos carbonatos, e que a diferença entre os módulos elásticos são bem maiores do que das densidades. Como a velocidade de propagação das ondas acústicas $\mathrm{P}$ e $\mathrm{S}$ é diretamente proporcional aos módulos elásticos e inversamente proporcional à densidade, temos, como resultado, que as velocidades nos agregados de $\mathrm{MgSiO}_{3}$ são sempre maiores que nos carbonatos, uma vez 
que nestes últimos a diminuição nos valores dos coeficientes elásticos apresenta uma taxa muito maior que o valor das densidades, implicando em velocidades de propagação de ondas acústicas bem menores. Assim, a presença de carbono em regiões do manto onde seja favorável a formação de carbonatos, como o $\mathrm{MgCO}_{3}$ e o $\mathrm{CaCO}_{3}$, tem por efeito principal uma redução na velocidade das ondas sísmicas. Por conseguinte, no manto inferior, nas ULVZ, existem regiões onde as ondas sísmicas sofrem uma redução em suas velocidades. As chamadas ULVZ estão presentes no manto inferior, próximo à fronteira com o núcleo. Nestas regiões a velocidade tanto das ondas $P$ como das ondas $S$ são reduzidas. Estas zonas não são globais, sendo que não há evidências destas regiões em algumas partes do manto inferior. Isso implica que apenas considerações termodinâmicas não são suficientes para explicar as ULVZ, sendo que alguma diferenciação química deve ser invocada. Com isso em mente, propomos que estas regiões de baixa velocidade no manto inferior possam ser provocadas pela presença de carbono, de tal forma que possibilite a formação destes carbonatos, o que explicaria esta redução nas velocidades. Adicionalmente, esses resultados também fornecem um modelo adicional para explicar onde e como o carbono pode ser armazenado no manto profundo. 



\section{Estabilidade de compostos de carbono em altas pressões}

There has always been enough carbon dioxide to keep Earth warm enough for life, but not too much to bake it to death.

- Stanley Rice, Life on Earth

\subsection{Introdução}

Devido à alta concentração de magnésio, cálcio e oxigênio no interior da Terra, a magnesita e a aragonita são considerados os principais minerais capazes de armazenar carbono no interior do planeta [25]. Entretanto, como o carbono é um elemento extremamente versátil, que pode se combinar com uma infinidade de outros elementos, existem vários outros materiais que podem ser gerados pela combinação destes elementos. É interessante estudar, do ponto de vista energético, a estabilidade destes minerais com relação a outros possíveis de serem formados no manto.

Dois minerais muito comuns no interior terrestre são o $\mathrm{MgO}$ e o $\mathrm{CaO}$ [29, $145,146]$, mas, recentemente, algumas questões também têm sido levantadas com respeito à possibilidade da existência de $\mathrm{CO}_{2}$ e oxigênio sólidos no manto inferior, devido às altas pressões a que estariam sujeitos. Com isso, se considerarmos um reservatório que contenha átomos de magnésio/cálcio, oxigênio, na presença de carbono, poderia ocorrer a dissociação do $\mathrm{MgCO}_{3} / \mathrm{CaCO}_{3}$, nos produtos $\mathrm{MgO} / \mathrm{CaO}+\mathrm{CO}_{2}$, mantendo-se, obviamente, as relações de estequiometria. Apesar de alguns experimentos mostrarem que a magnesita permanece 
estável em altas pressões [111], as pressões alcançadas experimentalmente, em laboratório, ainda são baixas, quando comparadas àquelas do manto inferior. Resultados de cálculos de primeiros princípios levaram à mesma conclusão, mas estes cálculos foram realizados apenas em condições estáticas, além de sofrerem limitações devido à alta complexibilidade do diagrama de fase do $\mathrm{CO}_{2}$. Além disso, ainda não foram realizados estudos teóricos de efeitos térmicos nas propriedades destes minerais.

Neste capítulo apresentamos estudos da estabilidade energética do $\mathrm{MgCO}_{3}$ e do $\mathrm{CaCO}_{3}$ com relação a outros possíveis compostos formados por carbono, mantendo as relações estequiométricas. Analisamos o diagrama de fases de diferentes compostos e estudamos a estabilidade dos carbonatos com relação a eles. Primeiramente, realizamos cálculos estáticos para comprovar, de fato, a estabilidade destes compostos. Em seguida, utilizando a aproximação quaseharmônica, estudamos a estabilidade destes sistemas em altas temperaturas, equivalentes àquelas do manto da Terra, a fim de se determinar se, sob estas condições extremas, os carbonatos de magnésio e de cálcio permanecem estáveis. Por fim, utilizamos um método recém desenvolvido para estudos de elasticidade, que permite calcular os coeficientes elásticos em altas temperaturas. Até o momento, no entanto, este método é aplicável apenas para redes cúbicas, tetragonais e ortorrômbicas. Por isso, efetuamos cálculos de elasticidade em altas temperaturas apenas para $0 \mathrm{CaCO}_{3}$ nas fases aragonita e pós-aragonita. Com isso pretendemos verificar se efeitos térmicos influenciam significativamente as conclusões elaborados no capítulo 4.

\subsection{Compostos de carbono}

\section{Dióxido de carbono em altas pressões}

O dióxido de carbono, um gás à temperatura e pressão ambientes, possui diversas estruturas a altas pressões e temperaturas. Seu diagrama de fases, mostrado na figura 5.1 [147, 148], tem sido muito estudado e ainda permanecem muitas dúvidas a respeito de sua estrutura a altas pressões e temperaturas.

$\mathrm{O} \mathrm{CO}_{2}$ apresenta uma vasta variedade de polimorfos. A figura 5.1 mos- 


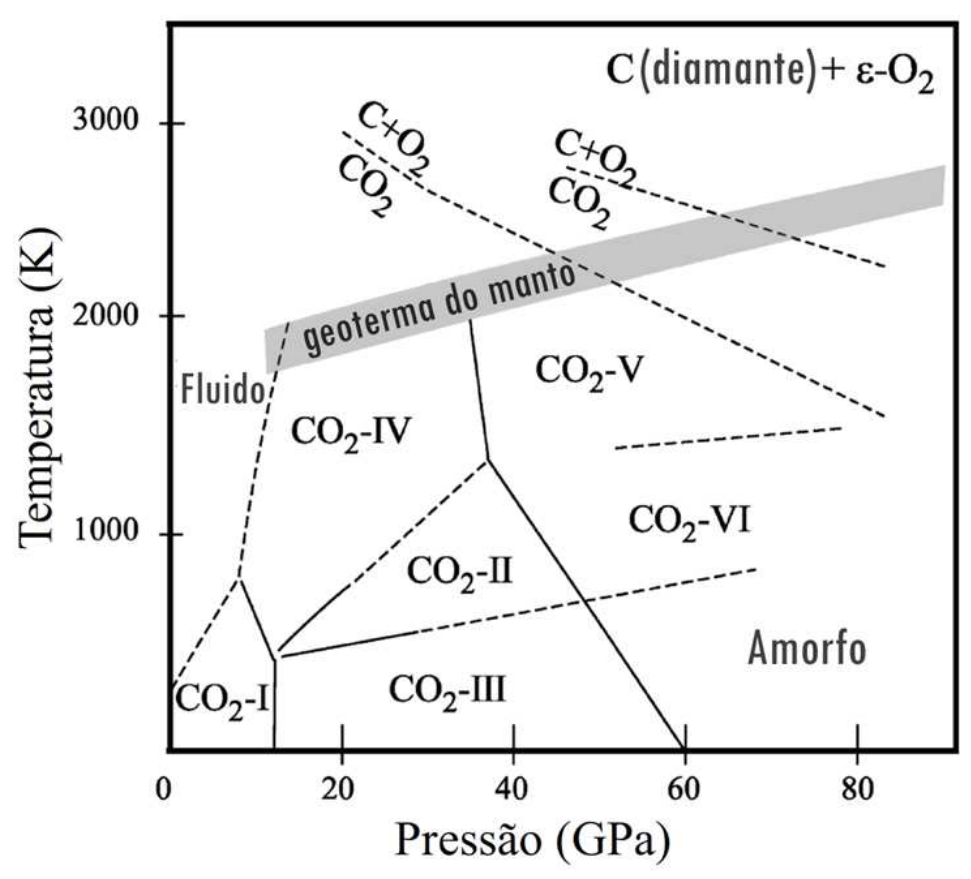

Figura 5.1: Diagrama de fases do $\mathrm{CO}_{2}$ e a geoterma do manto terrestre. Ref. [147]

tra, também, a geoterma do manto, permitindo observar-se que $0 \mathrm{CO}_{2}$ pode ser estável na fase $\mathrm{CO}_{2}$-IV no manto superior $(\mathrm{P} \approx 40 \mathrm{GPa})$, na fase $\mathrm{CO}_{2}-\mathrm{V}$ no manto inferior e se dissociar em maiores profundidades em $\mathrm{C}_{2}$ (diamante) + $\mathrm{O}_{2}$. Cálculos de primeiros princípios não prevêem essa decomposição e esta discrepância entre teoria e experimento ainda não foi solucionada [149].

Resultados recentes de difração de raios- $X$ mostram que tanto a fase $\mathrm{CO}_{2}-\mathrm{IV}$ como a $\mathrm{CO}_{2}-\mathrm{V}$ apresentam uma rede tetragonal, sendo que a primeira pertence ao grupo espacial $P 4_{1} 2_{1} 2[150,151]$ e a segunda ao grupo espacial $1 \overline{4} 2 \mathrm{~d}[147$, 152]. Ambas estruturas estão mostradas na figura 5.2.

Outra fase interessante de ser analisada é a fase $\mathrm{CO}_{2}-\mathrm{VI}$, pois, apesar do diagrama de fases, apresentado na figura 5.1, mostrar que ela não está presente na região do manto, ela é estável a baixas temperaturas e nossos cálculos teóricos iniciais são simulados a $T=0 \mathrm{~K}$. Métodos experimentais ainda não foram capazes de obter informações suficientes para refinar a estrutura da fase $\mathrm{CO}_{2}-\mathrm{VI}$ [153]. Entretanto, alguns estudos sugerem o grupo $\mathrm{P} \overline{4} \mathrm{~m} 2$, ou o grupo $\mathrm{P} 4_{2} / \mathrm{nmc}$, ou o grupo $\mathrm{P} 4_{2} / \mathrm{nmn}$, fase da stishovita (st), como as estruturas que 

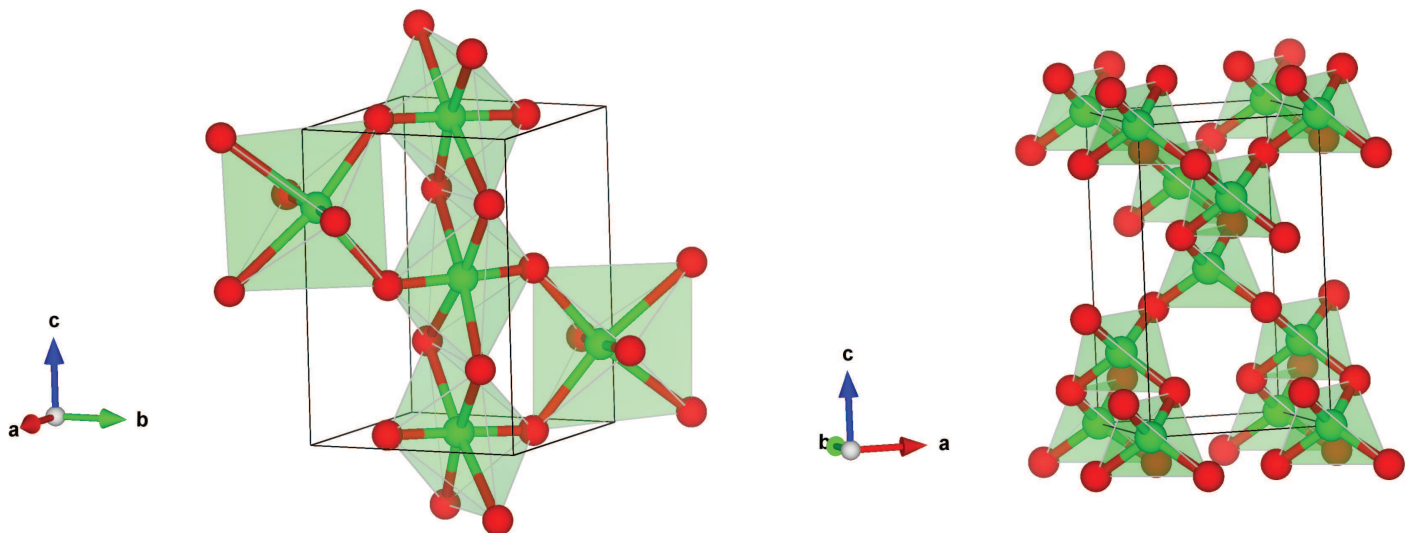

Figura 5.2: Estrutura cristalina do $\mathrm{CO}_{2}$ IV (esquerda), grupo espacial $\mathrm{P} 4_{1} 2_{1} 2$ e do $\mathrm{CO}_{2}-\mathrm{V}$ (direita), grupo espacial $1 \overline{4} 2 \mathrm{~d}$, onde as esferas verdes representam os átomos de carbono e as vermelhas os de oxigênio.

descrevem esta fase. A figura 5.3 mostra estas três estruturas, propostas na literatura, para a fase $\mathrm{CO}_{2}-\mathrm{VI}$.

A estrutura $\mathrm{P} \overline{4} \mathrm{~m} 2$ do dióxido de carbono forma camadas de tetraedros, compostos por átomos de oxigênio, orientados todos na mesma direção, por isso é chamada também de estrutura layer $\mathrm{AA}$. A estrutura $\mathrm{P} 4_{2} / \mathrm{nmc}$ também forma camadas de tetraedros, mas orientados em posições opostas, conforme mostra a figura 5.3 e, por isso, também é chamada de estrutura layer AB. Resultados
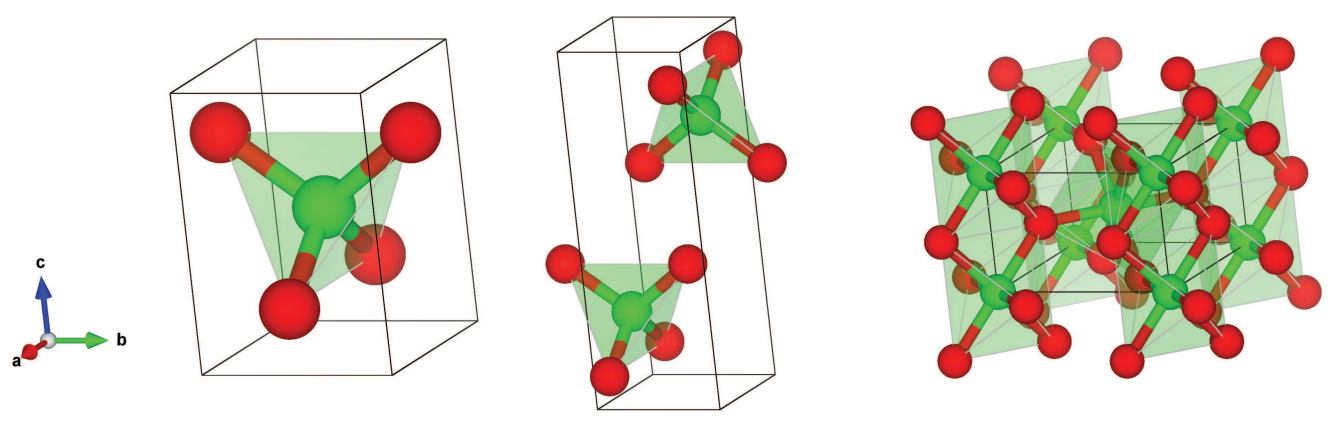

Figura 5.3: Estrutura cristalina do $\mathrm{CO}_{2}-\mathrm{VI}$, nos grupos espaciais $\mathrm{P} \overline{4} \mathrm{~m} 2$ (esquerda), $\mathrm{P}_{2} / \mathrm{nmc}$ (centro) e $\mathrm{P} 4_{2} / \mathrm{mnm}$ (direita). As esferas verdes representam os átomos de carbono e as vermelhas os de oxigênio. 


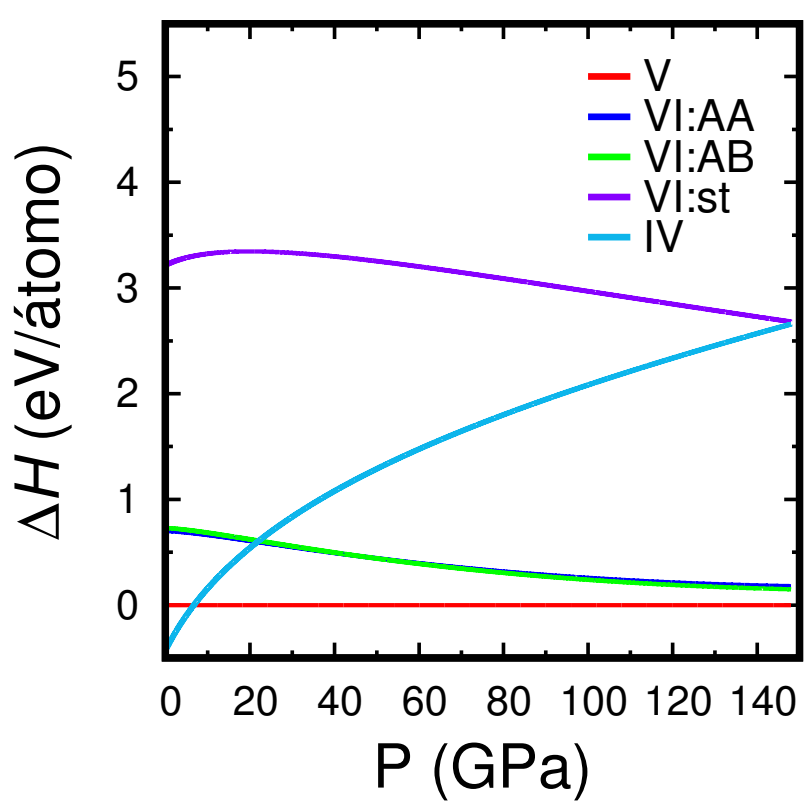

Figura 5.4: Entalpia relativa $(\Delta H)$, em função da pressão, do $\mathrm{CO}_{2}$ nas fases IV $\left(P 4_{1} 2{ }_{1} 2\right.$ - linha azul), VI:AA ( $\mathrm{P} \overline{4} \mathrm{~m} 2$ - linha azul marinho), VI:AB ( $\mathrm{P} 4_{2} / \mathrm{nmc}$ - linha verde) e $\mathrm{VI}$ :st ( $\mathrm{P} 4_{2} / \mathrm{nmn}$ - linha violeta), em relação à fase $\mathrm{V}(\mathrm{I} \overline{4} 2 \mathrm{~d}$ - linha vermelha).

de cálculos de propriedades energéticos podem ajudar a definir qual destas estruturas, de fato, o dióxido de carbono assume a altas pressões. O estudo da estabilidade energética de todas estas fases do $\mathrm{CO}_{2}$, em função da pressão, foi efetuado através do cálculo da entalpia das cinco fases estruturais descritas anteriormente. A figura 5.4 apresenta a entalpia, em função da pressão, das fases $\mathrm{CO}_{2}-\mathrm{IV}, \mathrm{CO}_{2}-\mathrm{V}, \mathrm{CO}_{2}-\mathrm{VI}: \mathrm{AA}, \mathrm{CO}_{2}-\mathrm{VI}: \mathrm{AB}$ e $\mathrm{CO}_{2}$-VI:st (stishovita).

Podemos observar que, em condições estáticas, a fase mais estável a baixas pressões é a $\mathrm{CO}_{2}$-IV. Há uma transição de fase para a estrutura $\mathrm{CO}_{2}-\mathrm{V}$ em torno de valores de pressão de $10 \mathrm{GPa}$. Esta pressão é muito menor que a pressão de transição mostrada na figura 5.1. Entretanto, nossos cálculos foram realizados em condições estáticas, enquanto que essa transição é observada em altas temperaturas. Nenhuma das estruturas consideradas para a fase $\mathrm{CO}_{2}-\mathrm{VI}$ é a mais estável, no intervalo de pressão considerado, sendo que as estruturas layer $\mathrm{AA}$ e layer $\mathrm{AB}$ apresentam valores e variação de entalpia muito semeIhantes. Estes resultados contradizem o diagrama de fases da figura 5.1, já 
que a fase $\mathrm{CO}_{2}$-VI deveria ser mais estável em baixas temperaturas e, portanto, em condições estáticas. A estrutura do $\mathrm{CO}_{2}-\mathrm{VI}$ ainda não está bem definida e, talvez, nenhuma daquelas estudadas aqui seja a correta. Outro problema que deve ser considerado é que algumas estruturas consideradas para descrever a fase $\mathrm{CO}_{2}-\mathrm{VI}$ são cristais moleculares, de tal forma que as interações eletrônicas de longo alcance, também conhecidas como interações de van der Waals, possam ser importantes para uma correta descrição destes sistemas. Os efeitos da introdução destas correções serão estudados mais adiante.

\section{Comparação com o $\mathrm{MgCO}_{3}$}

O estudo da estabilidade energética do $\mathrm{MgCO}_{3}$ foi efetuado assumindo a transformação: $\mathrm{MgCO}_{3}=\mathrm{MgO}+\mathrm{CO}_{2}$. Calculamos a entalpia, em função da pressão, das fases trigonal e monoclínica do $\mathrm{MgCO}_{3}$, do $\mathrm{MgO}$ na estrutura do cloreto de sódio, grupo $\mathrm{Fm} \overline{3} \mathrm{~m}$, e do $\mathrm{CO}_{2}$. Escolhemos a fase $\mathrm{CO}_{2}-\mathrm{V}$ para o cristal de dióxido de oxigênio pois, segundo o resultado dos nossos cálculos, é a fase mais estável em altas pressões. A figura 5.5 apresenta as entalpias relativas, com respeito àquela da magnesita $(R \overline{3} c)$, em função da pressão, do $\mathrm{MgCO}_{3}$ na fase monoclínica $(\mathrm{C} 2 / \mathrm{m})$ e da mistura dos elementos constituintes $\mathrm{MgO}+\mathrm{CO}_{2}$.

É interessante notar que o sistema $\mathrm{MgO}+\mathrm{CO}_{2}-\mathrm{V}$ se torna mais estável do que $0 \mathrm{MgCO}_{3}(\mathrm{R} \overline{3} \mathrm{c})$ em pressões em torno de $115 \mathrm{GPa}$. Entretanto, a fase monoclínica $(\mathrm{C} 2 / \mathrm{m})$ apresenta uma menor entalpia nessa região de pressão e, portanto, é energeticamente a fase mais estável. Nosso trabalho permite então concluir que se de fato a estrutura prevista por Oganov [113] for a estrutura do $\mathrm{MgCO}_{3}$ em altas pressões, não há dissociação para nenhum polimorfo do dióxido de carbono nas condições de pressão do interior da Terra. Sabe-se que um dos principais elementos do manto terrestre é o óxido de magnésio. Dessa forma, em regiões de alta pressão, com alta concentração local de carbono, a formação de cristais de $\mathrm{CO}_{2}$ coexistindo com o $\mathrm{MgO}$ não é favorável do ponto de vista energético, restringindo os possíveis elementos a serem encontrados no manto. Nossos resultados permanecem válidos mesmo que a estrutura $\mathrm{C} 2 / \mathrm{m}$ não seja a real fase do $\mathrm{MgCO}_{3}$ em altas pressões, pois qualquer que seja a fase do $\mathrm{MgCO}_{3}$, ela deve, necessariamente, ter uma entalpia menor que a fase $\mathrm{C} 2 / \mathrm{m}$. 


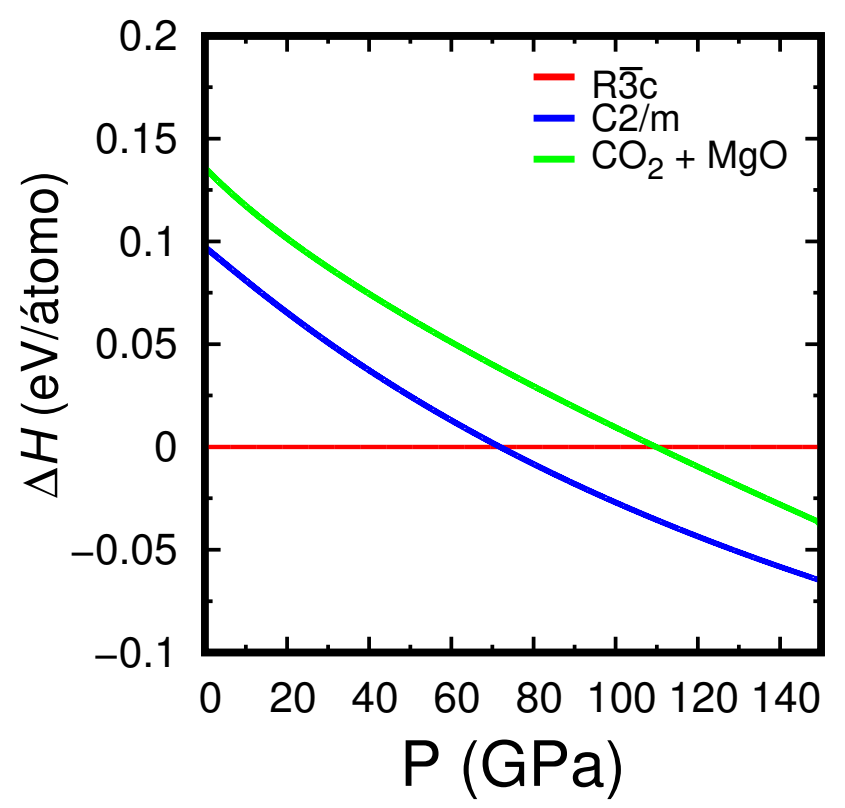

Figura 5.5: Entalpia relativa $(\Delta H)$, em função da pressão, do $\mathrm{MgCO}_{3}$ na fase monoclínica ( $\mathrm{C} 2 / \mathrm{m}$ - linha azul) e da mistura dos elementos constituintes $\mathrm{MgO}+\mathrm{CO}_{2}$ (linha verde), em relação à magnesita ( $\mathrm{R} \overline{3} \mathrm{c}$ - linha vermelha).

Podemos então concluir que a presença de $\mathrm{CO}_{2}$ no manto inferior pode tornar favorável a formação do $\mathrm{MgCO}_{3}$, tornando este material um possível hospedeiro para o carbono no interior da Terra.

\section{Comparação com o $\mathrm{CaCO}_{3}$}

O estudo da estabilidade energética do carbonato de cálcio foi efetuado assumindo-se a transformação: $\mathrm{CaCO}_{3}=\mathrm{CaO}+\mathrm{CO}_{2}$. Para isso, calculamos, utilizando o funcional LDA, a entalpia em função da pressão do $\mathrm{CaCO}_{2}$ nas fases calcita, aragonita e pós-aragonita, do $\mathrm{CaO}$ na estrutura do cloreto de sódio, grupo $\mathrm{Fm} \overline{3} \mathrm{~m}$, e do $\mathrm{CO}_{2}-\mathrm{V}$. A figura 5.6 apresenta as entalpias relativas, com respeito àquela da fase calcita $(\mathrm{R} \overline{3} \mathrm{c})$, em função da pressão, do $\mathrm{CaCO}_{3}$ nas fases aragonita (Pmcn) e pós-aragonita (Pmmn) e da mistura dos elementos constituintes $\mathrm{CaO}+\mathrm{CO}_{2}$.

Como mencionado anteriormente, a utilização do funcional LDA subestima 


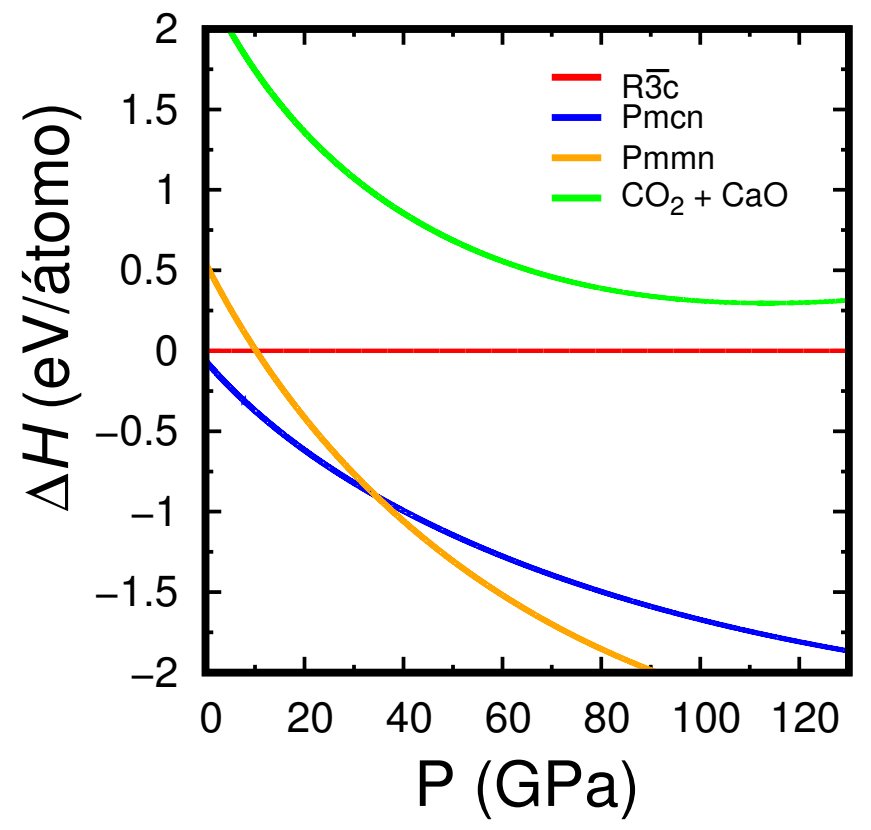

Figura 5.6: Entalpia relativa $(\Delta H)$, em função da pressão, do $\mathrm{CaCO}_{3}$ nas fases aragonita (Pmcn - linha azul) e pós-aragonita (Pmmn - linha laranja) e da mistura dos elementos constituintes $\mathrm{CaO}+\mathrm{CO}_{2}$ (linha verde), em relação à calcita $(\mathrm{R} \overline{3} \mathrm{c}$ linha vermelha).

o valor da pressão de transição do $\mathrm{CaCO}_{3}$ da estrutura $\mathrm{R} \overline{3} \mathrm{c}$ para a Pmcn, prevendo uma pressão de transição negativa. Por este motivo, a fase mais estável a pressão nula, prevista pelo funcional LDA, é a aragonita (Pmcn). Do ponto de vista energético, a mistura $\mathrm{CaO}+\mathrm{CO}_{2}$ não é mais estável do que nenhuma das estruturas consideradas para o $\mathrm{CaCO}_{3}$. No entanto, ainda não há um consenso sobre a estrutura do $\mathrm{CaCO}_{3}$ a altas pressões. Como mencionado no capítulo anterior, alguns resultados de cálculos de primeiros princípios sugerem que a fase pós-aragonita pertence ao grupo Pmmn, outros cálculos prevêem uma estrutura monoclínica. De qualquer forma, qualquer que seja a estrutura correta para $0 \mathrm{CaCO}_{3}$ em altas pressões, sua entalpia será menor do que a da estrutura Pmcn, de tal forma que pode-se concluir que, pelo menos em condições estáticas, não há a dissociação $\mathrm{CaO}+\mathrm{CO}_{2}$. Isto implica que a formação de dióxido de carbono em regiões do interior da Terra, com alta concentração de 
cálcio, não seria favorável do ponto de vista energético. Este resultado corrobora resultados experimentais que mostraram que o dióxido de carbono não se apresenta como uma fase livre em altas pressões, precisando dessa forma ser armazenado em forma de carbonatos [154-157].

\section{Oxigênio a altas pressões}

O diamante é um elemento de extrema importância para o estudo do interior da Terra. Em geral, estes minerais são formados em profundidades entre 150 e $200 \mathrm{~km}$ [158], mas existem os chamados diamantes ultraprofundos, que são formados na zona de transição do manto, em profundidades maiores do que $400 \mathrm{~km}$. Portanto, o estudo e a caracterização de impurezas existentes nestes diamantes podem fornecer diversas informações sobre as regiões profundas da Terra, tais como, por exemplo, a evidência de que o manto superior é rico em água [159] e, também, a presença de carbono no manto inferior [37]. Por estes e outros motivos, é importante estudar a estabilidade do carbono na forma de diamante, comparada com outros compostos também formados por carbono. Assim, considerando a estequiometria dos sistemas $\mathrm{MgCO}_{3}$ e $\mathrm{CaCO}_{3}$, podemos ter as seguintes transformações:

$$
\begin{aligned}
2 \mathrm{MgCO}_{3} & \left.=2 \mathrm{MgO}+\mathrm{C}_{2} \text { (diamante }\right)+2 \mathrm{O}_{2} \\
2 \mathrm{CaCO}_{3} & \left.=2 \mathrm{CaO}+\mathrm{C}_{2} \text { (diamante }\right)+2 \mathrm{O}_{2}
\end{aligned}
$$

ou seja, considerando um reservatório com átomos de magnésio/cálcio, oxigênio e carbono, podemos ter a formação de diamante, se também considerarmos a formação de óxido de magnésio e oxigênio. $\mathrm{O}_{2}$ é um composto gasoso à temperatura e pressão ambientes mas, em altas pressões e temperaturas, é um material bastante complexo, que se solidifica em diversas estruturas. Em pressões acima de cerca de $10 \mathrm{GPa}$ até cerca de $95 \mathrm{GPa}$, o oxigênio sólido apresenta uma fase chamada $\varepsilon-\mathrm{O}_{2}$, de estrutura monoclínica, grupo espacial $\mathrm{C} 2 / \mathrm{m}$. Acima de $95 \mathrm{GPa}$ ele apresenta uma transição para uma fase chamada de $\zeta-\mathrm{O}_{2}$, como mostra o diagrama de fases na figura 5.7. 


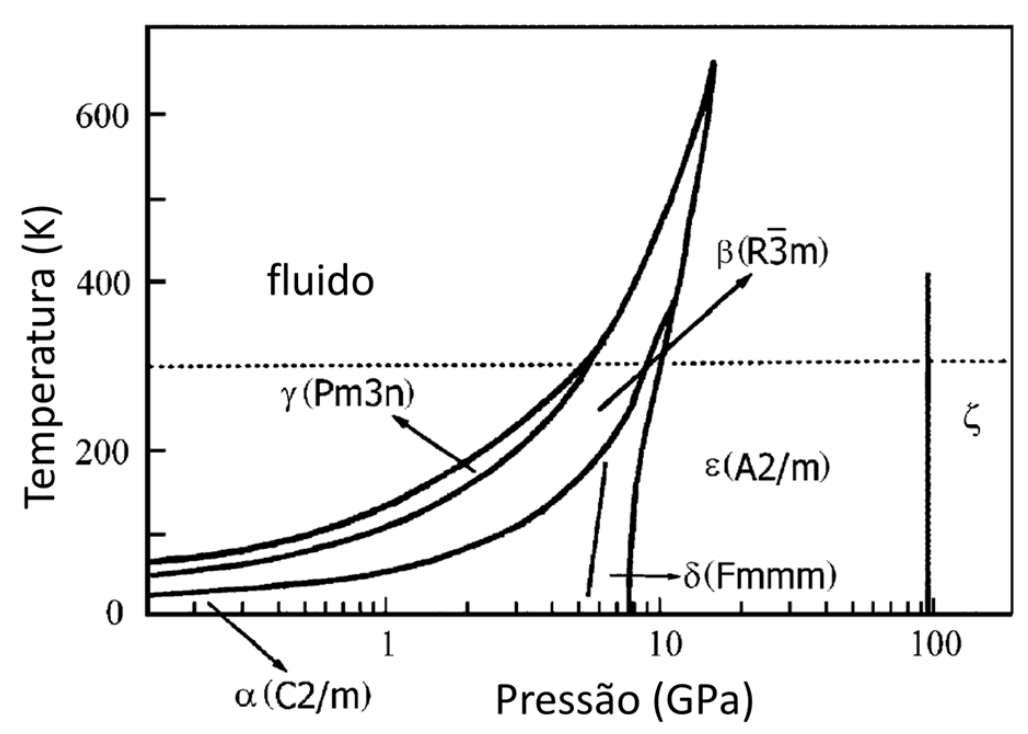

Figura 5.7: Diagrama de fases do Oxigênio em altas pressões. Ref. [160]

O diagrama de fases mostra que para o intervalo adequado de pressões para o estudo do manto inferior, a estrutura cristalina do oxigênio sólido está associada às fases $\zeta-\mathrm{O}_{2}$ e $\varepsilon-\mathrm{O}_{2}$. Elas são isoestruturais, possuindo simetria referente ao grupo espacial $\mathrm{C} 2 / \mathrm{m}^{1}$ [160-163]. A figura 5.8 mostra a estrutura cristalina do $\varepsilon-\mathrm{O}_{2}$.

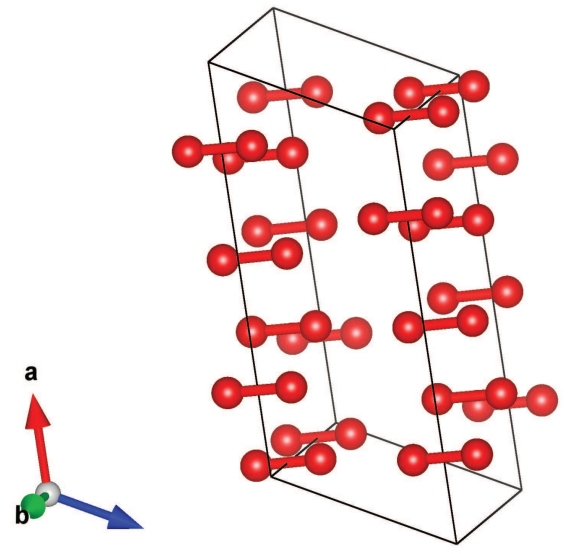

Figura 5.8: Estrutura cristalina do oxigênio sólido na fase $\varepsilon-\mathrm{O}_{2}$.

\footnotetext{
${ }^{1}$ No diagrama de fases está mostrada a estrutura A2/m. É o mesmo grupo espacial da C2/m, mas com a base centrada no plano $y z$, enquanto a base da $C 2 / m$ está no plano $x y$.
} 

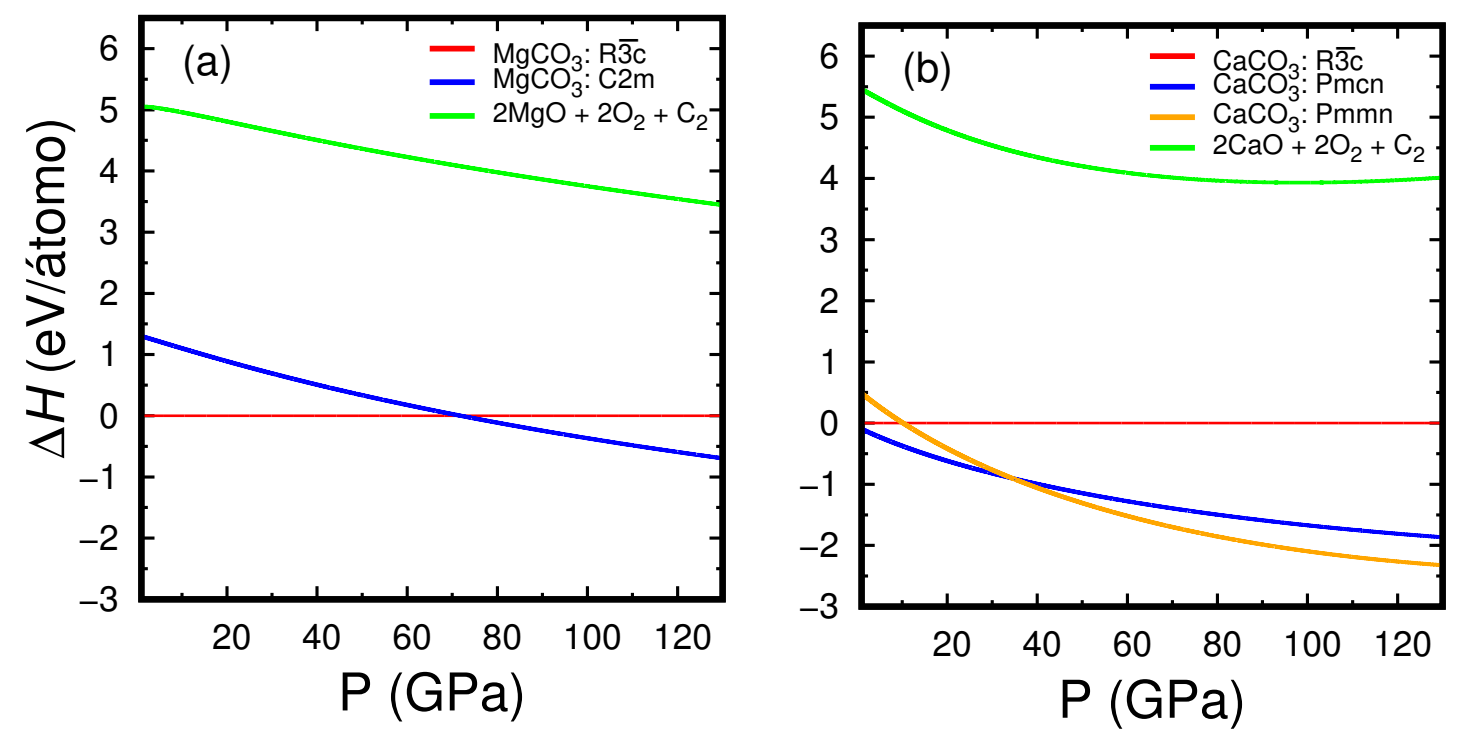

Figura 5.9: Entalpia $(\Delta H)$, em função da pressão: (a) $\mathrm{MgCO}_{3}$ na fase monoclínica ( $\mathrm{C} 2 / \mathrm{m}$ - linha azul) e do sistema formado pelos elementos constituintes $2 \mathrm{MgO}+\mathrm{C}_{2}$ (diamante) $+2 \mathrm{O}_{2}$ (linha verde), com respeito à entalpia da magnesita ( $\mathrm{R} \overline{3} \mathrm{c}$ - linha vermelha); (b) $\mathrm{CaCO}_{3}$ nas fases aragonita (Pmcn - linha azul) e pós-aragonita (Pmmn - linha laranja) e para o sistema formado pelos elementos constituintes $2 \mathrm{CaO}+\mathrm{C}_{2}$ (diamante) $+2 \mathrm{O}_{2}$ (linha verde), com respeito à entalpia da calcita ( $\mathrm{R} \overline{3} \mathrm{c}$ - linha vermelha).

O oxigênio sólido é um cristal molecular e, portanto, espera-se que uma correta descrição do sistema necessite da introdução das interações de van der Waals. A influência destas interações será estudada posteriormente. $O$ estudo da estabilidade energética do carbonato de cálcio e do carbonato de magnésio, em várias fases, em comparação com os cristais de diamante, $\mathrm{MgO}$, $\mathrm{CaO}$ e oxigênio, em função da pressão, foi efetuado através do cálculo da entalpia de todos estes sistemas. A figura 5.9 apresenta a entalpia das misturas $2 \mathrm{MgO}+\mathrm{C}_{2}$ (diamante) $+2 \mathrm{O}_{2}$ e $2 \mathrm{CaO}+\mathrm{C}_{2}$ (diamante) $+2 \mathrm{O}_{2}$ e dos minerais $\mathrm{MgCO}_{3}$ e $\mathrm{CaCO}_{3}$, respectivamente.

Comparando os resultados apresentados nas figuras 5.5 e $5.6 \mathrm{com}$ aqueles expostos na figura 5.9, podemos observar que eles vão ao encontro de outros 
resultados reportados na literatura, nos quais foi observado que não é energeticamente favorável que ocorra, no manto, a dissociação do $\mathrm{CO}_{2}$ em seus elementos constituintes [113]. Entretanto, resultados experimentais recentes indicam que a altas pressões a estrutura não molecular do $\mathrm{CO}_{2}-\mathrm{V}$ se dissocia em carbono e oxigênio [164]. Até o momento, esta discrepância entre os resultados experimentais e teóricos ainda não foi solucionada. Adicionalmente, outro fato a se considerar é a possibilidade de o oxigênio formar outros compostos após a dissociação. Por exemplo, como o manto é rico em silício, o oxigênio proveniente das transformações expressas nas equações (5.1) e (5.2) poderia também formar $\mathrm{SiO}_{2}$ [149]. Esta possibilidade de transformação foge do escopo deste trabalho.

\section{Interações de van der Waals}

Tanto o dióxido de carbono como o oxigênio são cristais moleculares, por isso, interações de van der Waals (vdW) podem ser importantes para a sua correta descrição. Uma grande desvantagem dos métodos de primeiros princípios baseados na DFT é que eles não descrevem corretamente as interações eletrônicas de longo alcance, responsáveis pelas forças de vdW. Em cristais moleculares, esta correção pode ser importante, por isso introduzimos este tipo de correção em nossos estudos com o objetivo de determinar se há alguma alteração no comportamento energético relativo dessas estruturas. No método utilizado neste trabalho, a energia de troca e correlação do sistema é reescrita na forma [165]:

$$
E_{x c}=E_{x}^{G G A}+E_{c}^{L D A}+E_{c}^{n l}
$$

em que podem ser usadas diferentes formas para o funcional energia de troca $E_{x}^{G G A}$. Resultados obtidos com a aproximação vdW-B88 [166-168], quando comparados com dados experimentais, apresentaram resultados excelentes. Utilizando esta metodologia para as dispersões de vdW, calculamos os parâmetros estruturais, através da equação de estado, dos cristais de $\mathrm{MgCO}_{3}, \mathrm{CaCO}_{3}$, $\mathrm{MgO}, \mathrm{CaO}, \mathrm{CO}_{2}$ e $\mathrm{O}_{2}$, os quais estão apresentados na tabela 5.1, juntamente com os resultados anteriormente obtidos com os funcionais LDA e GGA e com dados experimentais. 
Tabela 5.1: Parâmetros estruturais, obtidos da equação de estado, para os cristais de $\mathrm{MgCO}_{3}, \mathrm{CaCO}_{3}, \mathrm{MgO}, \mathrm{CaO}, \mathrm{CO}_{2}$ e $\mathrm{O}_{2}$. São mostrados os resultados obtidos utilizando o funcional LDA, o GGA e o vdW, que inclui interações de van der Waals, e dados experimentais. O volume $\left(V_{0}\right)$ é dado em $\AA^{3}$, o bulk modulus $\left(K_{0}\right)$ é dado em GPa e a derivada do bulk modulus ( $\left.K_{0}^{\prime}\right)$ é adimensional.

\begin{tabular}{|c|c|c|c|c|c|}
\hline & & $\mathrm{MgCO}_{3}(\mathrm{R} \overline{3} \mathrm{c})$ & $\mathrm{CaCO}_{3}(\mathrm{R} \overline{3} \mathrm{c})$ & $\mathrm{CaCO}_{3}(\mathrm{Pmcn})$ & $\mathrm{CaCO}_{3}(\mathrm{Pmmn})$ \\
\hline \multirow{3}{*}{ LDA } & $V_{0}$ & 268,34 & 352,45 & 211,90 & 98,07 \\
\hline & $K_{0}$ & 122 & 72 & 85 & 91 \\
\hline & $K_{0}^{\prime}$ & 4,44 & 3,65 & 3,91 & 4,91 \\
\hline \multirow{3}{*}{ GGA } & $V_{0}$ & 290,77 & 382,16 & 232,89 & 109,64 \\
\hline & $K_{0}$ & 100 & 68 & 74 & 67 \\
\hline & $K_{0}^{\prime}$ & 4,48 & 3,46 & 3,74 & 4,78 \\
\hline \multirow{3}{*}{$\mathrm{vdW}$} & $V_{0}$ & 282,85 & 382,22 & 226,08 & 104,24 \\
\hline & $K_{0}$ & 109 & 54 & 79 & 88 \\
\hline & $K_{0}^{\prime}$ & 4,48 & 4,03 & 3,78 & 4,55 \\
\hline \multirow{3}{*}{ Exp. } & $\overline{V_{0}}$ & $279,28^{(a)}$ & $368,11^{\text {(b) }}$ & $226,71^{(\mathrm{c})}$ & - \\
\hline & $K_{0}$ & 119 & 73 & 71 & - \\
\hline & $K_{0}^{\prime}$ & 4,02 & 4,00 & 4,63 & - \\
\hline & & $\mathrm{MgO}(\mathrm{Fm} \overline{3} \mathrm{~m})$ & $\mathrm{CaO}(\mathrm{Fm} \overline{3} \mathrm{~m})$ & $\mathrm{CO}_{2}-\mathrm{V}(\mathrm{I} \overline{4} 2 \mathrm{~d})$ & $\varepsilon-\mathrm{O}_{2}(\mathrm{C} 2 / \mathrm{m})$ \\
\hline \multirow{3}{*}{ LDA } & $V_{0}$ & 18,06 & 26,14 & 88,67 & 85,66 \\
\hline & $K_{0}$ & 173 & 129 & 145 & 16 \\
\hline & $K_{0}^{\prime}$ & 4,10 & 4,32 & 4,06 & 8,53 \\
\hline \multirow{3}{*}{ GGA } & $V_{0}$ & 19,30 & 28,22 & 94,83 & 93,98 \\
\hline & $K_{0}$ & 150 & 106 & 126 & 25 \\
\hline & $K_{0}^{\prime}$ & 4,10 & 4,27 & 4,09 & 5,22 \\
\hline \multirow{3}{*}{$\mathrm{vdW}$} & $V_{0}$ & 18,94 & 27,67 & 92,55 & 98,99 \\
\hline & $K_{0}$ & 157 & 114 & 136 & 11 \\
\hline & $K_{0}^{\prime}$ & 4,09 & 4,27 & 4,13 & 7,97 \\
\hline \multirow{3}{*}{ Exp. } & $\overline{V_{0}}$ & $18,67^{(d)}$ & $27,82^{(\mathrm{e})}$ & - & - \\
\hline & $K_{0}$ & 161 & 111 & - & - \\
\hline & $K_{0}^{\prime}$ & 3,94 & 4,82 & - & - \\
\hline
\end{tabular}
(a) Ref. [114]
(b) Ref. $[127,128]$
(c) Ref. [130]
(d) Ref. [169]
(e) Ref. [170] 
De acordo com a tabela, quando comparados com dados experimentais disponíveis, os volumes dos cristais, à pressão nula, são subestimados quando do uso do funcional LDA (4-6\%) e superestimados pelo funcional GGA (3-7\%). Podemos observar que a inclusão de correções da interação de vdW resulta em valores de volume maiores do que aqueles obtidos pelo uso do LDA e menores que os obtidos pelo GGA, aproximando-os dos valores experimentais. Esta tendência também é observada para os cristais de $\mathrm{CaCO}_{3}(\mathrm{Pmmn})$ e $\mathrm{CO}_{2}-\mathrm{V}$, para os quais não há valores experimentais. A única exceção é o cristal de oxigênio $\varepsilon-\mathrm{O}_{2}$, em que o valor do volume obtido com a inclusão de efeitos da interação de vdW é o maior de todos.

Como as equações de estado são melhor descritas com a inclusão destas interações de vdW, estudamos, novamente, a estabilidade energética do carbonato de cálcio e do carbonato de magnésio, em várias fases, em comparação com os cristais de diamante, $\mathrm{MgO}, \mathrm{CaO}, \mathrm{CO}_{2}$ e oxigênio, em função da pressão. Pretendemos, com isto, verificar se a incorporação das interações de vdW têm efeitos significativos nas transições e estabilidades estudadas anteriormente.

A figura 5.10 apresenta a entalpia, considerando as interações de vdW, dos minerais $\mathrm{MgCO}_{3}$ e $\mathrm{CaCO}_{3}$ e dos respectivos elementos constituintes envolvendo carbono e oxigênio.

Comparando os resultados apresentados nesta figura com aqueles das figuras 5.5, 5.6 e 5.9, observa-se que a consideração destas interações de vdW não alteram significantemente os valores das pressões de transição estrutural destes sistemas. Adicionalmente, a incorporação da energia de vdW não altera a conclusão anterior, obtida para o sistema em condição estática. Portanto, não há dissociação dos carbonatos nos elementos constituintes considerados, nas condições de pressão do interior da Terra. Assim, podemos inferir que as discrepâncias observadas, e relatadas anteriormente, provavelmente não estão relacionadas com a descrição dos cristais moleculares. 

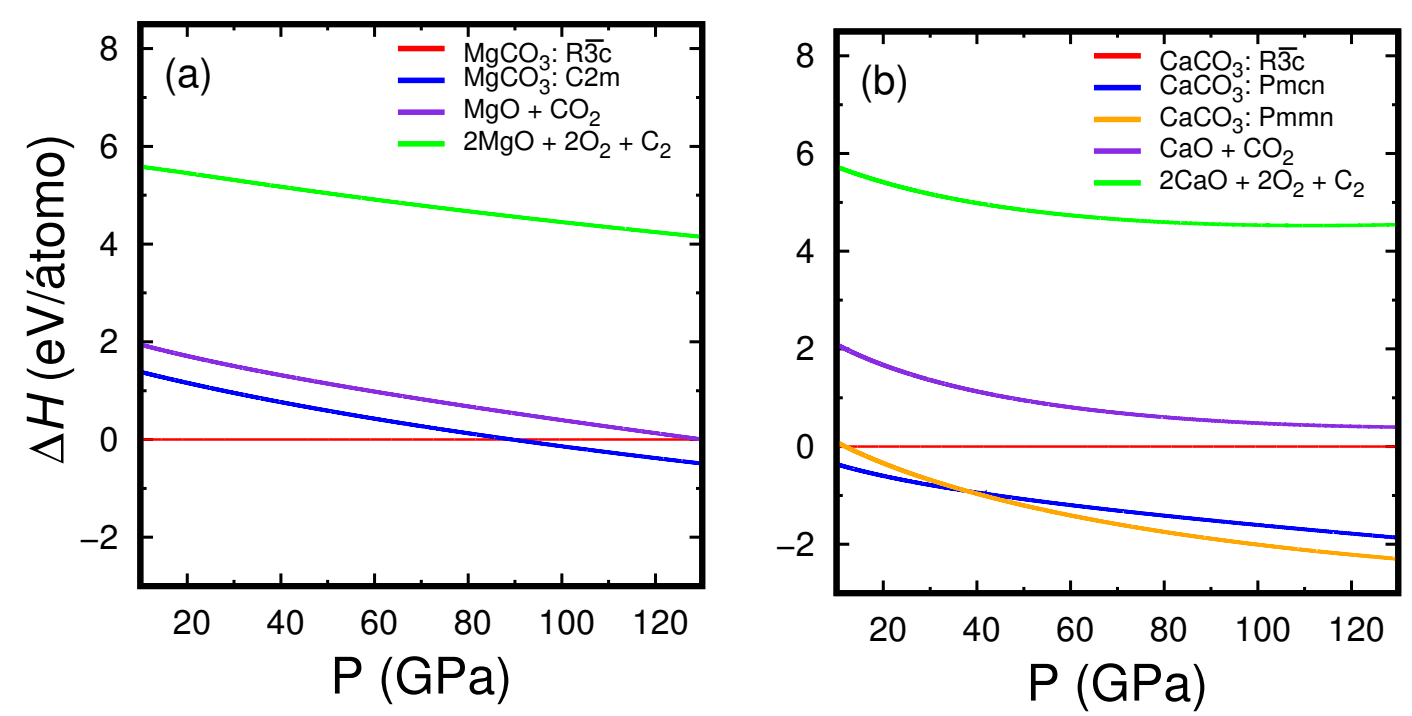

Figura 5.10: Entalpia $(\Delta H)$, em função da pressão, obtida com inclusão de correções de van der Waals, para: (a) $\mathrm{MgCO}_{3}$ na fase monoclínica ( $\mathrm{C} 2 / \mathrm{m}$ - linha azul) e dos sistemas formados pelos elementos constituintes $\mathrm{MgO}+\mathrm{CO}_{2}$ (linha violeta) e $2 \mathrm{MgO}+\mathrm{C}_{2}$ (diamante) $+2 \mathrm{O}_{2}$ (linha verde), em relação à magnesita ( $\mathrm{R} \overline{3} \mathrm{c}$ - linha vermelha); (b) $\mathrm{CaCO}_{3}$ nas fases aragonita (Pmcn - linha azul) e pós-aragonita (Pmmn - linha laranja) e para os sistemas formados pelos elementos constituintes $\mathrm{CaO}+\mathrm{CO}_{2}$ (linha violeta) e $2 \mathrm{CaO}+\mathrm{C}_{2}$ (diamante) $+2 \mathrm{O}_{2}$ (linha verde), em relação à calcita $(R \overline{3} c$ - linha vermelha $)$.

\subsection{Propriedades termodinâmicas}

No estudo da estabilidade energética relativa de sistemas à mesma pressão e temperatura, o sistema mais estável é aquele que possui a menor energia livre de Gibbs. Esta energia é dada por:

$$
G(P, T)=F(V, T)+P V
$$

em que $F(V, T)$ é a energia livre de Helmholtz, $P$ a pressão e $V$ o volume. Como demonstrado no capitulo 2 , dentro da aproximação quase-harmônica, a energia livre de Helmholtz é escrita como:

$$
F(V, T)=E_{0}(V)+E_{z p}(V)+E_{t h}(V, T)
$$


em que $E_{0}$ é a energia interna, $E_{z p}$ é a energia de ponto zero e $E_{t h}$ é a energia de vibração. Dentro da aproximação de Born-Oppenheimer, em que se desconsidera a energia cinética dos íons e, portanto, se tem uma rede estática, os dois últimos termos são nulos e a energia livre de Gibbs será dada por:

$$
G(P)=E_{0}+P V=H(P)
$$

em que $H$ é a entalpia do sistema. Por isso, até o momento, utilizamos a entalpia para verificar qual o sistema mais estável. Entretanto, como estas equações mostram, este procedimento nos dá apenas informações da rede estática e desconsidera efeitos térmicos. Para se incluir efeitos decorrentes da temperatura, devemos utilizar a equação (5.4) e, para isso, devemos calcular a energia livre de Helmholtz, utilizando a aproximação quase-harmônica, descrita no capítulo 2. Como demonstrado, na aproximação quase-harmônica se considera a dependência das frequências com o volume. Para tanto, determina-se a densidade de estados vibracionais para diferentes volumes e dessa forma obtém-se a energia livre de Helmholtz do sistema como função do volume e da temperatura. Uma vez que se tem esta equação, todas as propriedades termodinâmicas podem ser calculadas. Esta aproximação considera que as frequências não variam com a temperatura, que é o caso para baixas temperaturas como já foi demonstrado. Para os minerais do manto terrestre $\left(\mathrm{MgSiO}_{3}\right.$ e $\left.\mathrm{MgO}\right)$, a aproximação quase-harmônica é válida para temperaturas de até cerca de $2000 \mathrm{~K}$, ou seja, até aproximadamente a fronteira entre o manto inferior e o núcleo [39]. Como a aproximação quase-harmônica necessita das frequências de vibração do sistema, primeiramente validamos nossos resultados comparando-os com resultados experimentais de espectroscopia Raman e Infravermelho para depois obter as propriedades termodinâmicas.

\section{$\mathrm{MgCO}_{3}$}

Utilizou-se a célula primitiva romboédrica da magnesita para se calcular as frequências dos modos normais de vibração da rede, que possui uma base de duas unidades de $\mathrm{MgCO}_{3}$, totalizando dez átomos. Isso corresponde a 30 graus de liberdade e 30 frequências de vibração, sendo 3 (três) ramos acústicos 
e 27 ramos óticos. No ponto $\Gamma$, as frequências dos modos acústicos são nulas e, portanto, tem-se 27 valores de frequência não nulos. Estes modos normais de vibração, no ponto $\Gamma$, podem ser classificadas de acordo com as representações irredutíveis do grupo pontual $D_{3 d}$ :

$$
\Gamma_{\text {tot }}^{\mathrm{MgCO}_{3}}=A_{1 g}+2 A_{1 u}+3 A_{2 g}+3 A_{2 u}+4 E_{g}+5 E_{u}
$$

onde os modos $A_{1 g}$ e $E_{g}$ são ativos por espectroscopia Raman, $A_{2 u}$ e $E_{u}$ são ativos no infravermelho e os $A_{1 u}$ e $A_{2 g}$ são silenciosos. A tabela 5.2 apresenta os valores das frequências da magnesita, obtidas a $P=0$.

Comparando os resultados com os dados experimentais observa-se uma Tabela 5.2: Frequências dos modos normais de vibração ativas por Raman (R) e infravermelho $(\mathrm{I})$ do $\mathrm{MgCO}_{3}(\mathrm{R} \overline{3} \mathrm{c})$. Os modos estão dados em termos das representações irredutíveis do grupo de simetria $D_{3 d}$ e em unidades de $\mathrm{cm}^{-1}$. S significa modo silencioso. Dados experimentais de espectroscopia Raman são da referência [171] e no infravermelho da referência [172].

\begin{tabular}{||c|c|c|c|c||}
\hline \hline Modo & LDA & GGA & Exp. & Atividade \\
\hline \hline$E_{u}$ & 224,2 & 223,5 & 227 & $\mathrm{I}$ \\
$E_{g}$ & 230,4 & 203,8 & 213 & $\mathrm{R}$ \\
$A_{2 u}$ & 231,0 & 224,1 & 254 & $\mathrm{I}$ \\
$A_{2 g}$ & 311,8 & 296,2 & - & $\mathrm{S}$ \\
$E_{u}$ & 330,4 & 293,1 & 308 & $\mathrm{I}$ \\
$E_{g}$ & 342,3 & 311,9 & 329 & $\mathrm{R}$ \\
$A_{2 g}$ & 381,9 & 351,3 & - & $\mathrm{S}$ \\
$A_{1 u}$ & 384,3 & 356,5 & - & $\mathrm{S}$ \\
$E_{u}$ & 394,3 & 343,0 & 355 & $\mathrm{I}$ \\
$A_{2 u}$ & 402,1 & 347,7 & 380 & $\mathrm{I}$ \\
$E_{g}$ & 725,4 & 708,7 & 738 & $\mathrm{R}$ \\
$E_{u}$ & 734,4 & 715,8 & 749 & $\mathrm{I}$ \\
$A_{2 u}$ & 834,6 & 830,5 & 885 & $\mathrm{I}$ \\
$A_{2 g}$ & 844,4 & 837,6 & - & $\mathrm{S}$ \\
$A_{1 g}$ & 1107,2 & 1068,0 & 1094 & $\mathrm{R}$ \\
$A_{1 u}$ & 1109,0 & 1069,7 & - & $\mathrm{S}$ \\
$E_{u}$ & 1455,5 & 1396,0 & 1446 & $\mathrm{I}$ \\
$E_{g}$ & 1475,2 & 1413,2 & 1444 & $\mathrm{R}$ \\
\hline \hline
\end{tabular}


boa concordância e, na média, as frequências são superestimadas pelo funcional LDA e subestimadas pelo GGA. Os cálculos iniciais da dispersão de estados vibracionais para a magnesita, $\mathrm{MgCO}_{3}$ na estrutura $\mathrm{R} \overline{3} \mathrm{c}$, foi obtida para pressão nula. Foram realizados testes de convergência com respeito ao número de pontos q utilizados para efetuar a integração na primeira zona de Brillouin. Variando o conjunto de pontos q, de 8 até 64 pontos, verificamos que a rede mínima de 8 pontos já é suficiente para descrever o sistema, dentro do critério de convergência pré-estabelecido. Portanto, utilizamos a rede de 8 pontos q para obter a dispersão de fônons para diversos valores de pressão. A figura 5.11 ilustra os resultados obtidos para os valores $P=0$ e $P=75 \mathrm{GPa}$.

Percebe-se que o aumento da pressão aumenta a dispersão dos ramos, sendo que a região de frequências mais baixas é mais afetada. Observamos que para valores de pressão de até $150 \mathrm{GPa}$, pressão máxima estudada neste

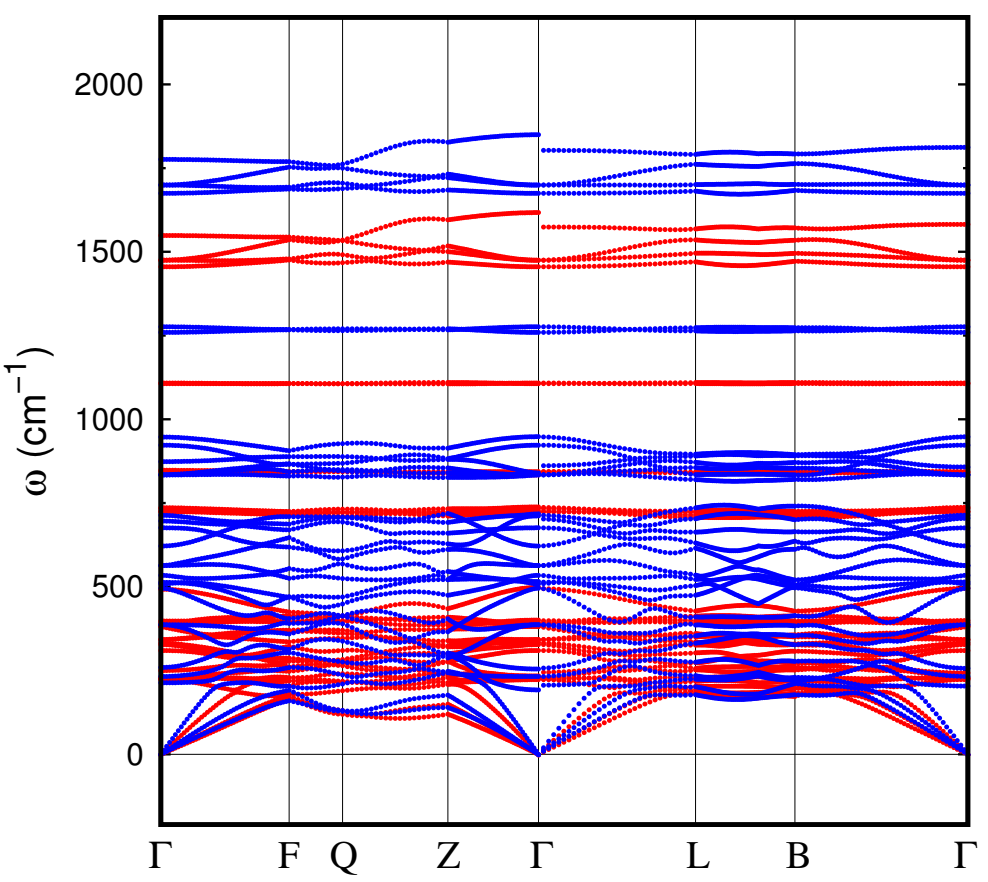

Figura 5.11: Dispersão de fônons, para várias direções de alta simetria da primeira zona de Brillouin, para a magnesita, $\mathrm{MgCO}_{3}$ na estrutura $\mathrm{R} \overline{3} \mathrm{c}$, para pressão nula (linhas vermelhas) e $P=75 \mathrm{GPa}$ (linhas azuis). 
trabalho, não são encontrados valores negativos para as frequências, indicando que esta estrutura cristalina seria dinamicamente estável nestas condições, apesar de existirem estruturas mais estáveis, como mostrado no capítulo anterior para cálculos estáticos (pressão de transição $\mathrm{R} \overline{3} \mathrm{c} \Rightarrow \mathrm{C} 2 / \mathrm{m}$ em $76 \mathrm{GPa}$ ).

A densidade de estados vibracionais (VDoS) foi calculada para diversos valores de pressão, de tal forma a se construir a energia livre de Helmholtz $F$ do sistema. Uma vez obtida esta função, todas as propriedades termodinâmicas podem ser calculadas, permitindo-se obter os parâmetros da equação de estado em diferentes valores de temperatura. A tabela 5.3 mostra estes resultados para $T=0$ (estático) e para a temperatura ambiente $T=300 \mathrm{~K}$.

O volume aumenta com o aumento da temperatura (efeitos de dilatação térmica). Como o funcional LDA, no caso estático, fornece um valor de volume menor que o experimental, a incorporação de efeitos térmicos faz com que este valor aumente, aproximando-se do valor experimental. O oposto ocorre com o funcional GGA, pois já prevê um valor de volume maior que o experimental e a inclusão de efeitos térmicos faz com que este valor aumente, afastando-se do valor experimental. Entretanto, podemos observar que o aumento de temperatura de $300 \mathrm{~K}$ resulta em um aumento de volume de apenas 0,9\% e 1,1\% nos resultados obtidos com os funcionais LDA e GGA, respectivamente. Por conseguinte, a introdução de efeitos térmicos afeta muito pouco o valor do volume do sistema, validando a prática usual de se comparar os resultados obtidos atra-

Tabela 5.3: Parâmetros da equação de estado da magnesita, $\mathrm{MgCO}_{3}$ na estrutura $\mathrm{R} \overline{3} \mathrm{c}$, à $T=0 \mathrm{~K}$ (estático) e à $T=300 \mathrm{~K}$. Dados experimentais são da referência [114]. O volume $\left(V_{0}\right)$ é dado em $\AA^{3}$, o bulk modulus $\left(K_{0}\right)$ é dado em GPa e a derivada do bulk modulus $\left(K_{0}^{\prime}\right)$ é adimensional.

\begin{tabular}{||l|c|c|c|c|c|c||}
\hline \hline \multirow{2}{*}{} & \multicolumn{3}{|c|}{ Estático $(T=0 \mathrm{~K})$} & \multicolumn{3}{c||}{$T=300 \mathrm{~K}$} \\
\cline { 2 - 7 } & $V_{0}$ & $K_{0}$ & $K_{0}^{\prime}$ & $V_{0}$ & $K_{0}$ & $K_{0}^{\prime}$ \\
\hline GGA & 290,77 & 100 & 4,48 & 293,46 & 96 & 3,70 \\
LDA & 268,34 & 122 & 4,44 & 271,30 & 115 & 3,86 \\
Exp. & - & - & - & 279,28 & 119 & 4,02 \\
\hline \hline
\end{tabular}


vés de cálculos estáticos com dados de experimentos feitos a $300 \mathrm{~K}$. Os erros introduzidos nos valores do volume devido ao funcional de troca e correlação utilizado é bem maior (cerca de 5\% para o GGA e 3\% para o LDA). Como já mencionado, há uma correlação entre o bulk modulus e o volume. Como efeitos de dilatação térmica aumentam o volume, os valores de $K$ diminuem com o uso de ambos funcionais. Entretanto, o erro cometido nas propriedades elásticas aumenta ligeiramente quando efeitos térmicos são considerados. A figura 5.12 mostra o coeficiente de expansão térmica $(\alpha)$ obtido para a magnesita.

A aproximação quase-harmônica, utilizada para construir a energia livre de Helmholtz, é uma boa aproximação para descrever as propriedades termodinâmicas desde que não haja interação entre os fônons. Esta situação é válida para baixas temperaturas. Entretanto, não existe uma maneira clara de se estabelecer para até qual valor de temperatura os resultados utilizando a aproximação quase-harmônica são válidos. Um fato conhecido experimentalmente é que a expansividade térmica $\alpha(T)$, a altos valores de $T$, apresenta uma variação aproximadamente linear com a temperatura, até o ponto de fusão do sistema. Assim, uma boa estimativa do limite de validade da aproximação quase-harmônica está relacionada com a segunda derivada, em relação à temperatura, de $\alpha(T)$, que deve ser nula [38]. Pelo resultado apresentado na figura 5.12, percebe-se que

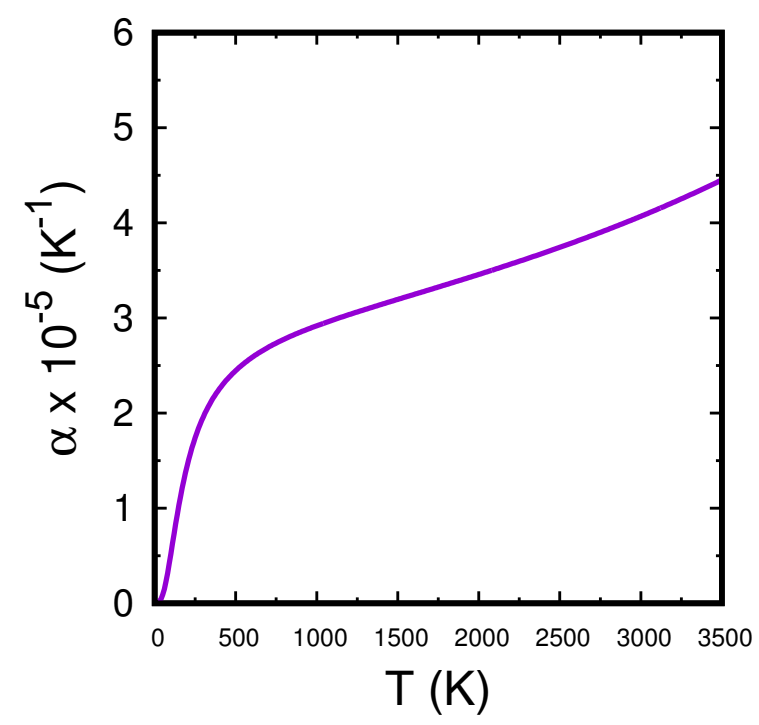

Figura 5.12: Expansividade térmica do $\mathrm{MgCO}_{3}$ na estrutura $\mathrm{R} \overline{3} \mathrm{c}$ (magnesita). 

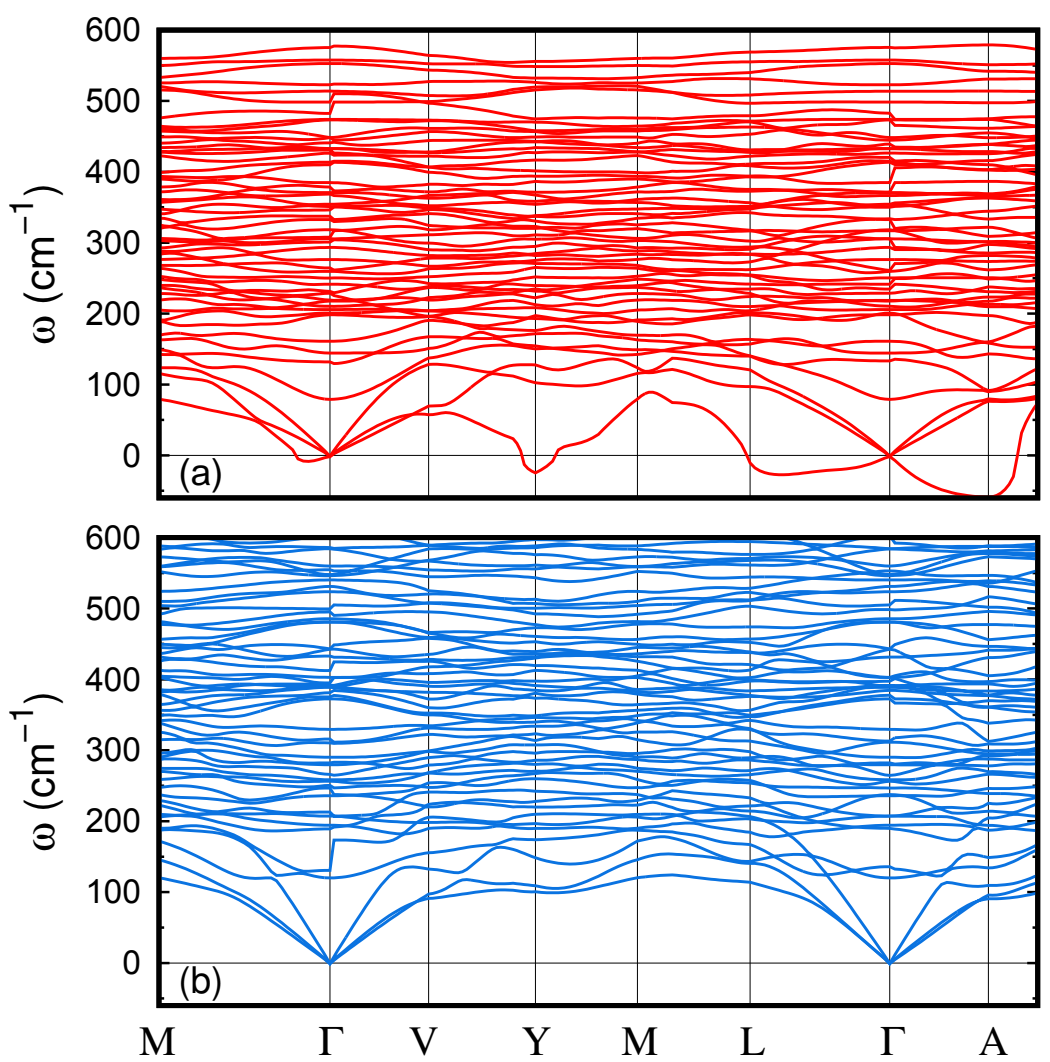

Figura 5.13: Dispersão de fônons, para várias direções de alta simetria da primeira zona de Brillouin, do $\mathrm{MgCO}_{3}$ na estrutura $\mathrm{C} 2 / \mathrm{m}$ para valores de pressão: (a) $P=0$ e (b) $P=30 \mathrm{GPa}$.

para valores de temperatura de até mais ou menos $3000 \mathrm{~K}$ a segunda derivada de $\alpha(T)$ é nula (pois o gráfico é próximo de uma reta) e, a partir desta temperatura, o gráfico apresenta uma leve curvatura. Assim, como o manto inferior chega a temperaturas de até $2500 \mathrm{~K}$, então a aproximação quase-harmônica, para esse material, é válida em toda a extensão de temperatura do manto inferior.

$\mathrm{Na}$ estrutura monoclínica do $\mathrm{MgCO}_{3}$, grupo espacial $\mathrm{C} 2 / \mathrm{m}$, a base possui 30 átomos e, então, possui 90 frequências de vibração, sendo três ramos acústicos e 87 ramos óticos. Obteve-se, também, a dispersão de fônons desta estrutura, que está mostrada na figura 5.13 para dois valores de pressão. Verifica-se que para $P=0$ e $P=10 \mathrm{GPa}$, existem diversas valores negativos de frequência 


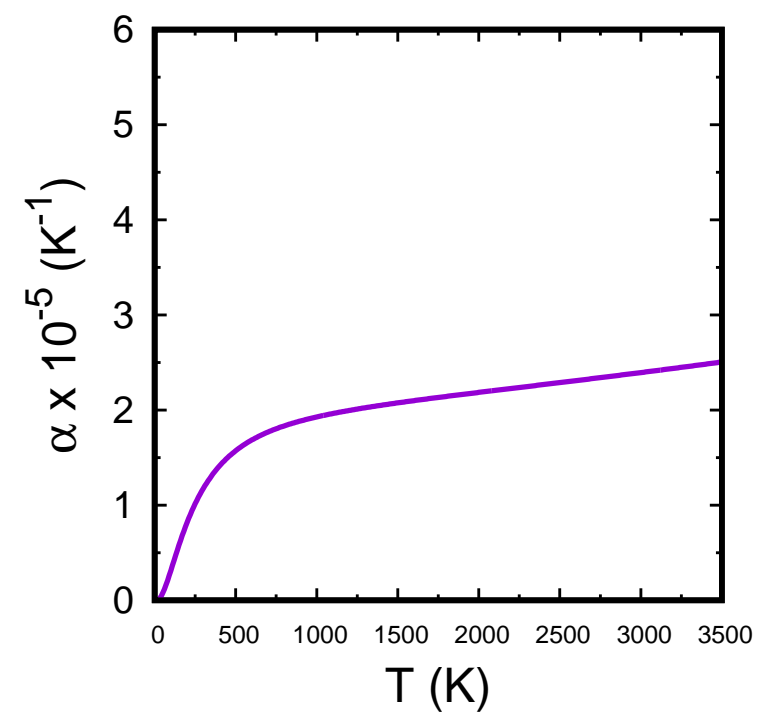

Figura 5.14: Coeficiente de expansão térmica do $\mathrm{MgCO}_{3}$ na estrutura $\mathrm{C} 2 / \mathrm{m}$, à pressão de $45 \mathrm{GPa}$.

no espectro de fônons, o que indica que esta estrutura não é estável nestas condições. Entretanto, para valores a partir de $30 \mathrm{GPa}$ as frequências são todas positivas, mostrando a estabilidade desta estrutura nestas condições. Novamente, com as frequências calculadas, utilizamos a aproximação quaseharmônica para construir a energia livre de Helmholtz, e com esta calcular as propriedades termodinâmicas deste material nesta estrutura. Na figura 5.14 é mostrada a expansividade térmica do $\mathrm{MgCO}_{3}$ na estrutura monoclínica. Como esta estrutura não é estável à pressão nula, esta expansão térmica é calculada à pressão de 40 GPa. Procedendo de modo análogo ao descrito anteriormente, para a estrutura $\mathrm{R} \overline{3} c$, podemos concluir que a aproximação quase-harmônica é válida para todo o intervalo de temperatura simulado, pois a expansividade térmica $\alpha(T)$ apresenta uma variação praticamente linear com a temperatura. Assim, esta metodologia é válida nas regiões de interesse para o estudo do manto terrestre.

De posse da energia livre de Helmholtz, obtivemos a energia livre de Gibbs para estudar a estabilidade do $\mathrm{MgCO}_{3}$ em altas temperaturas. Comparando a energia livre de Gibbs da estrutura $\mathrm{R} \overline{3} \mathrm{c}$ com a $\mathrm{C} 2 / \mathrm{m}$, construiu-se um diagrama $P \times T$, mostrado na figura 5.15, para a energia de transição, ou seja, para a situ- 


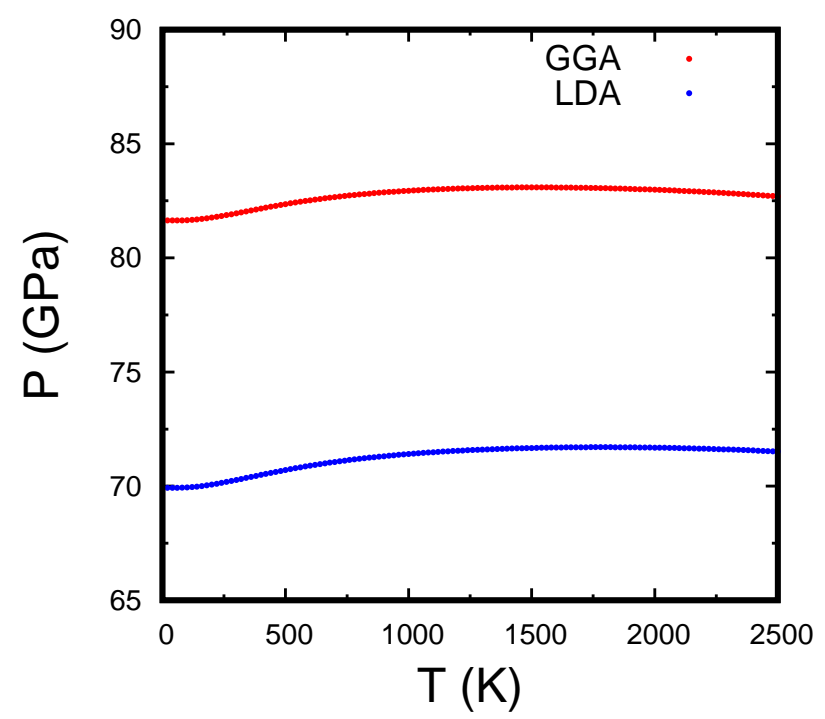

Figura 5.15: Diagrama da pressão de transição de fase da estrutura $R \overline{3} c$ para a $\mathrm{C} 2 / \mathrm{m}$ no $\mathrm{MgCO}_{3}$, em função da temperatura, obtido com a utilização dos funcionais LDA (linha azul) e GGA (linha vermelha), dentro da aproximação quaseharmônica.

ação onde a diferença entre os valores da energia de Gibbs dos dois sistemas é nula. Percebe-se que a pressão onde ocorre a transição de fase estrutural não é significativamente alterada com a inclusão de efeitos térmicos, apresentando um pequeno aumento com o aumento da temperatura. Este comportamento é interessante, pois mostra que as previsões teóricas para a mudança de fase do $\mathrm{MgCO}_{3}$ depende muito pouco da temperatura, o que implica na conclusão de que a profundidade em que essa transição irá ocorrer, no interior da Terra, não depende da geoterma. Este fato pode ser útil para a construção de modelos geofísicos, pois há uma grande incerteza na determinação da geoterma.

\section{$\mathrm{CaCO}_{3}$}

A calcita tem a mesma estrutura cristalina da magnesita e, portanto, apresenta 30 frequências de vibração, sendo três ramos acústicos e 27 ramos óticos, e no ponto $\Gamma$ os modos normais de vibração podem ser classificadas de acordo com as representações irredutíveis do grupo pontual $D_{3 d}$. A tabela 5.4 apresenta, 
Tabela 5.4: Frequências dos modos normais de vibração ativas por Raman (R) e infravermelho $(\mathrm{I})$ do $\mathrm{CaCO}_{3}$ calcita $(\mathrm{R} \overline{\mathrm{z}} \mathrm{c})$, obtidas utilizando-se os funcionais LDA e GGA. Os modos estão dados em termos das representações irredutíveis do grupo de simetria $D_{3 d}$ e em unidades de $\mathrm{cm}^{-1}$. S significa modo silencioso. Dados experimentais são da referência [171].

\begin{tabular}{||c|c|c|c|c||}
\hline \hline Modo & LDA & GGA & Exp. & Atividade \\
\hline$A_{2 u}$ & 111,1 & 93,8 & 92 & $\mathrm{I}$ \\
$E_{u}$ & 124,1 & 96,3 & 102 & $\mathrm{I}$ \\
$E_{g}$ & 156,7 & 164,5 & 156 & $\mathrm{R}$ \\
$A_{2 g}$ & 170,1 & 181,7 & - & $\mathrm{S}$ \\
$E_{u}$ & 207,9 & 219,4 & 223 & $\mathrm{I}$ \\
$E_{g}$ & 265,2 & 279,2 & 284 & $\mathrm{R}$ \\
$E_{u}$ & 270,3 & 294,0 & 297 & $\mathrm{I}$ \\
$A_{1 u}$ & 281,2 & 290,3 & - & $\mathrm{S}$ \\
$A_{2 u}$ & 279,7 & 308,2 & 303 & $\mathrm{I}$ \\
$A_{2 g}$ & 301,2 & 322,5 & - & $\mathrm{S}$ \\
$E_{u}$ & 687,1 & 689,1 & 712 & $\mathrm{I}$ \\
$E_{g}$ & 688,4 & 688,3 & 712 & $\mathrm{R}$ \\
$A_{2 u}$ & 838,6 & 828.2 & 872 & $\mathrm{I}$ \\
$A_{2 g}$ & 845,1 & 833,4 & - & $\mathrm{S}$ \\
$A_{1 u}$ & 1080,7 & 1069,9 & - & $\mathrm{S}$ \\
$A_{1 g}$ & 1081,7 & 1070,2 & 1086 & $\mathrm{R}$ \\
$E_{u}$ & 1401,6 & 1382,4 & 1407 & $\mathrm{I}$ \\
$E_{g}$ & 1433,3 & 1413,1 & 1434 & $\mathrm{R}$ \\
\hline \hline
\end{tabular}

para a calcita, os valores das frequências dos modos normais de vibração, a $P=0$, comparadas com resultados experimentais.

Comparando os resultados com os dados experimentais observa-se que as frequências estão razoavelmente bem descritas, tanto pela utilização do funcional LDA como do GGA. Foram realizados, também, testes de convergência com respeito ao número de pontos q utilizados para efetuar a integração na primeira zona de Brillouin e, como anteriormente, concluímos que a rede mínima de oito pontos já é suficiente para descrever o sistema. Portanto, utilizamos a rede de oito pontos q para obter a dispersão de fônons para diversos valores de pressão, sendo que a figura 5.16 mostra o espectro de fônons da calcita para 


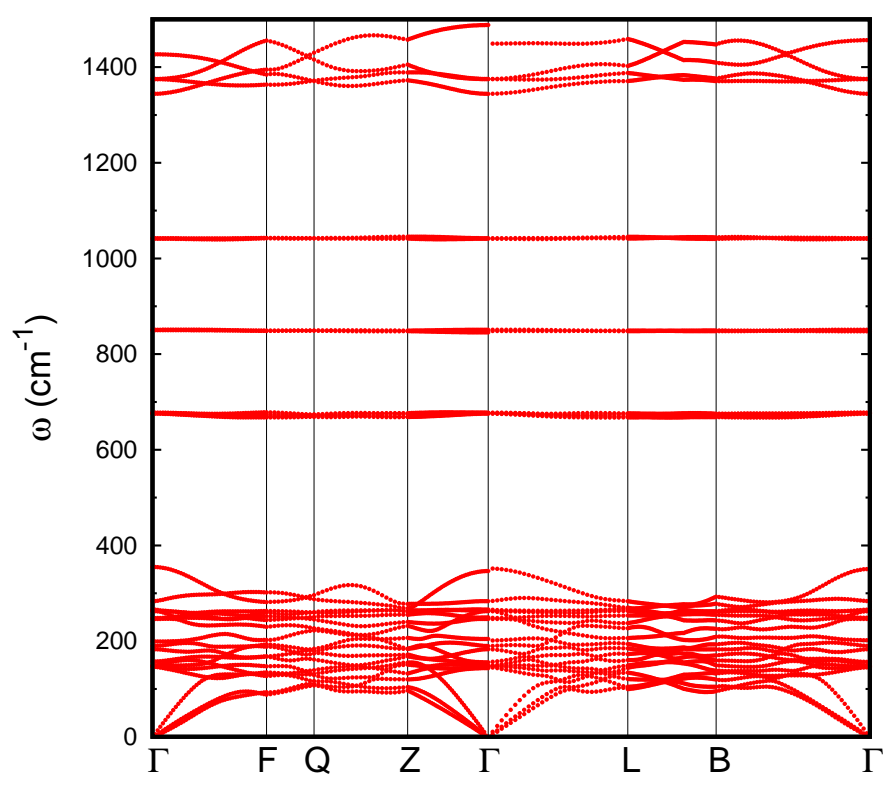

Figura 5.16: Dispersão de fônons, para várias direções de alta simetria da primeira zona de Brillouin, do $\mathrm{CaCO}_{3}$ calcita $(\mathrm{R} \overline{3} \mathrm{c})$, à $P=0$.

pressão nula.

Novamente, com a densidade de estados vibracionais, obtida para diversos valores de pressão, utilizamos a aproximação quase-harmônica para calcular as propriedades termodinâmicas deste material nas estruturas calcita $(R \overline{3} c)$ e aragonita (Pmcn). Como a aproximação quase-harmônica é válida desde que as frequências dependam apenas do volume, uma estimativa das temperaturas até onde pode-se confiar nos resultados pode ser obtida do coeficiente de expansão térmica $\alpha(T)$. Assim, apresentamos na figura 5.17 a expansividade térmica do $\mathrm{CaCO}_{3}$ nas estruturas calcita e aragonita.

Para a aragonita, podemos observar, analisando a figura 5.17(b), que a relação de $\alpha$ com $T$ é aproximadamente linear e começa a divergir para valores de temperatura em torno de $700 \mathrm{~K}$. Essa temperatura é muito baixa em relação àquelas do manto inferior e, portanto, essa aproximação não é adequada para se descrever este material para as temperaturas de interesse. Para a calcita, os resultados apresentados na figura 5.17(a) mostram que $\alpha$ diverge para valores 

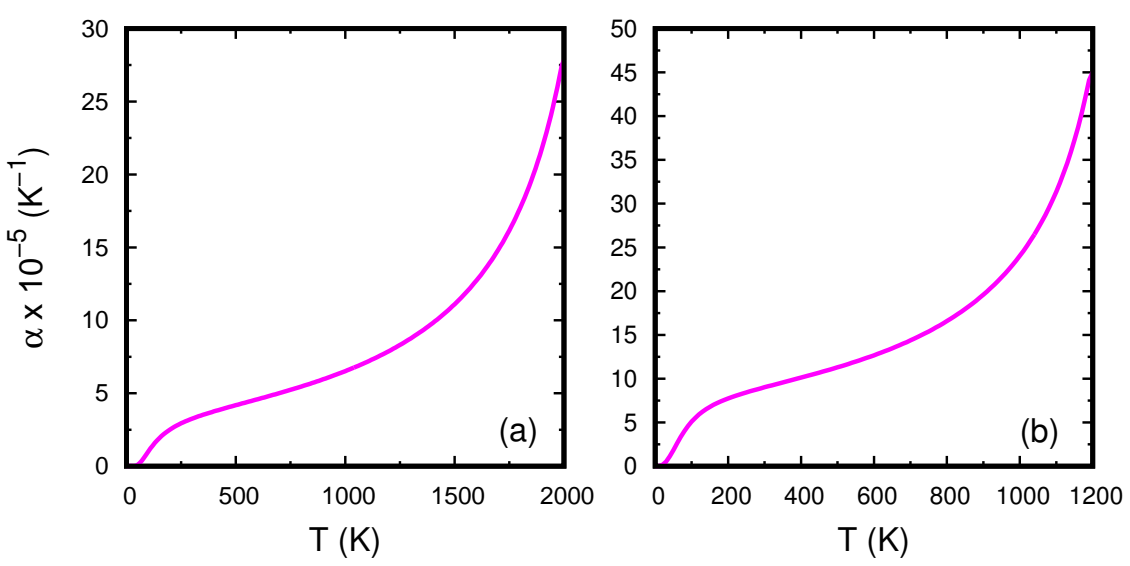

Figura 5.17: Coeficiente de expansão térmica do $\mathrm{CaCO}_{3}$ nas estruturas (a) calcita $(\mathrm{R} \overline{\mathrm{3}} \mathrm{c})$ e (b) aragonita (Pmcn).

de temperatura em torno de $1200 \mathrm{~K}$, valor quase o dobro do da aragonita, mas ainda muito inferior àquelas do interior terrestre, como pode ser observado na geoterma da figura 5.1. Estes resultados mostram que a aproximação quaseharmônica pode ser utilizada até temperaturas de aproximadamente $600 \mathrm{~K}$ para a aragonita e $1000 \mathrm{~K}$ para a calcita.

As tabelas 5.5 e 5.6 apresentam os parâmetros estruturais, obtidos através da equação de estado, para $T=0 \mathrm{~K}$ e $T=300 \mathrm{~K}$, para o $\mathrm{CaCO}_{3}$ nas estruturas calcita $(R \overline{3} c)$ e aragonita (Pmcn), respectivamente, juntamente com dados experimentais, quando disponíveis.

Tabela 5.5: Parâmetros da equação de estado à $T=0 \mathrm{~K}$ (estático) e à $T=300 \mathrm{~K}$ do $\mathrm{CaCO}_{3}$ na estrutura $\mathrm{R} \overline{3} \mathrm{c}$ (calcita). Dados experimentais são da referência [127]. $\mathrm{O}$ volume $\left(V_{0}\right)$ é dado em $\AA^{3}$, o bulk modulus $\left(K_{0}\right)$ é dado em GPa e a derivada do bulk modulus $\left(K_{0}^{\prime}\right)$ é adimensional.

\begin{tabular}{||c|c|c|c|c|c|c||}
\hline \hline \multirow{2}{*}{} & \multicolumn{3}{|c|}{ Estático $(T=0 \mathrm{~K})$} & \multicolumn{3}{c||}{$T=300 \mathrm{~K}$} \\
\cline { 2 - 7 } & $V_{0}$ & $K_{0}$ & $K_{0}^{\prime}$ & $V_{0}$ & $K_{0}$ & $K_{0}^{\prime}$ \\
\hline GGA & 380,98 & 70 & 4,64 & 386,78 & 63 & 4,47 \\
LDA & 348,66 & 85 & 4,27 & 351,55 & 80 & 4,78 \\
Exp. & - & - & - & 367,84 & 73 & 3,12 \\
\hline \hline
\end{tabular}


Tabela 5.6: Parâmetros da equação de estado à $T=0 \mathrm{~K}$ (estático) e à $T=300 \mathrm{~K}$ do $\mathrm{CaCO}_{3}$ na estrutura Pmcn (aragonita). Dados experimentais são da referência [130]. O volume $\left(V_{0}\right)$ é dado em $\AA^{3}$, o bulk modulus $\left(K_{0}\right)$ é dado em GPa e a derivada do bulk modulus $\left(K_{0}^{\prime}\right)$ é adimensional.

\begin{tabular}{||c|c|c|c|c|c|c||}
\hline \hline \multirow{2}{*}{} & \multicolumn{3}{|c|}{ Estático $(T=0 \mathrm{~K})$} & \multicolumn{3}{c||}{$T=300 \mathrm{~K}$} \\
\cline { 2 - 7 } & $V_{0}$ & $K_{0}$ & $K_{0}^{\prime}$ & $V_{0}$ & $K_{0}$ & $K_{0}^{\prime}$ \\
\hline GGA & 232,89 & 74 & 3,74 & 241,09 & 55 & 4,92 \\
LDA & 211,90 & 85 & 3,91 & 215,56 & 80 & 4,81 \\
Exp. & - & - & - & 226,92 & 71 & 4,63 \\
\hline \hline
\end{tabular}

Novamente, nota-se que a incorporação de efeitos térmicos leva os resultados obtidos com o funcional LDA a ficarem mais próximos de resultados experimentais. A utilização do funcional LDA, em geral, resulta em valores de volume menores que os experimentais, de forma que a inclusão de efeitos térmicos aproxima os resultados dos dados experimentais. Assim, a aproximação quase-harmônica resultou em uma melhor descrição tanto para o volume $V_{0}$ como para o bulk modulus.

A figura 5.18 mostra a energia de Gibbs em função da pressão para $T=0 \mathrm{~K}$ (aproximação de rede estática) e $T=700 \mathrm{~K}$. Como discutido e mostrado no
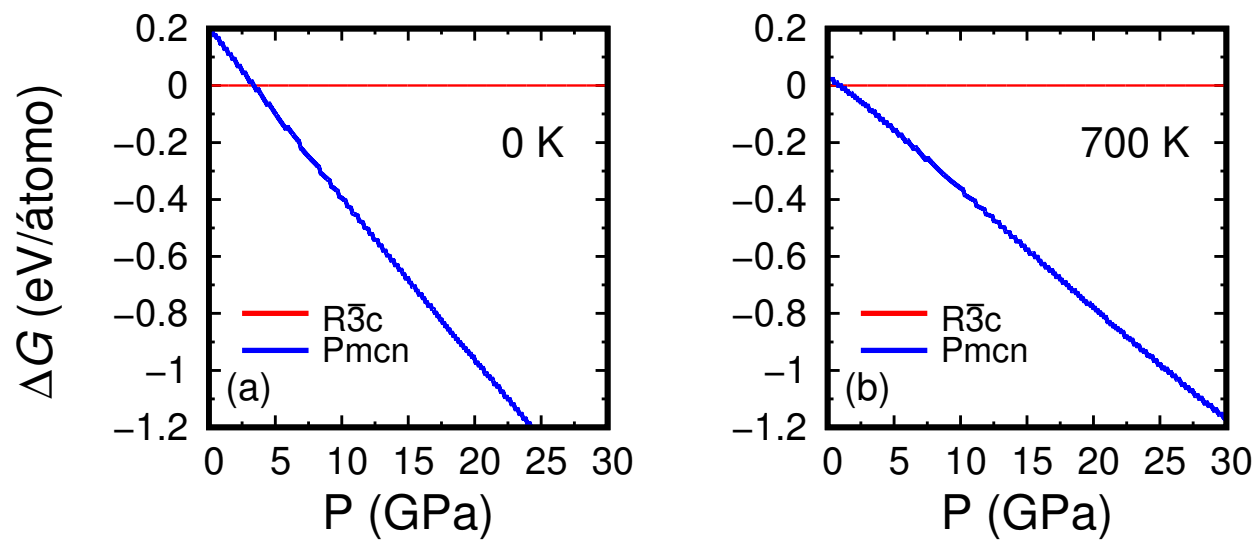

Figura 5.18: Energia livre de Gibbs, como função da pressão, do $\mathrm{CaCO}_{3}$ nas estruturas calcita $(\mathrm{R} \overline{\mathrm{3}} \mathrm{c})$ (linha vermelha) e aragonita (Pmcn) (linha azul), relativamente à energia da calcita, para (a) $T=0 \mathrm{~K}$ e (b) $T=700 \mathrm{~K}$. 
capítulo anterior para $\circ \mathrm{CaCO}_{3}$, há uma transformação estrutural, da fase $\mathrm{R} \overline{3} \mathrm{C}$ (calcita) para a Pmcn (aragonita). Neste ponto, estudamos essa transição de fase como função da temperatura, calculando a energia livre de Gibbs como função da pressão. $O$ valor da pressão de transição, obtida com o funcional LDA foi negativo e por isso utilizamos aqui aquele obtido com o funcional GGA, que forneceu o valor da pressão de transição em torno de $4 \mathrm{GPa}$.

$\mathrm{O}$ resultado a $T=0 \mathrm{~K}$, apresentado na figura 5.18(a), indica que a introdução de efeitos de ponto zero tem pouco influência, uma vez que a pressão de transição continua próxima de $P=4 \mathrm{GPa}$, como no caso estático mostrado no capítulo anterior. Entretanto, o resultado para $T=700 \mathrm{~K}$, apresentado na figura 5.18(b), mostra que a pressão de transição é menor, sugerindo que ela é dependente da temperatura. Para melhor analisar este resultado, a figura 5.19 mostra o gráfico $P \times T$ para a energia de transição, ou seja, para a situação em que a diferença entre os valores da energia de Gibbs das duas estruturas é nula.

Verifica-se que, ao contrário do que ocorre com $\circ \mathrm{MgCO}_{3}$, a pressão em que ocorre a transição de fase estrutural calcita-aragonita, para o $\mathrm{CaCO}_{3}$, é alterada com a temperatura, mas diminui com o aumento da temperatura, como

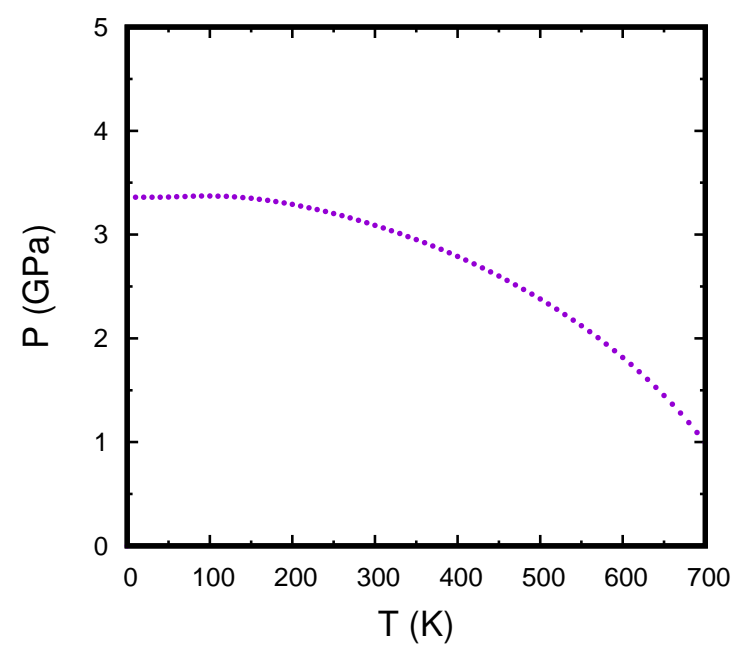

Figura 5.19: Diagrama da pressão de transição de fase da estrutura calcita ( $R \overline{3} c)$ para a aragonita (Pmcn) do $\mathrm{CaCO}_{3}$, em função da temperatura, com a utilização do funcional GGA, dentro da aproximação quase-harmônica. 


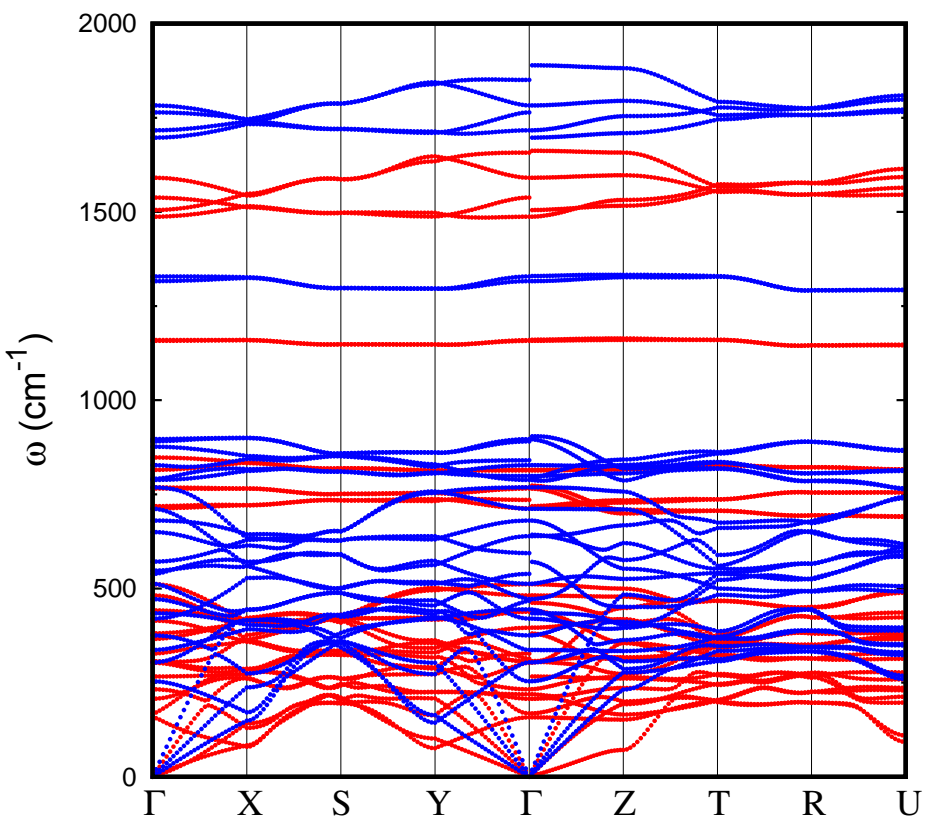

Figura 5.20: Dispersão de fônons, para várias direções de alta simetria da primeira zona de Brillouin, do $\mathrm{CaCO}_{3}$ na estrutura pós-aragonita (Pmmn) para $P=40 \mathrm{GPa}$ (linhas vermelhas) e $P=150 \mathrm{GPa}$ (linhas azuis).

mostra a figura 5.19. Apesar desta tendência ser inversa àquela dos resultados experimentais $[173,174]$, a variação da pressão com a temperatura é muito pequena e está dentro do erro cometido na equação de estado, utilizada no cálculo da energia de Gibbs. Entretanto, apesar destes resultados, a aragonita não é estável para os valores de pressão do manto terrestre.

Diversos estudos mostraram que nas condições extremas de pressão e temperatura, o $\mathrm{CaCO}_{3}$ sofre outra transformação de fase de tal forma a adotar uma estrutura correspondente ao grupo espacial Pmmn. Assim como a aragonita, esta estrutura também é ortorrômbica, mas com apenas dez átomos na base. No capítulo anterior estudamos estas estruturas e encontramos que o $\mathrm{CaCO}_{3}$ aragonita sofre uma transição de fase à $P \approx 40 \mathrm{GPa}$ para a fase pós-aragonita. A figura 5.20 ilustra os resultados da dispersão de fônons nesta fase para os valores $P=40 \mathrm{GPa}$ e $P=150 \mathrm{GPa}$. Com esta dispersão foi obtida a VDoS utilizando uma rede de oito pontos q, para diversos valores de pressão, iniciando 
em $P=40 \mathrm{GPa}$, uma vez que esta fase é menos estável que a fase aragonita para valores menores que este.

Nota-se um aumento no valor das frequências com o aumento da pressão, ou seja, conforme o volume da célula diminui, os valores das frequências são mais altos, o que está de acordo com o esperado. Adicionalmente, o aumento da pressão acarreta um aumento na dispersão dos ramos, afetando mais a região de frequências mais baixas. Observa-se, também, que esta estrutura é dinamicamente estável em todo o manto terrestre, apesar de não ser possível afirmar que esta é, de fato, a estrutura que o $\mathrm{CaCO}_{3}$ assume em toda extensão do manto, pois podem ocorrer estruturas mais estáveis. Para estimar as temperaturas até onde a aproximação quase-harmônica é válida para descrever as propriedades termodinâmicas, foi obtido a expansividade térmica do $\mathrm{CaCO}_{3}$ na estrutura pós-aragonita à $P=40 \mathrm{GPa}$, que está apresentada na figura 5.21.

Notamos que a relação de $\alpha$ com $T$ é praticamente linear para todo intervalo de temperatura e, portanto, podemos utilizar a aproximação quase-harmônica em toda extensão de temperatura do manto inferior. Para estudar como a pressão de transição de fase varia com a temperatura, obtivemos a energia livre de Gibbs como função da pressão. A figura 5.22 mostra os resultados obtidos para $T=0 \mathrm{~K}$ (aproximação de rede estática mais efeitos de ponto zero) e $T=700 \mathrm{~K}$.

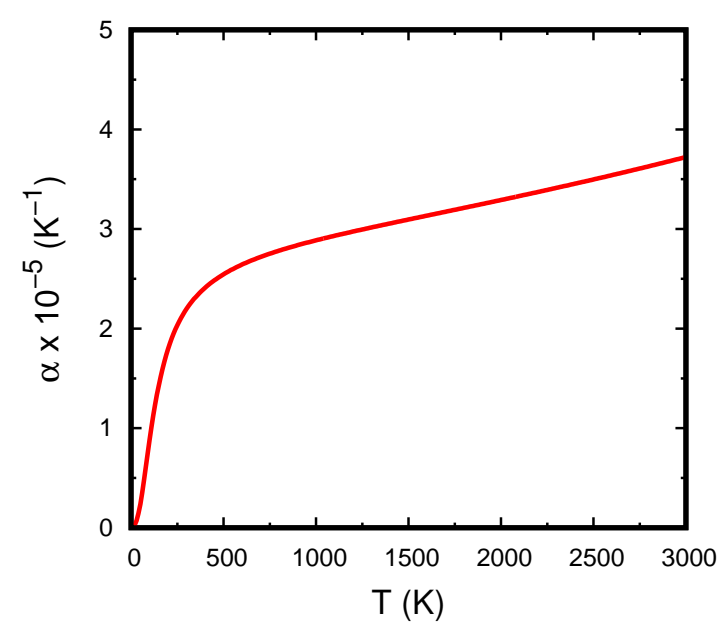

Figura 5.21: Coeficiente de expansão térmica do $\mathrm{CaCO}_{3}$ na estrutura pós-aragonita (Pmmn) para a pressão de $40 \mathrm{GPa}$. 

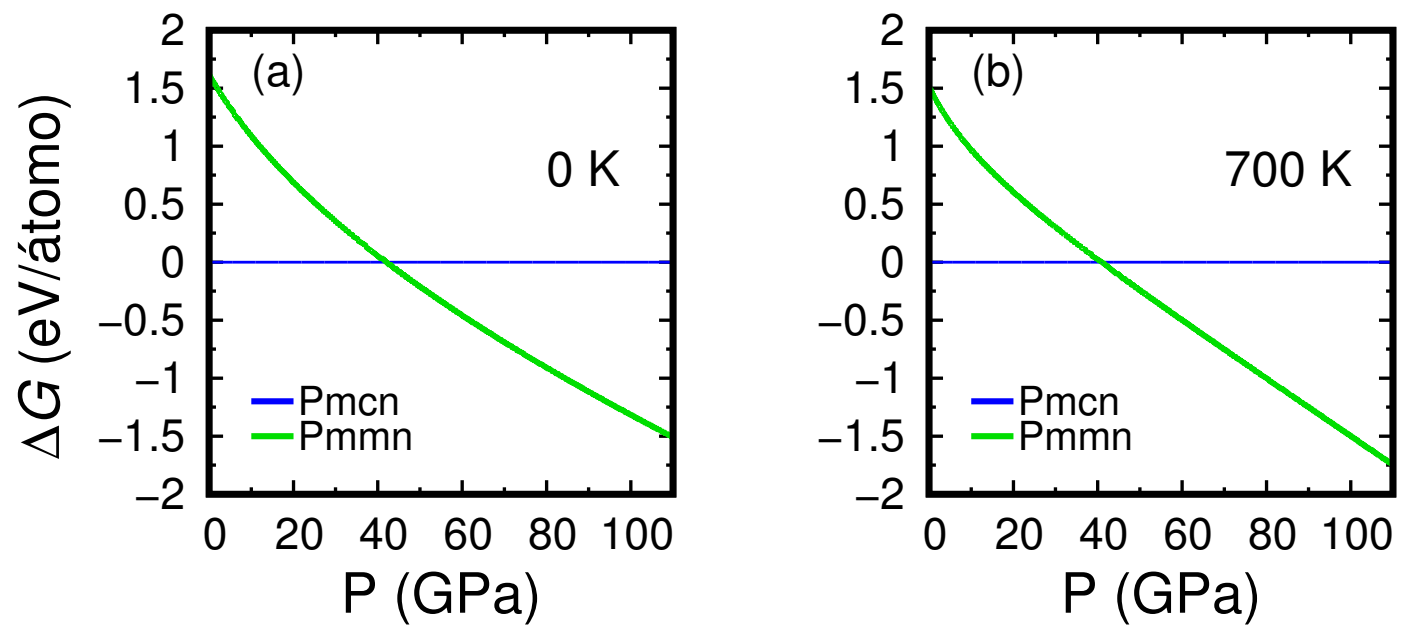

Figura 5.22: Energia livre de Gibbs, como função da pressão, do $\mathrm{CaCO}_{3}$ nas estruturas aragonita (Pmcn) (linha azul) e pós-aragonita (Pmmn) (linha verde), relativamente à energia da aragonita, para (a) $T=0 \mathrm{~K}$ e (b) $T=700 \mathrm{~K}$.

Contrariamente ao observado para a energia de Gibbs calcita-aragonita, em que a pressão de transição de fase depende da temperatura, a figura 5.22 mostra que o valor da pressão em que ocorre a transição de fase estrutural aragonita-pós-aragonita, para o $\mathrm{CaCO}_{3}$, praticamente não se altera com o aumento da temperatura, permanecendo em $P \approx 40 \mathrm{GPa}$ para $T=0 \mathrm{Ke} T=700 \mathrm{~K}$. Para estudar a estabilidade do $\mathrm{CaCO}_{3}$ em altas temperaturas, comparamos a energia livre de Gibbs da estrutura aragonita com a pós-aragonita, construindo um diagrama $P \times T$, mostrado na figura 5.23, para a energia de transição.

Novamente, podemos observar que a inclusão de efeitos de ponto zero não alteram os resultados, pois a pressão de transição de fase em $T=0 \mathrm{~K}$ é aproximadamente a mesma que para o caso estático, mostrado no capítulo anterior. $A$ pressão de transição de fase estrutural aragonita-pós-aragonita praticamente não se altera até aproximadamente a temperatura de $100 \mathrm{~K}$, diminuindo após esta temperatura. Assim, para esta transição, obtivemos que a pressão de transição é pouco alterada com a temperatura, possuindo uma inclinação de Clapeyron negativa. Como não existem resultados experimentais dessa transição, não há como concluir se ela é bem descrita pela teoria utilizada. 


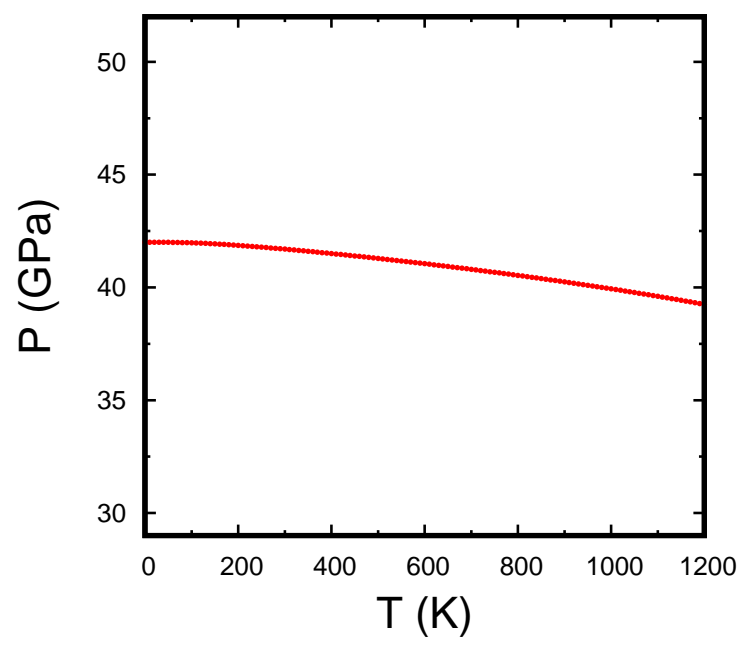

Figura 5.23: Diagrama da pressão de transição de fase da estrutura aragonita (Pmcn) para a pós-aragonita (Pmmn) do $\mathrm{CaCO}_{3}$, em função da temperatura, dentro da aproximação quase-harmônica.

\subsection{Propriedades elásticas a altas temperaturas}

Os resultados dos cálculos das propriedades elásticas, apresentados no capítulo anterior, não consideraram os movimentos dos íons que compõem a estrutura do material, representando os coeficientes elásticos estáticos do cristal. Estes coeficientes elásticos são facilmente calculados dentro da teoria do funcional da densidade, pois podemos utilizar o teorema do Hellman-Feynman generalizado para calcular o tensor de stress do material e, a partir deste, o tensor elástico é trivialmente obtido ${ }^{2}$. O tensor elástico de um material pode, também, ser obtido através de expansões da energia livre, de tal forma que [175]:

$$
C_{i j k l}=\frac{1}{V} \frac{\partial^{2} G(P, T)}{\partial e_{i j} \partial e_{k l}} .
$$

em que $G(P, T)$ é a energia livre de Gibbs, $V$ o volume e $e_{i j}$ uma distorção do cristal. A aproximação quase-harmônica nos permite calcular a energia livre de Helmholtz, dada pela equação 2.52, com a qual a energia de Gibbs é facilmente obtida. Poderíamos, então, utilizar a expressão (2.52) para calcular

\footnotetext{
${ }^{2}$ Ver capítulo 2 e apêndice $B$
} 
$G(P, T)$ e a expressão (5.7) para determinar os coeficientes elásticos como função da pressão e da temperatura. Entretanto, o cálculo destes coeficientes com a expressão (5.7) depende da derivada da energia de Gibbs como função de determinada distorção. Isso implica em se calcular a densidade de estados vibracionais não apenas nas configurações originais, mas também nas configurações distorcidas. Mesmo cálculos de fônons de sistemas simples representam um alto custo computacional. Assim, se imaginarmos um sistema ortorrômbico, por exemplo, com nove coeficientes elásticos, e considerando que precisamos de pelo menos três pontos para o ajuste da curva, necessário para o cálculo do tensor, isso implica em pelo menos 18 novos cálculos de fônons para uma única pressão. Isso torna este método para o cálculo do tensor elástico inviável e é raramente utilizado, a não ser para sistemas muito simples.

Recentemente, um método foi desenvolvido para se determinar o tensor elástico de um material, como função da temperatura, utilizando apenas os estados vibracionais da configuração não distorcida [176]. Isto é possível na aproximação quase-harmônica, pois as frequências são calculadas como função do volume e esta dependência volumétrica das frequências contém informações sobre a dependência das frequências com distorções no sistema. Wu e Wentzcovitch [176] extraíram essa dependência assumindo que a distribuição das frequências é isotrópica e, então, elaboraram um método para se calcular a dependência térmica dos coeficientes elásticos, mostrando que os erros introduzidos por essa aproximação são menores do que os erros experimentais. Atualmente, esse método está desenvolvido para o cálculo dos coeficientes elásticos, como função da temperatura, para as estruturas cúbica, ortorrômbica e tetragonal, e a generalização para qualquer tipo de rede de Bravais está em andamento.

Como as estruturas aragonita e pós-aragonita do $\mathrm{CaCO}_{3}$ são ortorrômbicas, utilizou-se este método para o cálculo dos coeficientes elásticos destas estruturas em diversas temperaturas.

A figura 5.24 mostra a variação das constantes elásticas, em função da pressão, para os resultados obtidos com os cálculos estáticos e para as temperaturas de $300 \mathrm{~K} \mathrm{e} 600 \mathrm{~K}$ para $\circ \mathrm{CaCO}_{3}$ na estrutura aragonita (Pmcn). Como a $P \approx 40 \mathrm{GPa}$ existe uma transição de fase aragonita-pós-aragonita para 0 $\mathrm{CaCO}_{3}$, a pressão máxima apresentada nos gráficos é de $40 \mathrm{GPa}$. Podemos 

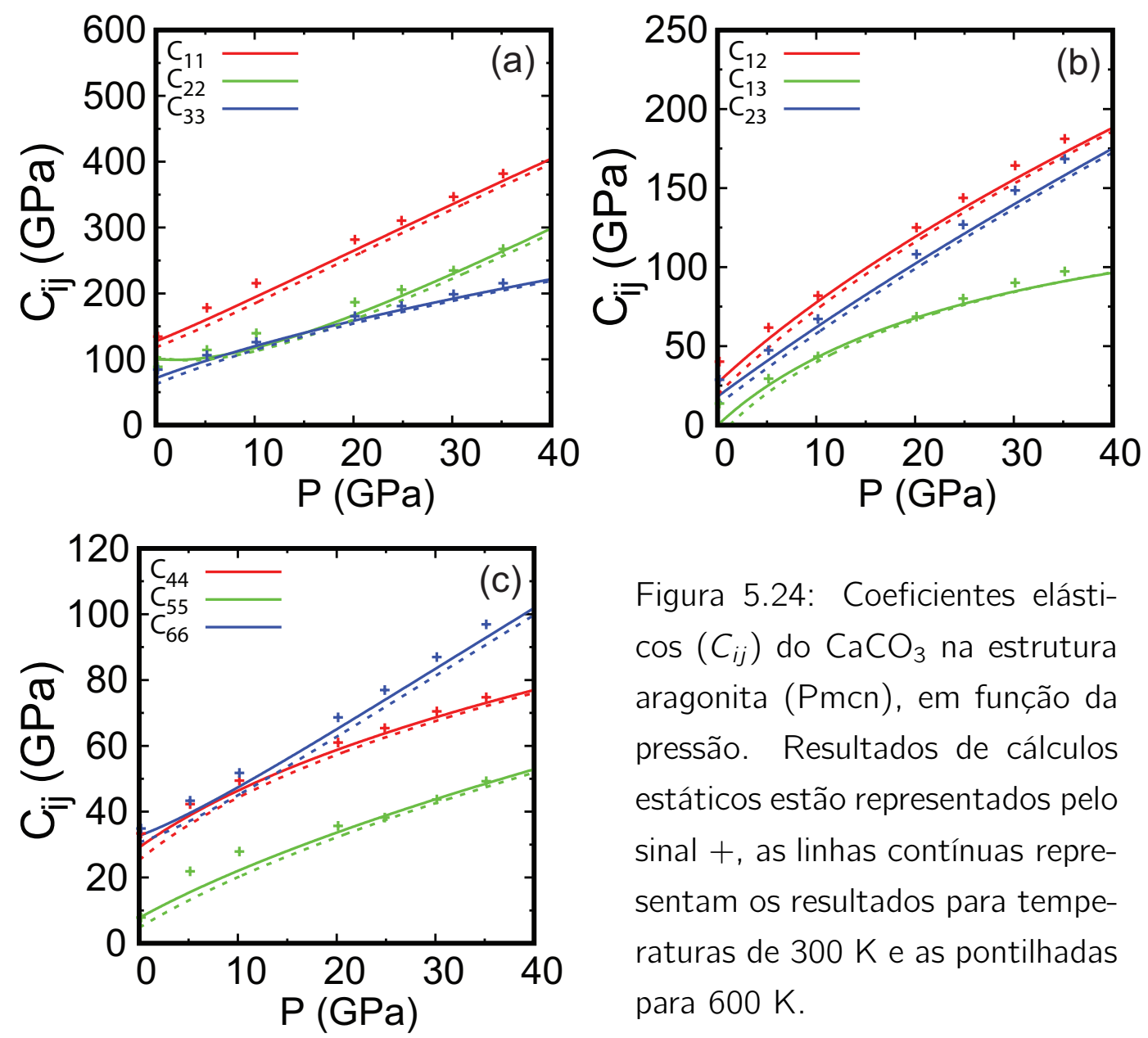

Figura 5.24: Coeficientes elásti$\cos \left(C_{i j}\right)$ do $\mathrm{CaCO}_{3}$ na estrutura aragonita (Pmcn), em função da pressão. Resultados de cálculos estáticos estão representados pelo sinal + , as linhas contínuas representam os resultados para temperaturas de $300 \mathrm{~K}$ e as pontilhadas para $600 \mathrm{~K}$.

observar que o perfil dos coeficientes $C_{i j}$ para a temperatura $T=300 \mathrm{~K}$, quando comparada com os obtidos com os cálculos estáticos, é muito semelhante. Percebemos, também, uma variação para o coeficiente $C_{55}$ a baixas pressões, mas conforme a pressão aumenta, o efeito da temperatura volta a ser pequeno. Para pressões aproximadamente nulas, o coeficiente $C_{22}$ apresenta um comportamento diferente dos demais, ficando aproximadamente constante. O coeficiente $C_{13}$ aparentemente fica negativo para baixas pressões e altas temperaturas. Isso pode ser consequência do fato desta estrutura não ser a mais estável nesta região de pressões.

Estudamos, também, a variação dos coeficientes do tensor elástico em função da temperatura, para diferentes valores de pressão, e, como esperado, os 

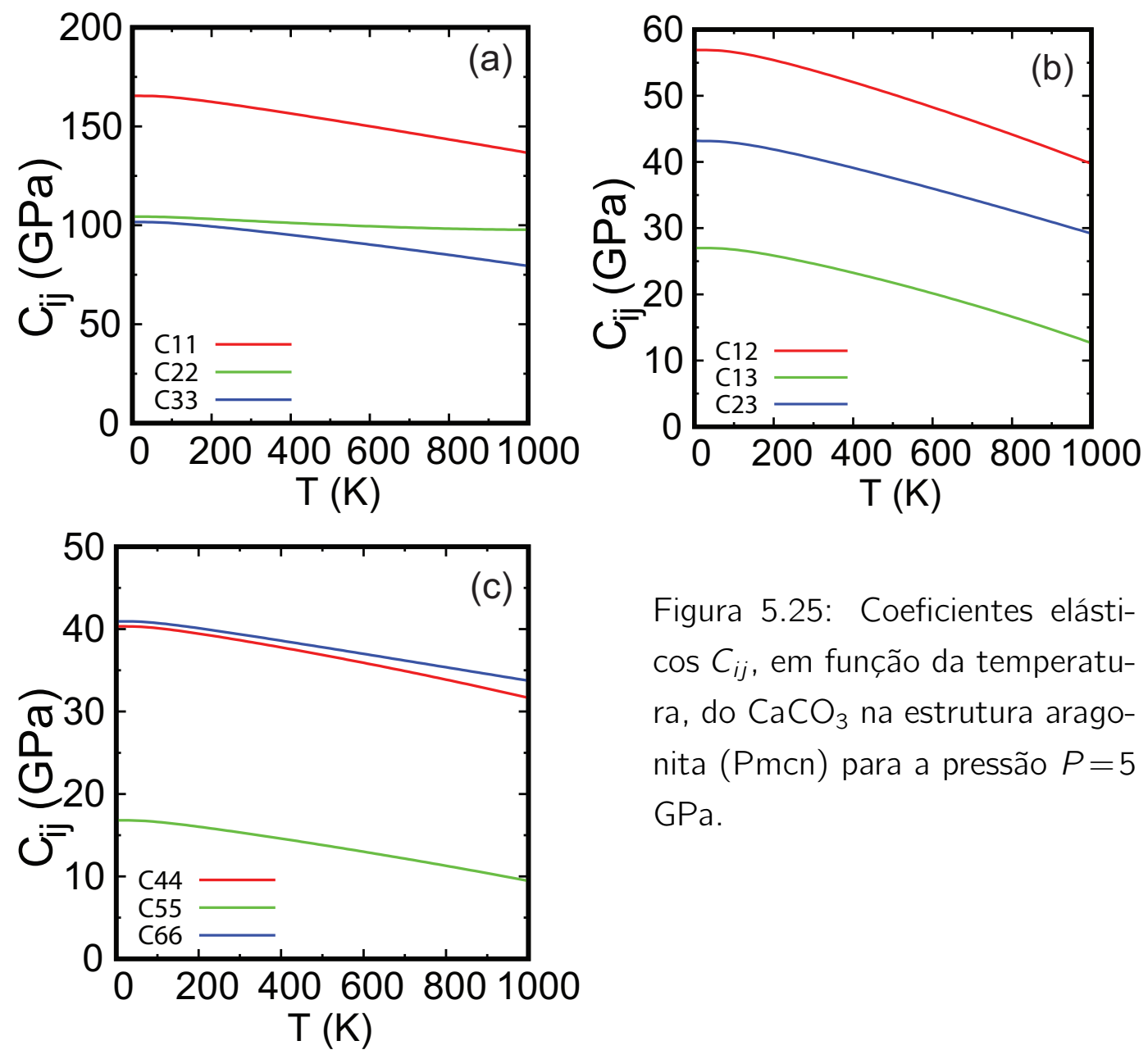

Figura 5.25: Coeficientes elásti$\cos C_{i j}$, em função da temperatura, do $\mathrm{CaCO}_{3}$ na estrutura aragonita (Pmcn) para a pressão $P=5$ $\mathrm{GPa}$.

valores dos coeficientes elásticos diminuem com o aumento da temperatura, conforme mostra a figura 5.25 para $P=5 \mathrm{GPa}$. Os coeficientes $C_{22}$ e $C_{33}$ apresentam valores próximos para temperaturas baixas, mas divergem para temperaturas maiores. Um comportamento semelhante pode ser observado para os coeficientes elásticos $C_{44}$ e $C_{66}$. Entretanto, como apresentado na seção anterior, a aproximação quase-harmônica só é válida para temperaturas de até aproximadamente $T=600 \mathrm{~K} \mathrm{e}$, consequentemente, para temperaturas maiores nossos resultados não são mais confiáveis para descrever este material, conforme foi mostrado na figura 5.17. Observamos, então, que o efeito da temperatura é pequeno, mas altera de maneira diferente os coeficientes elásticos podendo alterar a relação da velocidade com a direção de propagação. Assim, 
é importante saber se efeitos térmicos, de alguma forma, alteram a anisotropia do sistema. Na figura 5.26 apresentamos as velocidades das ondas acústicas $\mathrm{P}\left(V_{\mathrm{P}}\right)$ e $\mathrm{S}\left(V_{\mathrm{S}}\right)$ no cristal de $\mathrm{CaCO}_{3}$ na fase aragonita, ao longo de diferentes direções do cristal, para diferentes temperaturas.

Observa-se que o comportamento das velocidades acústicas, como função da direção do $\mathrm{CaCO}_{3}$ aragonita, é pouco afetado pelos efeitos térmicos. Podese notar que para algumas direções o aumento da temperatura não afeta a velocidade de propagação das ondas. O perfil dos gráficos permanece praticamente inalterado, indicando que efeitos térmicos não influenciam as velocidades de ondas acústicas neste cristal, em relação à dependência com a direção do cristal.

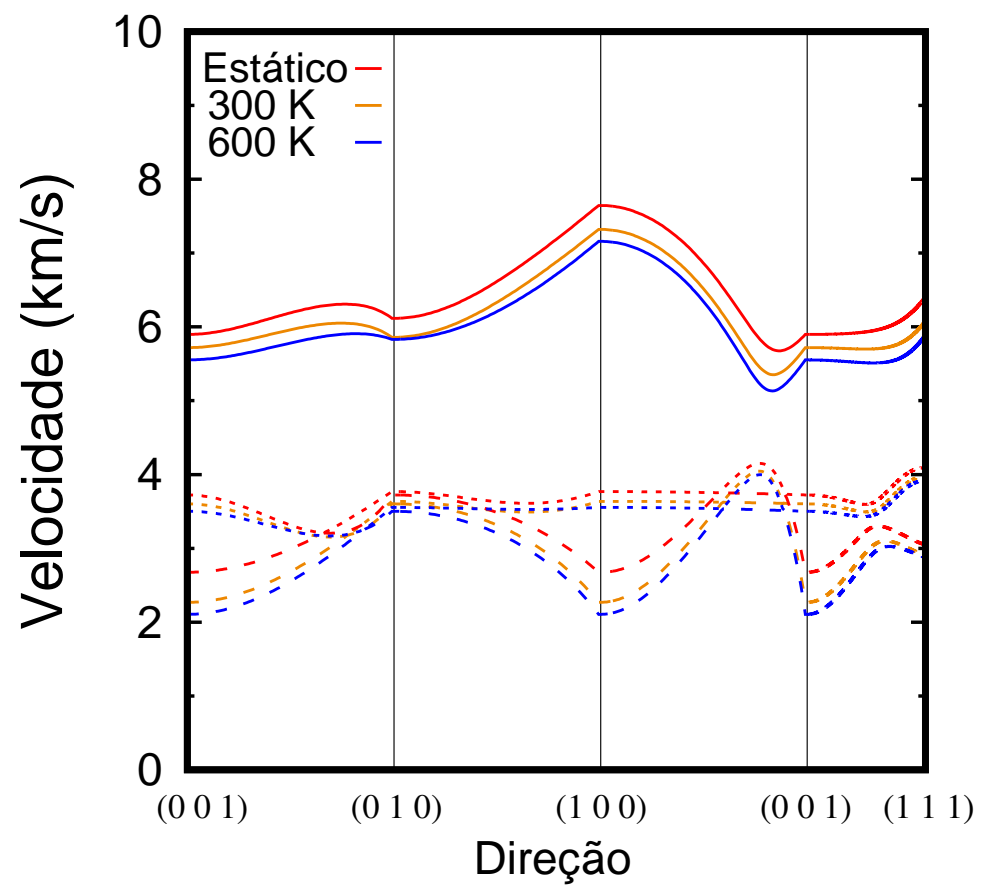

Figura 5.26: Velocidades de propagação de ondas acústicas P (linhas contínuas) e $\mathrm{S}$ (linhas tracejadas), ao longo de diferentes direções do cristal, para o $\mathrm{CaCO}_{3}$ na fase aragonita (Pmcn), para cálculos estáticos (linhas vermelhas), para $T=300 \mathrm{~K}$ (linhas laranjas) e $T=600 \mathrm{~K}$ (linhas azuis). 
Conforme mencionado nos capítulos anteriores, podemos considerar o planeta aproximadamente isotrópico e assim podemos calcular as propriedades elásticas de agregados isotrópicos destes cristais utilizando as médias de VoigtReuss-Hill. Obtivemos, então, as propriedades elásticas de agregados isotrópicos de $\mathrm{CaCO}_{3}$ aragonita. A figura 5.27 apresenta as velocidades de propagação de ondas acústicas $P\left(V_{P}\right)$ e $S\left(V_{S}\right)$, nesses agregados, em função da pressão, para diferentes temperaturas $(T=0,300$ e $600 \mathrm{~K})$, e em função da temperatura para $P=5 \mathrm{GPa}$.

Podemos averiguar que a velocidade de ondas acústicas em agregados isotrópicos varia consideravelmente com a temperatura e conforme a pressão aumenta, a diferença dos valores destas velocidades entre os cálculos estáticos e em temperatura ambiente diminui. Entretanto, há uma diferença da ordem de $1 \mathrm{~km} / \mathrm{s}$ na velocidade das ondas $P\left(V_{P}\right)$ quando se considera efeitos térmicos. A figura 5.27 também mostra que a velocidade das ondas $S\left(V_{S}\right)$ são menos
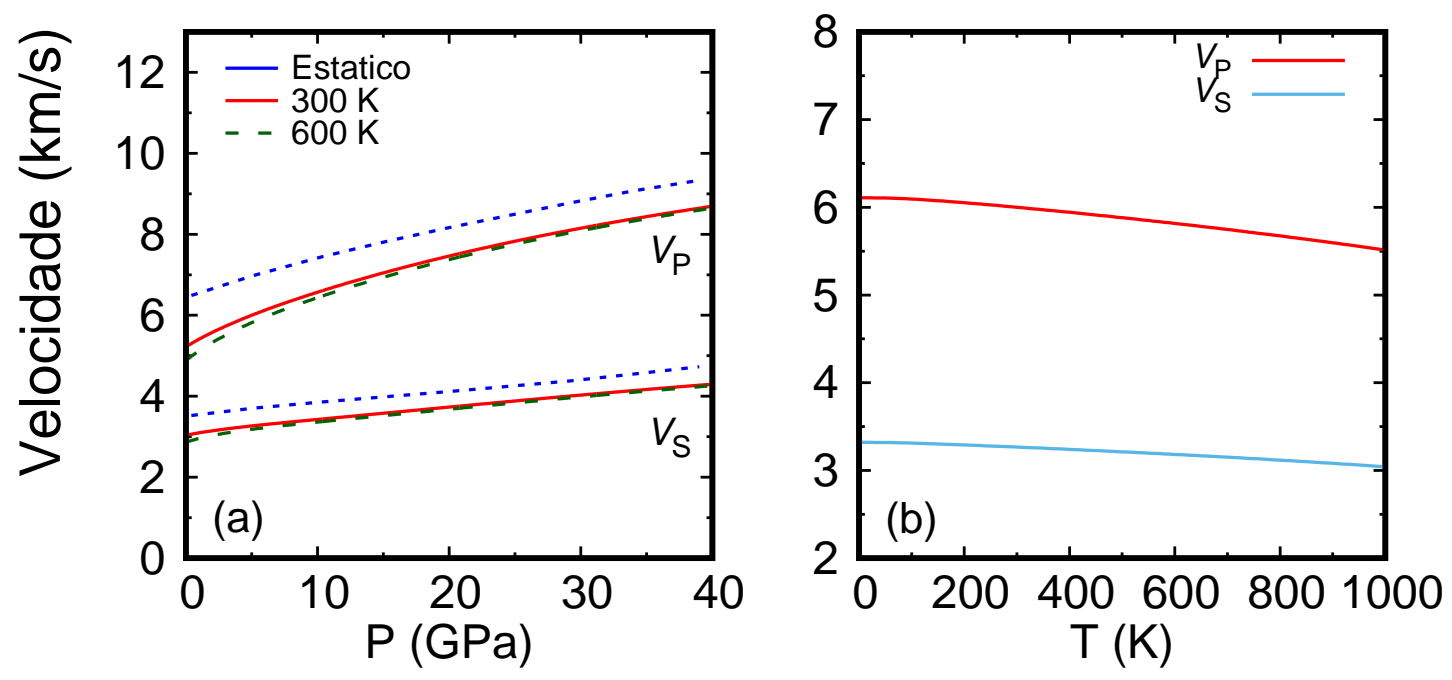

Figura 5.27: Velocidades de propagação de ondas acústicas $P\left(V_{P}\right)$ e $S\left(V_{S}\right)$ em agregados isotrópicos do $\mathrm{CaCO}_{3}$ na estrutura aragonita (Pmcn): (a) em função da pressão para cálculos estáticos (linhas tracejadas azuis) e para $T=300 \mathrm{~K}$ (linhas contínuas vermelhas) e $T=600 \mathrm{~K}$ (linhas tracejadas verdes); (b) em função da temperatura para a pressão $P=5 \mathrm{GPa}$. 
afetadas pela temperatura, sendo que diminuem da ordem de 0,5 km/s. Apesar de se ter uma diferença considerável nos valores das velocidades entre os cálculos estáticos e a $300 \mathrm{~K}$, a diferença dos valores das velocidades em $300 \mathrm{~K} \mathrm{e}$ em $600 \mathrm{~K}$ é muito pequena, sendo praticamente nula em altas pressões.

Estudos semelhantes foram realizados para o $\mathrm{CaCO}_{3}$ pós-aragonita (Pmmn), uma vez que ela apresenta uma estrutura ortorrômbica, permitindo a utilização do método proposto por Wu e Wentzcovitch [176] para a obtenção da dependência térmica dos coeficientes elásticos de materiais. De acordo com a figura 5.21, podemos assumir que a aproximação quase-harmônica é válida até altas temperaturas para esta fase do $\mathrm{CaCO}_{3}$, de tal forma que é possível estudá-la nas condições do manto inferior.

Vale ressaltar que estamos assumindo que a estimativa do limite de validade da aproximação quase-harmônica seja aquela para a qual a segunda derivada, em relação à temperatura, de $\alpha(T)$, é nula. A figura 5.28 mostra a variação das constantes elásticas, em função da pressão, para os resultados obtidos com os cálculos estáticos e para as temperaturas de $300 \mathrm{~K}$ e $1200 \mathrm{~K}$ para $0 \mathrm{CaCO}_{3}$ pós-aragonita.

A introdução de efeitos térmicos mostra que à temperatura ambiente a variação dos coeficientes elásticos com a pressão é praticamente igual àquela apresentada pelos cálculos estáticos. Entretanto, a altas temperaturas os efeitos são significativos para quase todos coeficientes elásticos, sofrendo reduções de cerca de $6 \%$ em comparação com os valores para $T=0 \mathrm{~K}$ e $T=300 \mathrm{~K}$. Além disso, podemos observar que os coeficientes elásticos continuam apresentando um perfil aproximadamente linear, de tal forma que a temperatura desloca todos os pontos da curva de valores iguais. O comportamento dos valores dos $C_{i j}$ com a temperatura é o mesmo, sendo que a inversão da direção mais dura, ou seja, onde $C_{22}$ fica maior que $C_{33}$, não depende da temperatura, ocorrendo a pressões de cerca de $110 \mathrm{GPa}$. Adicionalmente, vê-se que o aumento da pressão provoca diversas mudanças na ordem dos coeficientes elásticos, independentemente da temperatura. Em pressões de $50 \mathrm{GPa}$, o coeficiente $C_{13}$ fica maior que $C_{12}$ e em pressões de $100 \mathrm{GPa} 0 C_{23}$ para a ser maior que o $C_{12}$. Além disso, próximo de $60 \mathrm{GPa}, C_{55}$ passa a ser maior que $C_{66}$. Efeitos térmicos não modificam o comportamento de nenhuma dessas inversões, sendo que 

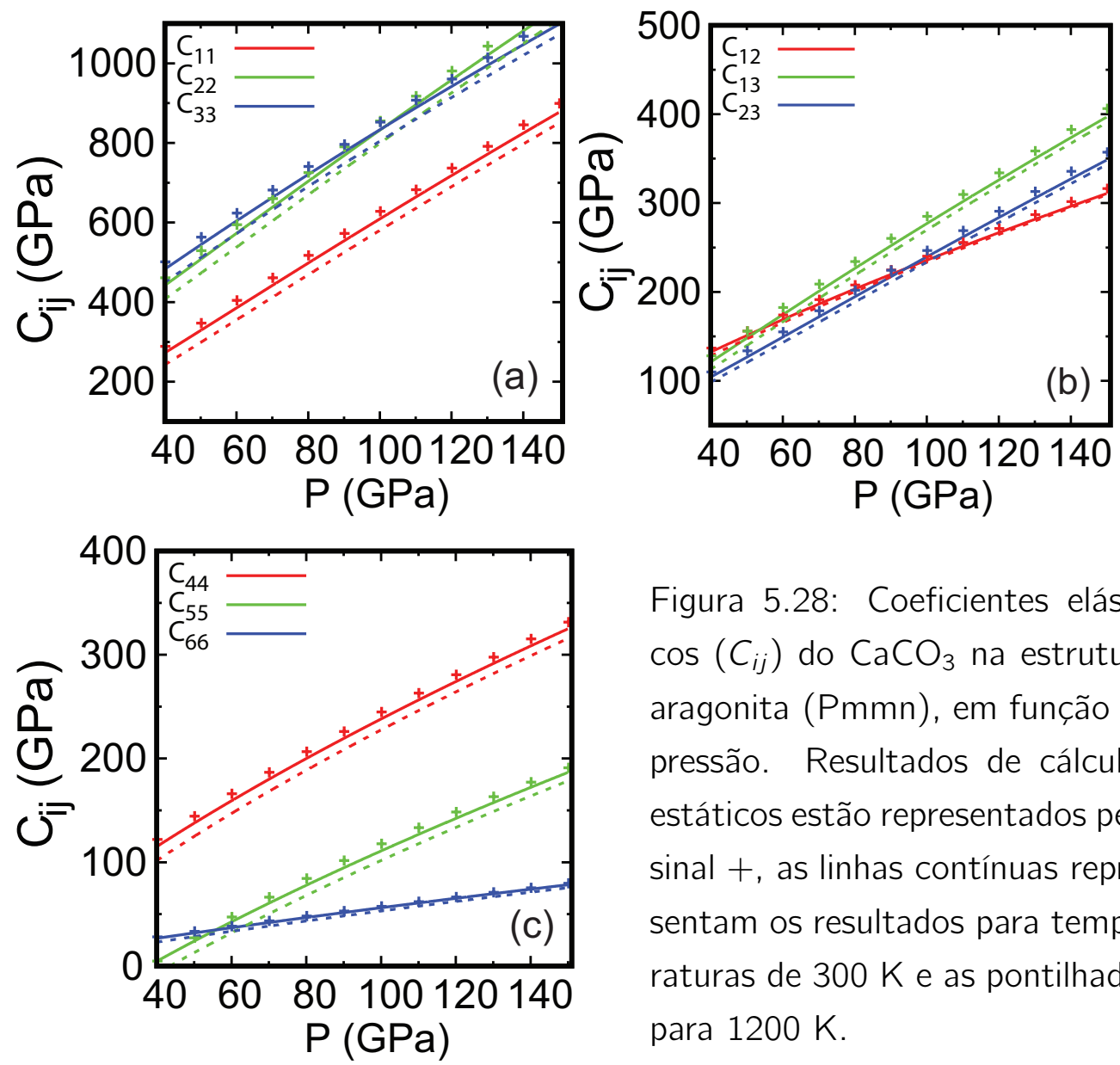

Figura 5.28: Coeficientes elásti$\cos \left(C_{i j}\right)$ do $\mathrm{CaCO}_{3}$ na estrutura aragonita (Pmmn), em função da pressão. Resultados de cálculos estáticos estão representados pelo sinal + , as linhas contínuas representam os resultados para temperaturas de $300 \mathrm{~K}$ e as pontilhadas para $1200 \mathrm{~K}$.

elas ocorrem no mesmo valor de pressão, independentemente da temperatura estudada.

Estudamos, também, a variação dos coeficientes do tensor elástico com a temperatura, para diferentes valores de pressão, e, como esperado, os valores dos coeficientes elásticos diminuem com o aumento da temperatura, conforme mostra a figura 5.29 para $P=110$ GPa. Percebe-se uma dependência aproximadamente linear. Como a variação de todos os coeficientes elásticos são aproximadamente da mesma forma, é esperado que o perfil das velocidades de propagação de ondas acústicas como função da direção do cristal também não tenha mudanças significativas, quando efeitos térmicos são introduzidos. $\mathrm{Na}$ figura 5.30 apresentamos as velocidades de propagação das ondas acústicas $P$ e $\mathrm{S}$ no cristal de $\mathrm{CaCO}_{3}$ na fase pós-aragonita, ao longo de diferentes direções 

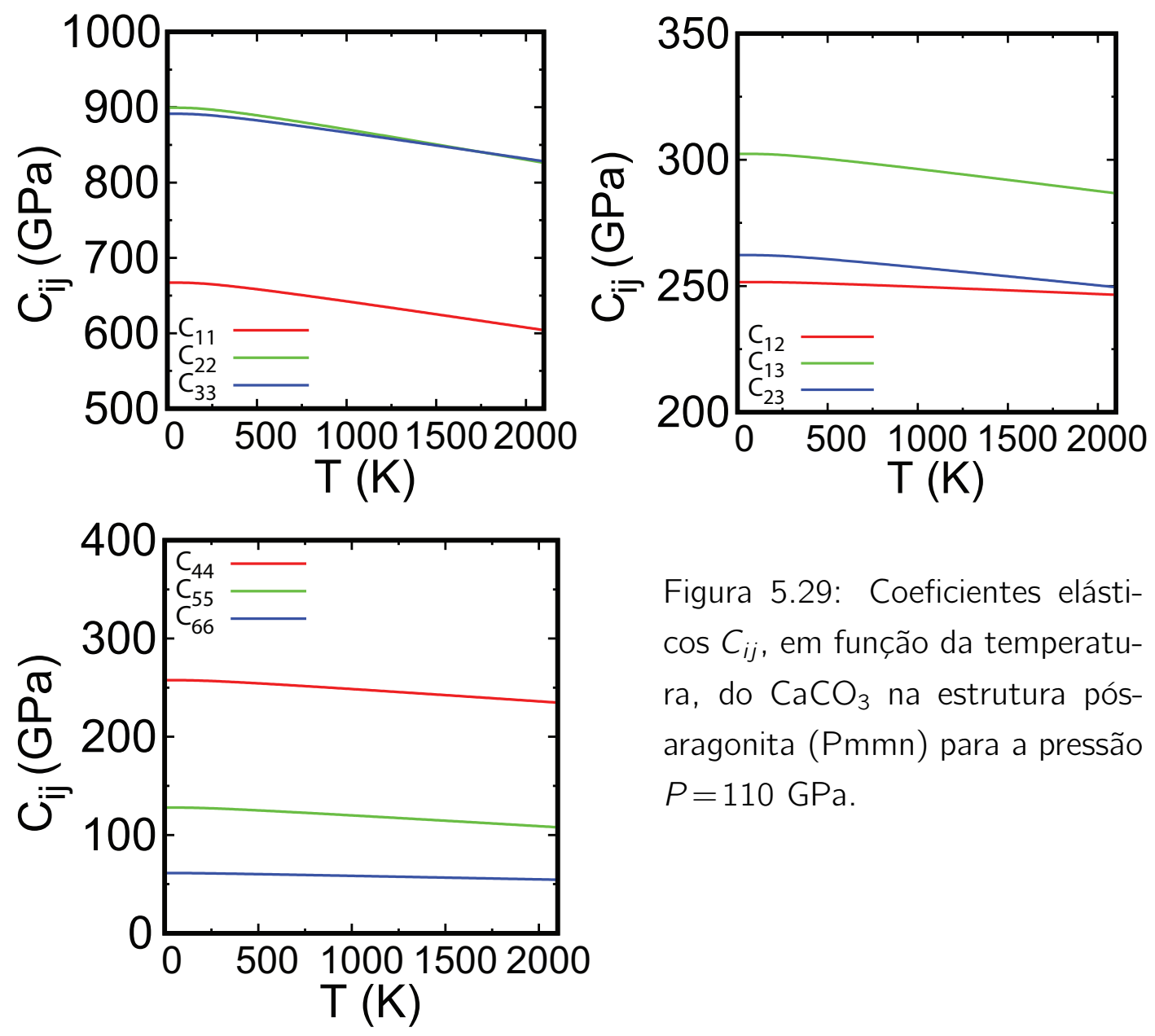

Figura 5.29: Coeficientes elásti$\cos C_{i j}$, em função da temperatura, do $\mathrm{CaCO}_{3}$ na estrutura pósaragonita (Pmmn) para a pressão $P=110 \mathrm{GPa}$.

do cristal, para diferentes temperaturas e pressão $P=110 \mathrm{GPa}$.

Observa-se que o perfil das curvas das velocidades acústicas como função da direção do $\mathrm{CaCO}_{3}$ pós-aragonita, é pouco afetado pelos efeitos térmicos, permanecendo praticamente inalterado, indicando que efeitos térmicos não influenciam as velocidades de ondas acústicas neste cristal, em relação à dependência com a direção do cristal. O perfil das curvas como função da direção permanece a mesma, indicando que a anisotropia do cristal não é afetada pela variação de temperatura.

Obtivemos, então, as propriedades elásticas de agregados isotrópicos de $\mathrm{CaCO}_{3}$ pós-aragonita. A figura 5.31 apresenta as velocidades de propagação de ondas acústicas $\mathrm{P}\left(V_{\mathrm{P}}\right)$ e $S\left(V_{S}\right)$, nesses agregados, em função da pressão, 


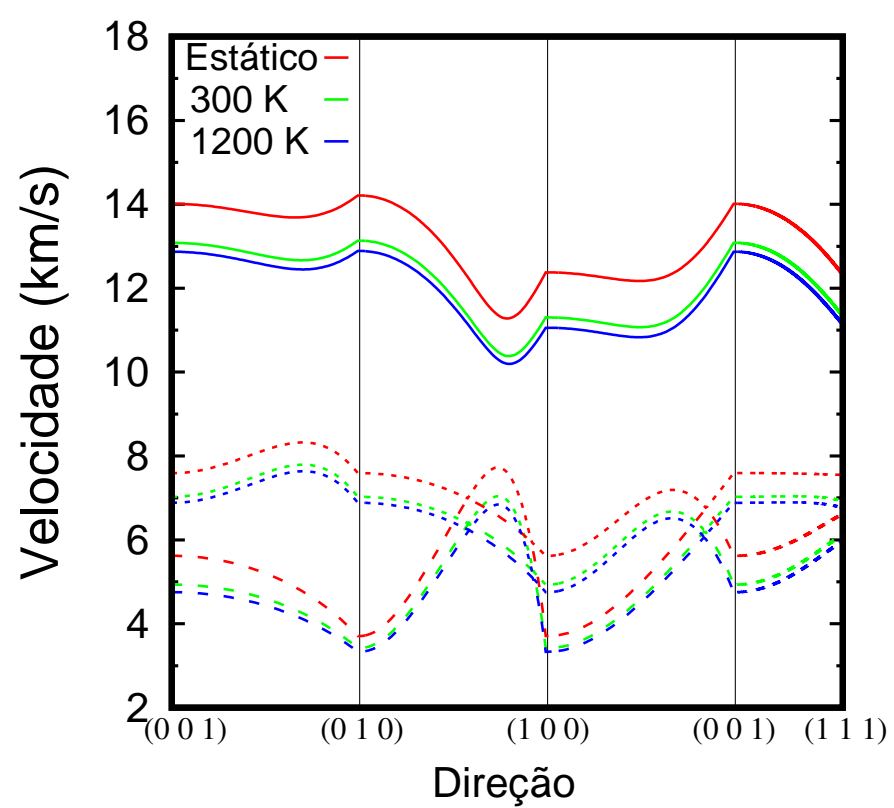

Figura 5.30: Velocidades de propagação de ondas acústicas P (linhas contínuas) e S (linhas tracejadas) para a pressão $P=110 \mathrm{GPa}$, ao longo de diferentes direções do cristal, para $\mathrm{O} \mathrm{CaCO}_{3}$ na fase pós-aragonita (Pmmn), para cálculos estáticos (linhas vermelhas) e para $T=300 \mathrm{~K}$ (linhas verdes) e $T=1200 \mathrm{~K}$ (linhas azuis).

para diferentes valores de temperatura $(T=0,300$ e $1200 \mathrm{~K})$, assim como em função da temperatura para a pressão $P=110 \mathrm{GPa}$.

Pelas figuras 5.30 e 5.31 (a) observa-se que a diferença entre os resultados estáticos e a $300 \mathrm{~K}$ é maior que a diferença entre $300 \mathrm{~K}$ e $1200 \mathrm{~K}$. Adicionalmente, observamos que a velocidade das ondas acústicas $\mathrm{P}$ e $\mathrm{S}$, em função da temperatura, para vários valores de pressão, são muito pouco afetadas, como mostra a figura 5.31 (b). A velocidade das ondas $\mathrm{P}$ e $\mathrm{S}$ a $T=0 \mathrm{~K}$ é bem menor que os valores estáticos. Com o aumento da temperatura, as velocidades são pouco afetadas, isso implica que a maior parte da contribuição para os coeficientes elásticos e para as velocidades acústicas provem de efeitos de ponto zero.

A introdução de efeitos térmicos mostra que não existe praticamente diferença entre os valores das velocidades das ondas $\mathrm{P}$ e $\mathrm{S}$ a temperatura ambiente e a 

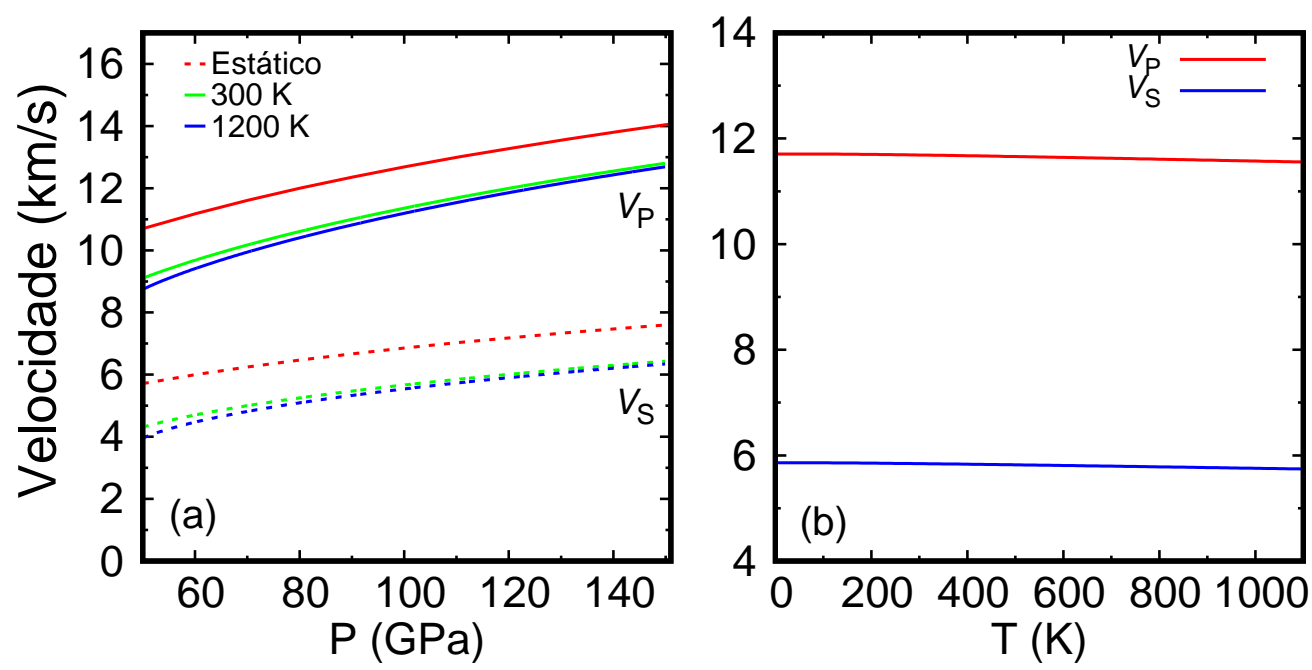

Figura 5.31: Velocidades de propagação de ondas acústicas $P\left(V_{P}\right)$ e $S\left(V_{S}\right)$ em agregados isotrópicos do $\mathrm{CaCO}_{3}$ na estrutura pós-aragonita (Pmmn): (a) em função da pressão para cálculos estáticos (linhas vermelhas) e para $T=300 \mathrm{~K}$ (linhas verdes) e $T=1200 \mathrm{~K}$ (linhas azuis); (b) em função da temperatura para a pressão $P=110 \mathrm{GPa}$.

$T=1200 \mathrm{~K}$, em função da pressão. Apesar de se ter uma diferença de $\approx 2 \mathrm{~km} / \mathrm{s}$ nos valores das velocidades entre os cálculos estáticos e a $300 \mathrm{~K}$, a diferença de valores destas velocidades para a temperatura ambiente e $1200 \mathrm{~K}$ é muito pequena, sendo praticamente nula em altas pressões. Cálculos teóricos para as velocidades acústicas do $\mathrm{MgSiO}_{3}$ como função da temperatura mostraram uma variação de velocidade da mesma ordem que a encontrada neste trabalho [123]. Com isso, podemos esperar que efeitos térmicos sejam parecidos em todos os minerais, de tal forma que podemos concluir que a temperatura não afeta os resultados obtidos no capítulo anterior. Portanto, podemos inferir que mesmo que sejam consideradas as altas temperaturas do manto inferior, as velocidades das ondas acústicas nos carbonatos ainda serão menores que as velocidades no $\mathrm{MgSiO}_{3}$ e, portanto, a proposta de que o carbono está incorporado no manto inferior em forma de carbonatos e que estes minerais explicam a existência das zonas de ultra-baixa velocidade continua válida. 


\subsection{Conclusões}

Neste capítulo foram estudados diversos compostos baseados em carbono possíveis de serem formados no manto interior. Nossos cálculos para o $\mathrm{CO}_{2}$ sólido indicam que a estrutura conhecida como $\mathrm{CO}_{2}-\mathrm{V}$, grupo espacial $1 \overline{4} 2 \mathrm{~d}$, é a mais estável em altas pressões. Como estes cálculos foram realizados em condições estáticas, essa conclusão contradiz o diagrama de fases do dióxido de carbono, que indica que a fase $\mathrm{CO}_{2}-\mathrm{VI}$ seria a mais estável. Ainda não há uma definição de qual é a estrutura correta do $\mathrm{CO}_{2}-\mathrm{VI}$, existindo a possibilidade de nenhuma das fases estudadas neste trabalho ser a correta.

O diamante é um dos mais importantes cristais composto por carbono e é de extrema importância para o estudo do interior da Terra. Por isso, estudamos a possibilidade de formação deste cristal, juntamente com a possibilidade da formação do cristal de oxigênio. Nas altas pressões correspondentes ao manto inferior, o oxigênio é um sólido molecular, pertencente ao grupo espacial $\mathrm{C} 2 / \mathrm{m}$.

Estudamos então a estabilidade energética do $\mathrm{MgCO}_{3}$, nas estruturas descritas no capítulo 4, com relação à formação de $\mathrm{CO}_{2}$ e $\mathrm{MgO}$. Apesar de em altas pressões a mistura $\mathrm{CO}_{2}+\mathrm{MgO}$ ser mais estável que o $\mathrm{MgCO}_{3}$ na estrutura $\mathrm{R} \overline{3} \mathrm{c}$, como este carbonato apresenta uma transição estrutural para a fase $\mathrm{C} 2 / \mathrm{m}$, sua formação continua sendo energeticamente favorável. Da mesma forma, chegamos à conclusão de que carbonatos de cálcio também são mais estáveis, não sendo favorável a formação de $\mathrm{CO}_{2}$. A estabilidade destes carbonatos com relação à possibilidade de formação de diamante também foi estudada e nossos cálculos mostram que a formação do diamante não é energeticamente favorável. Portanto, os carbonatos de cálcio e de magnésio são estáveis nas altas pressões do interior da Terra e sua formação é favorável.

Um problema considerado é o fato de algumas das estruturas propostas serem moleculares, de tal forma que interações de van der Waals podem ser importantes para descrever corretamente o sistema. Por esse motivo, efetuamos estudos destas transições de fase considerando as interações de van der Waals. Entretanto, mesmo a inclusão desta energia não altera as nossas conclusões.

O interior da Terra apresenta temperaturas muito elevadas de tal forma que a 
consideração de efeitos térmicos pode ser importante. Utilizando a aproximação quase-harmônica, estudamos a estabilidade dos carbonatos como função da temperatura. Verificamos que tanto $\circ \mathrm{MgCO}_{3}$ como o $\mathrm{CaCO}_{3}$ não apresentam variações significativas, com relação à sua estabilidade, com a introdução de efeitos térmicos, e averiguamos que a pressão de transição de fase é pouco afetada por estes efeitos.

Por fim, utilizando um método proposto recentemente para o cálculo das constantes elásticas como função da temperatura, verificamos se efeitos térmicos alteram significativamente os módulos elásticos e influenciam as velocidades de propagação de ondas acústicas no material. Por enquanto, este método só é aplicável a estruturas cúbica, tetragonal e ortorrômbica, por isso foram calculados os coeficientes termo-elásticos apenas do $\mathrm{CaCO}_{3}$ nas fases aragonita e pós-aragonita. Em todos os casos verifica-se que não há uma mudança significativa nos valores dos coeficientes elásticos, sendo que o maior efeito é a inclusão da energia de ponto zero. Por isso as velocidades não são significativamente alteradas, sendo apenas um pouco menores que no caso estático. Espera-se que, para a maioria dos cristais, efeitos térmicos tornem os materiais mais "moles", diminuindo as velocidades acústicas. De acordo com resultados de cálculos apresentados na literatura, utilizando este método, a variação das velocidades acústicas no $\mathrm{MgSiO}_{3}$ são da mesma ordem que as encontradas neste trabalho para $\circ \mathrm{CaCO}_{3}$. Podemos então inferir que a variação por efeitos térmicos nas velocidades acústicas no $\mathrm{MgCO}_{3}$ sejam também da mesma ordem. Assim podemos constatar que as conclusões apresentadas no capítulo 4 permanecem válidas nas altas temperaturas do manto inferior, de tal forma que a presença de carbono, em forma de carbonatos, pode explicar a presença de zonas de ultra baixa velocidade e serem os possíveis hospedeiros de carbono no interior da Terra. 


\section{Conclusão}

Sometimes small "probable errors" have been considered to be an indication of high accuracy of a conclusion, while actually they have been mainly an indication of good agreement between the observations.

- Beno Gutenberg, Physics of the earth's interior

Nossa proposta neste trabalho foi estudar, utilizando métodos de primeiros princípios, a influência da presença de carbono no manto inferior, em condições de altas pressões e temperaturas, e como compostos de carbono podem modificar as propriedades elásticas do interior do planeta, com objetivo de propor modelos para ajudar a mapear a presença de carbono na Terra.

Iniciamos nossa pesquisa estudando o $\mathrm{MgSiO}_{3}$, que é considerado o principal mineral do manto inferior, de forma a validar a metodologia utilizada. Nossos resultados para o $\mathrm{MgSiO}_{3}$, nas estruturas perovskita e pós-perovskita, mostraram boa concordância com dados experimentais e teóricos, indicando que o método utilizado é apropriado para descrever este tipo de material. Observamos que efeitos báricos não alteram significativamente o perfil das curvas das velocidades de propagação das ondas acústicas, em diferentes direções de propagação dos cristais, apresentando valores um pouco maiores na estrutura pós-perovskita do que na perovskita. Desse modo, podemos inferir que estas variações não são grandes o suficiente para explicar a descontinuidade $D^{\prime \prime}$. Contudo, observamos que a altas pressões, dependendo da direção cristalina, há uma diminuição brusca no valor das velocidades, consistente com a variação da velocidade de ondas sísmicas na região $\mathrm{D}^{\prime \prime}$ do manto. Portanto, propomos que um modelo adequado para explicar esta descontinuidade, em 
certas regiões do planeta, deve levar em consideração, também, uma orientação preferencial dos eixos cristalinos do $\mathrm{MgSiO}_{3}$.

Além de servir para validar os métodos teóricos utilizados, utilizamos os estudos do $\mathrm{MgSiO}_{3}$ como um molde do manto inferior do planeta para investigar as mudanças nas propriedades das ondas acústicas provocadas pela presença de carbono. Nestas condições extremas, o carbono poderia estar presente como uma inserção no $\mathrm{MgSiO}_{3}$, através da substituição de um radical silicato por um carbonato. Do ponto de vista energético, verificamos que, mesmo para baixas concentrações de carbono, o $\mathrm{MgSiO}_{3}$ é mais estável, favorecendo a suposição de que a presença de carbono no manto inferior deva estar associada a minerais na forma de carbonatos. Assim, optamos por estudar a estabilidade dos carbonatos de magnésio $\left(\mathrm{MgCO}_{3}\right)$ e de cálcio $\left(\mathrm{CaCO}_{3}\right)$ em altas pressões.

Investigamos as propriedades do $\mathrm{MgCO}_{3}$ e encontramos que a pressão de transição da estrutura romboédrica para a monoclínica $(\mathrm{C} 2 / \mathrm{m})$ é da ordem de $76 \mathrm{GPa}$. Nossos resultados mostram, ainda, uma grande variação da velocidade de propagação das ondas acústicas, em ambas estruturas, e que existe um aumento das velocidades, tanto das ondas $\mathrm{P}$, como das ondas $\mathrm{S}$, com $\mathrm{O}$ aumento da pressão. A anisotropia neste material é maior do que no $\mathrm{MgSiO}_{3}$, indicando que a presença de carbono aumentaria a anisotropia local do manto inferior. Isto poderia ser utilizado para restringir (ou ampliar) os possíveis minerais utilizados em modelos geofísicos.

$\mathrm{O} \mathrm{CaCO}_{3}$ possui diversos polimorfos, sendo que em baixas pressões ele é isoestrutural ao $\mathrm{MgCO}_{3}$ e é chamado de calcita. Encontramos que, em pressões da ordem de $2 \mathrm{GPa}, 0 \mathrm{CaCO}_{3}$ sofre uma transição de fase e assume a estrutura aragonita (Pmcn). Uma nova transição estrutural é observada para pressões da ordem de $40 \mathrm{GP}$, e o cristal passa para a fase pós-aragonita (Pmmn). As velocidades de propagação das ondas acústicas $\mathrm{P}$ e $\mathrm{S}$, nas três fases estruturais, apresentam grande anisotropia que, apesar de diminuir com o aumento da pressão, ainda é bem mais pronunciada do que nos cristais de $\mathrm{MgCO}_{3}$.

As velocidades das ondas acústicas em agregados isotrópicos de carbonatos $\mathrm{MgCO}_{3}, \mathrm{CaCO}_{3}$ e $\mathrm{MgCa}\left(\mathrm{CO}_{3}\right)_{2}$ são menores que as velocidades nos de silicatos $\mathrm{MgSiO}_{3}$. Assim, propomos que em regiões do manto inferior, onde existe uma alta concentração de carbono, a formação destes carbonatos é energetica- 
mente favorável e tem por efeito geofísico principal a redução da velocidade das ondas sísmicas. Com isso em mente, propomos que as regiões de baixa velocidade no manto inferior podem estar associadas à presença de carbonatos, explicando a redução de velocidade nas zonas de ultra-baixa velocidade (ULVZ) e contribuindo com novos modelos e métodos geofísicos que usam estas zonas para mapear reservatórios no interior da Terra.

Estudamos, também, a estabilidade destes carbonatos a altas pressões, em comparação com a possibilidade de formação de dióxido de carbono e de diamante, na presença de oxigênio. Nossos resultados mostraram que o $\mathrm{MgCO}_{3} \mathrm{e}$ - $\mathrm{CaCO}_{3}$ são energeticamente mais estáveis do que os compostos separados $\left(\mathrm{CO}_{2}+\mathrm{C}_{2}\right.$ (diamante) $\left.+\mathrm{O}_{2}\right)$, indicando que não é propício que ocorra a dissociação destes carbonatos para a formação de $\mathrm{CO}_{2}$ ou diamante. A inclusão de interações de van der Waals praticamente não altera os resultados, corroborando a conclusão de que os carbonatos de cálcio e de magnésio são estáveis nas condições de altas pressões do interior da Terra e sua formação é favorável na presença de carbono.

Adicionalmente, estudamos a estabilidade destes carbonatos como função da temperatura e verificamos que a estabilidade e os valores das pressões de transição estrutural destes sistemas são pouco afetadas com a consideração de efeitos térmicos. Além disso, não detectamos variações significativas, por efeitos térmicos, nas propriedades elásticas dos minerais, com relação aos cálculos estáticos, sendo que a maior variação se deve à inclusão de efeitos de ponto zero. As velocidades acústicas ficam praticamente inalteradas, sendo apenas um pouco reduzidas. Isso nos possibilita concluir que as altas temperaturas presentes no manto inferior não alteram as conclusões apresentadas neste trabalho. Assim, mesmo com a introdução de efeitos térmicos, a presença de carbono pode explicar as zonas de ultra baixa velocidade presentes em algumas regiões próximas à fronteira do manto inferior com o núcleo. Complementarmente, esses resultados também fornecem um modelo adicional para explicar onde e como o carbono pode ser armazenado no manto profundo. 



\section{Aproximações LDA e GGA}

Para se obter os estados eletrônicos de um sistema, utilizando-se as equações de Kohn-Sham, devemos tomar uma forma aproximada para o funcional energia de troca e correlação pois, na prática, para a maior parte das densidades, ele não é conhecido exatamente. Atualmente, existem várias aproximações para este termo de troca e correlação. A aproximação mais comum é a chamada aproximação da densidade local (LDA-Local Density Approximation) [45]. Nesta aproximação supõe-se que a contribuição de troca-correlação de todo o volume infinitesimal dependa apenas da densidade local daquele volume. Esta aproximação, apesar de simples, fornece resultados muito satisfatórios, para uma grande variedade de sistemas, e tem sido amplamente utilizada na física da matéria condensada e na geofísica. No entanto, em alguns casos, a aproximação LDA não funciona muito bem e o passo seguinte foi fazer com que a contribuição de troca-correlação de todo o volume infinitesimal não dependesse apenas da densidade local daquele volume, mas também da densidade nos volumes vizinhos, ou seja, incluindo a dependência do gradiente da densidade. Esta aproximação é chamada de aproximação do gradiente generalizado (GGA - Generalized Gradient Approximation) [54]. As aproximações LDA e GGA serão discutidas brevemente nas próximas seções. 


\section{A.1 Aproximação da Densidade Local}

A LDA foi a primeira ideia para uma aproximação para o potencial de troca e correlação. Ela foi proposta por Kohn e Sham em 1964 [45]. A ideia da LDA é considerar um volume infinitesimal do sistema e aproximar $E_{x c}$ desse volume pela energia de troca e correlação de um gás de elétrons homogêneo com a mesma densidade local do sistema original e, em seguida, somar as contribuições de cada elemento de volume da seguinte maneira

$$
E_{x c}^{L D A}[\rho(\vec{r})]=\int \rho(\vec{r}) \varepsilon_{x c}^{h o m}(\rho) d \vec{r}
$$

onde a função $\varepsilon_{x c}^{h o m}(\rho)$, não um funcional, é a energia de troca e correlação, por elétron, de um gás homogêneo de elétrons de densidade $\rho$, e pode ser decomposta em duas parcelas, uma relativa à densidade de energia de troca $\mathrm{e}$ outra à densidade de energia de correlação:

$$
\varepsilon_{x c}^{h o m}(\rho)=\varepsilon_{x}^{h o m}(\rho)+\varepsilon_{c}^{h o m}(\rho),
$$

onde a parcela relativa à densidade de energia de troca, para um gás de elétrons homogêneo, possui a forma analítica (em unidades atômicas):

$$
\varepsilon_{x}^{h o m}(\rho)=-3\left(\frac{3 \rho}{8 \pi}\right)^{\frac{1}{3}} .
$$

enquanto que a parcela relativa ao termo de correlação, para um gás de elétrons homogêneo, foi obtida através de métodos quânticos computacionais de Monte Carlo [177, 178].

Em sistemas onde se considera polarização de spin, a densidade de carga $\rho(\vec{r})$ é decomposta em duas densidades de spin, uma densidade $\rho_{\uparrow}(\vec{r})$ para os elétrons com spin up e uma densidade $\rho_{\downarrow}(\vec{r})$ para os elétrons com spin down, tal que a densidade total do sistema é $\rho(\vec{r})=\rho_{\uparrow}(\vec{r})+\rho_{\downarrow}(\vec{r})$ e a densidade de spin do sistema é $\rho_{\text {spin }}(\vec{r})=\rho_{\uparrow}(\vec{r})-\rho_{\downarrow}(\vec{r})$. Neste caso, o teorema de HK é generalizado de maneira que a energia total do sistema passa a ser um funcional das duas densidades de spin, ou seja,

$$
E[\rho(\vec{r})]=E\left[\rho_{\uparrow}(\vec{r}), \rho_{\downarrow}(\vec{r})\right]
$$


e a energia de troca e correlação levando em consideração a polarização de spin (LSDA), será

$$
E_{x c}^{\mathrm{LSDA}}\left[\rho_{\uparrow}(\vec{r}), \rho_{\downarrow}(\vec{r})\right]=\int \rho(\vec{r}) \varepsilon_{x c}^{h o m}\left(\rho_{\uparrow}, \rho_{\downarrow}\right) d \vec{r} .
$$

Como na LDA ou LSDA aproxima-se o sistema, localmente, por um gás de elétrons homogêneo, ela deve, a priori, ser válida para sistemas onde a densidade eletrônica varie muito lentamente. Para sistemas atômicos esta condição é raramente satisfeita sendo, na maior parte das vezes, seriamente violada. Entretanto a experiência mostra que para muitos sistemas cristalinos e moleculares ela fornece resultados extremamente úteis em muitas aplicações, tendo previsto e explicado várias propriedades dos estados fundamentais destes sistemas. Uma explicação plausível para este sucesso está no fato de as ligações entre os átomos, nas moléculas e nos sólidos, ocorrer na região de cauda das funções de onda atômicas, onde a densidade de carga eletrônica varia pouco. Existem, ainda, outros níveis de aproximação para a energia de exchange-correlação que vão além da LSDA.

\section{A.2 Aproximação do Gradiente Generalizado}

Na GGA [54], a contribuição de troca-correlação de todo o volume infinitesimal não depende apenas da densidade local daquele volume, mas também da densidade nos volumes vizinhos, ou seja, inclui a dependência no gradiente da densidade $\nabla \rho(\vec{r})$ [179-181].

$\mathrm{Na}$ aproximação GGA é usada uma expressão similar à equação (A.5), mas com $\epsilon_{x c}\left(\rho_{\uparrow}, \rho_{\downarrow}\right)$ sendo substituída por uma função local dependente da densidade e da intensidade de seu gradiente. Neste caso, o funcional energia de troca-correlação é escrito na forma:

$$
E_{x c}^{G G A}\left[\rho_{\uparrow}, \rho_{\downarrow}\right]=\int \rho(\vec{r}) f_{x}\left(\rho_{\uparrow}(\vec{r}), \rho_{\downarrow}(\vec{r}), \nabla \rho_{\uparrow}(\vec{r}), \nabla \rho_{\downarrow}(\vec{r})\right) d \vec{r},
$$

onde o termo $f_{x}$ é uma função universal das densidades de spin-up e spin-down e de seus gradientes. Existem diversas versões de GGA, mas em nosso trabaIho utilizamos a aproximação do gradiente generalizado proposta por Perdew, 
Burke e Ernzerhof que é chamada de PBE [54]. Como enfatizado anteriormente, a aproximação GGA, em geral, fornece resultados melhores para cálculos da energia total e das diferenças nas energias estruturais quando comparados com a aproximação LSDA para sistemas que apresentam densidades de carga não homogêneas. A expressão do funcional energia de troca e correlação na aproximação GGA-PBE é

$$
E_{x c}^{G G A}\left[\rho_{\uparrow}(\vec{r}), \rho_{\downarrow}(\vec{r})\right]=E_{x}^{G G A}\left[\rho_{\uparrow}(\vec{r}), \rho_{\downarrow}(\vec{r})\right]+E_{c}^{G G A}\left[\rho_{\uparrow}(\vec{r}), \rho_{\downarrow}(\vec{r})\right] .
$$

- funcional energia de correlação $\left(E_{c}^{G G A}\right)$ : construído levando-se em consideração três condições:

1. No limite em que a densidade varia lentamente, a energia de correlação deve tender para sua expansão do gradiente (GEA - Gradient expansion approximation): $E_{c}^{G G A} \longrightarrow E_{c}^{G E A}$.

2. No limite em que a densidade varia rapidamente, a energia de correlação deve tender para sua expressão da LDA: $E_{c}^{G G A} \longrightarrow E_{c}^{L D A}$.

3. No limite de altas densidades, sob uma transformação de semelhança uniforme $\left[\rho(\vec{r}) \rightarrow \lambda^{3} \rho(\lambda \vec{r})\right]$, a energia de correlação deve escalar para uma constante negativa: $E_{c}^{G G A} \longrightarrow$-const.

- funcional energia de troca $\left(E_{x}^{G G A}\right)$ : construído com base em 4 condições:

1. Sobre uma homotetia uniforme da densidade, como descrito no item 3 acima, a energia de troca deve escalar $\operatorname{com} \lambda: E_{x}^{G G A}\left[\rho_{\lambda}\right]=\lambda E_{x}^{G G A}[\rho]$.

2. A energia de troca deve obedecer à relação de escalonamento de spin [182]:

$$
E_{x}^{G G A}\left[\rho_{\uparrow}, \rho_{\downarrow}\right]=\frac{\left\{E_{x}^{G G A}\left[2 \rho_{\uparrow}\right]+E_{x}^{G G A}\left[2 \rho_{\downarrow}\right]\right\}}{2} .
$$

3. A resposta linear, para pequenas variações da densidade em torno da densidade uniforme, deve ser a mesma que a da LDA.

4. O limite de Lieb-Oxford [183] deve ser satisfeito: $E_{x c}^{G G A}=2,273 E_{x}^{L D A}$ 
Essas quatro condições levam ao fator de intensificação (enhancement):

$$
F_{x}(s)=1+\kappa-\frac{\kappa}{1+\mu s^{2} / \kappa}, \quad \text { com } \mu \simeq 0,21952 \text { e } \kappa \leq 0,804 \text {, (A.8) }
$$

onde $s=|\nabla \rho| /\left(2 \rho k_{F}\right)$, com $k_{F}^{3}=3 \pi^{2} \rho$, é um gradiente adimensional da densidade.

A aproximação GGA-PBE retém as características corretas da LSDA e as combina com as características mais importantes, energeticamente, da não localidade da densidade, corrigida pelo gradiente. 



\section{Constantes elásticas}

A seguir, são apresentadas as distorções usadas para o cálculo dos coeficientes elásticos de cada uma das estruturas dos sistemas estudados neste trabalho.

\section{Estrutura trigonal}

Os coeficientes elásticos dos minerais que se cristalizam na estrutura trigonal podem ser calculados com as seguintes três distorções:

$$
e_{k l}^{1}=\left(\begin{array}{lll}
\delta & 0 & 0 \\
0 & 0 & 0 \\
0 & 0 & 0
\end{array}\right) \quad e_{k l}^{3}=\left(\begin{array}{lll}
0 & 0 & 0 \\
0 & 0 & 0 \\
0 & 0 & \delta
\end{array}\right) \quad e_{k l}^{4}=\left(\begin{array}{lll}
0 & 0 & 0 \\
0 & 0 & \delta \\
0 & \delta & 0
\end{array}\right)
$$

com as quais se calculam:

$$
e_{k l}^{1} \Rightarrow\left\{\begin{array}{l}
\sigma_{11}=C_{11} \delta \\
\sigma_{12}=C_{12} \delta \\
\sigma_{13}=C_{13} \delta \\
\sigma_{14}=C_{14} \delta
\end{array} \quad e_{k l}^{3} \Rightarrow \sigma_{33}=C_{33} \delta \quad e_{k l}^{4} \Rightarrow \sigma_{23}=C_{44} \delta\right.
$$

\section{Estruturas ortorrômbica e monoclínica}

Para calcular as constantes elásticas dos minerais que se cristalizam nas estruturas ortorrômbica e monoclínica utilizamos seis tensores $e_{k l}$ com as se- 
guintes distorções:

$$
\begin{gathered}
e_{k l}^{1}=\left(\begin{array}{lll}
\delta & 0 & 0 \\
0 & 0 & 0 \\
0 & 0 & 0
\end{array}\right) e_{k l}^{2}=\left(\begin{array}{lll}
0 & 0 & 0 \\
0 & \delta & 0 \\
0 & 0 & 0
\end{array}\right) e_{k l}^{3}=\left(\begin{array}{lll}
0 & 0 & 0 \\
0 & 0 & 0 \\
0 & 0 & \delta
\end{array}\right) \\
e_{k l}^{1} \Rightarrow\left\{\begin{array} { l } 
{ \sigma _ { 1 1 } = C _ { 1 1 } \delta } \\
{ \sigma _ { 1 2 } = C _ { 1 2 } \delta } \\
{ \sigma _ { 1 3 } = C _ { 1 3 } \delta }
\end{array} \quad e _ { k l } ^ { 2 } \Rightarrow \left\{\begin{array}{l}
\sigma_{22}=C_{22} \delta \\
\sigma_{23}=C_{23} \delta
\end{array} \quad e_{k l}^{3} \Rightarrow \sigma_{33}=C_{33} \delta .\right.\right.
\end{gathered}
$$

No caso da estrutura monoclínica, temos, adicionalmente:

$$
e_{k l}^{1} \Rightarrow \sigma_{15}=C_{15} \delta \quad e_{k l}^{2} \Rightarrow \sigma_{25}=C_{25} \delta \quad e_{k l}^{3} \Rightarrow \sigma_{35}=C_{35} \delta
$$

Com as matrizes de distorção

$$
e_{k l}^{4}=\left(\begin{array}{lll}
1 & 0 & 0 \\
0 & 1 & \delta \\
0 & \delta & 1
\end{array}\right) \quad e_{k l}^{5}=\left(\begin{array}{lll}
1 & 0 & \delta \\
0 & 1 & 0 \\
\delta & 0 & 1
\end{array}\right) \quad e_{k l}^{6}=\left(\begin{array}{lll}
1 & \delta & 0 \\
\delta & 1 & 0 \\
0 & 0 & 1
\end{array}\right)
$$

calculamos as constantes elásticas das estruturas ortorrômbica e monoclínica:

$$
e_{k l}^{4} \Rightarrow \sigma_{23}=C_{44} \delta \quad e_{k l}^{5} \Rightarrow \sigma_{13}=C_{55} \delta \quad e_{k l}^{6} \Rightarrow \sigma_{12}=C_{66} \delta
$$

sendo que para a monoclínica ainda tem-se:

$$
e_{k l}^{4} \Rightarrow \sigma_{12}=C_{46} \delta
$$




\section{Referências Bibliográficas}

[1] B. R. Goldstein. Historia Mathematica 11, 411 (1984).

[2] nssdc.gsfc.nasa.gov/planetary/factsheet/earthfact.html, acessado em 04/Fev/2014.

[3] K. E. Bullen. The Earth's Density. John Wiley \& Sons, (1975).

[4] H. Cavendish. Scientific Papers, revisado por J. Lamor. Cambridge University Press, (1921).

[5] E. Wiechert. Nachr. Ges. Wiss. Göttingen Math. Physik KI. 1897, 221 (1897).

[6] R. E. Bisque, editor. Investigating the Earth. Houghton Mifflin Company, Boston, (1968).

[7] R. D. Oldham. Quart. J. Geol. Soc. 62, 456 (1906).

[8] T. F. Gaskell, editor. The Earth's Mantle. Academic Press, London, (1967).

[9] E. Wiechert. Nachr. Ges. Wiss. Göttingen Math. Physik Kl. 1907, 415 (1907).

[10] K. Zoeppritz e L. Geiger. Nachr. Ges. Wiss. Göttingen Math. Physik KI. 1909, 400 (1909).

[11] B. Gutenberg. Nachr. Ges. Wiss. Göttingen , 1 (1914).

[12] I. Lehmann. Bur. Centr. Seism. Internat. A 14, 3 (1936).

[13] K. E. Bullen. Nature 157, 405 (1946). 
[14] K. E. Bullen. Bull. Seism. Soc. Am. 30, 235 (1940).

[15] K. E. Bullen. Bull. Seism. Soc. Am. 32, 19 (1942).

[16] K. E. Bullen. Mon. Not. R. astr. Soc. 109, 457 (1949).

[17] A. K. McNamara, E. J. Garnero e S. Rost. Earth Planet. Sci. Lett. 299, 1 (2010).

[18] F. D. Stancey e P. M. Davis. Physics of the Earth. Cambridge University Press, (1986).

[19] S. Cottaar e B. Romanowicz. Earth Planet. Sci. Lett. 355-356, 213 (2012).

[20] M. S. Thorne, E. J. Garnero, G. Jahnke, H. Igel e A. K. MacNamara. Earth Planet. Sci. Lett. 364, 59 (2013).

[21] J. P. Brodholt, G. Helffrich e J. Trampert. Earth Planet. Sci. Lett. 262, 429 (2007).

[22] M. E. Wysession, T. Lay, J. Revenaugh, Q. Willians, E. J. Garnero, R. Jeanloz e L. Kellog. Geodynamics 28, 273 (1998).

[23] J. Wookey, S. Stackhouse, J. M. Kendall, J. Brodholt e G. D. Price. Nature 438, 1004 (2005).

[24] D. Antonangeli, J. Siebert, C. M. Aracne, D. L. Farber, A. Bosak, , M. Hoeshi, M. Krisch, F. J. Ryerson, G. Fiquet e J. Badro. Science 331, 64 (2011).

[25] R. M. Hazen, A. P. Jones e J. A. Baross, editores. Carbon in Earth, volume 75. Mineralogical Society of America, (2013).

[26] S. Karato. The dynamic structure of the deep earth: an interdisciplinary approach. Princeton University Press, (2003).

[27] A. E. Ringwood. Composition and Petrology of the Earth's Mantle. McGraw-Hill, (1975). 
[28] A. E. Ringwood. Geochem. Cosmochim. Acta 30, 41 (1966).

[29] Don L. Anderson. Theory of the Earth, 27. Boston: Blackwell Scientific Publications (1989).

[30] E. Ohtani. Earth Planet. Sci. Lett. 78, 70 (1985).

[31] C. B. Agee. Ann. Rev. Earth Planet. Sci. 21, 19 (1993).

[32] L. G. Liu. Geophys. Res. Lett. 1, 277 (1974).

[33] L. G. Liu. Nature 258, 510 (1975).

[34] E. Knittle e R. Jeanloz. Science 235, 668 (1987).

[35] R. M. Hazen e C. M. Schiffries. Rev. Miner. Geochem. 75, 1 (2013).

[36] M. Javoy. Geophys. Res. Lett. 24, 177 (1997).

[37] M. J. Walter, S. C. Kohn, D. Araujo, G. P. Bulanova, C. B. Smith, E. Gailloui, J. Wang, A. Steele e S. B. Shirey. Science 334, 54 (2011).

[38] J. Tsuchiya, T. Tsuchiya e R. M. Wentzcovitch. J. Geophys. Res. 110, B02204 (2005).

[39] R. M. Wentzcovitch, Y. G. Yu e Z. Wu. Rev. Min. Geo. 71, 59 (2010).

[40] R. M. Wentzcovitch, B. B. Karki, S. Karato e C. R. S. Da Silva. Earth Planet. Sci. Lett. 164, 371 (1998).

[41] K. Umemoto, H. Hsu e R. M. Wentzcovitch. Phys. Earth. Planet. Inter. 180, 209 (2010).

[42] G. Shukla, Z. Wu, H. Hsu, A. Floris, M. Cococcioni e R. M. Wentzcovitch. Geophys. Res. Lett. 42, 1749 (2015).

[43] G. Shukla, M. Topsakal e R. M. Wentzcovitch. Phys. Earth Planet. Int. 249, 11 (2015).

[44] P. Hohenberg e W. Kohn. Phys. Rev. 136, B864 (1964). 
[45] W. Kohn e L. J. Sham. Phys. Rev. 140, B1133 (1965).

[46] T. H. Thomas. Proc. Camb. Phil. Soc. 23, 542 (1927).

[47] E. Fermi. Rend. Accad. Naz. Lincei. 6, 602 (1927).

[48] A. Rappe, K. M. Rabe, E. Kaxiras e J. D. Joannopoulos. Phys. Rev. B 41, 1227 (1990).

[49] J. S. Lin, A. Qteish, M. Payne e V. Heine. Phys. Rev. B 47, 4174 (1993).

[50] G. P. Kerker. J. Phys. C 13, L189 (1980).

[51] N. Troullier e J. L. Martins. Phys. Rev. B 43, 1993 (1991).

[52] D. Vanderbilt. Phys. Rev. B 41, 7892 (1990).

[53] P. Giannozzi, S. Baroni, N. Bonini, R. Car M. Calandra, C. Cavazzoni, D. Ceresoli, G. L. Chiarotti, M. Cococcioni, I. Dabo, A. Dal Corso, S. Fabris, G. Fratesi, S. de Gironcoli, R. Gebauer, U. Gerstmann, C. Gougoussis, A. Kokalj, M. Lazzeri, L. Martin-Samos, N. Marzari, F. Mauri, R. Mazzarello, S. Paolini, A. Pasquarello, L. Paulatto, C. Sbraccia, S. Scandolo, G. Sclauzero, A. P. Seitsonen, A. Smogunov, P. Umari e R. M. Wentzcovitch. J. Phys.: Condens. Matter 21, 395502 (2009).

[54] J. P. Perdew, K. Burke e M. Ernzerhof. Phys. Rev. Lett. 77, 3865 (1996).

[55] J. C. Slater. Phys. Rev. 51, 846 (1937).

[56] C. Herring. Phys. Rev. 27, 1169 (1940).

[57] J. C. Philips e L. Kleinman. Phys. Rev. 116, 287 (1959).

[58] D. R. Hamann, M. Schluter e C. Chiang. Phys. Rev. Lett. 43, 1494 (1979).

[59] P. Blochl. Phys. Rev. B 50, 17953 (1994).

[60] P. Blochl, C. J. Frost e J. Schimpl. Bull. Mat. Sci. 26, 33 (2003).

[61] G. Kresse e D. Joubert. Phys. Rev. B 59, 1758 (1999). 
[62] G. P. Srivastava. The Physics of Phonons. CRC Press, (1990).

[63] E. A. Hylleraas. Z. Phys. 65, 209 (1930).

[64] E. Wigner. Math. Natur. Anz. (Budapest) 53, 477 (1935).

[65] J. G. Angyan. J. Math. Chem 46, 1 (2008).

[66] A. E. H. Love. A Treatise on the Mathematical Theory of Elasticity. Cambridge University Press, (1934).

[67] M. J. P. Musgrave. Crystal Acoustics. Holden-Day, (1970).

[68] K. E. Bullen. An Introduction to the Theory of Seismology. Cambridge University Press, (1963).

[69] E. Schrodinger. Adv. Phys. 82, 265 (1927).

[70] W. Pauli. Handbuch der Physik. Springer, (1930).

[71] O. H. Nielsen e R. M. Martin. Phys. Rev. Lett. 50, 697 (1983).

[72] V. Fock. Z. Phys. 63, 855 (1930).

[73] A. F. R. de Toledo Piza. Mecânica Quântica. EDUSP, (2009).

[74] O. H. Nielsen e R. M. Martin. Phys. Rev. B 32, 3780 (1985).

[75] S. Stackhouse, J. Brodholt, G. D. Price, J. Wookey e J. M. Kendall. Earth Planet. Sci. Lett. 230, 1 (2005).

[76] T. Tsuchiya, J. Tsuchiya, K. Umemoto e R. M. Wentzcovitch. Geophys. Res. Lett. 31, L14603 (2004).

[77] M. Murakami, S. V. Sinogeikin, J. D. Bass, N. Sata, Y. Ohishi e K. Hirose. Earth Planet. Sci. Lett. 259, 18 (2007).

[78] S. Karato. Pure Appl. Geophys. 151, 565 (1998). 
[79] L. Stixrude. Elastic Constants and Anisotropy of $\mathrm{MgSiO}_{3}$ in M. Gurnis, M. Wysession, E. Knittle, B. Buffet: The Core Mantle Region. American Geophysical Union, (1998).

[80] R. M. Wentzcovitch, J. L. Martins e G. D. Price. Phys. Rev. Lett. 70, 3947 (1993).

[81] R. M. Wentzcovitch. Phys. Rev. B 44, 2358 (1991).

[82] J. Badro, J. P. Rueff, G. Vankó, G. Monaco, G. Fiquet e F. Guyot. Science 331, 64 (2004).

[83] H. Horiuchi, E. Ito e D. Weidner. Am. Mineral. 72, 357 (1987).

[84] N. L. Ross e R. M. Hazen. Phys. Chem. Minerals 16, 415 (1989).

[85] W. Setyawan e S. Curtarolo. Comput. Mat. Sci. 49, 299 (2010).

[86] L. Lin, C. Shi, Z. Wang, W. Zhang e M. Yin. J. All. Compounds 466, 546 (2008).

[87] A. Yegaheh-Haeri. Phys. Earth. Planet. Inter. 87, 111 (1994).

[88] W. Voigt. Lehrbuch der Kristallphysic. Leibzig Teuber, (1929).

[89] A. Reuss. Z. angew. Math. Mech. 9, 55 (1928).

[90] R. Hill. Proc. Phys. Soc. A 65, 349 (1952).

[91] M. Murakami, S. V. Sinogeikin, H. Hellwig e J. Li J. D. Bass. Earth Planet. Sci. Lett. 256, 47 (2007).

[92] S. Lundin, K. Catalli, J. Santillan, S. H. Shim, V. B. Prakapenka M. Kunz e Y. Meng. Phys. Earth Planet. Int. 168, 97 (2008).

[93] D. Andrault, N. Bolfan-Casanova e N. Guignot. Nature 430, 442 (2004).

[94] G. Fiquet, A. Dewaele, D. Andrault, M. Kunz e T. Le Bihan. Geophys. Res. Lett. 27, 21 (2000). 
[95] T. Tsuchiya, J. Tsuchiya, K. Umemoto e R. M. Wentzcovitch. Earth Planet. Sci. Lett. 224, 241 (2004).

[96] M. Murakami, K. Hirose, K. Kawamura, N. Sata e Y. Ohishi. Science 304, 855 (2004).

[97] K. Hirose e T. Lay. Elements 4, 183 (2008).

[98] M. L. Marcondes e R. M. Wentzcovith. J. Appl. Phys. 117, 215902 (2015).

[99] T. litaka, K. Hirose, K. Kawamura e M. Murakami. Nature 430, 442 (2004).

[100] M. Nunez-Valdez, A. Yuen, N. Koker e R. M. Wentzcovitch. Geophys. Res. Lett. 40, 290 (2013).

[101] H. Hsu e R. M. Wentzcovitch. Phys. Rev. B 90, 195205 (2014).

[102] Z. Wu e R. M. Wentzcovitch. Proc. Natl. Acad. Sci. USA 111, 10468 (2014).

[103] Z. Wu, J. F. Justo e R. M. Wentzcovitch. Phys. Rev. Lett. 110, 228501 (2013).

[104] Y. Yu, V. Vinograd, B. Winkler e R. M. Wentzcovitch. Phys. Earth Planet. Int. 110, 36 (2013).

[105] R. M. Wentzcovitch, H. Hsu e K. Umemoto. Europ. J. Mineral. 24, 851 (2012).

[106] H. Hsu, Y. Yu e R. M. Wentzcovitch. Earth Planet. Sci. Lett. 359-360, 34 (2012).

[107] H. Hsu, P. Blaha, M. Cococcioni e R. M. Wentzcovitch. Phys. Rev. Lett. 106, 118501 (2011).

[108] C. J. Pickard e R. J. Needs. Phys. Rev. B 91, 104101 (2015).

[109] B. Marty e A. Jambo. Earth Planet. Sci. Lett. 83, 16 (1987).

[110] A. N. Halliday. Geochim. Cosmochim. Acta 105, 146 (2013). 
[111] H. P. Scott, V. M. Doczy, M. R. Frank, M. Hasan, J. Lin e J. Yang. Am. Mineral. 98, 1211 (2013).

[112] A. R. Oganov, C. W. Glass e S. Ono. Earth Planet. Sci. Lett. 241, 95 (2006).

[113] A. R. Oganov, S. Ono, Y. Ma, C. W. Glass e A. Garcia. Earth Planet. Sci. Lett. 273, 38 (2008).

[114] N. L. Ross. Am. Mineral. 82, 682 (1997).

[115] J. Yang, Z. Mao, J. Lin e V. B. Prakapenka. Earth Planet. Sci. Lett. 392, 292 (2014).

[116] G. Fiquet e B. Reynard. Am. Mineral. 84, 856 (1999).

[117] G. Fiquet, F. Guyot, M. Kunz, J. Matas, D. Andrault e M. Hanfland. Am. Mineral. 87, 1261 (2002).

[118] M. Isshiki, T. Irifune, K. Hirose, S. Ono, Y. Ohishi, T. Watanuki, E. Nishibori e M. Takata. Nature 427, 60 (2004).

[119] E. Boulard, A. Gloter, A. Corgne, D. Antonangeli, A. Auzende, J. Perrillat, F. Guyot e G. Fiquet. Proc. Natl. Acad. Sci. 108, 5184 (2011).

[120] N. V. Skorodumova, A. B. Belonoshko, L. Huang, R. Ahuja e B. Johansson. Am. Mineral. 90, 1008 (2005).

[121] W. R. Panero e J. E. Kabbes. Geophys. Res. Lett. 35, L14307 (2008).

[122] S. L. A. Valcke, M. Casey, G. E. Lloyd, J. M. Kendall e Q. J. Fisher. Geophys. J. Int. 166, 652 (2006).

[123] R. M. Wentzcovitch, B. B. Karki, M. Cococcioni e S. Gironcoli. Phys. Rev. Lett. 92, 018501 (2004).

[124] B. Gutenbeg. Bullen. Seism. Soc. Am. 38, 121 (1948).

[125] S. Maruyama, M. Santosh e D. Zhao. Gond. Res. 11, 7 (2007). 
[126] A. R. Hutko. Phys. Earth Planet. Int. 173, 60 (2009).

[127] A. T. Simon, T. Redfern e R. J. Angel. Contrib. Mineral. Petr. 134, 102 (1999).

[128] H. Sitepu. Powder Diffr. 24, 315 (2009).

[129] C. C. Chen, C. C. Lin, L. G. Lin, S. Sinogeikin e J. D. Bass. Am. Mineral. 86, 1525 (2001).

[130] Y. Li, Y. Zou, T. Chen, X. Wang, X. Qi, H. Chen, J. Du e B. Li. Am. Mineral. 100, 2323 (2015).

[131] S. Arapan e R. Ahuja. Phys. Rev. B 82, 184115 (2010).

[132] S. Ono, T. Kikegawa, Y. Ohishi e J. Tsuchiya. Am. Mineral. 100, 667 (2005).

[133] G. J. F. MacDonald. Am. Mineral. 41, 744 (1956).

[134] L. Lin, C. Chen e C. Lin. Phys. Chem. Minerals 32, 97 (2005).

[135] C. Biellmann, P. Guyot, J. Peyronneau e B. Reynard. Earth Planet. Sci. Lett. 118, 31 (1993).

[136] A. Buob, R. W. Schmidt e P. Ulmer. Am. Mineral. 91, 435 (2006).

[137] I. Martinez. Am. Mineral. 81, 611 (1996).

[138] JY. Zhu e Y. Ogasawara. Geology 30, 947 (2002).

[139] J. Santillán, Q. Willians e E. Knittle. Geophys. Res. Lett. 30, 1054 (2003).

[140] P. Humbert e F. Plicque. C. R. Acad. Sci. Paris 275, B391 (1972).

[141] Jay D. Bass. Elasticity of Minerals, Glasses, and Melts, 45. American Geophysical Union (2013).

[142] A. M. Martin e T. Hammouda. Eur. J. Mineral. 23, 5 (2011). 
[143] R. Tao, L. Zhang, Y. Fei e Q. Liu. Geochim. Cosmochim. Acta 143, 253 (2014).

[144] M. Merlini, W. A. Crichton, M. Hanfland, M. Gemmi, H. Müller, I. Kupenko e L. Dubrovinsky. Proc. Nat. Acad. Sci. 109, 13509 (2012).

[145] Z. Wu, R. M. Wentzcovitch, K. Umemoto, B. Li, K. Hirose e J. Zheng. J. Geophys. Res. 113, B06204 (2008).

[146] Z. Jhing e S. Karato. Chem. Geol. 262, 100 (2009).

[147] Y. Seto, D. Nishio-Hamane, T. Nagai, N. Sata e K. Fujino. Journal of Physics: Conference series 215, 012015 (2010).

[148] V. lota e C. S. Yoo. Phys. Rev. Lett. 86, 5922 (2001).

[149] A. R. Oganov, R. J. Hemley, R. M. Hazen e A. P. Jones. Rev. Mineralog. Geochem. 75, 47 (2013).

[150] J. Park, C. S. Yota, V. lota, H. Cynn, M. F. Nicol e T. Le Bihan. Phys. Rev. B 68, 014107 (2003).

[151] C. Yoo, V. lota e H. Cynn. Phys. Rev. Lett. 86, 444 (2001).

[152] F. Datchi, B. Mallick, A. Salamat e S. Ninet. Phys. Rev. Lett. 108, 125701 (2012).

[153] M. Santoro. High Pressure Crystalography: from fundamental fenomena to technologial applications. (2010).

[154] J. Matas, P. Gillet, Y. Ricard e I. Martinez. Eur. J. Mineral. 12, 703 (2000).

[155] D. Canil e C. M. Scarfe. J. Geophys. Res. 95, 15805 (1990).

[156] R. C. Newton e W. E. Sharp. Earth Planet. Sci. Lett. 26, 239 (1975).

[157] I. Kushiro, H. Satake e S. Akimoto. Earth Planet. Sci. Lett. 28, 116 (1975).

[158] Richard Lovett. Nature News, doi:10.1038/nature.2014.14862 (2014). 
[159] D. G. Pearson, F. E. Brenker, F. Nestola, J. Mcneill, L. Nasdala, M. T. Hutchinson, S. Matveev, K. Mather, G. Silversmit, S. Schimitz, B. Vekemans e L. Vincze. Nature 507, 221 (2014).

[160] Y. A. Freiman e H. J. Jodl. Phys. Rep. 401, 1 (2004).

[161] Y. Akahama, H. Kawamura, D. Hausermann, M. Hanfland e O. Shimomura. Phys. Rev. Lett. 74, 4690 (1995).

[162] Y. Ma, A. R. Oganov, e C. W. Glass. Phys. Rev. B 76, 064101 (2007).

[163] A. J. Ochoa-Calle, C. M. Zicovich-Wilson e A. Ramirez-Solis. Phys. Rev. B 92, 085148 (2015).

[164] K. D. Litasov, A. F. Goncharov e R. J. Hemley. Earth Planet. Sci. Lett. 309, 318 (2011).

[165] M. Dion, H. Rydberg, E. Schröder, D. C. Langreth e B. I. Lundqvist. Phys. Rev. Lett. 92, 246401 (2004).

[166] J. Klimes, D. R. Bowler e A. Michaelides. J. Phys.: Condens. Matter 22, 022201 (2010).

[167] J. Klimes, D. R. Bowler e A. Michaelides. Phys. Rev. B 83, 195131 (2011).

[168] Foram efetuados cálculos da equação de estado do $\mathrm{NaCl}$ com este funcional e os resultados obtidos concordaram muito bem com resultados experimentais, apresentando erros menores que $0,5 \%$. $O$ artigo está em fase de redação.

[169] A. Dewaele, G. Fiquet, D. Andrault e D. Hausermann. J. Geophys. Res 105, 2869 (2000).

[170] Z. P. Chang e E. K. Graham. J. Phys. Chem. Solids 38, 1355 (1977).

[171] P. Gillet, C. Biellmann, B. Reynard e P. F. McMillan. Phys. Chem. Miner. 20, 1 (1993). 
[172] A. Grzechnik, P. Simon, P. Gillet e P. McMillan. J. Phys. : Condens. Matter 262, 67 (1999).

[173] K. Suito, J. Namba, T. Horikawa, Y. Tanigushi, N. Sakurai, M. Kobayashi, A. Onodera, O. Shimomura e T. Kikegawa. Am. Mineral. 86, 997 (2001).

[174] S. A. J. Redfern, E. Salji e A. Navtrotsky. Contrib. Mineral. Petr. 101, 479 (1989).

[175] D. C. Wallace. Thermodynamics of Crystals. Dover, (1972).

[176] Z. Wu e R. M. Wentzcovitch. Phys. Rev. B 83, 184115 (2011).

[177] D. M. Ceperley e B. J. Alder. Phys. Rev. Lett. 47, 566 (1980).

[178] J. P. Perdew e A. Zunger. Phys. Rev. B 23, 5048 (1981).

[179] L. Hedin. Phys. Rev. 139, 796 (1965).

[180] A. D. Becke. Phys. Rev. A 38, 3098 (1988).

[181] J. P. Perdew e K. Burke. Int. J. Quant. Chem. 57, 309 (1994).

[182] G. L. Oliver e J. P. Perdew. Phys. Rev. A 20, 397 (1979).

[183] E. H. Lieb e S. Oxford. Int. J. Quant. Chem. 19, 427 (1981). 